\title{
CHEMISIRY FOR
}

PUBETO HEALT STUDENTS

\section{B. GABRIEL JONES}

(5)

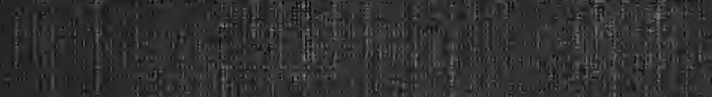

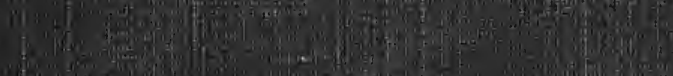

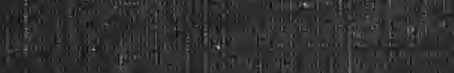

4 (1)

(1) (1.)

$$
\text { (1.) }
$$

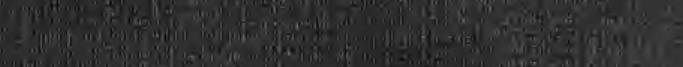

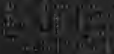

Q 4 (9) 
The University of Toronto Chemical Library

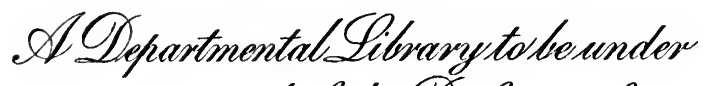
the controls the Strofessomat Chemistryaccosding to the conditions setoutinaletter from the Librarian of the Olnivensity dated March 21. :t 1938. 



Digitized by the Internet Archive in 2007 with funding from Microsoft Corporation 


\section{CHEMISTRY FOR PUBLIC HEALTH STUDENTS}




\section{TEXT-BOOKS OF CHEMISTRY}

A Text-book of Inorganic Chemistry. By GeORGE Senter, D.Sce, Ph.D., Principal and Head of Chemical Department, Birkbeck College, London. With 90 Diagrams. 6th Edition. Crown 8vo. 8s. 6d.

A Text-book of Practical Chemistry. By A. E. Dunstan, D.Sc., F.I.C., and F. B. Thole, D.Sc. With a Plate, 52 Diagrams, and Appendices. 2nd Edition.

Crown 8vo. 7s, 6d.

An Introduction to Quantitative Analysis. By S. J. M. Auld, D.Sc., Ph.D., Head of the Chemical Department, South-Fastern Agricultural College, Wye. With many Diagrams. $\quad$ Crown 8vo. 6s.

A First Year Course of Organic Chemistry. By A. E. Dunstan, D.Sc., F.I.C. With 2 Plates and many Diagrams. Crown 8 vo. 4s.

A Second Year Course of Organic Chemistry. By F. B. Thule, D.Sc. With Plates and Diagrams. Crown 8 vo. 4s. 6 d.

A Third Year Course of Organic Chemistry. By T. B. HildiTCH, D.Sc., F.I.C. With Plates and Diagrams. Crown 8vo. 7s. 6d.

Qualitative Organic Analysis. By F. B. Thole, D.Sc. Crown 8vo. 2s. 6 d.

Modern Research in Organic Chemistry. By F. G. POPE, B.Sc., F.C.S. With $26 \mathrm{I}$ Diagrams. and Edition.

Crown 8 vo. 7s. 6 d.

Outlines of Physical Chemistry. By George Senter, D.Sc., Ph.D. With many Diagrams. 8th Edition. Crown 8vo. 7s. 6d.

Practical Physical Chemistry. By J. B. FirTh, M.Sc., Department of Chemistry, Armstrong College, Newcastle.

Crown 8vo. 4s. 6 d. 


\title{
CHEMISTRY
}

\section{FOR PUBLIC HEALTH STUDENTS}

\author{
E. GABRIEL JONES, M.Sc., F.I.C.
}

LECTURER IN PUBLIC HEALTH CHEMISTRY IN THE UNIVERSITY OF LIVERPOOL DEPUTY PUBLIC ANALYST FOR THE CITY OF LIVERPOOL

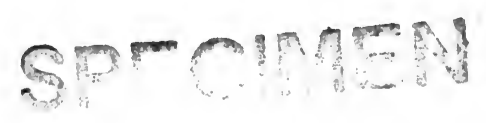

METHUEN \& CO. LTD.

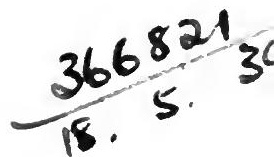
36 ESSEX STREET W.C. LONDON 
First Published in 1920 


\section{PREFACE}

THIS book has been compiled from work-sheets and notes of lectures provided for students preparing for the Diploma in Public Health. In publishing it, the author's aim is to produce a small and, it is hoped, easily readable book containing details of all the practical work required, together with other matter which may, if necessary, take the place of a short lecture course, as experience has shown that many candidates for the diploma have not the time to read thoroughly the large text-books dealing with this subject. It has not been possible within the scope of this work to deal very fully with many of the sections, and in order to assist those who desire to study further, a list of books and reports recommended for purposes of reference is contained in the Appendix. Many of these have been consulted in the preparation of the present volume. The author is indebted to several Universities and other examining bodies for the privilege of including a number of examination questions.

The methods described for the practical work are such as have been found both accurate and suitable for class purposes ; no apology is offered for the inclusion of the "examples of calculation" and of other somewhat elementary methods of treatment, as in the course of many years experience it has been found that these explanations are necessary, in order to avoid waste of time over the arithmetical part of the work. 
As the course is essentially a practical one, and students become familiar with the apparatus used, no sketches or diagrams have been introduced. Students are recommended to read carefully through the description of each process, before commencing to perform the experiment.

E. G. J. 


\section{CONTENTS}

\section{CHAPTER I}

USE OF BALANCE

Examples of Gravimetric Estimations.

\section{CHAPTER II}

VOLUMETRIC ANALYSIS

Preparation of Normal and other Standard SolutionsIndicators-Estimation of Acetic acid in VinegarAlkalinity of Lime-water etc.-Preparation and uses of Standard Potassium Permanganate Solution. Other Standard Solutions.

\section{CHAPTER III}

MILK

Average Composition-Nature of Proteins, Mineral Matter, etc. - Conditions affecting compositionStatutory Limits and Regulations-Methods of Analysis - Calculation of Adulteration-Analysis of Sour MilkDetection and Estimation of Preservatives-Colouring Matters-Heated Milk-Dirt in Milk.

\section{CHAPTER IV}

BUTTER AND MARGARINE

Composition and Legal Standards-Manufacture of Margarine-Methods of Analysis-Constitution and Analysis of Butter-fat.-Reichert-Wollny and Polenske processes-Detection of Cottonseed Oil and Sesame Oil -Refractive Indices - Microscopical ExaminationDetection and Estimation of Boric acid-Detection of Fluorides. 


\section{CHAPTER V}

ALCOHOLIC BEVERAGES

Estimation of Alcohol-Determination of Original Gravity-Proof Spirit-Sikes' Hydrometer-Beer and other Alcoholic Beverages-Test for traces of Alcohol.

\section{CHAPTER VI}

VARIOUS FOODS, THEIR COMPOSITION AND ADULTERATION WITH SOME DETAILS OF THE METHODS OF ANALYSIS

Standards-Condensed Milk, Dried Milk, Buttermilk, Cream, Cheese, Lard, Jams, Honey, Tea, Coffee, Cocoa, Cereals, Baking Powder, Infants' Foods, Vinegar, Spices, Olive oil, Sugar-Microscopical Examination of Foods-Food Values-Vitamines.

\section{CHAPTER VII}

METHODS OF PRESERVING FOODS

Chemical Preservatives, Regulations and Recommendations-Methods of Detection and EstimationMetallic Poisons in Foods, their Detection and Estimation-Arsenic in Foods.

\section{CHAPTER VIII}

WATER

Nature of Supplies-Sampling-Methods of AnalysisInterpretation of Results-Water Sediments-Examples of Water Analyses-Softening-Detection and Estimation of Poisonous Metals.

\section{CHAPTER IX}

SEWAGE EFFLUENTS .

Methods of Analysis-Standards of Royal Commission on Sewage Disposal. 


\section{CONTENTS}

\section{CHAPTER $\mathrm{X}$}

PAGE

AIR

Composition and Impurities-Effects of Respiration and Combustion-Detection and Estimation of Gaseous Impurities-Scheme for Identification of Gases-Estimation of Oxygen-Estimation of Carbon DioxideCarbon Monoxide-Injurious Quantities of GasesEstimation of Dust-Report of Committee on Atmospheric Pollution.

\section{CHAPTER XI}

\section{DISINFECTANTS}

Classification-Determination of Strength of Bleaching Powder, Carbolic Powder, Formalin,PermanganateMethods of Recognition of Disinfectants-Rag Flock.

\section{APPENDIX}

PREPARATION OF SOLUTIONS

Tables of Alcoholic Strength, Spirit Indication, Hardness of Water, Nitrates, Oxygen in Water, Atomic Weights-Examination Questions-Books of Reference. 


$$
\text { - }
$$




\section{CHEMISTRY FOR \\ PUBLIC HEALTH STUDENTS}

\section{CHAPTER I}

\section{USE OF THE CHEMICAL BALANCE}

Since a great deal of the work described in the following pages involves accurate weighing, some instructions as to the use of the chemical balance are inserted here.

The weights used, which are those of the metric system, are generally arranged as follows :-

\begin{tabular}{|c|c|c|c|c|c|c|}
\hline $5^{\circ}$ & grams & 0.5 & gram & & 500 & milligrams \\
\hline 20 & ," & 0.2 & ", & ", & 200 & ", \\
\hline Io & $"$, & O.I & , & , & 100 & ", \\
\hline Io & , & 0.1 & $"$, & ," & 100 & ", \\
\hline 5 & ", & 0.05 & , & , & $5^{\circ}$ & ", \\
\hline 2 & , & 0.02 & , & , & 20 & , \\
\hline & gram & 0.01 & , & ", & IO & ", \\
\hline I & ", & 0.01 & $"$ & ," & Io & " \\
\hline I & ", & 0.005 & ", & ", & 5 & ", \\
\hline & & 0.002 & $"$ & , & 2 & $"$ \\
\hline & & 0.001 & ", & ," & I & milligram \\
\hline & & 0.001 & ", & ", & I & ", \\
\hline
\end{tabular}

The weights from $5 \circ$ grams down to 1 gram are usually made of brass, plated with gold or platinum, and the smaller weights of platinum or aluminium. Instead of those from 0.005 gram downwards, a rider of fine wire is generally employed, and is placed on the beam of the balance, which is graduated into a 
number of divisions, each division indicating a certain number of milligrams.

It is necessary, firstly, to ensure that the balance is properly levelled and adjusted, the levelling being effected by means of the screws on which the balance stands, and spirit levels or a plumb line inside the case.

Any particles are removed from the pans by brushing them with a small camel-hair brush, and the balance is caused to swing by releasing the beam from the supports, and if necessary making a slight draught over one of the pans by moving the hand above it, without touching any part of the balance. If the pointer, which is attached to the beam, swings over an equal number of divisions of the scale on either side of the centre, the weighing may be proceeded with; if not, the balance must be adjusted by means of the screws at the ends of the beam, or in some cases by moving a vane situated above the centre of the beam. The pans are then brought to rest by raising the support; the article to be weighed is put on the left-hand pan, and weights to counterbalance it, as nearly as possible, on the right-hand pan, the exact adjustment being made by means of the rider.

It is advisable to start with a weight which will probably be too heavy and reduce this gradually, rather than to place weights on the pan at random until equilibrium is restored. For example, suppose the 20 gram weight is found to be too much, 5 grams should be tried, then, if necessary, ro grams, and when the number of grams has been determined, the weights of the first place of decimals $(0.5,0.2,0.1$ gram) should be tried in turn, and then those of the second place of decimals; the weights of each order being kept in a separate row on the pan.

Whilst placing weights on the pan or removing them, the supports must be raised so that the balance cannot swing, and in making the final adjustment with the rider, the balance case should be closed. The weights are then added up, the 
total entered in a notebook, and checked by comparison with the vacant spaces in the box; it follows that no weights must be left lying on the floor of the balance case, but those not in use must be replaced in their proper positions in the box.

Special attention is drawn to the following rules, which should be strictly observed :-

I. Do not put any chemicals directly on the balance pans, nor on paper, but always on a watch-glass or some other vessel. Any material which will absorb moisture from the air, emit fumes or undergo any other change, must be weighed in a stoppered weighing-bottle.

2. Dishes, flasks, etc., which have been heated must be quite cold before weighing.

3. Weights must always be held with forceps and not with the fingers.

4. Nothing must be put on or taken off the pans except when the beam is resting on the supports.

5. Weights not in use must be kept in their proper places in the box, and not left lying on the floor of the balance case or elsewhere.

6. The balance case should be closed while the rider is being used in the final adjustment.

7. The total should be entered in a notebook before removing the weights from the pan.

8. When the weighing is finished, all weights should be put into their proper places in the box, and the balance case should be closed.

9. In the majority of cases it is necessary to weigh to the nearest milligram.

ro. When estimating water or other volatile body by the loss of weight on heating, it is essential that the process should be continued until a constant weight is obtained. 


\section{Examples of Gravimetric Estimations}

The examples given are typical of those estimations in which the substance, the amount of which is to be ascertained, is precipitated from solution as an insoluble compound, which is filtered off and suitably treated, so as to convert it into a product of known composition, which is then weighed. From this weight the amount of the substance is calculated.

\section{Estimation of iron}

The iron, if any part of it is in the ferrous condition, is completely oxidized, and is precipitated as ferric hydrate, $\mathrm{Fe}(\mathrm{OH})_{3}$, which is then converted into ferric oxide, $\mathrm{Fe}_{2} \mathrm{O}_{3}$, by ignition.

Required :-

$\begin{array}{lc}\text { watch-glass } & \text { ferrous ammonium sulphate } \\ \text { glass rod } & \\ \text { beakers } & \text { nitric acid conc. } \\ \text { small porcelain crucible } & \\ \text { wash-bottle } & \text { ammonium hydrate } \\ \text { filter papers } & \\ \text { funnel } & \text { potassium ferricyanide solu- } \\ \text { platinum wire } & \text { tion } \\ \text { crucible tongs } & \end{array}$

Procedure :-

Weigh out 0.7 gram of ferrous ammonium sulphate on a watch-glass, wash it into a beaker with distilled water by means of a wash-bottle, taking care that none of the material remains on the watch-glass, add about roo c.c. of distilled water and dissolve completely. To the solution add 2 or 3 c.c. of concentrated nitric acia, boil for a few minutes, supporting the beaker on a tripod with a piece of wire-gauze, add a little more nitric acid, and if no further change of colour occurs the iron has been completely oxidized. This may be determined with certainty by removing a drop of the liquid on a rod to a white 
plate, and adding a drop of potassium ferricyanide ; if no blue precipitate is produced, but only a greenish colouration, the iron has all been converted into the ferric condition. If necessary, add more nitric acid, boil, and test again. Next run in some ammonia and stir well, coninuing until the liquid smells strongly of ammonia. Boil for a few minutes, allow the precipitate to settle, filter the supernatant liquid, pouring it down a glass rod held vertically over the filter, and treat the precipitate with hot water. Repeat the settling and decantation, and finally transfer the precipitate to the filter, continuing the washing with hot water until the odour of ammonia has disappeared, and the washings cease to produce a precipitate with barium chloride in presence of hydrochloric acid, showing that all the sulphate has been removed. To ensure the precipitate being completely transferred to the filter, the inside of the beaker should be rubbed with a glass rod, the end of which is covered with a piece of narrow india-rubber tubing. Place the filter containing the precipitate in a hot air-bath to dry, and in the meantime take a small porcelain crucible with a lid, support it on a pipeclay triangle over a tripod, and ignite it for a few minutes with a bunsen burner. Allow to cool in a desiccator and, when quite cool, weigh. Stand the crucible on a piece of paper, transfer to it as much as possible of the dried precipitate, and burn the filter paper with the remainder. This is best done by rolling the folded paper, apex inside, wrapping a piece of platinum wire round it, holding it over the crucible, and applying a flame. When the paper is completely burned and no carbon remains, drop the ash into the crucible, cover with the lid, support in a pipeclay triangle, and ignite for five minutes in a blowpipe flame. Transfer the crucible to a desiccator, allow to cool, and weigh. Re-ignite for five minutes and weigh again, repeating the ignition, if necessary, until the weight is constant. A deduction must be made for the filter ash, the weight of which is generally stated on the packet of filter papers. 
Example of calculation:-

Weight of ferrous ammonium sulphate taken .

0.700 gram

" crucible and lid, with $\mathrm{Fe}_{2} \mathrm{O}_{3}$ and filter ash . . . . 15.792 grams

" crucible and lid alone . . . 15.648 ",

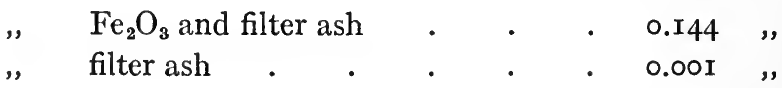

" $\mathrm{Fe}_{2} \mathrm{O}_{3}$. . . . . . 0.143 "

$\mathrm{Fe}_{2} \quad \mathrm{O}_{3}$ contains $2 \mathrm{Fe}$

$$
\begin{array}{cc}
(2 \times 56)+(3 \times 16) & 2 \times 56 \\
=160 & =112
\end{array}
$$

Hence, weight of $\mathrm{Fe}=0.143 \times \frac{\mathrm{II} 2}{\mathrm{I} 60}$ gram in 0.7 gram of material,

$$
\begin{aligned}
& =0.143 \times \frac{\mathrm{II} 2}{\mathrm{I} 60} \times \frac{\mathrm{I00}}{0.7} \text { grams in } 100 \mathrm{grams}, \\
& =\mathrm{I} 4.30 \text { per cent. }
\end{aligned}
$$

The equations representing the reactions involved are as follows :-

Precipitation :

$\mathrm{Fe}_{2}\left(\mathrm{SO}_{4}\right)_{3}+6 \mathrm{NH}_{4} \mathrm{OH}=2 \mathrm{Fe}(\mathrm{OH})_{3}+3\left(\mathrm{NH}_{4}\right)_{2} \mathrm{SO}_{4}$.

Ignition :

${ }_{2} \mathrm{Fe}(\mathrm{OH})_{3}=\mathrm{Fe}_{2} \mathrm{O}_{3}+{ }_{3} \mathrm{H}_{2} \mathrm{O}$.

\section{Estimation of arsenic}

The arsenic is precipitated as sulphide, $\mathrm{As}_{2} \mathrm{~S}_{3}$, by sulphuretted hydrogen in presence of hydrochloric acid, and as the precipitate cannot be ignited without loss, it is filtered through a weighed filter paper, the precipitate is washed, and the filter and precipitate together dried and weighed. The amount of arsenious sulphide is the difference between the total weight and that of the filter paper alone, and from this the amount of arsenic is calculated. 
Required:-

watch-glass

beakers

wash-bottle

funnel

filter papers

weighing-bottle

clock-glass arsenious oxide

sodium carbonate

hydrochloric acid dil.

litmus papers

sulphuretted hydrogen

carbon bisulphide

Procedure :-

Weigh accurately about 0.1 gram of arsenious oxide on a watch-glass, transfer it to a beaker with water, add about I gram of sodium carbonate, and warm the mixture until the arsenic has completely dissolved. Meanwhile, fold a filter paper as if for filtration, roll it up, put it in a small weighingbottle, and place in an air-bath at $100^{\circ} \mathrm{C}$., leaving the stopper loose. Now add dilute hydrochloric acid to the arsenic solution until it is slightly acid to litmus, covering the beaker with a clock-glass meanwhile to prevent loss by spurting, then pass sulphuretted hydrogen through the liquid for some few minutes. When the arsenic is completely precipitated there will be a tendency for the precipitate to settle, and the liquid will smell strongly of the gas. Cover the beaker and heat on a boiling water-bath until the precipitate is coagulated. Now remove the weighing-bottle and filter from the air-bath after about an hour's drying, insert the stopper, allow to cool in a desiccator, and weigh. Place the paper in a funnel, moisten it with water, and filter the precipitate through it; wash thoroughly with hot water until the smell of sulphuretted hydrogen has been removed, and dry in the air-bath for an hour. Transfer the filter to the weighing-bottle, allow to cool in a desiccator, and weigh. Heat again for half an hour and re-weigh, repeating if necessary until a constant weight is obtained. Place the filter and contents once more in a funnel and wash several times with carbon bisulphide, until the wash- 
ings cease to leave a residue on evaporation; this treatment is necessary because the precipitate of arsenious sulphide generally contains free sulphur. Put the filter in a warm place to dispel the last traces of carbon bisulphide, and dry at $100^{\circ} \mathrm{C}$. as before, until the weight is constant.

\section{Example of calculation:-}

Weight of arsenious oxide taken . . . . 0.099 gram

" weighing-bottle and filter, with $\mathrm{As}_{2} \mathrm{~S}_{3} \quad$ I 2.684 grams

" weighing-bottle and filter alone . 12.56I ,"

" $\quad \mathrm{As}_{2} \mathrm{~S}_{3} \cdot \mathrm{S}_{3}$ contains $2 \mathrm{As}$.

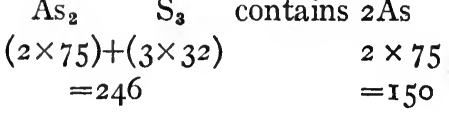

Hence, weight of $A s=0.123 \times \frac{150}{246}$ gram in 0.099 gram of material, $=0.123 \times \frac{150}{246} \times \frac{100}{.099}$ grams in 100 grams,

$=75.75$ per cent.

The reaction is represented by the equation :-

$$
\mathrm{As}_{2} \mathrm{O}_{3}+{ }_{3} \mathrm{H}_{2} \mathrm{~S}=\mathrm{As}_{2} \mathrm{~S}_{3}+{ }_{3} \mathrm{H}_{2} \mathrm{O} \text {. }
$$




\section{CHAPTER II}

\section{VOLUMETRIC ANALYSIS}

Volumetric analysis, as the name implies, is analysis by the measurement of volume; the present chapter will deal with volumetric processes in which standard solutions are used.

A volumetric estimation of this kind is performed by ascertaining the volume of a solution of known strength which is required to complete some definite chemical reaction. For example, the iron in ferrous ammonium sulphate, instead of being precipitated as ferric hydrate and weighed as ferric oxide (see page 4), may be estimated by finding the amount of a solution of potassium permanganate which is required to completely oxidize the iron, and if we know the quantity of iron which a definite volume, say, $\mathbf{x}$ c.c., of the permanganate solution will oxidize, the amount of iron in the substance is easily calculated.

It is obvious that we must commence by preparing solutions of known strength, or, as they are generally called, "standard solutions."

A standard solution may be defined as one which contains a definite weight of a substance in a definite volume of solution. A convenient system is that of "normal" solutions, in which the quantity of substance dissolved is such that a litre (Iooo c.c.) of the solution contains the "equivalent" of the active substance in grams. By the term "equivalent" is meant the weight of the substance which is chemically equivalent to unit weight of hydrogen. For example, the equivalent of hydrochloric acid is 36.5 (since I part by weight of hydrogen is contained in 36.5 parts by weight of hydrochloric acid), hence 
a normal solution of hydrochloric acid will contain 36.5 grams per 1000 c.c., such a solution being designated for brevity $\mathrm{N} / \mathrm{I} \mathrm{HCl}$. Other solutions frequently employed contain onehalf, one-tenth, one-hundredth, or some other fraction of the equivalent in grams per rooo c.c., these are called semi-normal, deci-normal, and centi-normal, respectively, and are for brevity expressed as N/2, N/Io and N/roo.

\section{Standard solutions of acids and bases}

The "active substance" in a molecule of an acid being hydrogen (i.e. the constituent upon which its acid properties depend), the equivalent of an inorganic acid is the weight which contains unit weight of hydrogen replaceable by metals, hence it is ascertained by dividing the molecular weight by the number of hydrogen atoms. For example :

$$
\begin{aligned}
& \mathrm{H} \mathrm{Cl} \text { mol. weight }=36.5, \text { equivalent }=\frac{36.5}{\mathrm{I}}=36.5 . \\
& \mathrm{I}+35.5 \\
& \mathrm{H}_{2} \mathrm{~S} \mathrm{O}_{4} \text { mol. weight }=98, \quad \text { equivalent }=\frac{98}{2}=49 . \\
& 2+32+64
\end{aligned}
$$

In the case of organic acids, the basicity of which depends upon the number of hydrogen atoms contained in carboxyl $(\mathrm{COOH})$ groups, the equivalent may be arrived at by dividing the molecular weight by the number of carboxyl groups. For example :

acetic acid, $\mathrm{CH}_{3} \mathrm{COOH}$, mol. weight $=60$, equivalent $=60$

oxalic acid, l $\mathrm{COOH}, \quad$ mol. weight $=90$, equivalent $=\frac{9 \circ}{2}=45$.

The equivalent of a base may be ascertained from the number of equivalents of a monobasic acid required to completely neutralize one molecule of the base. For example :

$$
\begin{aligned}
& \mathrm{HCl}+\mathrm{NaOH}=\mathrm{NaCl}+\mathrm{H}_{2} \mathrm{O}, \\
& 36.5 \quad 40
\end{aligned}
$$

40 parts $\mathrm{NaOH}$ require 36.5 parts $\mathrm{HCl}$ for neutralization, but 
36.5 is the equivalent of $\mathrm{HCl}$, hence 40 is the equivalent of $\mathrm{NaOH}$, i.e. the weight which is required to replace unit weight of hydrogen by sodium.

$$
\begin{aligned}
& \mathrm{Na}_{2} \mathrm{CO}_{3}+2 \mathrm{HCl}=2 \mathrm{NaCl}+\mathrm{H}_{2} \mathrm{O}+\mathrm{CO}_{2}, \\
& \text { ro6 } 2 \times 36.5
\end{aligned}
$$

Io6 parts $\mathrm{Na}_{2} \mathrm{CO}_{3}$ require 73 parts $\mathrm{HCl}$, hence the equivalent of $\mathrm{Na}_{2} \mathrm{CO}_{3}$ is 53 .

In the case of hydroxides, the equivalents may be found in a similar manner, or the molecular weight may be divided by the number of hydroxyl $(\mathrm{OH})$ groups. For example :

$\mathrm{Ca}(\mathrm{OH})_{2}$ molecular weight $=74$, equivalent $=37$.

Normal solutions of alkalis are such that any given volume

\begin{tabular}{|c|c|c|c|c|c|c|c|}
\hline \multicolumn{5}{|c|}{ c.c. $\mathrm{N} / \mathrm{ro} \mathrm{NaOH}$ contains } & \multicolumn{3}{|c|}{ 0.0040 gram $\mathrm{NaOH}$} \\
\hline & $"$, & , & & is equivalent to & 0.0053 & & $\mathrm{Na}_{2} \mathrm{CO}_{3}$, \\
\hline & ," & ", & ", & " & $0.003 \mathrm{I}$ & & $\mathrm{Na}_{2} \mathrm{O}$ \\
\hline & ," & ", & ," & ," & 0.0056 & & $\mathrm{KOH}$, \\
\hline &, & ,, & ,, & will neutralize & 0.00365 & & $\mathrm{HCl}$ \\
\hline & , & ," & ," & ", & 0.0049 & ," & $\mathrm{H}_{2} \mathrm{SO}_{4}$. \\
\hline
\end{tabular}
requires an equal volume of normal acid for neutralization.

Apparatus required in the use of standard solutions

Graduated measuring flasks are employed for adjusting accurately the volume of standard solutions ; they are of such capacities as 1000 c.c., 500 c.c., and roo c.c., the volume being measured to a mark engraved on the neck of the flask.

Pipettes are used to measure the quantity of liquid which is taken for an estimation. They are usually made to deliver a definite volume when filled to a mark on the stem and completely emptied.

Burettes are used to measure the volume of liquid required to effect the reaction. They are usually divided into tenths of I c.c., the whole volume calibrated being, as a rule, 50 or roo c.c. Burettes and pipettes are usually calibrated at $15^{\circ} \mathrm{C}$. by 
weighing the quantity of water which they deliver at that temperature. Pipettes are generally allowed to drain about fifteen seconds after emptying, but for very accurate work it is necessary to find by experiment what amount of draining is required to obtain the correct quantity from each pipette used. If the error in a pipette is large it must be re-calibrated by putting a piece of gummed paper on the stem, and, by weighing the water delivered from various points, finding the place at which the correct mark must be permanently made.

Similarly, measuring flasks are checked by weighing dry and also filled with water at $15^{\circ} \mathrm{C}$.

Graduated cylinders are employed for measuring the volumes of liquids used, or for making solutions up to bulk, when great accuracy is unnecessary, otherwise they should never be substituted for the foregoing apparatus.

The operation of ascertaining the volume of a standard solution required to complete a definite reaction is known as "titration."

The following rules should be strictly observed :-

r. Standard solutions should always be mixed before use, and should not be left exposed to the air, whether in bottles or burettes.

2. Burettes and pipettes must be washed out before use, with the solutions which are to be measured in them.

3. Graduated cylinders must not be substituted for measuring flasks or pipettes, where accuracy of measurement is required.

4. In using a burette it is necessary to remove all air from the tap and jet by filling the burette above the zero mark and running some of the liquid out. It is sometimes difficult with a clip burette to get rid of the air completely : in such a case some of the solution must be drawn up by dipping the lower end of the burette into the liquid and sucking the air out at the top, opening the clip meanwhile.

5. When reading the level of a liquid in a burette, it is best 
to hold a piece of white paper behind the burette and at an acute angle to it, and note the mark at which the bottom of the dark part of the meniscus stands. In the case of darkcoloured liquids, such as potassium permanganate solution, it is easier to read the level of the upper edge of the meniscus.

6. Whenever possible, two or more titrations should be made, and if these agree within the limits of experimental error, generally about 0.1 c.c., the mean is taken for the purpose of calculation. Should the two titrations differ by a larger amount, the procedure must be repeated until two are obtained which are sufficiently in agreement. The quantities and strength of the solutions should be such that the titrations are neither very small nor very large, the accuracy is impaired on the one hand by relying on a titration of 2 or 3 c.c., and on the other by using so much of the solution as to necessitate refilling the burette in the middle of a titration. It is best to aim at a titration of from Io c.c. to 30 c.c.

\section{The use of indicators}

When performing a titration, in order to ascertain the point at which the reaction is complete, an "indicator" is used.

Some solutions used in volumetric estimations themselves serve as indicators; for example, potassium permanganate, which has a purple colour, and the slightest excess of which is shown by the pink tint imparted to the liquid.

In the titration of acids and alkalis, the indicators used are substances which change colour according as the acid or alkali is in excess. The indicators most frequently employed for this purpose are methyl orange, phenolphthalein and litmus.

Methyl orange is yellow when alkaline, and pink when acid; it is used in aqueous solution, a convenient strength being o.I per cent. Methyl orange can be employed with the commoner mineral acids and strong bases; it is scarcely affected by carbon dioxide so can be used in cases where that gas is 
liberated during the reaction, but it is not sensitive to organic acids and it is decomposed by nitrous acid. The smallest quantity of this indicator which will distinctly colour the liquid should be used.

Phenolphthalein is red when alkaline, and colourless when acid ; it is used in alcoholic solution, about 0.5 per cent., and it can be employed in the titration of mineral acids and also organic acids. Phenolphthalein is sensitive to carbon dioxide so it is best to substitute methyl orange, if possible, in cases where carbon dioxide is set free in the course of the reaction, otherwise the liquid must be boiled. Phenolphthalein cannot be used in presence of ammonium salts.

Litmus is blue when alkaline, red when acid, and purple when neutral; it is used in aqueous solution and may be substituted for the previous indicators in certain cases, notably in the estimation of ammonia. Litmus is affected by carbon dioxide, and the same procedure is necessary as in using phenolphthalein should that gas be liberated during the titration.

Potassium chromate is used in the titration of chlorides by silver nitrate solution. A few drops of a solution of potassium chromate are added, sufficient to tinge the liquid yellow, and when the silver nitrate is run in, the red colour at first produced quickly disappears. When, however, the whole of the chlorine has been precipitated as silver chloride, the red colour becomes permanent and so indicates the end point. The colouration is due to the formation of silver chromate, which is decomposed so long as any chlorine remains in solution.

Starch solution is the usual indicator for iodine, with which it produces a blue colour. When titrating a solution containing free iodine with sodium thiosulphate, the latter is run in until the yellow colour of the iodine becomes faint, then a few drops of starch solution are added, and the titration continued until the blue colour just disappears.

Starch-potassium iodide paper is used as an external indicator in the valuation of bleaching powder by arsenious acid, the 
end point being reached when a drop of the liquid ceases to produce a blue colouration on the paper.

\section{Alkalimetry and Acidimetry}

Preparation of decinormal sodium carbonate solution

$\mathrm{N} / \mathrm{ro} \mathrm{Na}_{2} \mathrm{CO}_{3}=5 \cdot 3$ grams per 1000 c.c.

Required:-

burette and stand

beaker

pure anhydrous sodium carbonate

graduated flask 500 c.c. (best prepared by igniting bipipette 25 c.c. carbonate)

weighing-bottle

wash-bottle

\section{Procedure :-}

Weigh accurately 2.65 grams of pure anhydrous sodium carbonate, using a stoppered weighing-bottle for the purpose, transfer the material to a beaker, washing out the weighingbottle with distilled water into the beaker, and dissolve the sodium carbonate completely. Pour the solution into a 500 c.c. graduated flask, rinse the beaker several times with distilled water, adding the washings to the contents of the flask, and make up the solution to the mark. Mix thoroughly; the solution is decinormal, and I c.c. contains 0.0053 gram $\mathrm{Na}_{2} \mathrm{CO}_{3}$.

\section{Preparation of decinormal sulphuric acid solution}

$\mathrm{N} / \mathrm{I} \circ \mathrm{H}_{2} \mathrm{SO}_{4}=4.9$ grams per 1000 c.c.

\section{Required:-}

apparatus used in last experiment pure sulphuric acid

pipette graduated in c.c. methyl orange

\section{Procedure :-}

Take a 500 c.c. graduated flask about half-filled with distilled water and run in from a pipette 2 c.c. of pure sulphuric acid, 
make up the volume to 500 c.c. with distilled water and mix thoroughly. Pipette 25 c.c. N/Io sodium carbonate solution into a beaker, add two or three drops of methyl orange, stand the beaker on a white plate or piece of white paper, and titrate with the sulphuric acid solution until the liquid just becomes pink. Repeat the titration, using a further quantity of sodium carbonate solution, the two titrations should not differ by more than 0.I c.c.; the quantity of acid required will be found to be less than 25 c.c., showing that the solution is too strong. Calculate the amount of dilution required, as follows :-

Suppose 25 c.c. $\mathrm{N} / 10 \mathrm{Na}_{2} \mathrm{CO}_{3}$ require 20.7 c.c. of the $\mathrm{H}_{2} \mathrm{SO}_{4}$ solution, then every 20.7 c.c. of the acid require dilution to 25 c.c. with water to make the solution equivalent to the sodium carbonate solution, that is, decinormal. Then to make 500 c.c. $\mathrm{N} / \mathrm{ro}_{2} \mathrm{SO}_{4}$ the amount of the solution which must be diluted is $20.7 \times \frac{500}{25}=4 \mathrm{r} 4$ c.c. After adding the necessary 86 c.c. of water and mixing, titrate two further quantities of $\mathrm{N} /$ ro $\mathrm{Na}_{2} \mathrm{CO}_{3}$ to ensure that the acid is exactly decinormal ; should it be found to be still too strong, more water must be added and the solution again checked.

\section{Preparation of decinormal sodium hydrate solution}

$\mathrm{N} /$ ro $\mathrm{NaOH}=4.0$ grams per roo० c.c.

Required :-

apparatus as in previous experiments

sodium hydrate (solid, or strong solution)

phenolphthalein

Procedure:-

Weigh in a stoppered weighing-bottle about 2.5 grams of sodium hydrate, as free as possible from carbonate, or measure a quantity of a strong solution containing this amount, and make up with distilled water to 500 c.c. Titrate a measured quantity of the solution with $\mathrm{N} / \mathrm{I} O \mathrm{H}_{2} \mathrm{SO}_{4}$, using methyl orange 
as indicator, calculate the amount of water required for dilution, and adjust the strength of the solution so that 25 c.c. exactly neutralizes 25 c.c. of $\mathrm{N} / 1 \circ \mathrm{H}_{2} \mathrm{SO}_{4}$.

Repeat the final titrations, using phenolphthalein as indicator, in this case titrating the acid with the alkali.

N.B.--It is important, when phenolphthalein is used, to avoid unnecessary exposure to the air during the titration, as carbon dioxide has an appreciable effect.

\section{Applications of standard acid and alkali}

Determination of the alkalinity of water.

Many natural waters contain bicarbonates of calcium and magnesium, causing "temporary hardness" (see page 138 ), and the alkalinity due to these compounds may be estimated by titration with standard acid, using methyl orange as indicator. It is customary to calculate the result in parts of $\mathrm{CaCO}_{\mathbf{3}}$ per I00,000 parts of water.

$$
\begin{aligned}
& \mathrm{Ca} \mathrm{C} \mathrm{O}_{3}+\mathrm{H}_{2} \mathrm{~S} \quad \mathrm{O}_{4}=\mathrm{CaSO}_{4}+\mathrm{CO}_{2}+\mathrm{H}_{2} \mathrm{O}, \\
& 40+\mathrm{r} 2+48 \quad 2+3^{2+64} \\
& \quad=100 \quad=98
\end{aligned}
$$

hence, the equivalent of $\mathrm{CaCO}_{3}$ is 50 , and

$$
\text { I cc. } \mathrm{N} / \mathrm{I} \circ \mathrm{H}_{2} \mathrm{SO}_{4}=0.005 \text { gram } \mathrm{CaCO}_{3} \text {. }
$$

Required:-

burette

N/Io sulphuric acid solution

pipette roo c.c.

beaker methyl orange

\section{Procedure :-}

Pipette 100 c.c. of the water into a beaker, add methyl orange, and titrate with $\mathrm{N} /$ 10 $\mathrm{H}_{2} \mathrm{SO}_{4}$. Repeat the titration with a further Ioo c.c. of the sample.

Example:-

If the titrations are (I) r.9 c.c., (2) I 8 c.c., mean 1.85 c.c., then $\mathrm{CaCO}_{3}=\mathrm{I} .85 \times 0.005$ gram in 100 c.c. of water, 
$=\mathrm{I} .85 \times 0.005 \times \frac{100,000}{100}$ grams in 100,000 c.c. of water, $=9.25$ parts per 100,000.

The above is Hehner's method for the estimation of temporary hardness.

\section{Estimation of acetic acid in vinegar}

A measured quantity of vinegar is diluted with water, and an aliquot part of the solution is titrated with standard sodium hydrate solution. As acetic acid is an organic acid the indicator used is phenolphthalein. The result is expressed as grams of acetic acid per Ioo c.c. vinegar.

$\mathrm{CH}_{3} \mathrm{COOH}$ molecular weight $=60$, equivalent $=60$, hence I c.c. $\mathrm{N} / \mathrm{I} \circ \mathrm{NaOH}=0.006$ gram acetic acid.

Required :-

burette

pipettes ro c.c. and 20 c.c. N/Io sodium hydrate solution graduated flask roo c.c. beaker phenolphthalein

\section{Procedure :-}

Pipette ro c.c. of vinegar into a Ioo c.c. graduated flask, and make up the bulk to roo c.c. with distilled water. Mix, pipette 20 c.c. of the solution into a beaker and titrate with $\mathrm{N} /$ ro $\mathrm{NaOH}$, adding several drops of phenolphthalein as indicator. Repeat the titration, using a further 20 c.c. of the vinegar solution.

Example :-

If the titrations are (I) I4.I c.c., (2) I4.0 c.c., mean I4.05 c.c., then acetic acid $=14.05 \times 0.006$ gram in 20 c.c. of solution, $=14.05 \times 0.006 \times 5$ gram in 100 c.c. of solution, which contain ro c.c. vinegar, $=14.05 \times 0.006 \times 5 \times 10$ grams in 100 c.c. vinegar, $=4.22$ grams per 100 c.c. vinegar. 


\section{Estimation of calcium hydrate in lime-water}

A measured quantity of the lime-water is titrated with standard acid (hydrochloric acid for preference), using methyl orange as indicator, and the result is calculated as grams of calcium hydrate per 100 c.c.

$$
\begin{aligned}
& \mathrm{Ca}(\mathrm{OH})_{2}+{ }_{2} \mathrm{HCl}=\mathrm{CaCl}_{2}+2 \mathrm{H}_{2} \mathrm{O} \text {, } \\
& 40+2(\mathrm{I} 6+\mathrm{I}) \quad 2(\mathrm{I}+35 \cdot 5) \\
& =74 \quad=73
\end{aligned}
$$

hence I c.c. $\mathrm{N} / \mathrm{\text {Io }} \mathrm{HCl}=0.0037$ gram $\mathrm{Ca}(\mathrm{OH})_{2}$.

Required :-

burette

N/ro hydrochloric acid solution

pipette 50 c.c.

beaker

methyl orange

\section{Procedure:-}

Pipette 50 c.c. of the lime-water into a beaker, add two or three drops of methyl orange, and titrate with $\mathrm{N} / \mathrm{r} \circ \mathrm{HCl}$. Repeat the titration with a further 50 c.c. of the sample.

Example:-

If the titrations are (I) I9.3 c.c., (2) I9.2 c.c., mean I9.25 c.c., then $\mathrm{Ca}(\mathrm{OH})_{2}=19.25 \times 0.0037$ gram in 50 c.c. of solution,

$=19.25 \times 0.0037 \times 2$ gram in 100 c.c.,

$=0.14$ gram in 100 c.c.

Preparation of decinormal silver nitrate solution

Standard silver nitrate solution is frequently used for the estimation of chlorine in combination as chlorides.

$$
\begin{aligned}
& \mathrm{Ag} \quad \mathrm{N} \quad \mathrm{O}_{3}+\mathrm{Na} \quad \mathrm{Cl}=\mathrm{AgCl}+\mathrm{NaNO}_{3} \text {, } \\
& \mathrm{I0} 8+\mathrm{I} 4+48 \quad 23+35.5 \\
& =\mathrm{I} 70 \quad=58.5
\end{aligned}
$$

I 70 parts of $\mathrm{AgNO}_{3}$ are equivalent to 35.5 parts of $\mathrm{Cl}=\mathbf{I}$ part $\mathrm{H}$, hence $\mathrm{N} /$ I० $\mathrm{AgNO}_{3}=17$ grams per 1000 c.c., and I c.c. $\mathrm{N} / \mathrm{I} \circ \mathrm{AgNO}_{3}=0,00355$ gram Cl,

$$
=0.005^{8} 5 \text { gram NaCl} \text {. }
$$


Weigh 17 grams of pure silver nitrate, dissolve in water, and make the solution up to rooo c.c. Should the silver nitrate not be quite pure, take rather more than 17 grams and standardize the solution by means of a decinormal solution of sodium chloride ( 5.85 grams per rooo c.c.), using potassium chromate as indicator (see page I4).

\section{-Standard potassium permanganate solution}

Potassium permanganate $\left(\mathrm{KMnO}_{4}\right)$ has many uses as an oxidizing agent, and under certain conditions it parts with a fixed proportion of its oxygen. The conditions necessary are:-the presence of oxidizable material and a sufficient quantity of sulphuric acid, the oxygen given up being in the proportion of five atoms for every two molecules of permanganate, or

\section{$2 \mathrm{KMnO}_{4}$ yields $5 \mathrm{O}$,}

and the five atoms of oxygen are called the " available oxygen."

The full equation is :-

$$
2 \mathrm{KMnO}_{4}+{ }_{3} \mathrm{H}_{2} \mathrm{SO}_{4}=\mathrm{K}_{2} \mathrm{SO}_{4}+2 \mathrm{MnSO}_{4}+3 \mathrm{H}_{2} \mathrm{O}+5 \mathrm{O} \text {. }
$$

\section{Preparation of decinormal potassium permanganate solution}

A decinormal solution is, as we have already seen, one which contains one-tenth of the equivalent of the active substance in grams in Iooo c.c. of the solution. The "active substance" in this case is the available oxygen, hence $\mathrm{N} / \mathrm{ro} \mathrm{KMnO}_{4}$ is a solution of such a strength that 1000 c.c. will yield 0.8 gram of oxygen.

$$
\begin{aligned}
& 2 \mathrm{~K} \quad \mathrm{Mn} \mathrm{O}_{4} \text { yield } 5 \mathrm{O} \\
& 2(39+55+64) \quad 5 \times 16 \\
& =316 \quad=80
\end{aligned}
$$

* The oxygen is here expressed as a number of atoms (O), instead of molecules $\left(\mathrm{O}_{2}\right)$, as is usual, to indicate that it is not liberated in the gaseous condition, but combines with the oxidizable material while it is " nascent." See pages 125 and 126. 
or, 3 1.6 grams yield 8 grams of oxygen,
3.16 ,
0.8 gram of oxygen,

hence $\mathrm{N} / \mathrm{I} \circ \mathrm{KMnO}_{4}$ contains 3.16 grams $\mathrm{KMnO}_{4}$ per 1000 c.c.

Required :-

watch-glass

graduated flask 500 c.c. potassium permanganate

beaker

wash-bottle

\section{Procedure :-}

Weigh on a watch-glass $\mathbf{r} .5^{8}$ grams of pure potassium permanganate, transfer to a beaker, and treat with a small quantity of distilled water. Shake the liquid carefully, allow to stand for a few minutes, and decant the solution into a 500 c.c. graduated flask. Repeat the treatment with water and decantation until all the permanganate has dissolved, then make up the solution to the mark on the flask, and mix. This procedure is preferable to putting the permanganate directly into the flask, as the liquid rapidly becomes too dark to be transparent, and there is difficulty in ascertaining when all the crystals have dissolved.

The solution, which is decinormal, may be used for various quantitative estimations.

\section{Estimation of iron in the ferrous condition}

Ferrous salts are readily oxidized by potassium permanganate, in presence of sulphuric acid, forming ferric compounds. As the simplest example, we may take the case of the oxides: the conversion of ferrous oxide into ferric oxide is represented by the equation:-

$$
{ }_{2} \mathrm{FeO}+\mathrm{O}=\mathrm{Fe}_{2} \mathrm{O}_{3},
$$

since one atom of oxygen oxidizes two atoms of iron, it is obvious that two molecules of potassium permanganate, which 
yield five atoms of oxygen, will oxidize ten atoms of iron from the ferrous to the ferric state.

Let us take ferrous sulphate, $\mathrm{FeSO}_{4}$, as an example. On oxidation in presence of sulphuric acid this becomes ferric sulphate, $\mathrm{Fe}_{2}\left(\mathrm{SO}_{4}\right)_{3}$, these two sulphates being analogous to the oxides, $\mathrm{FeO}$ and $\mathrm{Fe}_{2} \mathrm{O}_{3}$. Two molecules of $\mathrm{KMnO}_{4}$ will oxidize ten molecules of $\mathrm{FeSO}_{4}$, forming five molecules of $\mathrm{Fe}_{2}\left(\mathrm{SO}_{4}\right)_{3}$. To complete the equation we must remember that $\mathrm{K}_{2} \mathrm{SO}_{4}$ and $2 \mathrm{MnSO}_{4}$ are also formed, and supplying the necessary number of molecules of $\mathrm{H}_{2} \mathrm{SO}_{4}$, we finally arrive at the following :-

$$
\begin{gathered}
2 \mathrm{KMnO}_{4}+\mathrm{IOFeSO}_{4}+8 \mathrm{H}_{2} \mathrm{SO}_{4}={ }_{5} \mathrm{Fe}_{2}\left(\mathrm{SO}_{4}\right)_{3}+\mathrm{K}_{2} \mathrm{SO}_{4}+ \\
2 \mathrm{MnSO}_{4}+8 \mathrm{H}_{2} \mathrm{O} .
\end{gathered}
$$

In practice it is usual to add more sulphuric acid than is required theoretically, consequently some of the acid remains in the final product.

The permanganate solution was made of such a strength that rooo c.c. of the solution contained 0.8 gram of available oxygen, hence I c.c. $=0.0008$ gram oxygen.

From the equation: $2 \mathrm{FeO}+\mathrm{O}=\mathrm{Fe}_{2} \mathrm{O}_{3}$,

we see that one atom of oxygen oxidizes two atoms of iron, or 16 parts by weight of oxygen $=2 \times 5^{6}$ parts by weight of iron, or 8

$$
=56
$$

therefore I c.c. $\mathrm{N} /$ Io $\mathrm{KMnO}_{4}=0.0056$ gram Fe.

\section{Estimation of iron in ferrous ammonium sulphate}

Required :-

As in last experiment, also :graduated flask $25^{\circ}$ c.c.

pipette 50 c.c.

cylinder $5 \circ$ c.c.

burette ferrous ammonium sulphate sulphuric acid dil.

\section{Procedure :-}

Weigh 3 grams of ferrous ammonium sulphate, dissolve in 
water, and make up the solution to 250 c.c. Pipette 50 c.c. of the solution into a beaker, add about 20 c.c. of dilute sulphuric acid, and titrate with $\mathrm{N} /$ Io $\mathrm{KMnO}_{4}$ until a faint pink colour remains permanent. Should the liquid on the addition of permanganate become brown and turbid, insufficient acid has been added.

\section{Example:-}

3.0 grams of ferrous ammonium sulphate were used, and the mean of the two titrations was $\mathrm{r} 5.3$ c.c. $\mathrm{N} / \mathrm{r} \circ \mathrm{KMnO}_{4}$ for 50 c.c. of the solution,

then $\mathrm{Fe}=15.3 \times 0.0056$ gram in 50 c.c. of solution, $=15.3 \times 0.0056 \times 5$ gram in 250 c.c. of solution, i.e. in 3.0 grams of the salt,

hence, $\mathrm{Fe}=\mathrm{I} 5.3 \times 0.0056 \times 5 \times \frac{\mathrm{I00}}{3}=\mathrm{I} 4.28$ per cent.

\section{Estimation of oxalic acid}

By suitable oxidizing agents, ox lic acid is decomposed into carbon dioxide and water, according to the equation :-

\section{$\mathrm{COOH}$}

$\left.\right|_{\mathrm{COOH}}+\mathrm{O}=2 \mathrm{CO}_{3}+\mathrm{H}_{2} \mathrm{O}$.

The equation rèpresenting the action of potassium permanganate in presence of sulphuric acid is :-

$$
\begin{gathered}
{ }_{2} \mathrm{KMnO}_{4}+5(\mathrm{COOH})_{2}+3 \mathrm{H}_{2} \mathrm{SO}_{4}=\mathrm{IOCO}_{2}+\mathrm{K}_{2} \mathrm{SO}_{4}+ \\
{ }_{2} \mathrm{MnSO}_{4}+8 \mathrm{H}_{2} \mathrm{O} .
\end{gathered}
$$

The molecular weight of oxalic acid is 90 , and from the former of the above equations it is seen that 90 parts by weight of oxalic acid are oxidized by 16 parts by weight of oxygen, or 45 parts of oxalic acid require 8 parts of oxygen, hence

I c.c. $\mathrm{N} / \mathrm{10} \mathrm{KMnO}_{4}=0.0045$ gram oxalic acid.

The reaction is slow in the cold, but rapid if the solution is 
heated to about $60^{\circ} \mathrm{C}$., and the method is a convenient one for the estimation of oxalic acid and oxalates.

Required :-

watch-glass

graduated flask roo c.c. ammonium oxalate (solid)

burette

pipette 25 c.c.

cylinder 50 c.c.

wash-bottle sulphuric acid dil.

$\mathrm{N} /$ I 0 potassium permanganate solution

beaker

Procedure :-

Weigh I.o gram of crystallized ammonium oxalate, $\left(\mathrm{NH}_{4}\right)_{2} \mathrm{C}_{2} \mathrm{O}_{4} \cdot \mathrm{H}_{2} \mathrm{O}$, dissolve in water and make up the solution to Ioo c.c. Take 25 c.c. of the solution, dilute with about 50 c.c. of water, add about 20 c.c. dilute sulphuric acid, and heat the mixture nearly to boiling in a beaker. Titrate the hot liquid with $\mathrm{N} /$ ro $\mathrm{KMnO}_{4}$, and calculate the percentage of oxalic acid, and of ammonium oxalate.

\section{Use of factors with standard solutions}

In the case of solutions which alter in strength on keeping, and which consequently have always to be checked before use, it is convenient to use "factors," that is, numbers by which the titration results must be multiplied in order to obtain the corresponding number of c.c. of normal, decinormal or other solution.

For example, sodium thiosulphate $\left(\mathrm{Na}_{2} \mathrm{~S}_{2} \mathrm{O}_{3}\right)$ solution has to be frequently standardized, a weighed quantity of iodine being conveniently used for this purpose. A decinormal solution of sodium thiosulphate requires 0.0127 gram of iodine for each c.c., but suppose it is found by titration that the solution is weak and that I c.c. $=0.0125$ gram of iodine, then the factor for the thiosulphate is $\frac{0.0125}{0.0127}=0.984$, and if in a particular 
titration $\mathrm{I} 7.8$ c.c. of thiosulphate are used, the actual amount of $\mathrm{N} / 1 \circ \mathrm{Na}_{2} \mathrm{~S}_{2} \mathrm{O}_{3}$ required will be $17.8 \times 0.984=17.5$ c.c.

If, on the other hand, the thiosulphate solution is stronger than decinormal, the factor will be greater than $\mathbf{r}$; for example, suppose I c.c. is found to require 0.0129 gram of iodine, then the factor is $\frac{0.0129}{0.0127}=\mathrm{r} .016$, and if $\mathrm{I} 7.8$ c.c. of the solution are used, the corresponding amount of $\mathrm{N} / \mathrm{ro} \mathrm{Na}_{2} \mathrm{~S}_{2} \mathrm{O}_{3}$ will be $\mathrm{r} 7.8 \times \mathrm{r} .0 \mathrm{I} 6=\mathrm{I} 8 . \mathrm{I}$ c.c.

When it is practicable, as is usually the case, to prepare a standard solution with which no factor is necessary, it is desirable to do so, as the use of a factor introduces complications into the calculation of results.

\section{Other standard solutions}

Standard solutions are often used of which I c.c. contains o.I milligram or some other convenient quantity of a substance without reference to the chemical equivalent. In water analysis such solutions are largely employed, and their use simplifies the calculation of the results.

For example, in the estimation of ammonia in water a solition of ammonium chloride is used of which I c.c. contains 0.00005 gram $\mathrm{NH}_{3}$, the quantity of ammonium chloride required being calculated as follows :-

0.00005 gram per I c.c. $=0.05$ gram per ro00 c.c.,

53.5 grams $\mathrm{NH}_{4} \mathrm{Cl}$ contain 77 grams $\mathrm{NH}_{3}$

$x$ grams $\mathrm{NH}_{4} \mathrm{Cl}$ contain 0.05 grams $\mathrm{NH}_{3}$

$$
x=53.5 \times \frac{0.05}{\mathrm{I} 7}=0 . \mathrm{I} 57 \mathrm{gram} .
$$

Thus, if 0.157 gram $\mathrm{NH}_{4} \mathrm{Cl}$ is dissolved in rooo c.c. of water, I c.c. contains 0.00005 gram $\mathrm{NH}_{3}$.

It is convenient in practice to make up a solution ten times this strength and dilute it as required. 
Another solution used in water analysis is that of potassium permanganate, I c.c. containing $0.000 \mathrm{I}$ gram of available oxygen, i.e. o.I gram per rooo c.c. We have already seen (page 20 ) that $3^{\mathrm{I} 6}$ grams of potassium permanganate contain 80 grams of available oxygen, hence 0.1 gram is contained in

$$
316 \times \frac{0.1}{80}=0.395 \text { gram of permanganate. }
$$

To prepare the solution, 0.395 gram of pure potassium permanganate is dissolved in 1000 c.c. of water. 


\section{CHAPTER III}

\section{MILK}

Cow's milk has the following average composition :-

Fat • • • • • $\quad 3.7$ per cent.

Lactose . . . 4.7 per cent.

Proteins . . 3.4 "

Mineral Matter - 0.75 ,

Non-fatty Solids . . . . 885 ",

Water . . . . . 87.45 ",

100.00, ,

"Vieth's ratio" for lactose, proteins and mineral matter is I $3: 9: 2$.

The fat is in very small globules forming an emulsion; there has been a great deal of controversy as to the existence of a nitrogenous membrane surrounding the fat globules, but this view is not now generally accepted.

The proteins consist principally of caseinogen (which is precipitated by acids and produces casein on coagulation by rennet) and lact-albumen, the percentage of nitrogen in milk being normally between 0.50 and 0.55 . The casein is probably in combination with alkalis.

The mineral matter consists principally of calcium and potassium phosphates and chlorides, the ash amounting to about 8.5 per cent. of the non-fatty solids. In normal milk the percentage of $\mathrm{CaO}$ is 0.17 and of $\mathrm{P}_{2} \mathrm{O}_{5}$ 0.23. Milk also contains a small quantity of citric acid. 
There are slight seasonal variations in the composition of milk, the fat being lowest from April to June, and highest about November, and the non-fatty solids are lowest in July and August.

The longer the interval that elapses between successive milkings the greater is the quantity of milk, but the poorer it is in fat. Morning milk contains slightly less fat then evening milk from the same cows.

The first portion of the milk, or "fore milk," is poorer in fat than the latter portion, or "strippings," hence if the milking is not complete a product containing less fat is obtained.

Occasionally a cow yields abnormal milk, and if in such a case the proportion of non-fatty solids is low, the deficiency is generally in milk sugar (Richmond). As a rule, the milk of a number of cows is mixed, so that the abnormality of the milk from one animal does not seriously affect the whole product.

The following results published by Arup, Huish and Droop Richmond ("Analyst" I9I 7, 42, I I9), give the monthly averages of over 14,000 samples of milk analysed by them in 19r6 :-

\section{Morning Milk Evening Milk Mean}

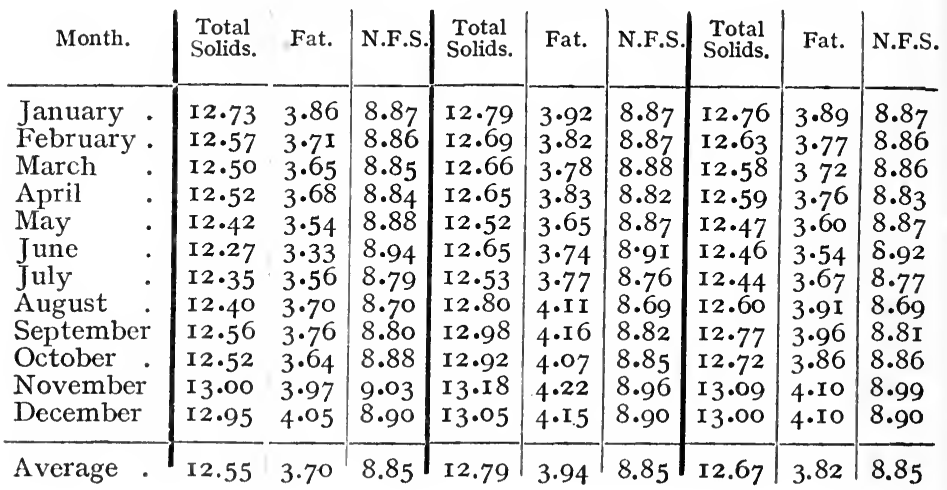


The Sale of Milk Regulations, I9or, made by the Board of Agriculture in exercise of powers conferred by the Sale of Food and Drugs Act, I899, are as follows :-

r. Where a sample of milk (not being sold as skimmed, or separated, or condensed milk) contains less than 3 per cent. of milk-fat, it shall be presumed for the purposes of the Sale of Food and Drugs Acts, I 875 to 1899 , until the contrary is proved, that the milk is not genuine, by reason of the abstraction therefrom of milk-fat, or the addition thereto of water.

2. Where a sample of milk (not being sold as skimmed, or separated, or condensed milk) contains less than 8.5 per cent. of milk-solids other than milk-fat, it shall be presumed for the purposes of the Sale of Food and Drugs Acts, I875 to I899, until the contrary is proved, that the milk is not genuine, by reason of the abstraction therefrom of milk-solids other than milk-fat, or the addition thereto of water.

By the Sale of Milk Regulations, 1912, skimmed milk must contain not less than 8.7 per cent. of non-fatty solids.

\section{Analysis of milk}

It is very important that milk should be well mixed immediately before taking a portion for analysis, as the cream rapidly rises. The sample should not, however, be shaken violently, because if the milk is turning sour the shaking will tend to curdle it, and thereby render the analysis more difficult.

The most important estimations are those of fat and total solids, the non-fatty solids being obtained as the difference of the two. The determination of specific gravity is also useful in the preliminary sorting of samples of milk; taken in conjunction with the percentage of fat it gives a fair idea of the quality of a milk (see "Richmond's Milk Scale," page 35).

The specific gravity increases for some time after milking, and should not be determined for at least six hours afterwards. The average specific gravity is 1032 at $15^{\circ} \mathrm{C}$. Since milk-fat is the lightest constituent, its abstraction from milk increases the 
specific gravity, while the addition of water lowers it, so it is quite possible for a sample of milk to have a normal specific gravity although it has been adulterated both by skimming and watering, consequently the determination of this figure alone is of little value.

The specific gravity is most easily ascertained by a hydrometer, the correctness of which must be proved by means of liquids, the densities of which have been accurately determined, e.g. by a Sprengel tube (see page 70 ).

\section{Estimation of total solids}

Required :-

milk basin, or porcelain dish, size o०

pipette ro c.c.

crucible tongs

pipeclay triangle

\section{Procedure :-}

Take a milk basin or small porcelain dish, put some distinguishing mark with ink inside and close to the edge, and ignite on a pipeclay triangle over a bunsen burner. Allow to cool in a desiccator, and weigh. Mix the milk thoroughly and pipette ro c.c. into the dish, allowing the pipette to drain well, then weigh the dish and milk. Dry on a boiling water-bath for three hours, transfer to a steam oven (or an air-bath kept at $100^{\circ} \mathrm{C}$.) for an hour, cool in the desiccator, and weigh. Heat again in the oven for half an hour, cool, and re-weigh. If the loss in weight after the second drying exceeds two or three milligrams the heating must be continued until the weight is constant.

$N . B$.- It is essential that the water-bath should be actually boiling, otherwise there will be difficulty experienced in obtaining a constant weight:

The estimation of total solids in milk may be hastened by the addition of a few drops of dilute acetic acid, but the result is not so reliable as that obtained by simple evaporation. 
Example of calculation :-

Weight of dish and milk . $\quad 35.943$ grams

" dish alone . . 25.763 "

" milk taken . . I0.I80 ",

Weight of dish and solids . $\quad$ 26.977 grams

" dish alone $\quad . \quad \frac{25.763}{1.214} "$

Total solids $=\mathrm{I} .2 \mathrm{I} 4 \times \frac{100}{10.180}=\mathrm{II} .92$ per cent.

\section{Estimation of fat}

The generally accepted standard method is :-

\section{Adams' Process.}

For this method specially prepared strips of absorbent paper are used which have been extracted with a solvent (alcohol with a little acetic acid may be used) to remove all fatty matter. The milk is spread on one of these and dried, after which the fat is extracted with ether and weighed.

Required :-

pipette ro c.c.

Soxhlet extractor fitted with flask and condenser small water-bath paper strip (as above) ether (dried over calcium chloride)

\section{Procedure :-}

Suspend one of the paper strips from the bench by means of a pin, turn up the lower end of the paper about half an inch and pipette 1o c.c. of the well-mixed milk carefully on to it (the same pipette is used as was employed in the estimation of total solids, allowing it to drain to the same extent, then the weight of milk will be the same); the milk should be completely and rapidly absorbed. Allow the paper to dry in the air, then roll it round a glass rod and fasten by putting the pin through it. 
Place the coil in an air-bath at $100^{\circ} \mathrm{C}$. for an hour, then transfer to a Soxhlet extractor, attach a dry weighed flask, and extract for three hours with dry ether. Detach the flask, connect it with a condenser, and distil off the ether by warming over a water-bath. Remove the flask, blow air through it with a bellows to dispel the last traces of ether, and place the flask and fat in an air-bath at about $105^{\circ} \mathrm{C}$. Blow air through frequently, allow to cool, and weigh, repeat the heating and re-weigh, when there should be not more than one or two milligrams lost. Calculate the percentage of fat.

Example of calculation:-

$$
\begin{array}{cc}
\text { Weight of milk taken } & \cdot 10.180 \text { grams } \\
" \quad \text { flask and fat } & \cdot 56.374 ", \\
" \quad \text { flask alone } & \cdot \frac{56.005}{} " \\
\text { Weight of fat } & \cdot 0.369 " \\
\text { Fat }=0.369 \times \frac{\text { 100 }}{10.180}=3.62 \text { per cent. }
\end{array}
$$

N.B.-If, as is sometimes the case, there is difficulty in completely absorbing ro c.c. of milk on the paper, 5 c.c. may be used, the weight of this being found as before.

\section{Werner-Schmid Process.}

In this process the milk is heated with hydrochloric acid, which dissolves the greater part of the casein, liberating the fat, the latter is then extracted with ether, and weighed.

Required:-

pipette 1o c.c. (as used for total solids)
Schmid tube ether
hydrochloric acid conc.

flask about 300 c.c.

apparatus for distilling ether

\section{Procedure:-}

Mix the milk, and pipette Io c.c. into a Schmid tube (the 
same pipette being used as was employed for total solids estimation). Add ro c.c. of concentrated hydrochloric acid and immerse the tube in a boiling water-bath, shaking occasionally, until the mixture has become brown and most of the casein has dissolved. Remove the tube from the water-bath, allow to stand a few minutes and cool completely by holding it under a cold water tap; add ether up to the 50 c.c. mark and insert the cork tightly. Invert the tube two or three times, then remove the cork for a moment to release the pressure, replace the cork tightly and shake well but not violently. Allow to stand until the ethereal solution has separated (this may be hastened by rotating the tube), the flocculent layer at the bottom of the ether should not occupy more than about I c.c. Read the volume of the ethereal solution, including two-thirds of the flocculent layer. In the meantime, take a dry flask, heat it for a short time in an air-bath, allow it to cool, and weigh. Pipette as much as possible of the ethereal solution into the flask (holding the tube close to the flask), without disturbing the lower liquid, and read the volume of ether remaining in the tube. Pour a little ether through the pipette and add it to the contents of the flask. Distil off the ether, blow air through the flask, dry the fat in an air-bath at $100^{\circ} \mathrm{C}$. and weigh. Repeat the drying for half an hour and weigh again, continuing until the weight is constant.

\section{Example of calculation:-}

Weight of milk taken . . . I0.180 grams

Total volume of ethereal solution . 28 c.c.

Volume of ethereal solution remaining 4 ,

$$
\text { Ethereal solution used } \quad 24 \text { c.c. }
$$

Weight of flask and fat . . . 48.772 grams

$\begin{array}{lll}\quad \text { flask alone } & \cdot \quad \frac{48.469}{0.303} \text { gram }\end{array}$




$$
\begin{aligned}
\text { Fat } & =0.303 \times \frac{28}{24}=0.354 \text { gram from } 10.180 \text { grams of milk, } \\
& =0.354 \times \frac{100}{10.180}=3.48 \text { per cent } .
\end{aligned}
$$

\section{Leffmann-Beam process.}

The Leffmann-Beam process is an example of rapid centrifugal methods of fat estimation, useful for sorting purposes but not so accurate as the foregoing processes.

For this method special bottles are employed, having a capacity of about 30 c.c. and with long necks graduated into a number of divisions, each corresponding, when 15 c.c. of milk are used, to $0 . \mathrm{I}$ per cent. of fat.

Required :-

Leffmann-Beam bottles mixture of hydrochloric acid pipettes 15 and 3 c.c. conc. and amyl alcohol ( $I$ to $\mathbf{r}$ ) *burette and stand beaker commercial sulphuric acid (about 96 per cent.)

sulphuric acid solution ( $\mathrm{x}$ in 3 )

\section{Procedure:-}

Mix the milk, pipette 15 c.c. into one of the bottles, add 3 c.c. of the mixture of hydrochloric acid and amyl alcohol and shake. Run in from a burette* 9 c.c. sulphuric acid in small quantities, shaking well after each addition; by the time all the acid has been added the casein should be completely dissolved, the solution being of a reddish-brown colour (see under Formaldehyde, page 45). Fill nearly to the top of the neck with hot dilute sulphuric acid ( $\mathrm{I}$ in 3 ), place the bottle in a centrifuge and whirl for three minutes at a speed of about twelve hundred revolutions per minute. Warm the bottle on a water-bath and read off the number of divisions occupied by the fat ; this number divided by ten is the percentage of fat in the milk.

* A special burette with a wide jet is used for this purpose. 


\section{Richmond's milk scale}

If the percentage of fat and the specific gravity have been determined, the approximate amount of total solids can be found by means of Richmond's milk scale. This is a sliderule based upon the formula :-

$$
\mathrm{T}=0.25 \mathrm{G}+\mathrm{I} .2 \mathrm{~F}+0.14 \text {, }
$$

where $\mathrm{T}=$ percentage of total solids,

$\mathrm{G}=$ the last two figures of the specific gravity (water $=\mathrm{I} 000$ ),

and $\mathrm{F}=$ percentage of fat.

The scale is graduated on one side for percentages of fat and on the other side for total solids, whilst the central sliding portion carries a scale of specific gravities and also has an arrow marked on it. When this arrow is pointing to the figure representing the amount of fat in the milk, then opposite the specific gravity figure (determined at $60^{\circ} \mathrm{F}$.) will be found the percentage of total solids.

There is also a scale for the correction of the specific gravity, to be used when the temperature of the milk is higher or lower than $60^{\circ}$.

\section{Calculation of the amount of adulteration of milk}

Having determined the percentages of fat and total solids, the amount of adulteration, if any, is calculated on the basis of the limits for fat and non-fatty solids laid down in the Sale of Milk Regulations, I90I (page 29), as in the following examples :-

r. Total solids Fat .

Non-fatty solids . - II 47 per cent. 2.62 " 8.85 ",

The milk is deficient in fat, but the non-fatty solids being above the limit of 8.5 per cent., there is no evidence of added water. The deficiency amounts to $3.00-2.62=0.3^{8}$ per cent. 


\section{PUBLIC HEALTH CHEMISTRY}

in 3 per cent., that is, the percentage deficiency is

$$
0.38 \times \frac{100}{3}=12.6
$$

2. Total solids Fat .

Non-fatty solids .

- II $\cdot 36$ per cent.

- 3.34 "

8.02,

The milk is low in non-fatty solids, presumably due to the addition of water. The adulteration is calculated as follows :8.5 per cent. N.F.S. correspond to roo per cent. milk, therefore $8.02 \quad$ " $\quad \quad \quad \quad \quad 100 \times \frac{8.02}{8.5^{\circ}}=94.4$ per cent. milk, hence the added water $=100-94 \cdot 4=5.6$ per cent.

3. Total solids

Fat .
. 10.49 per cent.

. 2.57 "

\section{Non-fatty solids . . . . 7.92 ",}

The milk is watered and there is a deficiency in fat which might, or might not, be wholly due to that cause. It is necessary in such a case to calculate the amount of added water and then to ascertain whether the milk contained 3.0 per cent. of fat before the addition of water, or whether there must have even then been a deficiency.

Calculating as in the previous example, the added water smounts to

$$
100-\left(100 \times \frac{7 \cdot 92}{8 \cdot 5^{0}}\right)=6.8 \text { per cent. }
$$

Before the addition of water the fat would be :-

$$
2 \cdot 57 \times \frac{8 \cdot 5^{\circ}}{7 \cdot 9^{2}}=2 \cdot 76 \text { per cent., }
$$

hence the deficiency in fat was :-

$$
\begin{aligned}
3.00-2.76 & =0.24 \text { in } 3 \text { per cent. } \\
& =0.24 \times \frac{100}{3}=8.0 \text { per cent. }
\end{aligned}
$$


The conclusion arrived at, therefore, is that the milk contains 6.8 per cent. of added water and is also deficient to the extent of 8.0 per cent. of its fat.

4. Total solids Fat .

Non-fatty solids .
- $10.3^{8}$ per cent.

. 2.88 ,

The milk is low in both fat and non-fatty solids. Calculating as in the last example, the added water amounts to :-

$$
100-\left(100 \times \frac{7 \cdot 50}{8 \cdot 50}\right)=I I .8 \text { per cent., }
$$

and before the addition of water the fat would be :-

$$
2.88 \times \frac{8 \cdot 50}{7 \cdot 50}=3.26 \text { per cent., }
$$

hence the milk contains II.8 per cent. of added water, but there is no evidence of it having been skimmed.

\section{Estimation of ash}

Required :-

beaker 50 c.c. small glass rod wash-bottle pipeclay triangle

crucible tongs

\section{Procedure :-}

Take the dish containing the milk solids, support it on a pipeclay triangle and heat over a bunsen burner until the solids are thoroughly charred. Allow to cool, put a little distilled water into the dish, heat on the water-bath and stir with a glass rod; allow to settle for a minute, then decant the liquid carefully into a 50 c.c. beaker, leaving the insoluble portion in the dish. Place the dish on the water-bath to dry the residue, transfer it to the burner and ignite until all the carbon has been removed. When sufficiently cool, add the aqueous liquid 
and evaporate to dryness on the water-bath, completing the drying in a hot air-bath. Ignite the dish and contents gently over a burner, allow to cool in a desiccator and weigh. Deduct the weight of the dish, ascertained previously, and calculate the percentage of ash.

In normal milk the quantity of ash is about 8.5 per cent. of the non-fatty solids.

\section{Estimation of nitrogen (Kjeldahl's process)}

The residue left on evaporation of a known weight of milk is heated with sulphuric acid and potassium sulphate until all the organic matter has been destroyed, the nitrogenous constituents being thus converted into ammonium sulphate. The ammonia is then liberated by the addition of sodium hydrate and is distilled into standard acid, the excess of acid being determined by titration.

Required :-

round-bottomed flask of hard pure sulphuric acid glass (300 c.c. long-necked) potassium sulphate glassbulb (toclose mouthof flask) sodium hydrate solupipette ro c.c. (as used for total solids)

pipette 50 c.c.

distillation apparatus

funnel

cylinder roo c.c.

tion (50 per cent.)

zinc

litmus solution

$\mathrm{N} /$ Io sulphuric acid

$\mathrm{N} /$ ro sodium hydrate

filter papers

\section{Procedure :-}

Pipette ro c.c. of milk into a round-bottomed flask and evaporate by immersing in a boiling water-bath; the drying can be hastened by blowing air through the flask occasionally with a bellows. When quite dry run in 20 c.c. of pure sulphuric acid, add ro grams of potassium sulphate, close the mouth of. the flask loosely with a glass bulb or funnel and heat over a 
bunsen burner in a fume chamber until the carbon has all disappeared and the liquid is almost colourless. Allow to cool, dilute with about 200 c.c. of water and filter the solution into a flask of not less than 500 c.c. capacity, washing the filter with water. Add a few drops of litmus solution and 75 c.c. of 50 per cent. sodium hydrate solution (poured carefully down the side of the flask so that it forms a separate layer at the bottom). Add also two or three pieces of zinc. Connect with a condenser and mix the liquid, which should then be alkaline, otherwise the flask must be disconnected and more sodium hydrate added. Distil into a flask containing 50 c.c. decinormal sulphuric acid, until about 1oo c.c. have passed over. To the liquid in the receiver add a few drops of litmus solution and titrate the excess of acid with decinormal sodium hydrate.

Example of calculation:-

weight of milk taken . . . . . I0.16 grams

$\mathrm{N} / \mathrm{I} \circ \mathrm{NaOH}$ required to neutralize excess acid $=\mathbf{I} 2 \cdot \mathbf{I}$ c.c., therefore, N/10 $\mathrm{H}_{2} \mathrm{SO}_{4}$ neutralized by ammonia=50.0-I2.I

$$
=37.9 \text { c.c., }
$$

hence Nitrogen $=37.9 \times 0.0014 \times \frac{100}{10.16}=0.52$ per cent.

N.B.-The materials used should be as free as possible from ammonia, but as it is difficult to obtain them quite free a blank experiment should be made with the same quantities of sulphuric acid, potassium sulphate and sodium hydrate, distilling into standard acid as before, and the amount of ammonia found should be deducted.

The total proteins can be calculated by multiplying the percentage of nitrogen by $6 \cdot 38$.

\section{Estimation of lactose (Pavy's method)}

The milk, suitably diluted, is added from a burette to a standard ammoniacal copper solution, containing Rochelle salt, which is kept boiling in a flask. The sugar reduces the 
copper to the cuprous condition, the solution becoming colourless, and from the quantity of milk solution required the amount of lactose can be found. As the ammoniacal copper solution is easily oxidized, the flask is closed with a rubber stopper through which the end of the burette passes, also a glass tube which carries the ammonia gas into water or acid.

Required :-

burettes and stands

flask 300 c.c. with rubber stopper

Pavy's solution

pipette 5 c.c.

graduated flask roo c.c.

cylinder 50 c.c.

\section{Procedure:-}

Take 5 c.c. of milk, the weight of which is found as usual, add 45 c.c. of ammonium hydrate (specific gravity 0.90 ) and dilute with water to 100 c.c. Measure 50 c.c. of Pavy's solution from a burette into a flask of about 300 c.c. capacity. Insert a rubber stopper through which pass the nozzle of a burette and a glass tube connecting the flask with a large bottle which is also fitted with a rubber stopper having two holes. Through the second of these holes is passed a tube to lead the ammonia gas into dilute acid in another vessel. Bring the copper solution to boiling and run in the solution of milk, I c.c. at a time, until the blue colour is nearly discharged, then add it more slowly until the end point is reached. Repeat the titration with a fresh quantity of the copper solution. The boiling must not be too prolonged or cuprous oxide will be precipitated.

50 c.c. of Pavy's solution $=0.048$ gram of lactose, but it is advisable to check the solution by titrating with a standard solution of lactose containing 0.25 gram per $\mathrm{I} \circ 0$ c.c.

Example of calculation :-

Weight of milk taken

Titrations (I) I9.0 c.c., (2) I9.I c.c. 
Lactose $=0.048 \times \frac{100}{19.05} \times \frac{100}{5 \cdot 15}=4.89$ per cent.

Lactose can also be conveniently estimated by the polarimeter.

\section{Analysis of sour milk}

The analysis of curdled milk presents some difficulty, as not only is it impossible without some preliminary treatment to obtain a homogeneous sample by means of a pipette, but in addition sour milk is not absorbed by the paper strips used for Adams' method of fat estimation, and moreover the non-fatty solids are decreased in quantity, owing to the decomposition of lactose with the formation of volatile bodies, which are lost when the milk is evaporated.

Thorpe ("Analyst," 1905, 30, 197) has contributed very considerably to our knowledge of the changes which occur when milk becomes sour. The fat is not materially affected, and the principal change occurs in the lactose, which is first hydrolyzed with the formation of dextrose and galactose :-

$$
\underset{\text { (lactose) }}{\mathrm{C}_{12} \mathrm{H}_{22} \mathrm{O}_{11}}+\mathrm{H}_{2} \mathrm{O}=\underset{\text { (dextrose) }}{\mathrm{C}_{6} \mathrm{H}_{12} \mathrm{O}_{6}}+\underset{\text { (galactose) }}{\mathrm{C}_{6} \mathrm{H}_{12} \mathrm{O}_{6} .}
$$

Galactose then becomes changed into lactic acid :-

$$
\mathrm{C}_{6} \mathrm{H}_{12} \mathrm{O}_{6}={ }_{2} \mathrm{CH}_{3} \mathrm{CH}(\mathrm{OH}) \mathrm{COOH} \text {, }
$$

(lactic acid)

but this alteration does not involve any loss in weight, yet in fifteen experiments it was found that losses of non-fatty solids in periods varying from two to fourteen weeks ranged from 0.23 per cent. to 0.87 per cent. Investigation showed that many volatile compounds are produced by the souring, these include acetic acid, butyric acid (in very small quantity), carbon dioxide, alcohol and ammonia. It is believed that butyric acid results from the decomposition of lactic acid, probably according to the following equation :-

${ }_{2} \mathrm{CH}_{3} \mathrm{CH}(\mathrm{OH}) \mathrm{COOH}=\mathrm{CH}_{3} \mathrm{CH}_{2} \mathrm{CH}_{2} \mathrm{COOH}+{ }_{2} \mathrm{CO}_{2}+{ }_{2} \mathrm{H}_{2}$, and acetic acid from the oxidation of lactic acid :-

$\mathrm{CH}_{3} \mathrm{CH}(\mathrm{OH}) \mathrm{COOH}+\mathrm{O}_{2}=\mathrm{CH}_{3} \mathrm{COOH}+\mathrm{CO}_{2}+\mathrm{H}_{2} \mathrm{O}$, 
or from the oxidation of ethyl alcohol. The quantity of alcohol varied from 0.09 to 0.35 per cent. after eight weeks, it is probably produced according to the following equation:-

$$
\mathrm{C}_{12} \mathrm{H}_{22} \mathrm{O}_{11} \cdot \mathrm{H}_{2} \mathrm{O}={ }_{4} \mathrm{C}_{2} \mathrm{H}_{5} \mathrm{OH}+4 \mathrm{CO}_{2} \text {. }
$$

The approximate specific gravity of sour milk can be found by adding a few drops of strong ammonium hydrate and mixing well, the error introduced by the ammonia being determined by ascertaining the reduction of the specific gravity of some fresh milk when ammonia in the same proportion is added to it.

In a similar way the fat can be estimated by the LeffmannBeam process, or the Werner-Schmid method may be used, the milk in the latter case being weighed instead of being measured by a pipette.

The most accurate method for the analysis of sour milk is that used in the Government Laboratory, described below. Moreover, unless the milk has undergone considerable decomposition, the author has found that estimation of the fat and non-fatty solids, after neutralization with strontia (see below), gives results closely in agreement with those obtained from the original fresh milk by ordinary methods.

The method adopted in the Government Laboratory is briefly as follows :-

The contents of the sample bottle are transferred to a suitable vessel and thoroughly mixed with a wire whisk. Portions of the sample, about ro grams in each case, are weighed out into flat-bottomed platinum capsules, each of which has been tared along with a short glass rod having a flattened end. The weighed quantities are next neutralized with $\mathrm{N} / \mathrm{ro} \mathrm{Sr}(\mathrm{OH})_{2}$, using phenolphthalein as indicator, and the measure of strontia used is noted. The milk is then evaporated over the waterbath until the residue, which towards the end should be dried at a very gentle heat and with constant stirring, attains the consistency of dry cheese. About 20 c.c. of dry ether are next poured over the milk solids, which are then carefully triturated with the glass rod. The ethereal solution of the fat is passed 
through a filter, which has previously been dried and weighed in a weighing-bottle, and the maceration of the milk is continued with eight successive quantities of ether. At the conclusion of the process the non-fatty solids should be in a fine state of division. Before becoming quite dry, the solids are transferred as far as practicable to the weighing-bottle, the filter paper, washed free from fat, is replaced in the bottle, and the whole, with the platinum capsule containing the small adherent quantity of solids, is dried at $100^{\circ} \mathrm{C}$. for three hours and then weighed. The weight is again taken after drying for a further two hours, and a final weighing after another hour. The last two weights should not differ by more than I mgm. Deducting 0.00428 gram for each I c.c. of $\mathrm{N} / \mathrm{r} \circ \mathrm{Sr}(\mathrm{OH})_{2}$ used in the neutralization, the result gives the amount of non-fatty solids present in the quantity of milk taken.

The ethereal solution of the fat is received in a small weighed flask, and after distillation of the ether the residue of fat is weighed.

When the milk has undergone considerable decomposition, it is necessary, in order to obtain results which shall agree closely with the composition of the original fresh milk, to estimate the amounts of alcohol, volatile acids and ammonia. For details of the methods employed the reader is referred to the original paper.

\section{Preservatives in milk}

The preservatives most frequently employed are boric acid, or a mixture of boric acid and borax, and formaldehyde; hydrogen peroxide and other preservatives have also occasionally been used. A Local Government Board circular issued in I906 states that the presence in milk of formaldehyde to an amount which is ascertained by examination within three days to exceed one part per 100,000 raises a strong presumption that the article has been rendered injurious to health, and that a 
similar presumption is raised where boron preservatives are present in milk to an amount exceeding 57 parts boric acid per I00,000, or 40 grains per gallon.

The addition of preservatives to milk has been prohibited by the Public Health (Milk and Cream) Regulations, I9I2, the term "milk" including separated, skimmed, condensed and dried milk.

According to Richmond, in order to be of any use in hot weather at least 0.1 per cent. of boric acid or 0.004 per cent. of formaldehyde is necessary, and even then the effect is only equal to that produced by cooling the milk about $10^{\circ} \mathrm{F}$.

\section{Detection of preservatives in milk}

Required :-

test-tubes $6 " \times I^{\prime \prime}$ and $6^{\prime \prime} \times \frac{5 "}{8}$ hydrochloric acid dil. graduated cylinder 50 c.c. hydrochloric acid conc. watch-glass funnel filter papers sulphuric acid conc. nitric acid dil. turmeric paper sodium hydrate solution ferric chloride solution potassium iodide starch solution potassiumbichromate solution ether

\section{Procedure :-}

Boric acid and borax.

To a few c.c. of the milk in a test-tube add two or three drops of dilute hydrochloric acid, shake, and immerse in the liquid a strip of turmeric paper. Remove the paper and dry it thoroughly on a watch-glass in a warm place; in the presence of boric acid or borax a red colouration is produced. Moisten with a drop of sodium hydrate solution, the colour is changed to greenish-black, which quickly fades. 


\section{Formaldehyde.}

Hehner's test. Into a test-tube $\left(6^{\prime \prime} \times \mathbf{I}^{\prime \prime}\right)$ pour about 5 c.c. of milk and an equal quantity of water, and into a similar tube Io c.c. concentrated sulphuric acid containing a trace of ferric chloride (commercial sulphuric acid answers the purpose without any addition). Hold the tubes almost horizontally and pour the mixture of milk and water carefully on to the surface of the acid, avoiding any mixing. Bring the tube containing the liquids to a vertical position and allow to stand ; in presence of formaldehyde a violet ring appears at the junction of the two liquids.

Liverseege's test. Put Io c.c. of milk into a test-tube $\left(6^{\prime \prime} \times \mathrm{I}^{\prime \prime}\right)$ and into a similar tube ro c.c. of milk which is known to be pure. To each add, about I c.c. at a time, sulphuric acid containing a few drops of ferric chloride solution, shaking well after each addition, until about 6 c.c. have been added to each. Milk containing formaldehyde develops a purple colour, while pure milk becomes reddish-brown.

Shrewsbury and Knapp's test. To 5 c.c. of milk in a testtube $\left(6^{\prime \prime} \times I^{\prime \prime}\right)$ add ro c.c. of concentrated hydrochloric acid containing nitric acid in the proportion of $I$ in 1000 (the reagent should be freshly prepared), shake well and heat in a water-bath at a temperature of $50^{\circ} \mathrm{C}$. for ten minutes; a purple colour indicates formaldehyde.

N.B.-When the Leffmann-Beam method of fat estimation is used, a purplish-blue colouration is produced on the treatment with sulphuric acid, instead of the usual reddish-brown, in the presence of formaldehyde; this colour soon disappears.

\section{Hydrogen peroxide.}

I. To a few c.c. of the milk add a crystal of potassium iodide, or a few drops of a perfectly colourless solution of the salt; iodine is liberated, if hydrogen peroxide is present, and colours the liquid yellow. Add starch solution, a blue colour is produced. 
2. Take about ro c.c. of the milk and curdle with dilute sulphuric acid, filter. To the filtrate add a few c.c. of ether and a drop of potassium bichromate solution, and shake; in presence of hydrogen peroxide a blue compound is produced (probably perchromic acid) which dissolves in ether giving a blue solution.

\section{Estimation of boric acid in milk \\ (R. T. Thomson, "Analyst," I 896, 21, 64)}

One or two grams of sodium hydrate are added to roo c.c. of milk and the whole evaporated to dryness in a platinum dish. The residue is thoroughly charred, heated with 20 c.c. of water, and hydrochloric acid added drop by drop until all but the carbon is dissolved. The whole is transferred to a I oo c.c. flask, the bulk not being allowed to exceed 50 or 60 c.c., and 0.5 gram dry calcium chloride added. To this mixture a few drops of phenolphthalein solution are added, then a ro per cent. solution of caustic soda until a permanent slight pink colour is produced, and finally 25 c.c. of lime-water. In this way all the phosphoric acid is precipitated as calcium phosphate.

The mixture is made up to roo c.c., thoroughly mixed, and filtered through a dry filter. To 50 c.c. of the filtrate normal sulphuric acid is added until the pink colour is gone, then methyl orange, and the addition of acid continued until the yellow is just changed to pink. Fifth-normal sodium hydrate solution is now added until the liquid assumes the yellow tint, excess of soda being avoided. At this stage all acids likely to be present exist as salts neutral to phenolphthalein, except boric acid which, being neutral to methyl orange, exists in the free condition, and a little carbonic acid which is expelled by boiling for a few minutes.

The solution is cooled, a little phenolphthalein added, and as much glycerine as will give at least 30 per cent. of that substance in the titrated solution, and titrated with fifthnormal sodium hydrate until a distinct permanent pink colour 
is produced; each c.c. of fifth-normal soda is equal to 0.0124 gram of boric acid (see page 66).

Thomson points out that the solution should not contain more than 0.2 per cent. of boric acid otherwise irregular results are obtained. Also, the incineration should not be carried further than is necessary to obtain a colourless solution, on account of the risk of loss of boric acid by too prolonged heating.

\section{Estimation of formaldehyde}

The Liverseege reaction may be employed for quantitative estimations. A number of test-tubes of the same size are taken and ro c.c. of pure milk put into each, and a standard solution of formaldehyde is added from a burette in different quantity to each tube. Equal quantities of the reagent are added to the contents of the tubes, also to ro c.c. of the milk under examination, with thorough mixing. By comparison of the depth of colour developed in the sample and in the standards, the quantity of formaldehyde in the sample is found.

The Shrewsbury and Knapp reaction may also be employed in a similar way.

$N . B$.- It must be remembered that formaldehyde rapidly disappears after its addition to milk, so that the quantity found is always likely to be less than that originally added.

\section{"Mystin"}

A preservative for milk and cream was introduced a few years ago under the name of "Mystin," and proved to be a solution of sodium nitrite containing a small quantity of formaldehyde. This mixture does not respond to the ordinary tests for formaldehyde, but it was found by Monier-Williams that, after addition to 5 c.c. of milk of 0.05 gram of urea and I c.c. of normal sulphuric acid and heating in boiling water for two minutes, the destruction of the nitrite enabled the formaldehyde to be detected and estimated by the usual methods 
(Reports to the Local Government Board on Public Health and Medical Subjects, Food Report No. I7).

\section{Colouring matter in milk}

Artificial colouring matter in milk is prohibited by the Milk (Amendment) Order, I9I 7 .

The presence of an artificial colouring matter in milk will generally be shown by allowing the sample to stand for some hours; natural colour rises with the cream whereas artificial colours will largely remain distributed throughout the liquid.

Annatto, one of the commonest colouring matters used, can be detected by soaking filter paper for twenty-four hours in the milk, after rendering alkaline with sodium carbonate ; a brown stain changed to pink by hydrochloric acid indicates annatto.

Some of the aniline colours used in milk are turned pink by the addition of dilute hydrochloric acid.

Leach's method for the detection of artificial colouring matters in milk is as follows :-

I 50 c.c. of milk are taken, a small quantity of acetic acid is added and the mixture heated in a dish over a flame; the liquid is stirred to coagulate the curd into one mass and the whey poured off. The curd is pressed and shaken with ether in a corked flask, then allowed to soak for several hours. Annatto is extracted with the fat, and if the residual curd is white no other colouring matter is present. If the milk contains a coal-tar dye or caramel, the curd remains coloured after the ether extraction.

Annatto. The ether extract is evaporated on a water-bath, the residue made alkaline with sodium hydrate and poured on a small wet filter, which retains the fat. On washing off the fat gently under a water-tap, all the annatto will be found concentrated on the filter, producing an orange colour. With stannous chloride a characteristic pink colour is obtained.

If the milk is coloured with an azo dye, the coloured curd becomes pink on treatment with hydrochloric acid. With 
caramel the acid solution of the coloured curd gradually becomes blue (the more readily if the fat has been thoroughly extracted, and the result is not positive unless the curd was coloured).

\section{Heated milk}

Milk which has been sterilized by heat may be recognized as follows :-

I. The cream rises very slowly on standing.

2. On the addition to the milk of a few particles of paraphenylene-diamine, followed, after shaking, by a few drops of hydrogen peroxide, milk which has been heated above $80^{\circ} \mathrm{C}$. gives no colouration after ten minutes, whereas fresh milk is coloured blue by this treatment. According to Richmond, metaphenylene-diamine hydrochloride may advantageously be substituted in this test, or "ortol" (sold as a photographic developer), which gives a red colour with fresh milk.

3. The soluble albumen, which amounts to about 0.4 per cent. in ordinary milk, is much reduced in heated milk. This may be estimated by removal of the casein (and the altered albumen) by saturation of the milk with magnesium sulphate, allowing to stand overnight, and then filtration, the precipitate being washed with saturated magnesium sulphate solution. The soluble albumen is then precipitated by tannic acid; the nitrogen in the precipitate, multiplied by $6 \cdot 38$, gives the amount of soluble albumen.

\section{Dirt in milk}

Dirt in milk generally consists of cow dung; one of the best methods for its estimation is that adopted by Lowe ("Chemical News," 1912, 106, 61).

500 c.c. of milk are allowed to stand overnight in a conical funnel to which is attached, by a rubber tube, a small glass tube two inches long, graduated in 0.01 c.c. This tube is 
widened out at the top and closed with a rubber stopper at the bottom. The proportion by volume of the sediment closely agrees with the weight of cow dung originally present.

The sediment usually consists of undigested fibre of the food, stained yellowish with bile, but it may contain sand, and in some cases wool and cotton fibres, etc. from household dust.

The presence of bile can be detected by mixing the sediment on a watch-glass with a few drops of cane sugar solution, decanting the liquid and drying the residue. On treatment with concentrated sulphuric acid a crimson colour develops in presence of bile acids. 


\section{CHAPTER IV}

\section{BUTTER AND MARGARINE}

Butter is defined by the Margarine Act, 1887 , as "the substance usually known as butter, made exclusively from milk or cream, or both, with or without salt or other preservative, and with or without the addition of colouring matter."

Butter consists of fat derived from milk together with water and small quantities of the other constituents of milk, viz. proteins, lactose and salts. The maximum amount of water is fixed at 16 per cent. by the Sale of Butter Regulations, I902. The average amount of fat is about 85 per cent., the curd (mainly proteins) about $\mathrm{I}$ per cent., and the proportion of salt varies, but does not usually exceed 3 per cent. The salt is added for flavouring and preservative purposes; as much as 2I per cent. has been found, but this quantity is an adulteration.

"Milk-blended butter" may contain 24 per cent. of water, provided it is sold under such name as may be approved by the Board of Agriculture and Fisheries and delivered to the purchaser in a wrapper on which, in addition to the approved name, is stated the percentage of water it contains. In other respects the conditions applicable to the sale or description of margarine apply to milk-blended butter (Butter and Margarine Act, 1907).

Margarine is defined by the Butter and Margarine Act, 1907, as "any article of food, whether mixed with butter or not, which resembles butter and is not milk-blended butter."

An interesting account of the manufacture of margarine is 
given by W. Clayton ("Journal of the Society of Chemical Industry," 1917, 36, 1205). The chief animal fats employed are lard, oleo, "premier jus," and stearine. "Premier jus," obtained from the best beef fat, can be fractionated to yield oleo and stearine, the former by hydraulic pressure at $48^{\circ} \mathrm{C}$., the latter by fractional crystallization for some days at $28^{\circ} \mathrm{C}$. A great variety of vegetable oils is employed, including coconut and palm-kernel oils, which are solid, and cottonseed, arachis, soya bean and sesame oils, and more recently kapok, maize and wheat oils. Lastly, hardened or hydrogenated oil is employed; for instance, by the addition of about I per cent. of hydrogen to cottonseed oil (in presence of a catalyst, usually nickel), a fatty product of at least the consistency of lard may be obtained. Hydrogenated oils have excellent keeping qualities, and are said to help margarine in this respect.

Milk is used in margarine manufacture for two primary reasons, viz., as a basis for flavouring development and as an emulsifying agent. For the destruction of undesirable bacteria, especially of the pathogenic type, the milk is pasteurized by heating to $82^{\circ} \mathrm{C}$. for a few minutes, and is then inoculated with lactic acid bacilli in order to develop a butter-like flavour. The milk having been prepared for churning, the oils are emulsified with it at a temperature of $25^{\circ}$ to $35^{\circ} \mathrm{C}$, the granules, or "crystals," of margarine so produced containing about 33 per cent. of water. The "crystals" are removed to a maturing-room, where, under constant thermal conditions, the bacteria introduced by the milk can develop, the best margarines being allowed the longest time in this process. Maturing accomplished, it is necessary to knead the "crystals" together to form a coherent, butter-like mass, and at the same time to expel the excess of water, consequently the matured "crystals" are rolled in drums, or passed between a set of rollers.

The buttery mass is now blended by mixing with salt, 
colouring matter, preservative, etc., and it is usual at the same time to add some substance which will bring about frothing and browning when the margarine is heated; among the materials proposed or in use for this purpose are butter, milk powder, casein, lecithin, yeast and patent emulsions of lecithin and sesame oil.

By the Sale of Food and Drugs Act, I899, the maximum quantity of butter-fat in margarine is fixed at ro per cent., and by the Butter and Margarine Act, 1907, the water is restricted, as in butter, to 16 per cent. The law requires also that every package containing margarine shall be branded or durably marked "Margarine" on the top, bottom and sides, in printed capital letters not less than three-quarters of an inch square; if margarine is exposed for sale by retail there shall be attached to each parcel, in such manner as to be clearly visible to the purchaser, a label marked in printed capital letters not less than one and a half inches square, "Margarine," and every person selling margarine by retail, save in a package branded or marked as above, shall in every case deliver it to the purchaser in a paper wrapper on which the word "Margarine " is printed in capital block letters not less than half an inch long and clearly legible, and no other printed matter shall appear on the wrapper.

It was recommended by the Departmental Committee on Preservatives and Colouring Matters in Food that the only preservative allowable in butter and margarine should be boric acid or a mixture of boric acid and borax, the quantity not to exceed 0.5 per cent. expressed as boric acid.

\section{Analysis of butter and margarine}

The usual analysis consists of estimations of water, fat and salt, the curd being obtained by difference, an examination of the fat by chemical and physical methods, and the determination of the nature and quantity of any preservative present. 
Estimation of water and fat

The water is driven off by heating and the loss in weight determined, the fat is then removed and the residue weighed.

Required :-

porcelain dish, size 3

flask

glass rod about 4 inches long

pipeclay triangle

sandbath

crucible tongs

funnel

spatula

ether

filter papers

\section{Procedure :-}

Take a porcelain dish, size 3 (about 4 inches in diameter), put a distinguishing mark upon it with ink and ignite sufficiently to fix the mark on the porcelain. Place in the dish a glass rod, the length of which is equal to the diameter of the dish, allow to cool, and weigh. Weigh into the dish 20 or 25 grams of the sample, taking portions from different parts of the bulk. Place the dish on a sandbath and heat gently over a burner, stirring continually, until all the water has been removed, as shown by the curd, at the bottom of the dish, commencing to turn brown; avoid excessive heating as the decomposition of the curd will cause the result to be too high. In the case of butter, or margarine containing much butter-fat, the approach of the end point is indicated by the contents of the dish frothing, and it is necessary to remove the dish occasionally from the sandbath and move the froth to one side with the rod in order to examine the colour of the curd. Allow to cool, remove any sand which may be adhering to the dish, and weigh; the loss in weight represents the water, the percentage of which is calculated.

Warm the dish sufficiently to melt the fat, pour off as much as possible, without disturbing the curd, into another dish and keep the fat for further examination. Pour ether over the residue in the dish, stir well and decant through a filter, which 
has previously been wetted with ether, into a flask. Repeat the washing with fresh quantities of ether until all the fat has been removed, taking care that none remains on the sides of the dish. Wash the filter with ether, and scrape any particles of curd adhering to it into the dish. Put in a warm place to expel the ether and dry in an air-bath at $100^{\circ} \mathrm{C}$. for one hour. Allow to cool and weigh, the difference between this weight and the previous one represents the fat.

$N . B$.- In the above estimation the glass rod is weighed throughout with the dish.

\section{Estimation of salt}

The residue, left after the removal of fat, is charred and the salt is extracted with hot water. The chlorides are then estimated by titration with standard silver nitrate solution and the result calculated to $\mathrm{NaCl}$.

\section{Required :-}
wash-bottle
$\mathrm{N} /$ Io silver nitrate solution
funnel
graduated flask $25^{\circ}$ c.c.
potassium chromate solution
filter papers
pipette 1o c.c.
porcelain dishes, size 3 or 4

\section{Procedure :-}

Wipe the rod with a small piece of filter paper and put the paper into the dish, heat the dish carefully over a burner in a fume-chamber until the curd is thoroughly charred, but avoiding very strong ignition. Allow to cool and extract several times with hot distilled water, pouring the liquid after each extraction through a filter paper into a 250 c.c. graduated flask. Cool the solution and make it up to the mark, pipette ro c.c. into a porcelain dish, add a few drops of potassium chromate solution, and titrate with $\mathrm{N} / \mathrm{ro}$ silver nitrate solution. Repeat 
the titration and from the mean of the two calculate the percentage of sodium chloride.

$$
\text { I c.c. } \mathrm{N} / \text { ro } \mathrm{AgNO}_{3}=0.00585 \text { gram } \mathrm{NaCl} \text {. }
$$

Example:-

If the average of the titrations is 5.7 c.c. and the weight of sample originally taken was 25 grams, then :-

$$
\begin{aligned}
\mathrm{NaCl} & =5.7 \times 0.00585 \times \frac{250}{10} \times \frac{100}{25} \\
& =5.7 \times 0.585=3.33 \text { per cent. }
\end{aligned}
$$

The percentages of water, fat and salt are added together and the total deducted from Ioo, the result being expressed as "curd."

The above method is rapid and, if carefully carried out, is accurate. If the sample is small, less than 20 grams may be used, but the accuracy is proportionately less, and in such case the following process is recommended for preference.

\section{Alternative method for estimation of water and fat}

Required:-
flat glass dish 3 inches diameter ether
glass rod 4 inches long
funnel
filter papers
Soxhlet extractor fitted with flask

Procedure :-

Dry the dish and rod at $100^{\circ} \mathrm{C}$., ignite about 20 grams of sand over a burner and when it has cooled somewhat transfer it to the dish. Allow to cool completely in a desiccator, weigh the dish, rod and sand together, and weigh into the dish 5 grams of the well-mixed sample. Place in an air-bath at $100^{\circ} \mathrm{C}$., for a few minutes, remove the dish and stir the contents well, in order to thoroughly mix the sand with the melted butter. Put it back into the air-bath and allow it to remain 
there for two hours, cool in a desiccator and weigh. Reheat for half an hour, and weigh again, repeating the drying until a constant weight is obtained. From the loss in weight the percentage of water is calculated.

Treat the mass in the dish with ether and filter the ethereal solution into a weighed flask. Transfer the sand, curd, etc., to the filter paper and place them together in a Soxhlet extractor, attach the flask containing the ethereal solution and extract for two or three hours. Disconnect the flask, distil off the ether and dry the fat at $100^{\circ} \mathrm{C}$. to constant weight. Calculate the percentage of fat.

If it is desired to estimate the salt, the sand used must be quite free from chlorides, then the residue left from the fat estimation is transferred to a porcelain dish and gently ignited to char the curd, after which the salt is extracted with water and the solution titrated with standard silver nitrate solution.

An approximate estimation of the water and fat can be made by melting a portion of the sample in a graduated tube, whirling in a centrifuge and measuring the relative volumes of water and fat.

\section{Detection of foreign fats in butter-fat}

Butter-fat consists of the glycerides of myristic acid, $\mathrm{C}_{13} \mathrm{H}_{27} \cdot \mathrm{COOH}$, palmitic acid, $\mathrm{C}_{15} \mathrm{H}_{31} \cdot \mathrm{COOH}$, stearic acid, $\mathrm{C}_{17} \mathrm{H}_{35} . \mathrm{COOH}$, (belonging to the acetic series), and oleic acid, $\mathrm{C}_{17} \mathrm{H}_{33} . \mathrm{COOH}$, which are non-volatile and insoluble in water, together with smaller quantities of the glycerides of acids which are volatile and soluble in water, the principal of which is butyric acid, $\mathrm{C}_{3} \mathrm{H}_{7} \cdot \mathrm{COOH}$. The glyceride of butyric acid is known as tributyrin, and it is the presence of this compound that gives to butter-fat its distinctive character. The quantity of butyric acid in butter-fat is on the average 5 per cent., while the fats of which margarine is made, with the exception of coconut oil, contain very small amounts of volatile soluble acids, 
hence the estimation of these acids is used to distinguish between butter and margarine, and to detect the presence of foreign fats in butter.

The procedure consists in heating the fat with caustic alkali in presence of a solvent, such as alcohol, an operation known as "saponification," since alkaline salts of the fatty acids, or soap, are produced, then liberating the fatty acids by the addition of sulphuric acid and separating the volatile acids by distillation. The distillate is then titrated with standard alkali.

The volatile acids are not completely removed by a single distillation, hence it is necessary to work always under the same conditions, the results being then comparative. The standard process is the

Reichert-Wollny process.

Required:-

hard glass flask 300 c.c.

pipette for 5 grams of fat

pipette ro c.c. graduated to

O.I C.c.

graduated cylinder 50 c.c.

measuring flasks 100 and

IIo c.c.

Liebig condenser and clamp

T-tube with short glass rod and tube

distillation-tube with bulb

small water-bath

asbestos square with circular

hole $5 \mathrm{cms}$. in diameter

funnel

burette and stand sodium hydrate solution (equal weights of sodium hydrate and water) alcohol $9^{2}$ per cent. by weight

$\mathrm{N} / \mathrm{x}_{2} \mathrm{SO}_{4}$

$\mathrm{N} / \mathrm{ro} \mathrm{NaOH}$

phenolphthalein

ignited pipeclay

\section{Procedure :-}

Take the fat which was poured off in the estimation of fat, melt it and filter through a dry filter paper in a hot air-bath. 
Weigh a hard glass flask, capacity 300 c.c., and introduce 5 grams of the fat into it, taking care that none remains in the neck (this can conveniently be done by using a pipette graduated to deliver nearly 5 grams, and adjusting the weight exactly by adding, if necessary, a few more drops). Add 2 c.c. of the strong sodium hydrate solution and ro c.c. of alcohol,* attach the flask to a reflux condenser by means of a T-tube, the side tube of which is turned upwards and closed by a piece of rubber tubing in which is inserted a short glass rod. Immerse the flask in a boiling water-bath and heat for 20 to 30 minutes, shaking the flask occasionally, then turn the T-tube so that the side tube points downwards, remove the glass rod, insert a glass tube in its place (to convey the alcohol to another vessel) and continue the heating and shaking until the alcohol is removed and the residue is nearly dry. Detach the flask and add roo c.c. of boiling distilled water to dissolve the soap, then 40 c.c. of normal sulphuric acid and a piece of ignited pipeclay. The addition of pipeclay is absolutely essential, otherwise the liquid becomes superheated and boils with explosive violence. Now lower the condenser, attach the flask to it with a distillation tube (having a bulb about $5 \mathrm{cms}$. above the cork), support the flask on a square of asbestos millboard with a hole in the centre and apply a small flame to melt the insoluble acids. Raise the flame and distil off rro c.c. into a graduated flask; the time of boiling should be between 28 and 32 minutes. Mix the distillate, filter 100 c.c. into another graduated flask, transfer to a beaker and titrate with decinormal sodium hydrate, using phenolphthalein as indicator. Multiply the figure so obtained by r.x to obtain the "Reichert-Wollny number."

As a small quantity of volatile acids (acetic and carbonic) is obtained from the alcohol and soda, it is necessary to perform a blank experiment occasionally. This is done in exactly

* Saponification with soda and glycerol (as described under the Polenske process, page 6r), may be substituted with advantage, the water-bath and reflux condenser being dispensed with. 
the same way as the above but omitting the fat; the amount of decinormal sodium hydrate required is deducted from the Reichert-Wollny numbers found.

The reactions involved can be represented by the following equations :-

I. $\mathrm{CH}_{2} \mathrm{O} \cdot \mathrm{COC}_{3} \mathrm{H}_{7}$

CHO.COC $\mathrm{H}_{3}+3$

1

$\mathrm{CH}_{2} \mathrm{O} \cdot \mathrm{COC}_{3} \mathrm{H}_{7}$

tributyrin

$\mathrm{CH}_{2} \mathrm{OH}$

$+{ }_{3} \mathrm{C}_{3} \mathrm{H}_{7} \cdot \mathrm{COONa}$

2. ${ }_{2} \mathrm{C}_{3} \mathrm{H}_{7} \cdot \mathrm{COONa}+\mathrm{H}_{2} \mathrm{SO}_{4}={ }_{2} \mathrm{C}_{3} \mathrm{H}_{7} \cdot \mathrm{COOH}+\mathrm{Na}_{2} \mathrm{SO}_{4}$.

It is probable, however, that the reactions are not quite so simple as here represented.

Calculation of the amount of foreign fats in butter

The Reichert-Wollny number adopted as a minimum for butter-fat is 24 ; this is below that usually found, and 30 is no uncommon figure. In calculating the quantity of foreign fats some analysts use the number 28 and assume that all the volatile acids are derived from butter; others use the figure 24 and deduct 2 for the acids contributed by the foreign fats. The following examples illustrate the two methods :-

Suppose the Reichert-Wollny number to be 16 , by the first method of calculation the quantity of butter-fat is :-

$$
\frac{16}{28} \times 100=57 \text { per cent. }
$$

and by the second method :-

$$
\frac{(16-2)}{(24-2)} \times 100=63 \text { per cent. }
$$

From these, the percentages of foreign fats in the butter-fat will be 43 and 37 per cent. respectively, and if the quantity 
of fat in the sample is 85 per cent. the amount of foreign fats in the sample will be $43 \times \frac{85}{100}=3^{6}$ per cent., or $37 \times \frac{85}{100}=3^{1}$ per cent., according to the method adopted.

\section{Detection of coconut oil (Polenske process)}

Before the introduction of coconut oil in the manufacture of margarine, a Reichert-Wollny number of 4 was the maximum permissible for margarine fat ; this allowed 3 for 10 per cent. of butter-fat and I for the traces of volatile fatty acids yielded by the other fats and oils. But coconut oil, which is now largely used, gives a Reichert-Wollny number of about 7 to 8 , hence in the presence of this oil the Reichert-Wollny number affords no indication of the amount of butter-fat present. Coconut oil, however, contains in addition to the soluble volatile fatty acids, which are estimated in the above process, a considerable quantity of volatile fatty acids insoluble in cold water, principally caprylic acid, $\mathrm{C}_{7} \mathrm{H}_{15} . \mathrm{COOH}$, whereas butter-fat contains a much smaller quantity of acids of this kind; on these facts is based the Polenske process.

In the Polenske process both the soluble and insoluble volatile acids are estimated, and from the relative quantities of the two an indication is afforded of the amounts of butterfat and coconut oil respectively present.

The process is described fully in the "Analyst," I904, 29, 154. In order that concordant results may be obtained, the process must be carried out under fixed conditions and in a specified form of apparatus.

For the saponification of the 5 grams of fat taken, 2 c.c. of sodium hydrate solution ( $5 \circ$ per cent. by weight) and 20 grams of glycerol are used, the mixture being heated in a flask of 300 c.c. capacity over a bunsen flame with a continual circular movement; the completion of the saponification is indicated by the mixture suddenly becoming clear. After cooling sufficiently, the soap is dissolved in 90 c.c. of hot water, 50 c.c. 
of normal sulphuric acid solution and o.I gram of powdered pumice are added, then IIo c.c. are distilled off, the flame being regulated so that the distillation takes from 19 to 21 minutes. Without mixing the contents the receiver is placed in a bath of water at a temperature of $10^{\circ} \mathrm{C}$. for ten minutes; the insoluble fatty acids rise into the neck of the flask, and in the case of butter form solid white opaque granules, whilst with pure coconut oil clear oily drops are obtained. Mixtures containing more than ro per cent. of coconut oil also yield oily droplets. After mixing and filtering the contents of the iro c.c. flask, the Reichert-Wollny number is determined on the filtrate. The inner tube of the condenser is next washed with 18 c.c. of cold water, which is run into the receiver and then poured over the filter previously used. The filter is now transferred to a clean flask, and the acids insoluble in water are dissolved by pouring neutralized alcohol through the condenser tube into the receiver and then through the filter. The alcoholic solution is titrated with decinormal alkali, using phenolphthalein as indicator, the number of c.c. so used being termed the "new butter-value " of the fat.

The "new butter-value " of coconut oil is about $I 7$ and that of butter-fat about I.5 to 3.0 , the latter rising as the ReichertWollny number increases. Polenske stated that a rise of 0.1 in this figure indicated the presence of I per cent. of coconut oil in butter. For example, if the Polenske values are 20 for soluble acids and 5.5 for insoluble acids, the amount of coconut oil would be :-

$(5 \cdot 5-\mathrm{I} \cdot 3) \times \mathrm{IO}=42$ per cent., $\mathrm{I} \cdot 3$ being the "new butter-value" corresponding to a Reichert-Wollny number of 20 .

Later it was pointed out ("Analyst," I9I3, 38, 558) that the amount so calculated is in excess of the true quantity, which is more correctly given by the expression :-

$$
(5 \cdot 5-1.3) \times 10 \times \frac{100}{100+4^{2}}=30 \text { per cent. }
$$

In order to employ the Polenske process for the estimation 


\section{BUTTER AND MARGARINE}

of butter-fat in margarine containing coconut oil, the most satisfactory method is to analyse mixtures containing ro per cent. of butter-fat and different proportions of coconut oil and other fats, then by comparison with the Polenske numbers so obtained, it can be found whether or not any sample of margarine exceeds the legal limit of butter-fat. Similarly, by comparison with analyses of mixtures containing different quantities of butter-fat, the percentage of that ingredient in a margarine can be approximately determined.

Palm-kernel oil, which is very similar in composition to coconut oil, is also employed in the manufacture of margarine. Methods for the differentiation of the two fats and their estimation in margarine being beyond the scope of this book, the reader is referred to papers on these subjects by Shrewsbury and Knapp, Cribb and Richards, Elsdon and others, in the "Analyst," I9I0 to I9I 7.

Detection of cottonseed oil (Halphen test)

Required:-

test-tube $6 " \times \frac{5}{8}$

water-bath amyl alcohol or fusel oil

I per cent. solution of sulphur in carbon bisulphide

\section{Procedure :-}

Into a test-tube put about 2 c.c. of the oil, or melted fat, to be tested and add about 2 c.c. each of amyl alcohol and of a I per cent. solution of sulphur in carbon bisulphide. Place the tube in a boiling water-bath; a red colour appears if cottonseed oil is present, the time required being from a few minutes to half an hour, according to the quantity.

\section{Detection of sesame oil}

Required:-

test-tube $6^{\prime \prime} \times \frac{5}{8} \quad$ hydrochloric acid conc.

I per cent. solution of furfural in proof spirit. 


\section{Procedure :-}

Into a test-tube put 5 c.c. of the oil, or melted fat, add 5 c.c. of concentrated hydrochloric acid and 0.5 c.c. of I per cent. solution of furfural in proof spirit, and shake. On standing, a pink colour is developed if sesame oil is present.

\section{Refractive indices of fats}

The refractive indices of fats and oils often furnish a means of distinguishing between them or of ascertaining their purity. They are determined by means of a refractometer at a definite temperature, sufficiently high to keep the fats in a liquid state.

The refractive index of butter-fat is $\mathrm{I} .4600$ at $25^{\circ} \mathrm{C}$., of cottonseed oil $\mathrm{x} \cdot 4700$, and of coconut oil $\mathrm{I} \cdot 454^{\circ}$. Beef stearin gives a figure of about $\mathrm{I} \cdot 448$ at $60^{\circ} \mathrm{C}$.

\section{Microscopical examination of butter and margarine}

A useful preliminary test for butter is the microscopical examination, using polarized light and a selenite plate; in the case of butter the colour of the field is uniform, whereas with margarine a mottled appearance is observed. This test is not always conclusive, as butter if very rancid may show some mixture of colours, and, on the other hand, margarine, if slightly warm, loses its characteristic appearance.

A small piece of the sample is placed on a microscope slide and a cover-slip pressed down upon it so as to form a thin wedge. The slide is placed over a selenite plate on the stage of the microscope and examined by polarized light.

\section{Preservatives in butter and margarine}

Detection of boric acid.

Required:-

test-tube $\left(6^{\prime \prime} \times 5^{\prime \prime}\right)$, fitted with turmeric paper cork 
watch-glass

hydrochloric acid dil.

spatula

\section{Procedure:-}

Put a few grams of the sample into a test-tube (warming the tube in a flame to facilitate this), add about I c.c. of water and immerse in a boiling water-bath to melt the fat; the aqueous liquid will sink to the bottom carrying with it most of the boric acid; this separation is more easily made if a centrifuge is used. Cork the tube tightly and invert it in cold water, until the fat has solidified. Remove the cork, pour the aqueous liquid into a watch-glass, add a drop of dilute hydrochloric acid and test with turmeric paper (see page 44).

\section{Estimation of boric acid.}

The boric acid is removed from the sample by shaking a weighed portion with hot water. A definite fraction of the solution is rendered alkaline, evaporated to dryness and gently ignited (to destroy protein matter), then extracted with hydrochloric acid and the solution boiled to remove carbon dioxide. The hydrochloric acid is neutralized to methyl orange, when the boric acid, which does not affect that indicator, is left uncombined. Glycerol is now added; boric acid combines with glycerol and can be titrated to phenolphthalein, behaving under these conditions as a monobasic acid.

\section{Required :-}

flasks about 200 c.c.

pipettes, 25 and 50 c.c.

porcelain dish, size $0 \circ$ (platinum dish is preferable) measuring cylinder 50 c.c. spatula

burette and stand
$\mathrm{N} /$ Io sodium hydrate hydrochloric acid dil. glycerol methyl orange phenolphthalein sodium hydrate solution 


\section{Procedure :-}

Weigh a flask of about 200 c.c. capacity, transfer to it about Io grams of the sample and weigh again. Pipette 50 c.c. of water into the flask, heat on a boiling water-bath and shake occasionally. Cool completely, withdraw 25 c.c. of the aqueous liquid with a pipette and transfer to a small dish (platinum for preference). Render the solution alkaline with sodium hydrate, evaporate to dryness and ignite until well charred. When cool, treat the residue in the dish with about 20 c.c. of water, add a few drops of methyl orange and just sufficient dilute hydrochloric acid to render pink (carefully avoiding excess of acid). Heat for a minute, filter into a flask, wash, boil the solution for not more than two minutes to expel carbon dioxide, and cool. Neutralize exactly with N/ro sodium hydrate solution, avoiding excess (if the solution is strongly acid, a stronger solution of sodium hydrate may first be used but the neutralization must be finished with the decinormal solution), add a quantity of glycerol about equal to half the volume of the solution and several drops of phenolphthalein, mix, and titrate with $\mathrm{N} / \mathrm{x}$ sodium hydrate until just pink.

$$
\mathrm{H}_{3} \mathrm{BO}_{3}=3+\mathrm{II}+48=62 \text {. }
$$

In calculating the result, it is sufficiently accurate to assume that Io grams of butter contain I c.c. of water, and the percentage of boric acid becomes

$$
\text { c.c. } \mathrm{N} / \text { Io } \mathrm{NaOH} \times 0.0062 \times \frac{5^{\mathrm{I}}}{25} \times \frac{\text { Ioo }}{\text { weight taken }} .
$$

N.B.-A quantity of the glycerol, equal to that used in the experiment, should be titrated for acidity, and if any is found it is deducted from the result.

Method of Richmond and Harrison ("Analyst," 1902, 27, 181), slightly modified. 


\section{BUTTER AND MARGARINE}

Required:-

beaker about 200 c.c. solution containing 6 grams of pipettes 20 and 25 c.c. milk-sugar and 4 c.c. N/I sulglass rod

flask about 200 c.c. burette and stand phuric acid per Ioo c.c. $\mathrm{N} /$ Io sodium hydrate solution glycerol phenolphthalein

\section{Procedure :-}

Weigh ro grams of the sample into a beaker, and add 25 c.c. of a solution containing 6 grams of milk-sugar and 4 c.c. of normal sulphuric acid solution per roo c.c. Place in a steamoven until the fat is just melted and stir well ; allow the aqueous portion to settle for a few minutes and draw off 20 c.c. Add phenolphthalein, bring to the boil and titrate with N/Io sodium hydrate until a faint pink colour just appears, then add $\mathbf{2} 2$ c.c. of glycerol and titrate again until a pink colour appears. The difference between the two titrations, less the amount of alkali, if any, required by I2 c.c. of glycerol, multiplied by 0.00735 , will give the quantity of boric acid in 20 c.c. of the solution, whence the percentage can be calculated.

The reason for the use of the factor 0.00735 , instead of 0.0062 as employed in the previous method, is that, in this process, the second titration is found to indicate 84.4 per cent. of the boric acid present, hence the factor has to be increased by multiplying by $\frac{100}{84 \cdot 4}$.

\section{Detection of fluorides in butter and margarine}

(Monier-Williams, Reports to the Local Government Board, Food Report No. I7)

Put Io grams of the melted sample into a separating funnel and shake with ether and I or 2 c.c. of water. Run off the aqueous layer into a test-tube, add a few drops of hydrogen peroxide and I c.c. of a solution containing about 2 per cent. 
of titanium sulphate in ro per cent. sulphuric acid. Perform a blank test in exactly the same way with 10 grams of pure butter or margarine. If the original sample contained fluoride, the orange-yellow colour of the peroxidized titanium solution will be partially discharged, and on comparison with the colour obtained in the blank test the difference is seen to be very marked. 


\section{CHAPTER V}

\section{ALCOHOLIC BEVERAGES}

Estimation of alcohol.

The usual method of estimating alcohol in admixture with water is by determination of the specific gravity, from which the percentage of alcohol can be found by reference to tables compiled from experiments. Alcoholic beverages contain, besides alcohol and water, substances in solution, such as sugar, which increase the specific gravity, hence before an accurate estimation of the alcohol can be made, it must be separated by distillation. In the case of spirits, which usually contain small amounts of dissolved solids in comparison with the quantity of alcohol, the strength can be approximately determined from the specific gravity without distillation, but with beer this is impossible because the amount of solid matter in solution is large compared with that of the alcohol.

Estimation of alcohol in beer.

A quantity of the beer, rather more than that required for the distillation, is tossed, by pouring it from one beaker to another several times, in order to remove most of the carbon dioxide. A measured quantity is then distilled, the volume of distillate collected being sufficient to ensure that all the alcohol has been carried over (in the case of beer threequarters is sufficient, from spirits nine-tenths should be distilled). The distillate is then made up to the bulk of the original liquid, so that it contains all the alcohol in that volume free from the dissolved solids which would interfere with the estimation. 
The specific gravity can be determined by the Sprengel tube, specific gravity bottle, or by a hydrometer. The last-named method can only be used if the accuracy of the hydrometer has been carefully checked.

Required :-

graduated flask, roo c.c.

flask about 300 c.c.

condenser

bent glass connecting tube

Sprengel tube or specific

beakers, 300 c.c. and 50 c.c. thermometer

wash-bottle

ignited pipeclay

gravity bottle

\section{Procedure:-}

Take rather more than 100 c.c. of the beer and toss it by pouring from one beaker to another six or eight times, in order to remove carbon dioxide and so reduce the frothing which occurs when the liquid commences to distil. Measure Ioo c.c. in a graduated flask, transfer it to a flask of about 300 c.c. capacity and wash out the measuring flask with about 20 c.c. of water, adding this to the beer. Put in a piece of ignited pipeclay, to ensure regular boiling, and connect the flask to the condenser by means of a wide bent glass tube (preferably one containing a bulb, as used in the Reichert-Wollny process). Use the roo c.c. measuring flask as the receiver, placing the mouth of it over the end of the condenser, but avoid rendering the junction air-tight. Put a small flame under the distilling flask and heat carefully; if, as is often the case, there is a tendency to frothing, the flame must be removed for a moment and the flask cooled, this being continued until the frothing ceases and the liquid boils quietly. Collect 75 or 80 c.c., make up the distillate in the receiver to roo c.c. with distilled water, mix, and determine the specific gravity at $15.5^{\circ} \mathrm{C}$.

Specific gravity by Sprengel tube.

The apparatus has capillary side-tubes, one of which is wider 
than the other and has a mark etched on it. Glass caps are ground to fit the two ends, in order to prevent the liquid running out or evaporating.

The tube and caps are dried and weighed, the tube is filled with distilled water, which has been recently boiled and complegtely cooled, and is weighed again. Next it is filled with the liquid the specific gravity of which is required, (after rinsing with the liquid) and the weight is again ascertained; by deducting the weight of the empty tube that of the liquid is obtained. The specific gravity at any given temperature is the weight of liquid divided by the weight of an equal volume of water, both ascertained at that temperature. Specific gravities are generally determined at $\times 5.5^{\circ} \mathrm{C}$.

The best way to fill the tube is by attaching a piece of rubber tubing to the narrower of the side-tubes and sucking the liquid in through the wider one so as to fill the apparatus completely. The rubber tube is removed and the Sprengel tube immersed in a beaker of water at the required temperature. After five minutes a piece of filter paper is applied to the narrow tube in order to draw off the liquid until it reaches the mark on the wide tube, the cap is placed securely on the narrow tube, the apparatus is removed from the water, the outside completely dried, and, after attaching the other cap, the whole is weigned.

$N . B$. - When putting on the caps it is advisable to hold the side of the tube on which the cap is being placed, in order to avoid risk of breaking the apparatus.

Having determined the specific gravity of the distillate, the percentage of alcohol by weight or by volume is found on reference to alcohol tables (see Appendix, page 222).

In the estimation of alcohol in spirits, it is necessary that the volume taken for distillation and that of the distillate when made up to bulk should be measured at the same temperature, on account of the high expansibility of strong solutions of alcohol. "Tossing" is unnecessary, as there is no tendency to frothing. 


\section{"Original gravity" of beer}

The "original gravity" of beer is the specific gravity of the "wort," that is, the saccharine liquid from which the beer is produced by fermentation. In the process of brewing, some of the sugar is decomposed into alcohol and carbon dioxide, with small quantities of other bodies, while some remains unchanged; the original gravity is found by adding together the specific gravity of the solution of unchanged sugar and the "degrees of gravity lost," the latter being determined from the quantity of alcohol in the beer.

To find the original gravity, a measured quantity is distilled and both distillate and residue are made up to the bulk of the original beer, their specific gravities being then determined and expressed in terms of water $=1000$. The specific gravity of the distillate subtracted from rooo gives what is termed the "spirit indication," and from tables compiled for the purpose the corresponding number of degrees of gravity lost is ascertained (see Appendix, page 224); the latter added to the specific gravity of the residue from the distillation gives the original gravity of the beer.

\section{Example :-}

Specific gravity of distillate . $\quad . \quad$. $\quad . \quad 993.9$

Specific gravity of residue . $. \quad . \quad$. $\quad . \quad$ IOI6.5

Spirit indication $=1000-993 \cdot 9=$. . . 6.I

Degrees of gravity lost (from tables) . $\quad$. $\quad 26.9$

Original gravity $=1016.5+26.9=. \quad$. $\quad$ 1043.4

Should a beer be very acid, an addition has to be made to the original gravity found in order to correct for the excess acidity; tables giving the necessary corrections are published.

\section{Proof spirit}

The alcoholic strength of spirits is generally expressed in terms of proof spirit, which is defined as a spirit "which at $5^{\circ}{ }^{\circ} \mathrm{F}$. weighs exactly twelve-thirteenths of an equal measure 
of distilled water." Proof spirit contains 57.06 per cent. alcohol by volume and 49.24 per cent. by weight.

A spirit is said to be 20 per cent. or $20^{\circ}$ " over proof " when I00 volumes contain as much alcohol as 120 volumes of proof spirit, and a spirit 20 per cent. or $20^{\circ}$ " under proof " contains in roo volumes the same quantity of alcohol as 80 volumes of proof spirit. In other words, the former is 120 per cent., and the latter 80 per cent., proof spirit, and the percentages of alcohol by volume are, respectively-

$$
57.06 \times \frac{120}{100} \text { and } 57.06 \times \frac{80}{100} .
$$

The percentage of alcohol by volume can ${ }^{-}$also be calculated from the formula $\frac{\% \text { proof spirit }}{\mathrm{x} \cdot 75^{2}}$, and the percentage by weight from the formula $\frac{\% \text { proof spirit }}{\text { sp. gr. } \times 2 \cdot 208}$.

Sikes' Hydrometer is an instrument used to determine the strength of spirits. It is a metal hydrometer having a series of weights, numbered from ro to 90 , which can le attached to the lower part of the instrument. The stem of the hydrometer is graduated into ro degrees and each of these degrees is subdivided into five divisions. To find the strength of a spirit, the different weights are tried, until the one is found which allows the hydrometer to float in the liquid at such a depth that the surface of the liquid is at some point on the graduated stem (there will be at any given temperature only one weight that will do this). The temperature of the spirit is determined in Fahrenheit degrees, and by reference to the tables supplied with the hydrometer the strength is found in degrees over or under proof.

The hydrometer must be occasionally checked with spirits of known strength and any necessary corrections applied, as it loses weight by continued use. Further, in order to find the true strength of a spirit it must be distilled before being tested. The present law requires that spirits shall be sold not weaker 
than $50^{\circ}$ U.P. nor stronger than $30^{\circ}$ U.P., the prices being fixed according to the strength.

\section{Beer and other alcoholic beverages}

Beer is a fermented liquid, manufactured from malt, or a substitute, and hops or other bitter flavouring agent. The malt substitute may be glucose, invert sugar, or starch which has been hydrolyzed, i.e. converted into sugar, by treatment with acid.

The infusion so prepared, known as "wort," is fermented by yeast and clarified. The nature of the water used in brewing is of great importance, water containing permanent hardness being the best for the manufacture of ale, while the best stout is made with water which contains temporary hardness.

Beer contains alcohol ( 2 to 5 per cent. by weight), sugar, dextrin, protein matter, traces of acetic, carbonic and other acids, and mineral matter. The quantity of sodium chloride is sometimes excessive, it should not exceed 50 grains per gallon; sulphurous acid is occasionally present as a preservative.

Beers are classified under the Beer (Prices and Description) Order, I9I9, according to their original gravities, the prices being fixed accordingly.

Stout owes its colour and flavour largely to burnt malt.

Spirits are prepared by the distillation of fermented liquids such as infusions of malt or maize, or grape juice. In addition to alcohol, spirits contain higher alcohols ("fusel oil "), esters (or "ethers"), furfural, other aldehydes, volatile and fixed acids. Chemically there are not very great differences between various spirits. Two types of still are used, the pot-still and the patent (continuous) still, the former yielding a spirit which contains more ethers, higher alcohols, etc., than that obtained from the patent still.

Whiskey is prepared from malted barley and other cereals. The Royal Commission on Whiskey and other Potable Spirits 
came to the conclusion that the term "whiskey" could not be restricted to a spirit distilled in any particular form of still, that it is prepared by distillation from a mash of cereal grains saccharified by the diastase of malt, and that "Scotch whiskey" and "Irish whiskey" are spirits, so manufactured, distilled respectively in Scotland and in Ireland.

Brandy is made by the distillation of fermented grape juice. The ethers are usually between 70 and iाo parts per 100,000 of absolute alcohol. The flavour and aroma are of importance in judging the quality.

"British brandy" is a spirit prepared from grain suitably flavoured.

Gin is a spirit flavoured with oil of juniper and spices, and sometimes sweetened with sugar.

Rum is made from fermented molasses.

Wines are prepared from fermented grape juice, the character of the wine varying with the nature of the grapes and the method of preparation and treatment. Sweet wines are frequently "fortified" by the addition of alcohol, in this country Io per cent. of brandy may be added.

Calcium sulphate ("plaster of Paris") is sometimes added to wine to precipitate tartaric acid and so improve the flavour ; it also acts as a preservative. This is known as "plastering" and is said to be essential in manufacturing sherry.

France, the principal wine-producing country, allows the following treatment of wines : the mixing of wines, freezing to partially concentrate, pasteurization, and clarification by means of albumen, blood, casein, gelatine, etc., with the addition of sufficient tannin, and by charcoal. Treatment with sulphur dioxide is also allowed, but the wine must not retain more than 0.035 per cent., free and combined.

In this country, beverages which contain less than 2 per cent. of proof spirit are not subject to excise duty. Many of these consist of solutions of sugar flavoured with orris root or artificial essences, and coloured with aniline dyes. 
Test for traces of alcohol.

Traces of alcohol can be detected by heating the liquid in a flask (preferably attached to a condenser), and, when it commences to boil, cooling the neck of the flask by pressing the fingers upon it; "tears" of alcohol form on the cooled surface and run back into the liquid. If a few c.c. are distilled off the iodoform reaction can be applied; a few drops of a solution of iodine in potassium iodide are added and sufficient sodium hydrate solution to decolourize it, on warming the characteristic odour of iodoform is produced and, unless the quantity of alcohol is exceedingly small, a yellow precipitate forms, consisting of hexagonal crystals. 


\section{CHAPTER VI}

\section{VARIOUS FOODS, THEIR COMPOSITION AND}

ADULTERATION

Condensed Milk should contain the fatty and non-fatty solids of milk, unless labelled as condensed skimmed milk, the only addition allowable being that of sugar. The concentration is generally slightly under one-third, that is to say, the fat is about ro per cent., proteins ro per cent., lactose I 4 per cent., and mineral matter 2 per cent., the amount of added sugar being about 40 per cent.

Condensed Separated or (Condensed) Skimmed Milk must be labelled " Machine Skimmed Milk," or "Skimmed Milk," as the case may require, in large and legible type (Sale of Food and Drugs Act, 1899).

Coutts (Reports to the Local Government Board, Food Report No. 15) gives the following results, based upon analyses by various observers :-

\begin{tabular}{|c|c|c|c|c|c|c|c|}
\hline & \multicolumn{4}{|c|}{ Full Cream. } & \multirow{2}{*}{\multicolumn{2}{|c|}{$\begin{array}{l}\text { Machine- } \\
\text { skimmed. } \\
\text { Sweetened. }\end{array}$}} \\
\hline & & \multicolumn{2}{|c|}{ Sweetened. } & \multicolumn{2}{|c|}{ Unsweetened. } & & \\
\hline & & Lowest. & Highest. & Lowest. & Highest. & Lowest. & Highest. \\
\hline Total solids & . & 68.I & $83 \cdot 6$ & $29 \cdot 2$ & 38.0 & 56.9 & $79 \cdot I$ \\
\hline Fat & . & 8.0 & I $3 \cdot 7$ & 8.2 & I I.99 & 0.1 & 6.5 \\
\hline Protein . & . & $7 \cdot 3$ & I I. 4 & 8.0 & I0.0 & $7 \cdot 6$ & $12 \cdot 3$ \\
\hline Ash & . & I.6 & $3 \cdot 4$ & I .6 & $2 \cdot 5$ & I. 6 & 2.9 \\
\hline Lactose & . & II. 6 & 17.6 & I I.I & I 6.0 & 10.9 & $17 \cdot 0$ \\
\hline Cane Sugar & . & $36 . I$ & $44 \cdot 6$ & nil & nil & $30 \cdot 4$ & 52.6 \\
\hline
\end{tabular}

Possible adulterants are preservatives, such as boric acid, 
and starch or other thickening agents, while there may be a deficiency in milk-fat.

The analysis of condensed milk is made by taking a weighed quantity ( 10 or 20 grams), making up to soo c.c. with water, and estimating total solids and ash in the usual way, fat by Adams' process, proteins by Kjeldahl's process and lactose by Pavy's method, the cane sugar being found by difference from roo.

The concentration can be found by dividing the percentage of ash by 0.72 , and the amounts of fat, proteins and lactose when divided by the concentration will show the approximate composition of the original milk.

The use of condensed milk for infant feeding is fully discussed in Coutts' report (see above).

Dried Milk consists of the solids of milk in the form of a fine powder, and contains a small percentage of moisture. The following is the average composition of a number of whole cream milk powders :-

Moisture

Fat

Proteins

Lactose .

Ash

Dried milks are also made from machine-skimmed and partially skimmed milks.

The concentration is best determined by dividing the sum of the percentages of proteins and lactose by 8.15, the average figure for proteins+lactose in milk. In the above example, the concentration is found by this method to be $7 \cdot 5$, and dividing the various constituents by this factor the composition of the original milk is found to be :-

Fat Proteins

- 4.65 per cent.

$$
\text { . } 26.85 \text { " }
$$

. 24.55 ",

- $36 \cdot 54$

6.10 


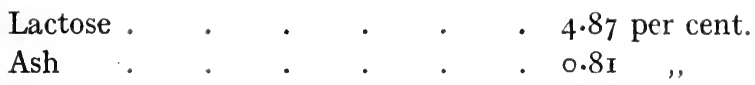

The ash of dried milks is frequently high compared with the other constituents, as in some methods of manufacture small amounts of alkali are added.

The fat in dried milks is best estimated by the Werner-Schmid process, using a small weighed quantity, the other constituents may be determined by methods used similar to those in milk analysis.

The composition and analysis of dried milks, with special reference to their use in infant feeding, are described at length in Coutts' Report to the Local Government Board (Food Report No. 24).

Buttermilk contains added water, used to assist the separation of the fat ; 25 per cent. is regarded as the maximum permissible, any quantity in excess of this amount being adulteration. The analysis is conducted as for sour milk (see page 42 ).

Cream usually contains 35 to 60 per cent. of milk-fat if separated by centrifugal means, less if hand skimmed, but there is no standard. Preservatives are not allowed, except in "preserved cream" (see page 95). Thickening materials, such as starch, gelatine, condensed milk and sucrate of lime, have sometimes been used to adulterate cream.

The analysis of cream is carried out similarly to that of milk, diluting with a definite proportion of water before the estimation of total solids and fat. Boric acid may be estimated by Thomson's process as in milk.

Cheese consists of the proteins and fat of milk together with water and a small quantity of lactose and mineral matter; it is prepared by the coagulation of milk by rennet, with subsequent ripening due to bacterial action.

Average cheese contains about 30 per cent. each of fat and proteins. Sometimes, owing to the use of partially skimmed milk, the quantity of fat is much lower than this, while the percentage of water is over $5^{\circ}$ per cent., but this cannot be 
regarded as being genuine, and there have been several convictions for the sale of such cheese.

Margarine Cheese is made by churning various fats with skimmed milk. It can only be sold under conditions similar to those in force for margarine.

The fat in cheese can be conveniently estimated by the Leffmann-Beam process, after digesting a weighed quantity of cheese in a crumbled condition with hot dilute sulphuric acid, using a sufficient quantity of the acid to fill the bottle. The quantity of water in cheese is found by the loss on drying to constant weight, and the proteins are estimated by Kjeldahl's process. The fat can be examined by the Reichert-Wollny process and by the refractometer.

Gorgonzola cheese has on occasions been found to be adulterated by the addition of an external coating composed mainly of barium sulphate, which considerably increased the weight.

Lard was formerly the name given to the fat from the abdomen of the pig, but it now has a wider meaning, lard being prepared also from other parts of the animal.

The commonest adulterants are beef stearin and cotton-seed oil, the former being detected by the Belfield test, in which the crystals deposited from an ethereal solution of the sample are examined microscopically. For the detection of cotton-seed oil see page 63. Lard should be clear on melting, showing freedom from water.

By an Order recently issued by the Ministry of Food-

Vegetarian Lard must be made of $5^{\circ}$ per cent. of coconut oil, 20 per cent of ground nut oil and 30 per cent. of palm-kernel oil, and the moisture must not exceed 0.25 per cent. ; and

Vegetarian Butter must be prepared from 37.5 per cent. of coconut oil, 37.5 per cent. of palm-kernel oil and 25 per cent. of nut cream (manufactured from hazel nuts, cashew nuts, walnuts, or almonds), and the moisture must not exceed r.5 per cent.

Jams. The commonest adulteration is the substitution of 
cheaper fruit, notably apple pulp ; occasionally salicylic acid is present. Regulations made by the Ministry of Food in 1918 limit the addition of "other fruit juice" to a maximum of Io per cent. by weight and prescribe a minimum of 62 per cent. for the solid matter soluble in water. It is further required that where a jam is composed of more than one fruit, there shall be not less than 25 per cent. of each by weight.

Honey consists mainly (about 70 to 80 per cent.) of dextrose and lævulose, the latter being usually slightly in excess, so that the mixture is lævo-rotatory, i.e. rotates the plane of polarized light to the left. It also frequently contains a small percentage of sucrose (up to 8 per cent., according to some authorities). The commonest adulterants are glucose and sucrose, which are detected by examination with the polarimeter.

Tea. The principal constituents are caffeine (or theine) about 2.5 per cent., tannin about $\mathrm{I}_{5}$ per cent., and about 0.5 per cent. of an essential oil. On careful heating, the caffeine sublimes and can be collected and examined. The ash is 5.5 to 6.0 per cent., at least 3.0 per cent. being soluble in water.

Tea is examined by the Customs authorities on importation, as provided by the Sale of Food and Drugs Act, I875, so that very little adulterated tea is sold. Sometimes the leaves of other plants are mixed with tea, these can be detected by careful examination after soaking the sample in hot water, genuine tea leaves have serrated margins and the veins do not reach the edges but are joined together forming loops. Exhausted tea leaves are characterized by the small amount of ash soluble in water.

In the past, tea has sometimes been adulterated with iron filings and other mineral matter ; more recently an adulterant composed of coloured wheat flour made up to resemble tea stalks has been detected.

Coffee contains about I per cent. of caffeine, Io to I5 per cent. of oil, acid substances, etc. Raw coffee contains sugars, but these are destroyed almost entirely in the roasting process, 
at the same time an important flavouring matter, known as caffeol, is produced.

The principal adulterant is roasted chicory root, and sometimes various cooked cereals are used. These adulterants can be detected by the microscope. Chicory is estimated by determining the amount of hot water extract (E. W. T. Jones' method); dried coffee yields about 24 per cent., and dried chicory about 70 per cent., and from the quantity of extract the proportions of the two can be calculated.

Cocoa contains when in the condition known as "Cocoa nibs " 40 to 50 per cent. of fat (cocoa butter), I to I. 5 per cent. of theobromine, other nitrogenous substances, starch, etc. Much of the fat is removed in preparing the ordinary powdered cocoa. Cocoa is frequently treated with alkali to render the fat more easily emulsified and so make the cocoa apparently more soluble.

The principal adulterants are foreign starches, such as cornflour and arrowroot, sugar, and sometimes ground cocoa shell.

The Cocoa Powder Order, I918, permits the sale as "Grade B" of cocoa containing not more than 5 per cent. of cocoa bean shell, and not less than 22.5 per cent. nor more than 30 per cent. of cocoa butter ; "Grade A" cocoa must not contain more than 2 per cent. of cocoa bean shell.

The microscopical examination of cocoa will detect most of the likely adulterants.

Cereals, etc., approximate composition.

\begin{tabular}{|c|c|c|c|c|c|c|}
\hline & & Proteins. & Fat. & $\begin{array}{c}\text { Carbo- } \\
\text { hydrates, etc. }\end{array}$ & Ash. & Water. \\
\hline Wheat (grain) & & $12 \cdot 4$ & I. 7 & 70.6 & I. 8 & I $3 \cdot 5$ \\
\hline Barley . . & . $\quad$. & I I.O & $2 \cdot \mathrm{I}$ & $71 \cdot 3$ & 2.6 & I 3.0 \\
\hline Oats . & . . & $10 \cdot 4$ & $5 \cdot 2$ & $69 \cdot I$ & $3 \cdot 0$ & I $2 \cdot 3$ \\
\hline Rice (hulled) & . $\quad$. & $7 \cdot 0$ & 0.9 & $79 \cdot 3$ & 0.3 & $12 \cdot 5$ \\
\hline Maize . . & . & 10.0 & $4 \cdot 7$ & 70.8 & I. 5 & 13.0 \\
\hline Arrowroot & . & $I \cdot O$ & $n i l$ & $83 \cdot 7$ & 0.3 & I 5.0 \\
\hline White flour & . $\quad$. & I3.0 & I. 5 & 68.4 & 0.6 & I6.5 \\
\hline White bread & . $\quad$. & 6.9 & 0.4 & $47 \cdot 8$ & 0.8 & $44 \cdot I$ \\
\hline
\end{tabular}


Wheat flour is sometimes bleached with nitrogen peroxide, which can be detected by applying the usual tests for nitrites to an aqueous extract of the flour.

Hamill in a report to the Local Government Board (Food Report No. I2) stated as a result of his investigations that it seemed probable that bleaching, when carefully carried out, produces no appreciable effect upon the baking qualities of flour, but that it is capable of improving the colour and therefore the commercial value of the lower grades. Evidence as to injurious effects of bleached flour is contradictory, but Hamill came to the conclusion, after reviewing the experimental and other data, that "it would be unwise to conclude that the process is attended by absolute freedom from risk."

In the same report Hamill mentioned the addition of various "improvers" to certain flours, to improve their baking qualities by modifying the gluten, so as to increase the strength and water absorbing capacity of the flour and at the same time to increase the activity of yeast in bread-making. This was intended to enhance the value of a weak wheat from the trade point of view. Some improvers tried were acid potassium phosphate, diastase, acid calcium phosphate and phosphoric acid. It is pointed out that low grade acid phosphate frequently contains arsenic and large amounts of calcium sulphate. The report concludes: "It does not appear desirable that such an indispensable foodstuff as flour, the purity and wholesomeness of which are of first importance to the community, should be manipulated and treated with foreign substances, the utility of which, from the point of view of the consumer, is more than questionable."

Rice is frequently faced with talc, which is used together with oil and ultramarine to polish the grains and render them translucent. It has been recommended that not more than 0.5 per cent. should be allowed. The quantity of talc can be estimated by burning the rice to ash and treating with very dilute hydrochloric acid, which completely dissolves the natural mineral matter but leaves the talc unaffected. 
Pearl Barley is also occasionally faced with talc or with rice flour.

Baking Powder consists of sodium bicarbonate with an acid material (tartaric acid, cream of tartar, acid calcium phosphate, etc.) and rice or other flour. It should yield not less than 6 per cent. of carbon dioxide on treatment with water. The acid substances are liable to contain arsenic, and acid calcium phosphate sometimes contains a large quantity of calcium sulphate; not more than Io per cent. of the latter, calculated on the superphosphate, is allowed. The calcium sulphate may be extracted by digesting the powder with dilute hydrochloric acid. Infants' Foods.

A report to the Local Government Board by Coutts and Baker (Food Report No. 20) discusses very fully the nature and composition of various proprietary infants' foods, and, apart from special preparations of cow's milk, divides them broadly into five classes :-

I. Foods with a basis of dried cow's milk but mixed with flour (the term "flour" including flour from leguminous seeds, arrowroot, banana, etc.).

2. Foods consisting mainly of flours, the starch of which is practically unaltered, or altered only by heating.

3. Foods consisting mainly of flours mixed with malt flour or malt extract, but containing much unaltered starch which is not converted during the process of preparing the food for infants in accordance with the directions given on the packet.

4. Foods containing flours, but also containing active diastase or pancreatic ferment, so that if the food is carefully prepared according to the directions on the package the starch is appreciably altered.

5. Foods manufactured from flours, the starch of which has been mainly or partially converted into soluble products during the course of manufacture.

Out of twenty-nine preparations analysed by Baker in connection with this investigation, twenty consisted mainly of 
cereal flours, the starch of which was not appreciably altered when the food was prepared according to directions. Coutts expressed the opinion, as the result of his enquiry, that foods containing unchanged starch, or starch altered only by heating, should not be given to babies under seven months of age, except on the advice of and under the supervision of a medical man.

Vinegar. The Local Government Board in a circular suggested the following definitions :-

"Vinegar is a liquid derived wholly from alcoholic and acetous fermentations. It shall contain not less than 4 grams of acetic acid in roo c.c., it shall not contain arsenic in amounts exceeding $0.0143 \mathrm{mgm}$. per roo c.c., nor any sulphuric or other mineral acids, lead or copper, nor shall it contain any foreign substance or colouring matter except caramel."

"Malt Vinegar is derived wholly from malted barley or wholly from cereals the starch of which has been saccharified by the diastase of malt."

Artificial Vinegar is "any vinegar or substitute for vinegar containing, or derived from any preparation containing, any added acetic acid which is not wholly the product of alcoholic and subsequent acetous fermentations."

Malt vinegar is distinguished from other kinds of vinegar by the relatively large quantities of phosphoric acid and proteins which it contains.

Mineral acid in vinegar can be detected by the acid reaction of the ash, unadulterated vinegar leaving after incineration an alkaline residue.

Black Pepper is the whole pepper berry, picked while in an unripe condition.

White Pepper is pepper from which the outer layers of the pericarp (husk) have been removed.

The chief flavouring constituents are piperine, essential oil and resin; pepper also contains a considerable quantity of starch.

Adulterants of white pepper which have been used are husk, 
sometimes bleached to mask its presence, ground olive stones (poivrette) and rice flour; these can be detected by microscopical examination. The quantity of husk can be determined by estimation of the "woody fibre," obtained by successive extraction with ether, boiling sulphuric acid solution (I.25 per cent.) and boiling sodium hydrate solution ( 1.25 per cent.). The residue is weighed and the mineral matter left after burning is deducted. Genuine white pepper yields by this method 4 to 5 per cent. of woody fibre, while pepper husk gives about 35 to 40 per cent.

Ginger contains, besides starch, resin and volatile oil, which produce the characteristic flavour. Ground ginger has in the past been extensively adulterated with "spent ginger" which has been extracted with a solvent for the preparation of the essence or for the flavouring of ginger-beer, etc. ; such adulteration can frequenily be detected by the microscope. Previous extraction with water would be indicated by the small quantity of ash soluble in water (which should be 2 per cent. or more), and the amount of extract yielded to cold water would also be low. If ginger has been previously treated with alcohol, the quantities of alcoholic extract and ether extract will be small.

Sometimes ground ginger contains an excessive amount of mineral matter, owing to whole ginger coated with lime or calcium sulphate having been ground.

Mustard consists of the ground black mustard and white mustard seeds, and contains a volatile oil produced by the action of enzymes on certain constitutents. It does not normally contain starch, but mixtures with wheat flour are sold as "mustard condiment" and sometimes contain turmeric. The latter can be detected by extraction with alcohol and the application of the boric acid test.

Olive oil is sometimes adulterated with cottonseed oil, or the latter is substituted for it. Halphen's test (page 63) can be used for the detection of this adulterant. Arachis (earth nut) oil has also been used. 


\section{MICROSCOPICAL EXAMINATION OF FOODS 87}

There have recently been prosecutions for the sale of artificially coloured mineral oil as "salad oil."

Sugar is prepared from the sugar-cane or from the beetroot. The former contains in addition to sucrose a small quantity of glucose, which is removed during the refining process; hence ordinary white sugar should not reduce Fehling's solution to an appreciable extent. A trace of ultramarine is sometimes used to improve the colour of white sugar; it can be detected by dissolving a large quantity of the sugar in water and allowing it to stand; when the blue colouring matter settles out.

White sugar artificially coloured has been substituted for Demerara sugar.

\section{Microscopical Examination of Foodstuffs}

For the examination of the starches, very small quantities should be used; for other materials rather more should be taken. The various structures should be sketched, in order to help to memorize them, and compared with those shown in textbooks on food microscopy (see Appendix, page 238), and with specimens of known purity. A half-inch or two-thirds inch objective should first be used, then a one-sixth inch.

Starches :

Mount in

Observations

I. Wheat

2. Barley

3. Maize (Cornflour)

4. Oat

5. Rice

6. Potato

7. Arrowroot

8. Sago

9. Tapioca water

,

,

,

,

,

,

,

,
Placed in order, according to size of largest granules found, they are :$6,8,7,1,2,9,3,4,5$, No. 6 being the largest. The shapes are, approximately, I and 2 circular, 3, 4 and 5 angular, 6 and 7 oval, 8 and 9 irregular with truncated forms.

Note striations, well marked in potato and arrowroot, and hilum in these two, also in maize, sago and tapioca; compound granules in oats and rice.

Examine also by polarized light. 
Mount in

Coffee

Chicory

Coffee and Chi- glycerine cory mixture

$\begin{array}{lr}\text { Cocoa } & \text { (I) water } \\ \text { Cocoa with } & \text { (2) weak } \\ \quad \text { arrowroot } & \text { iodine } \\ \text { Mustard } & \text { (I) water } \\ \text { Mustard and } & \text { (2) weak } \\ \quad \text { wheat mix- } & \text { iodine } \\ \quad \text { ture } & \end{array}$

Section of Pepper Berry

White Pepper

White Pepper with added husk

White Pepper with ground olive stones water or dilute iodine

(I) water

(2) weak iodine As for white pepper

Observations.

Grind, not too finely, in mortar, and crush on slide with knife-blade. Bleach portion with dilute hypochlorite solution.

Note dotted vessels and lightcoloured parenchyma of chicory.

Note small starch granules and examine for foreign starches and for spiral vessels of cocoa-shell.

Note absence of starch in pure mustard. Observe large cells of mucilage and fragments of seed coats, also numerous oil globules.

Note woody cells of outer husk, vascular zone, oil cells, masses of starch, etc.

Angular masses of starch are most abundant, separate granules very small. Inner seed-coats are normally

(3) clove oil. present, but outer husk only in traces.

Husk is dark and opaque unless bleached; it is best examined in clove oil.

Olive stones are best seen in iodine.

Examine also by polarized light, using a selenite plate.

\section{Food values}

The value of a food is often expressed in terms of the quantity of heat to which it will give rise on complete combustion, in other words, the number of "Calories" produced. A Calorie is the quantity of heat required to raise $I$ kilogram of water from $0^{\circ}$ to $\mathrm{I}^{\circ} \mathrm{C}$. ; and it has been found by careful experiments that I gram of protein or carbohydrate will give 4.I Calories, and I gram of fat.9.3 Calories, on combustion in the body, after making allowance for incomplete absorption. 
Hence a food containing 10 per cent. of fat, 20 per cent. of protein, and $5^{\circ}$ per cent. of carbohydrate will yield per 100 grams :-

$$
\begin{aligned}
& (\text { I } \times 9.3)+(20 \times 4.1)+(50 \times 4 . I)=380 \text { Calories; or } \\
& 380 \times 4.54=1725 \text { Calories per pound. }
\end{aligned}
$$

Estimates of the total number of Calories required by a man doing ordinary work vary from 2500 to 3500 per day; that needed by a woman is generally taken as 0.8 of a man's requirement; while the allowance for children is 0.3 or more of that provided for a man, according to age. For hard muscular work a greater number of Calories is needed.

The ratio, Calories supplied by protein : total Calories, is referred to as the "nutritive ratio," and it is recommended that this should be about $\mathrm{I}: 6$ or $\mathrm{I}: 8$, though some authorities advocate less protein than this.

\section{Vitamines}

Study of the disease "beri-beri" has shown that most foods contain "accessory substances," to which the name "vitamines" has been applied, and without which health cannot be maintained. It was discovered that animals fed on polished rice develop beri-beri, and that an extract, in water or alcohol, of the rice-polishings contains some substance minute quantities of which will cure the disease.

Although attempts to isolate and analyse vitamines have not been very successful, it is known that there are at least two such substances, one soluble in water and the other in oils. The former is present in most foodstuffs, but absent from polished rice, white flour and arrowroot; it resists cooking for some time at $100^{\circ} \mathrm{C}$., but is slowly destroyed at $120^{\circ} \mathrm{C}$. The fat-soluble substance is contained in yolk of egg, most animal fats, milk, green leaves, etc., but is absent from lard and vegetable oils. Lack of the second type of vitamine is said to give rise to sore eyes (Xerophthalmia) in rats and mice, and to prevent their growth. 
It is believed that a third vitamine is a preventive of scurvy and that it is present in fresh vegetables, fruit and meat, but absent, or nearly so, from dried vegetables and dried seeds.

Ramsden ("Journal of the Society of Chemical Industry," I918, 37, $53 \mathrm{~T}$ ), has summed up the knowledge gained in this subject by various experimenters ; his paper should be consulted for more detailed information. 


\section{CHAPTER VII}

\section{METHODS OF PRESERVING FOODS}

THE commonest methods of preserving foods are :-

I. Sterilization by heat and storage in air-tight receptacles;

2. Cold storage;

3. Exclusion of air ;

4. Salting and pickling;

5. Smoking ;

6. Use of preservatives.

Also, though not quite comparable with the above,

7. Removal of water;

8. Extraction with water and evaporation of the extract.

I. This method is very largely used in the preservation of fruits, fish, condensed milk, etc., the articles being placed in tins or other receptacles and heated, and while still hot the vessels are closed. This method originated in Paris over one hundred years ago, it has been improved by sealing the tins after driving out the air and replacing it by steam, so that on cooling a vacuum results. The tins are re-heated after standing for a day, in order to allow of the development and destruction of spore-forming bacteria. Foods of an acid character are liable to dissolve tin, and lead should be excluded from the coating of the containers; the substitution of glass is much preferable. When large quantities of sugar are added, as in the case of sweetened condensed milk, the sugar tends to prevent decomposition. The ends of the tins should always be concave from the outside, if they bulge outwards it generally indicates that decomposition has taken place after the closing of the tins. 
2. Cold storage is largely used for conveying meat and other perishable articles on long voyages. Cold is rather an antiseptic than a germicide ; it does not kill bacteria entirely but kills most animal parasites and reduces the number of harmful bacteria. In the case of meat, it is best to hang it in a current of dry air before refrigerating, otherwise moisture condenses on the surface and by dissolving extractive matter makes a suitable medium for moulds and bacteria.

Sometimes the refrigerating chambers are sprayed with formaldehyde, in which case that antiseptic can usually be detected in the outer parts of the food.

3. Exclusion of air is effected in the case of eggs by the use of water-glass (sodium silicate), which closes the pores of the shells. The packing of sardines in oil is another example of this method of preservation.

4. For pickling, the brine contains usually 18 to 25 per cent. of salt. In this process some of the proteins and bases are dissolved out and the fibres are hardened, hence the nutritive value and digestibility are somewhat diminished. Chemical preservatives are sometimes added to the brine. Concentrated sugar solutions have a similar effect in preventing the growth of bacteria and moulds.

5. The foods are exposed directly to the smoke from wood fires, in some cases after a preliminary salting. They become impregnated with acetic acid, creosote and, possibly, formaldehyde, to a certain depth.

6. The preservatives employed include such materials as salt, sugar and vinegar, which are unobjectionable ; also many other antiseptics the use of which is open to criticism. The chemical preservatives most commonly used are :-

In foods of animal origin :

borax and boric acid, in milk, butter, potted meat, etc., formaldehyde, in milk, meat, etc., saltpetre, on hams and other meats. 
In foods of vegetable origin :

salicylic acid, in jams, non-alcoholic beverages, etc., sulphurous acid and sulphites, in lime-juice, beer, etc., benzoic acid, in tomato sauce, etc.

7. Removal of water is sometimes employed in order to preserve the essential ingredients of a food, but entails an alteration in the character of it. An example is the preparation of dried milk, which is made by the rapid evaporation of milk. Milk powder and dried eggs may be preserved almost without limit of time if kept perfectly dry.

This method is not so well adapted to meat as to fruit and vegetables, as meat loses its natural flavour in the process. The fruits in drying are frequently exposed to the fumes of burning sulphur, which acts as a preservative and also prevents darkening of the colour; but the dried fruits retain considerable amounts of sulphites, hence the practice is an objectionable one.

8. An example of this method is the preparation of meat extracts.

\section{Chemical preservatives in foods}

The use of antiseptics for preserving foods is now widespread, and it is very unfortunate that there is in this country very little attempt made to regulate this practice. Many of the preservatives so employed are drugs, some actual poisons, yet, with the exception of milk and cream, it is left to local authorities to allow, or attempt to prevent, their admixture with foodstuffs. The law should at least provide that the nature and quantity of any preservative should be stated on the label.

It is sometimes argued that the use of preservatives, by preventing putrefaction, tends to obviate the risk of injury due to the consumption of decomposing food and at the same time prevents waste ; but there are many facts which outweigh these arguments. In the first place, the indiscriminate use of preservatives allows of carelessness and uncleanliness in the preparation and storage of food. Then there is abundant 


\section{PUBLIC HEALTH CHEMISTRY}

evidence that most of the antiseptics so used have injurious effects if taken regularly over a long period.

Wiley proved this in the case of healthy adults, and it naturally follows that the results would be more serious where children and invalids are concerned.

According to Kenwood, salicylic acid is depressing, has an irritant effect on the kidneys and is liable to be cumulative in action ; benzoic acid is irritating; sulphurous acid is a gastric irritant and formaldehyde combines with proteins, reducing their digestibility. All antiseptics are likely to have a retarding effect upon the enzymes concerned in the digestive processes.

By some people, benzoic acid is regarded as the least harmful of these preservatives, because it is said to combine with glycocoll, produced by the liver, to form hippuric acid. It is not, however, a very powerful antiseptic.

Hydrogen peroxide is regarded as comparatively harmless in small quantities, but it is seldom used in this country. The enzymes in milk decompose hydrogen peroxide to the extent of about 0.25 per cent. in twenty-four hours.

Formaldehyde and fluorides are generally condemned as food preservatives.

The Departmental Committee on Preservatives and Colouring Matters in Food (1901) made the following recommendations :-

(a) That the use of formaldehyde or formalin, or preparations thereof, in food or drinks, be absolutely prohibited, and that salicylic acid be not used in greater proportion than one grain per pint in liquid food and one grain per pound in solid food. Its presence in all cases to be declared.

(b) That the use of any preservative or colouring matter whatever in milk offered for sale in the United Kingdom be constituted an offence under the Sale of Food and Drugs Acts.

(c) That the only preservative which it shall be lawful to use in cream be boric acid or mixtures of boric acid and borax, and in amount not exceeding 0.25 per cent. expressed as boric 
acid. The amount of such preservative to be notified by a label on the vessel. (See below.)

(d) That the only preservative permitted to be used in butter and margarine be boric acid or mixtures of boric acid and borax, to be used in proportions not exceeding 0.5 per cent. expressed as boric acid.

(e) That in the case of all dietetic preparations intended for the use of invalids or infants, chemical preservatives of all kinds be prohibited.

$(f)$ That the use of copper salts in the so-called greening of preserved foods be prohibited.

(g) That means be provided, either by the establishment of a separate court of reference or by the imposition of more direct obligation on the Local Government Board, to exercise supervision over the use of preservatives and colouring matters in foods, and to prepare schedules of such as may be considered inimical to the public health.

In regard to $(f)$, a member of the Committee recommended that not more than the equivalent of half a grain of metallic copper per pound should be allowed, the actual amount used being declared, on the ground that the value of a food depends to a certain extent upon its appetizing appearance.

The Public Health (Milk and Cream) Regulations, 1912, prohibit the addition of any preservative to milk. By the same regulations, amended by an Order of 1917 , cream may only contain preservative under the following conditions :-

I. It must be described as "Preserved Cream."

2. It must contain not less than 35 per cent. of milk-fat.

3. The only preservatives allowable are boric acid or mixtures of boric acid and borax, in amount not exceeding 0.4 per cent. expressed as boric acid, or hydrogen peroxide.

4. It may only be sold in a receptacle labelled in accordance with these regulations (nature and size of label specified), and, in the case of preservation with boric acid or borax, the maximum amount present expressed as boric acid must be stated 
on the label. The label must also contain the words: "Not suitable for infants or invalids."

\section{Detection of salicylic acid}

The salicylic acid is extracted with ether and is left as a crystalline residue on evaporation of the solvent. If the material tested is a solid, the salicylic acid is extracted from it with hot water, and, after cooling, the aqueous solution is shaken with ether. In case the preservative is present as a salicylate, the aqueous solution is acidified in order to liberate the free salicylic acid.

Detection in jam.

Required:-

porcelain dish and glass rod

funnels

cambric

filter papers

small separating funnel

small flasks

burette stand

apparatus for distilling ether ether

sulphuric acid dil.

ferric chloride, I per cent.

\section{Procedure :-}

Take about Io grams of the jam in a dish, cover it with hot water and stir well with a glass rod. Filter the solution through cambric into a small separating funnel, cool, add a few drops of dilute sulphuric acid and sufficient ether to form a separate layer, and shake well but not violently. Allow the liquids to separate, run off the aqueous portion by the tap and shake the ethereal solution with a few c.c. of cold water, running this off as before. Filter the ether through a $d r y$ filter paper into a $d r y$ flask, distil off the ether and blow a very gentle current of air through the flask with a bellows; in presence of salicylic acid a crystalline residue will be left on the side and bottom of 
the flask. Treat the contents of the flask with hot water, filter, cool, and to a portion of the solution add a few drops of I per cent. ferric chloride solution, whén a purple colour will be produced if salicylic acid is present.

Detection in liquids (lime-juice, etc.).

Add a few drops of dilute sulphuric acid, shake with ether and proceed as before.

The amount of salicylic acid may be estimated by carrying out the above process with a weighed (or, in the case of liquids, measured) quantity of material, extracting thoroughly with hot water and ether, and, after dissolving the salicylic acid in hot water, making up the solution to a convenient bulk and matching the colouration produced by ferric chloride in an aliquot part against standard salicylic acid solution treated similarly.

Benzoic acid can be detected by the same procedure as salicylic acid; it yields a light red colouration or precipitate with ferric chloride.

\section{Detection of sulphurous acid and sulphites}

Required:-

small flask

filter papers hydrochloric acid dil.

potassium bichromate solution

\section{Procedure :-}

Place some of the material to be tested in a small flask, if it is a solid add a little water. Acidify with dilute hydrochloric acid and heat to boiling, covering the mouth of the vessel with a piece of filter paper which has been moistened with potassium bichromate solution; in presence of sulphurous acid the odour of sulphur dioxide will be produced, and the colour of the bichromate changed to green.

An estimation of the quantity may be made by distilling the sulphur dioxide, from a weighed or measured amount of the 
material, into dilute sodium hydrate solution, oxidizing the sulphite so produced with bromine water and precipitating the sulphate, after addition of excess of hydrochloric acid, with barium chloride. From the weight of barium sulphate obtained the amount of sulphurous acid can be calculated.

\section{Poisonous Metals in Foods}

The poisonous metals which are most frequently found in food-stuffs are lead, copper, tin and zinc.

Lead may be introduced by the action of acid juices on solder or on impure tin used in the containing vessels, or from lead pipes used to convey barm beer and similar liquids which have considerable solvent action on that metal. Tartaric acid and cream of tartar frequently contain traces of lead accidentally taken up during the process of manufacture, and a limit of 0.002 per cent. (one-seventh of a grain per pound) has been adopted for these articles. It has been pointed out (Masters, "Analyst," I9I9, 44, I64) that vessels of fire-proofed pottery ware may contain in the glaze serious amounts of lead which is extracted by boiling for a short time with liquids containing acetic or other organic acids.

Copper occurs naturally in many foods, the quantity being usually very small ; oysters, however, contain an appreciable amount. The practice of "greening" peas and other vegetables by treatment with copper salts is well known; the equivalent of 0.5 of a grain of copper per pound is generally allowed, provided its presence is notified by a label (see page 95).

Tin is contained, usually in traces only, in most tinned foods; in some instances, when the material has been in the tins for a long period or has been opened and reheated, the amount of tin taken up by the food may be considerable. It has been recommended that not more than 2 grains of tin per pound should be permitted.

Zinc has been found in traces in tinned pineapple and other fruits, probably derived from galvanized iron with which they 
have been in contact, or from soldering fluid. Zinc has also been found in oysters.

Method of detection.

Required:-

porcelain dishes, sizes 4 and oo hydrochloric acid dil.

beakers, 300 and 50 c.c.

nitric acid conc.

funnels

wash-bottle

test-tubes

filter papers

pipeclay triangle

crucible tongs sodium hydrate solution ammonium hydrate acetic acid dil. potassium chromate solution

potassium ferrocyanide ammonium chloride solution

sulphuretted hydrogen apparatus

Procedure :-

(N.B.-It is important that in the following tests the solutions should be kept small in bulk.)

Take 25 to roo grams, according to the quantity available, in a No. 4 porcelain dish and char thoroughly, avoiding very strong heating. Extract with hot dilute hydrochloric acid, filter, dry and burn the insoluble portion to ash; add the acid solution and heat on a water-bath. Filter.

Take half the solution and test for tin as follows :-

Pass sulphuretted hydrogen and heat, and, if any precipitate is visible, filter. Keep filtrate for examination for zinc. Wash the precipitate on the filter paper with water, treat with hot sodium hydrate solution, collecting the liquid in a small beaker, acidify the solution with dilute hydrochloric acid and again pass sulphuretted hydrogen; a brown precipitate, which settles out on standing, indicates tin.

Take the remaining half of the solution and examine for lead and copper as follows:-

Evaporate to dryness in a porcelain dish on the water- 
bath, add a little water and evaporate again to remove the excess of acid. Treat the residue with hot water and one drop of dilute hydrochloric acid, heat and filter. Pass sulphuretted hydrogen, if there is no colouration lead and copper are absent. If a brown colouration appears, heat and filter through a small filter paper. Keep filtrate for zinc test. Transfer the paper to a small porcelain dish, pressing it down well, dry on the water-bath and burn to ash over a bunsen flame (draughts must be avoided, as the ash may easily be carried away). Treat the ash with one or two drops of strong nitric acid and dry on the water-bath, then add one drop of ammonium hydrate; a blue colour indicates copper. Add a slight excess of acetic acid and a few drops of water, heat and filter. The lead and copper will now both be in solution, freed from other metals. Test one portion of the solution, after cooling, for lead by adding a drop of potassium chromate solution, which produces a yellow turbidity, and another portion for copper with potassium ferrocyanide solution, which gives a red colouration.

Examination for zinc. Take the combined filtrates after the removal of lead, copper and tin, boil off sulphuretted hydrogen, add a little strong nitric acid and boil (to oxidize iron), then add ammonium chloride and excess of ammonium hydrate, filter and pass sulphuretted hydrogen through the liquid; zinc produces a white precipitate. Confirm the presence of zinc by filtering off the precipitate, washing with water and dissolving in dilute hydrochloric acid; boil the solution, cool and add a fresh solution of potassium ferrocyanide, when a white precipitate will be produced.

The quantities of these metals may be estimated as follows :-

Tin. The sulphide, after dissolving in sodium hydrate solution and reprecipitating, as described above, is filtered off, washed, dried and ignited to $\mathrm{SnO}_{2}$, which is weighed.

A colorimetric method for the estimation of traces of tin in foods is described by Buchanan and Schryver in a report to the Local Government Board, Food Report No. 7. 
Lead and copper are precipitated in the form of sulphides, as above, filtered off and washed with sulphuretted hydrogen solution. The filter paper and precipitate are transferred to a small beaker and boiled for a few minutes with nitric acid ( $\mathrm{I}$ to 2 ) to pulp the paper, the solution is filtered into a small porcelain dish and evaporated to dryness, while the filter paper and residue are dried in another dish. Both dishes are gently ignited in order to destroy organic matter and the residues are treated with a few drops of strong nitric acid, then dried on a water-bath. A few drops of ammonium hydrate are added, and excess of acetic acid, the solutions are boiled and both transferred to a 50 c.c. measuring flask. The solution is cooled, made up to bulk with water and mixed.

Lead is estimated in an aliquot part of the solution by adding excess of ammonium hydrate, a few drops of a strong solution of potassium cyanide, and 5 c.c. of a saturated solution of sulphuretted hydrogen, comparing the colour with those given by different quantities of a standard lead solution to which the same amounts of ammonia, potassium cyanide and sulphuretted hydrogen solution are added.

Copper is determined in another portion of the solution by adding ammonium chloride and potassium ferrocyanide solutions and comparing the red colour with standard copper solution treated similarly.

If the amount of lead is small compared with that of the copper, the colorimetric estimation of the lead is unsatisfactory. In such a case the lead, if the quantity is not too small, may be precipitated by potassium chromate from the solution in ammonium acetate, and, after allowing to stand, the lead chromate is filtered through a tared filter paper (see page 7), washed, dried, and the weight ascertained.

Lead and copper may also be conveniently estimated by electrolytic methods, when the quantities are comparatively large.

Zinc can be estimated by filtering off the sulphide, obtained 
as above, washing, drying and igniting gently to $\mathrm{ZnO}$, which is weighed.

\section{ARSENIC IN Foods}

The accidental contamination of food with arsenic was first brought seriously to notice in 1900 , when an epidemic of arsenical poisoning, due to beer, broke out. How long it had previously been going on is uncertain, but it is probable that before that date many cases of so-called "alcoholic neuritis" were in reality due to poisoning by arsenic. In I 900 it was found that a very large number of cases which were being treated in public institutions in the north of England were cases of arsenical poisoning, and following on this discovery very numerous instances were brought to light; altogether at least 6000 cases, of which some 70 proved fatal, were definitely traced to this cause. It was found on investigation that brewing sugar, in the manufacture of which highly arsenical sulphuric acid was used, was the original cause of the trouble, the arsenic thus finding its way into the beer. The amounts of arsenic found in beer at that time varied from traces to one and a half grains per gallon, and as it was stated that some persons consumed a gallon, or even more, of beer per day, the results could not but be serious.

Arsenic is liable to be introduced similarly into a variety of other articles of food, since sulphuric acid is used, directly or indirectly, in many preparations. The arsenic is derived in the first place from iron pyrites which supplies the sulphur in the manufacture of the acid, and sulphuric acid used in the preparation of brewing sugar in I900 was found to contain in certain cases as much as 1.9 per cent. of arsenic.

Other materials which are employed in the preparation of foodstuffs and which may contain arsenic derived from sulphuric acid are :-

Hydrochloric acid, used in the manufacture of glucose ;

Glucose, in brewing and confectionery ; 


\section{ARSENIC IN FOODS}

Invert sugar, in brewing and in non-alcoholic drinks;

Glycerine, in confectionery and in medicine;

Phosphoric acid and acid phosphates, in sugar refining and in baking powders ;

Coal-tar colours, mineral colours and caramel, in confectionery, etc. ;

Boric acid and borates, used as preservatives.

The finished foods which are liable to arsenical contamination, in addition to beer, are :-

Foods containing glucose, malt or yeast;

Table syrups ;

Vinegar ;

Foods containing baking-powder ;

Foods containing colouring matters.

Another source of arsenic in beer was discovered as the result of a smaller epidemic at Halifax in 1902, when it was found that malt which, in drying, had been exposed to the smoke from gas coke was highly arsenical. Traces of arsenic have been noted in roasted chicory, probably due to a similar cause.

The Royal Commission on Arsenical Poisoning recommended that penalties should be imposed when beer or any other liquid food, or any liquid entering into the composition of food, is sold containing one-hundredth of a grain or more of arsenic in the gallon; and with regard to solid food-no matter whether it is habitually consumed in large or in small quantities, or whether it is taken by itself (like golden syrup) or mixed with water or other substances (like chicory)-when it is sold containing one-hundredth of a grain or more of arsenic in the pound.

\section{Detection of arsenic}

Reinsch test.

The liquid to be examined is boiled with hydrochloric acid 
and pure copper foil, when arsenic if present is deposited on the copper. The copper is removed from the liquid, and on heating it in a glass tube closed at one end the arsenic is oxidized and sublimes, being deposited in the form of octohedral and tetrahedral crystals on the cooler part of the tube; these can be recognized under the microscope. Antimony and mercury are also deposited on copper in the same way, but the sublimate from the former is amorphous and from the latter consists of globules.

If the material to be tested is a solid, it is digested with hot water and the test applied to the mixture ; if the arsenic is likely to be only on the surface, as in unground malt, it is sufficient to wash it with warm dilute hydrochloric acid and test the liquid. Should there be any possibility of the arsenic being in the oxidized condition (as $\mathrm{As}_{2} \mathrm{O}_{5}$ ), the liquid must be saturated with sulphur dioxide, or a few crystals of potassium metabisulphite or of sodium thiosulphate added, and then boiled to expel the excess of sulphur dioxide, before performing the test.

Detection in Beer.

Required :-

beakers

sand bath hydrochloric acid conc. (free from arsenic)

graduated cylinder, roo c.c. thin electrolytic copper foil sublimation tubes

filter papers

small rose burner

\section{Procedure :-}

Take roo c.c. of the beer in a beaker, add ro c.c. of concentrated hydrochloric acid and a piece of very thin electrolytic copper foil (about $\left.\frac{1}{2} \times \frac{1}{4}^{\prime \prime}\right)$. Boil gently, adding boiling water from time to time to keep the bulk approximately to the original quantity. Examine the copper occasionally, pouring off the liquid into another beaker meanwhile, and note 
if any change takes place in the appearance of the metal; in presence of arsenic in very slight traces the copper becomes slightly tarnished and has a purple iridescence, with a larger quantity there is a steel-blue coating, while still more produces a silvery deposit. The boiling should be kept up for two hours before concluding that the beer is quite free from arsenic, but should the copper be coated in half an hour or less, it may be removed and the boiling continued with another piece of the metal. Wash the foil thoroughly with water, dry it between filter papers and then in an air-bath, and roll it as tightly as possible round a fine pin, then place it at the bottom of a narrow hard glass tube closed at one end ("arsenic sublimation tube "). Heat the closed end of the tube very gently over a rose burner, arsenic sublimes from the copper and is deposited as oxide on the cooler part of the tube, and on microscopical examination the characteristic crystals can be seen.

N.B.-The crystals of arsenious oxide when first sublimed are frequently moist, so that their shape cannot be accurately seen. In such a case, after the first microscopical examination, the deposit should be driven down the tube, by warming carefully in the flame, and then resublimed and again examined.

\section{Marsh-Berzelius method}

This test depends upon the fact that when hydrogen is generated in a liquid containing arsenic, the arsenic combines with hydrogen forming arseniuretted hydrogen $\left(\mathrm{AsH}_{3}\right)$, and on heating the gases the hydride is decomposed, liberating arsenic. By effecting the decomposition in a narrow glass tube, very small quantities of arsenic can be detected by means of the stain produced, and by preparing standards with known amounts of arsenic the method can be made quantitative.

In 1902 a committee was appointed by the Commissioners of Inland Revenue "to specify the ingredients of beer, and the materials used in their preparation, which are liable to 
be contaminated by arsenic, and to prescribe tests by which their freedom from arsenic may be ascertained." The report of the committee, published in 1903, states:-

"Of the various methods which have been suggested for the detection and estimation of the relatively small quantities of arsenic which may be present in beer . . . we are of opinion that those methods which depend upon the conversion of the arsenic into arseniuretted hydrogen, and the subsequent deposition of the arsenic in the elementary form by heating the gas, are, on the whole, to be preferred. The arseniuretted hydrogen may be formed in practice by the action of so-called "nascent" hydrogen upon the arsenic present. The hydrogen may be evolved either electrolytically, or through the agency of dilute hydrochloric acid upon zinc admixed with, or containing, such an amount of copper or other suitable metal as to give rise to a sufficiently rapid evolution of the gas.

The amount of the arsenic deposited is then determined by comparison with deposits obtained in precisely the same manner from wort, beer, etc., containing known quantities of arsenic."

\section{Zinc and acid method.}

In the method in which zinc is employed as a means of generating hydrogen, the apparatus recommended is as follows :-

A flask is fitted with a ground glass stopper through which passes the stem of a funnel furnished with a stopcock. The stopper also has an exit tube, on which is a bulb, and which is bent twice at right angles and connected by grinding with a calcium chloride drying tube. A hard glass tube, in which the arsenic is to be deposited, is connected with the drying tube by a short piece of rubber tubing, the ends of the glass tubes being in close contact beneath the rubber.

The hard glass tube is made from tubing of $5 \mathrm{~mm}$. external and $3.5 \mathrm{~mm}$. internal diameter, softened in the blowpipe flame 


\section{ARSENIC IN FOODS}

and drawn out so that at a distance of $\mathrm{r} \mathrm{cm}$. from the shoulder of the tube the external diameter is $2 \mathrm{~mm}$., a size which should be maintained as nearly as possible throughout the length of the constricted part. The tube is cut off near the end of the drawn-out portion, the last $\mathrm{cm}$. of which is turned up at right angles.

The drying tube is packed as follows:-

A plug of cotton wool is first inserted and then pure granulated anhydrous calcium chloride for a length of $5 \mathrm{cms}$. Another loose plug of cotton wool is placed upon the calcium chloride, followed by a roll of lead acetate paper. A small spiral coil of lead acetate paper is also placed within the enlarged end of the exit tube to which the calcium chloride tube is attached.

The hard glass tube is supported in a horizontal position by resting it in slots in the edge of a cone which surrounds the bunsen burner. A piece of platinum (or copper) gauze is wrapped round the glass tube at the point where it is to be heated by the flame.

The materials required are zinc, hydrochloric acid, fuming nitric acid and copper sulphate. Arsenic is frequently present in zinc, hence it must be ascertained that the zinc is free from arsenic before it is used in the test. It has also been established that some varieties of commercial zinc, owing, it is presumed, to the presence of small quantities of iron, will not furnish a deposit of arsenic when small quantities of arsenic are added to the solution in the generating flask. It is therefore necessary to ascertain, firstly, if the zinc is free from arsenic and, secondly, if it yields a normal arsenic deposit from a solution containing a known amount of arsenious oxide when used in the prescribed manner.

In regard to the other materials used, their freedom from arsenic must be ascertained by means of blank experiments, which are carried out in a similar manner to the estimations of arsenic. The hydrochloric acid used has a specific gravity of I.I. 


\section{Preparation of the substances to be tested.}

Beer. Basic method. To 25 c.c. of the beer, contained in a porcelain or, preferably, platinum dish, are added 20 c.c. of arsenic-free lime-water, and 0.5 gram of magnesia; the mixture must be alkaline to litmus paper. The dish is placed over a low flame and the liquid evaporated to dryness; the residue is charred and finally heated until the organic matter is destroyed. The ash is moistened with water and dissolved in ro c.c. of hydrochloric acid (sp. gr. r.r.). The solution is then added to the generating flask.

Acid method. 25 c.c. of the beer are put into a roo c.c. round-bottomed flask and evaporated to a thick syrup on a sand-bath. The syrup is cooled and 5 or 6 c.c. of fuming nitric acid added, the mixture is then very gently warmed until the reaction starts. Care must be taken to moderate it if necessary by immersing the flask in cold water. The flask is then replaced on the hot sand-bath and heated until the greater part of the nitric acid has been driven off. To the residue $I$ or 2 c.c. of fuming nitric acid are added and the flask heated as before; this operation is repeated until a total of about ro c.c. of the acid has been added. The contents of the flask are finally heated until there is no further evolution of brown fumes. When cold the resulting crystalline mass is dissolved in Io c.c. of hydrochloric acid, diluted with an equal bulk of water, and the solution transferred to the apparatus.

Glucose and other sugars. 5 grams are weighed in a beaker and dissolved in 20 c.c. of water. To the solution ro c.c. of hydrochloric acid are added and it is then ready for the test.

For other materials, one of the above methods of preparation can be used.

Mode of working.

Io grams of granulated zinc are placed in the flask and covered with 55 c.c. of water to which are added 5 c.c. of 


\section{ARSENIC IN FOODS}

hydrochloric acid. After a minute or two it is thoroughly washed and covered with 15 c.c. of a 2 per cent. copper sulphate solution, which is allowed to act for about ten minutes, after which the copper-zinc couple is repeatedly washed with water.

The flask is then fitted with the stopper, the drying tube is fixed in position and the hard glass constricted tube is attached by the rubber connection to the end of the drying tube. The bunsen burner is also placed in position, so that the flame will heat about $2 \mathrm{~cm}$. of the tube just before the constriction commences. Around this heated part of the tube a piece of wire gauze is placed.

When all the connections have been made, about ro c.c. of hydrochloric acid (sp. gr. I.I) are gradually added. At the end of ten minutes the apparatus will be practically free from air, and the hydrogen may be lighted; at the same time the burner is also lighted and the heating of the tube so regulated that the wire gauze is maintained at a red heat. Then, during twenty minutes, a further quantity of ro c.c. of hydrochloric acid is added. The hydrogen flame should be from 2 to $3 \mathrm{~mm}$. in height, and the acid is to be added throughout the experiment so as to secure this. During the heating of the tube a deposit of arsenic, best secn by holding a white card beneath the tube, will be formed if the zinc or acid is not arsenic-free. In such a case the experiment must be discontinued, the flask washed out and fresh materials employed.

When the materials are thus proved to be free from arsenic, the solution to be tested is gradually run in, so that its addition to the flask is spread over a period not exceeding fifteen minutes, and the hydrogen flame is maintained at a height of 2 to $3 \mathrm{~mm}$. When the whole of the solution has been added, the generation of the hydrogen is continued for at least a further fifteen minutes by the addition, as required, of more hydrochloric acid. For that purpose from ro to 15 c.c. are added.

The tube, if it contains a deposit of arsenic, is sealed up while full of hydrogen. This is effected by opening the tap 
of the apparatus and directing a small pointed flame against the narrow tube about $3 \mathrm{~cm}$. from the deposit, between the deposit and the turned up end, which is meanwhile held with a pair of forceps. The tube at once collapses and the end is drawn off. The wide part of the tube is then similarly heated and drawn off just above the shoulder, but the deposit of arsenic must on no account be heated by the flame during the sealing of the tube. The short tube containing the deposit may then be mounted on a white card for reference.

\section{Preparation of the standard deposits.}

It is best to prepare deposits by the addition of known amounts of arsenic to pure specimens of each class of substance. The quantity of substance taken, and the manner of preparing the solution, must be the same as are used in testing that material, the only difference being the addition of a definite amount of arsenic. The quantities of arsenic generally used are $0.002,0.004,0.006 \mathrm{mgm}$. and upwards, to $0.018 \mathrm{mgm}$. of arsenious oxide.

For the preparation of a solution of arsenic of definite strength, pure arsenious oxide is ground to a fine powder and dried at $100^{\circ}$ C. ; 0.1 gram is weighed and transferred to a litre flask with I or 2 c.c. of concentrated hydrochloric acid. The liquid must not be heated. When the solution is complete, it is diluted to I litre with water and thoroughly mixed. roo c.c. of this solution are transferred to another litre flask and diluted with water to I litre; this solution contains 0.0000 I gram, or $0.01 \mathrm{mgm}$., of arsenious oxide.

It is convenient to seal up the tubes containing the standard deposits, as described above, and to mount them on a white card.

$N . B$. - It is found necessary to frequently renew the calcium chloride in the drying tube.

The process, which has come to be known as the MarshBerzelius method, is similar in principle to that recommended 
by a Joint Committee of the Society of Public Analysts and of the Society of Chemical Industry ("Journal of the Society of Chemical Industry," r902, 94-96).

\section{Electrolytic method.}

The apparatus employed in this method is similar in many respects to that used for the zinc and acid process, instead, however, of the generating flask it has the following parts :-

A glass vessel, open at the bottom, provided with a ground glass stopper and connections, and calcium chloride drying tube ;

A porous cell, in which the glass vessel rests;

A glass jar surrounding the porous cell ;

A cooling vessel.

The glass vessel forms with the porous vessel the inner cell for the cathode, where the hydrogen and arseniuretted hydrogen are produced on passing the electric current. The glass vessel is open at the bottom and fitted at the top with a ground glass stopper; through which is passed the stem of a tap funnel. The glass stopper also carries the gas exit tube and the calcium chloride drying tube, and through it is fused a stout platinum wire for making the connection on the outside with the current, and within the vessel with the electrode.

The inner electrode, forming the cathode, is of sheet platinum and cone-shaped, with several perforations. It is suspended from the end of the wire passing through the glass stopper. The anode consists of a band of platinum passing loosely round the porous cell, and connected with the current by means of a stout platinum wire. The liquid in the glass jar should be kept below $50^{\circ} \mathrm{C}$, and the vessel is therefore placed in a larger dish containing cold water.

Sulphuric acid solution ( $\mathrm{I}$ in 8 of water) is employed in the apparatus; it must be tested to ascertain its freedom from arsenic before it is used.

Certain of the solutions to be tested are liable to froth when 
introduced into the apparatus. This may be obviated by adding I or 2 c.c. of amyl alcohol to the liquid undergoing electrolysis.

The methods used for the preparation of the substances to be tested are in general similar to those employed in the zinc and acid method, with the difference that sulphuric acid is used instead of hydrochloric acid and that half a gram of potassium metabisulphite is usually added, and the solution boiled until free from sulphurous acid, in order to ensure that the arsenic is in the reduced condition.

\section{B.P. quantitative limit test for arsenic}

Apparatus. A wide-mouthed bottle capable of holding about 120 c.c. and fitted with a rubber stopper through which passes a glass tube. The latter has a total length of $200 \mathrm{~mm}$. and an internal diameter of $5 \mathrm{~mm}$. (external diameter $7 \mathrm{~mm}$.) and is open at both ends. The upper end is slightly widened to a diameter of $8 \mathrm{~mm}$., while the lower end is drawn out to about $\mathrm{I} \mathrm{mm}$. in diameter, and a hole about $2 \mathrm{~mm}$. in diameter blown in the side of the tube where it is constricted.

Lead papers are pieces of thin filter paper $100 \mathrm{~mm}$. by $40 \mathrm{~mm}$. soaked in lead acetate solution and dried.

Mercuric chloride papers are circles of smooth white filter paper $5.5 \mathrm{~cm}$. in diameter soaked in a saturated aqueous solution of mercuric chloride and dried. (Note.-These papers should be stored in a stoppered bottle in the dark.)

Reagents for this test are distinguished by the letters "As $\mathrm{T}$ " (see Appendix, page 2 I8).

Method of performing the test.

By a variable method suitable to the particular needs of each case there is prepared from the substance to be tested a solution which contains the whole of the arsenic originally in that substance. It is this solution which is introduced in the actual test. 
General test. A strip of lead paper is rolled up and placed in the glass tube so that the upper end is not less than $2 \mathrm{~cm}$. below the top of the tube. A piece of the mercuric chloride paper is now placed over the top of the tube and secured by means of a rubber ring (see below). The tube is inserted in the rubber stopper. The solution to be examined, prepared as specified, is placed in the bottle and Io grams of zinc As T. added. The rubber stopper with glass tube attached is quickly placed in position so that the lower end of the tube is clear above the surface of the liquid, and the hole in the lower part of the tube is below the bottom of the stopper. The action should be allowed to proceed for thirty to forty minutes, the mercuric chloride paper not being exposed to strong sunlight. The yellow stain which is produced on the paper if arsenic be present is compared by daylight with stains produced by operating in a similar manner with known quantities of the solution of arsenic As T. The comparison of the stains should be made at the completion of the test and those used for comparison should be freshly prepared, as the stains fade on keeping.

Note.-The action may be accelerated by standing the apparatus on a hot plate, care being taken that the mercuric chloride paper remains quite dry.

Instead of attaching the mercuric chloride papers to the tube of the apparatus by means of a rubber ring, the author has found the following arrangement more satisfactory, a circular uniform stain being more easily obtained by its use. A grey india-rubber stopper ( $\mathrm{I} \frac{3}{8}$ inch) is cut into three "slices" about five-eighths of an inch thick in planes parallel to the ends, each of these "slices" is used to prepare one of the attachments for the arsenic apparatus. The rubber is pierced with a hole just large enough to allow the glass tube of the apparatus to be passed through it, the hole being bored slightly to one side of the centre. The rubber is then slit in a plane parallel to the ends for about two-thirds of its width and the 
glass tube is passed through the hole in the lower part of it, the widened mouth of the tube projecting slightly within the slit.

In performing a test a small piece of mercuric chloride paper is placed over the mouth of the tube, the two parts of the rubber are pressed together, and two clips are applied to hold the paper firmly in position and prevent any escape of gas through the slit. Screw clips have been found suitable for the purpose ("Analyst," 1919, 44, 235).

Standard stain. Prepare a solution by adding to 50 c.c. of hot water ro c.c. of stannated hydrochloric acid As T. and I c.c. of solution of arsenic As T. The resulting solution, when treated as described in the "General Test," will yield a stain on the mercuric chloride paper hereinafter referred to as the "Standard stain."

In using the method for the testing of drugs, the quantity taken in each case is such that the stain produced is exactly equal to the standard stain when the amount of arsenic in such drug is the maximum allowed by the "Pharmacopœia."

For the methods of preparation and the control tests for the reagents, the "British Pharmacopœia" (I9I4) should be consulted.

The following are examples of the methods recommended :-

In many cases, such as the testing of tartaric acid, glycerine and magnesium sulphate, the material is dissolved in water and stannated hydrochloric acid added; the solution is then introduced into the apparatus.

Carbonates are dissolved in water and brominated hydrochloric acid, the excess of bromine removed by adding a few drops of stannous chloride and the solution then tested. Potassium acid tartrate is tested in the same way.

Benzoic and salicylic acids are mixed with lime water, dried and gently ignited; the residue is dissolved in brominated hydrochloric acid and water, and the excess of bromine removed by the addition of stannous chloride. 


\section{CHAPTER VIII}

\section{WATER SUPPLIES}

THE sources from which water is obtained for domestic purposes are: Rain, upland surface supplies, rivers, wells and springs.

Rain water contains impurities derived from the air through which it has fallen, viz. ammonia, carbon dioxide, organic matter and chlorides, sometimes nitric and sulphuric acids, the quantities of the impurities varying with the locality. Owing to its lack of mineral constituents, and frequently its acidity, rain water easily dissolves lead, zinc, and other metals, hence care is required in the collection and storage, if it is to be used for drinking and cooking. It is advisable to reject the first portion by means of a separator and to filter the water before use.

Rain water after reaching the ground is partly evaporated, to an extent depending principally upon temperature. Of the remainder, some is absorbed by the land and helps to feed underground sources of water, while the rest flows into streams and lakes.

Upland surface waters, which constitute some of the principal supplies in this country, are collected from high, preferably uncultivated, land, the streams which carry the water sometimes ending in a natural lake; in other cases a dam is erected across the valley through which the water flows, in order to impound it. The gathering ground should be carefully examined and if possible streams which drain from peat bogs should be excluded. The number of fields under cultivation and like sources of pollution should be reduced to a minimum, 


\section{PUBLIC HEALTH CHEMISTRY}

and the whole area, including the storage reservoir, should be under control.

From the nature of its origin, upland surface water generally contains organic matter but is almost free from mineral matter; it is frequently acid, especially if it includes water of peaty origin, hence it often requires treatment before it can safely be conveyed by lead pipes, owing to its solvent action. on that metal (see page 157). Its quality is generally improved by filtration through sand.

Rivers and streams. Waters from these sources vary considerably in composition. When near the source, and when passing through uninhabited and uncultivated land the water may be of good quality; but in the neighbourhood of towns and villages rivers are very liable to pollution and care has to be exercised in using them for domestic supplies, although the regulations enforced for the treatment of sewage protect such water to a certain extent. The lengthy exposure to air which river water undergoes undoubtedly tends to purify it; but the intake should be as far as possible above likely points of pollution and no water should be taken from the river at times of flood. Should the river be subject to considerable pollution, the water should not be used for drinking, and, in any case, storage and efficient filtration ought to be arranged for. It has been proved (by Houston and others) that storage for a week almost entirely removes typhoid bacilli from water and that three weeks storage practically eliminates all pathogenic organisms.

A practice sometimes adopted is to construct channels, or sink bore-holes, close to a river, in order to take advantage of the filtration thereby provided, such method yielding a purer water than can be obtained from the river itself.

Wells are classed as "deep" and "shallow," the terms applying not so much to the depth of the bore-hole as to the nature of the strata through which it passes. If the water is 
drawn from below a bed of impervious material, such as cliay, and surface water is excluded, the well is a "deep " one ; but if the well merely collects subsoil water the term "shallow" is applied to it.

Deep wells usually furnish safe supplies, because the water has to pass a considerable distance underground and is slowly filtered before reaching the bore-hole. The upper portion of the well must be lined in such a way as to prevent the entrance of surface water by fissures or otherwise.

The water from deep wells contains considerably more mineral matter than that from surface sources, and in some cases the hardness is very great. The amount of organic matter is generally very small, but the chlorides and nitrates are often considerable.

Shallow wells constitute the bulk of the supplies to rural districts. They are undesirable as sources of drinking water unless the surroundings are such that the water cannot be contaminated. It is possible for shallow wells to yield safe supplies, if due consideration be given to the distance from likely sources of pollution, the direction of the flow of the water and the amount of depression caused in the well by pumping ; the greater the depression the longer should be the distance from defiling sources. It is necessary to guard against access of surface water, road drainage, etc., by covering the well, and lining it to a depth of several feet with brickwork and cement or iron tubes. The mouth of the well should be built up a few inches above the ground level and an area surrounding it concreted.

Many shallow wells, however, are situated close to houses, farm buildings, or even cesspools, which may drain into them, and such wells are obviously quite unfit for domestic use. Even though the water may appear to be of good quality at one time, a heavy rainfall would probably prove too much for effective filtration of the water, with the consequence that the drainage, along with its bacteria, would be washed into 


\section{PUBLIC HEALTH CHEMISTRY}

the well. A well water which becomes turbid after rain is extremely suspicious.

Artesian well is the name applicd to a well in which the water rises automatically, sometimes above the surface of the ground. This may occur when a slope in the water-bearing formation causes a "head" of water in the higher part of the stratum.

Springs are derived either from deep strata or from the subsoil, and the supplies are of the same character as those obtained from deep and shallow wells respectively. They result generally from the overflow of water from permeable strata resting upon an impervious bed, or they may be of an artesian nature produced by a fault in the rocks, the water thus being forced to the surface from a depth. A deep spring is more likely to yield a safe water supply than a subsoil spring, the latter being satisfactory only if there be no source of pollution in the direction from which the water flows.

Waters may be improved in quality by filtration, by treatment with ozone or ultra-violet light, or by other means. For information on these subjects the reader is referred to books on water supplies (see Appendix, page $23^{8}$ ).

\section{Taking the sample of water.}

The most convenient vessel in which to collect the sample is a stoppered "winchester" which has a capacity of half a gallon (about two and a half litres), this quantity being ample for an ordinary analysis for sanitary purposes. The bottle must be thoroughly cleaned, preferably by washing with a mixture of chromic and sulphuric acids, and then rinsing with water until the washings cease to give an acid reaction to litmus paper. The stopper must also be washed, and should be put immediately into the bottle and not laid down anywhere.

If a stoppered bottle is not available and a cork has to be 
used, it should be a new one and must be thoroughly washed with water. Earthenware jars are not so suitable as glass bottles, they are more difficult to clean and sometimes affect the hardness of the water; another disadvantage is the impossibility of an inspection of the sample without pouring it into another vessel.

Before taking the sample, rinse the bottle two or three times with the water, then if possible fill it directly without using an intermediate vessel. If the water is from a tap or pump, allow it to run to waste for a few minutes, in order to reject any which has been standing in the pipes. Fill the bottle completely, then pour away a small quantity so as to leave an air space when the stopper is inserted.

Sealing wax should not be put on the stopper, as particles are apt to drop in when the bottle is opened, but if it is desired to seal the sample the stopper should be covered with a piece of calico or other material which is then tied down with string and the string sealed.

Label the sample with some distinguishing mark, as well as the date and time of collection, also make a note of the source of the supply with any information available of a geological nature, and the distance from any potential sources of pollution, such as drains or cesspools.

If the analysis cannot be commenced on the day on which the sample is taken, the water should be kept in a cool place and analysed as soon as possible.

\section{Analysis of Water}

Preliminary notes.

As the quantities of impurities in waters, even when badly polluted, are really very small, it is most important that all apparatus used should be scrupulously clean and that the greatest accuracy should be practised. Care must be taken to keep away any atmospheric impurities which would vitiate 
the results, for example ammonia; for this reason it is not advisable to smoke when estimating ammonia in water. All apparatus used should be labelled, or numbered, to prevent mistakes. Before commencing the analysis the sample should be mixed, except when there is a considerable sediment which may have to be estimated and examined separately, in which case it should be allowed to settle or else the sample should be filtered. If filtration is resorted to, the filter paper must be washed with water until it is free from ammonia.

The results of water analyses are usually expressed as parts per 100,000 , occasionally as grains per gallon; it is useful to remember that a gallon contains 70,000 grains, hence to convert parts per 100,000 into grains per gallon it is necessary to multiply by $7 / 10$, the factor for the reverse calculation being, of course, ro/7.

The main object of the ordinary sanitary analysis of water is to determine whether it has, either recently or otherwise, been contaminated with animal excreta, which may or may not be in themselves harmful, but which are often accompanied by pathogenic organisms.

The necessity for chemical analyses, as well as bacteriological examinations, is emphasized by Rideal, who gives the following reasons ("Water and its Purification") :-

I. Changes in the composition of a water reveal the presence of active bacteria.

2. When pathogenic organisms are present in small numbers their detection by bacteriological methods is doubtful.

3. Bacteria do not thrive without nitrogenous food, which is detected by chemical analysis.

4. Their entrance into a water supply is almost always accompanied by sewage products, which are revealed by analysis.

One of the first changes which occur on the decomposition of animal matter is the production of ammonia compounds, hence the presence of these substances, especially if accom- 
panied by organic matter, is generally an indication of sewage pollution; vegetable matter yields very little ammonia on decomposition. Similarly, chlorine in large quantity frequently indicates the same thing, as human urine contains chlorine to the extent of about 500 parts per 100,000.

Before a water can be properly judged, a number of estimations and tests must be made, and the relative quantities of the various constituents, as well as the nature of the source of the water, must be taken into consideration.

The usual examination comprises the following estimations :-

I. Free and saline ammonia ;

2. Ammonia from organic matter (albuminoid ammonia);

3. Oxygen absorbed (from potassium permanganate);

4. Combined chlorine;

5. Nitrogen in the form of nitrates;

6. Total solid matter in solution;

7. Hardness ; also

8. Qualitative test for nitrites ;

9. Reaction to litmus ;

I0. Physical characters (colour, odour and turbidity);

II. Microscopical examination of deposit.

Of the above, the most important for the detection of sewage pollution are Nos. I, 2, 4, 5, and 8.

Free and saline ammonia.

A measured quantity of the water is distilled after the addition of a small quantity of pure sodium carbonate, the distillate collected in fractions and Nessler solution added. The colouration produced in each fraction is matched by means of a standard solution of ammonium chloride, to different quantities of which Nessler solution is added, the various amounts of ammonium chloride used being added together.

The product of the reaction between ammonia and Nessler solution is a compound having the formula $\mathrm{NHg}_{2} \mathrm{I}_{2} \mathrm{H}_{2} \mathrm{O}$. 
Required :-

distillation flask or retort, ignited sodium carbonate

I000 to I 500 c.c.

condenser

Nessler cylinders

graduated flask 500 c.c.

burette and stand

ammonia-free distilled water

standard ammonium chloride

(I c.c. $=0.00005$ gram $\mathrm{NH}_{3}$ )

pipette 2 c.c.

Nessler solution

small watch-glasses

N.B.- It is very important that the distillation apparatus should be steamed out for some hours before use, in order to remove all traces of ammonia. This is especially necessary when new rubber stoppers or tubing are used.

\section{Procedure:-}

Take 50 c.c. of the sample in a Nessler cylinder and add 2 c.c. of Nessler solution by means of a pipette, dipping the pipette to the bottom of the cylinder and blowing down it, in order to mix the solution thoroughly with the water. If only a yellow or brown colouration is produced in two or three minutes, 500 c.c. of the sample is taken for the estimation, if a brown precipitate is thrown down or the colouration is very deep a smaller quantity of the sample is used and diluted to 500 c.c. with ammonia-free water.

Place about I gram of freshly ignited sodium carbonate in the neck of the distillation flask (or retort) and wash it in with the measured quantity of water, attach to the condenser and support on a retort ring. If a retort is used, a piece of wire gauze should be placed under, and in contact with, the bottom of it, and the neck should be inclined slightly upwards; the distillation flask can be rested upon a ring of asbestos millboard and wire gauze need not as a rule be used.

Heat by means of a large bunsen burner and collect the distillate in fractions of roo c.c. in Nessler cylinders. When the first fraction has been obtained, cover the cylinder, label it 
and reserve it until the second roo c.c. has been collected. Add 2 c.c. of Nessler solution to the second fraction and mix by blowing down the pipette, match the colouration after a minute or two by placing different quantities of the standard ammonium chloride solution in cylinders exactly similar to that containing the distillate, making each up to roo c.c. with ammonia-free water and adding 2 c.c. of Nessler solution. The matching is effected by looking through the length of the cylinders over a white surface in a good light but avoiding direct sunlight. The amount of ammonia found in the second roo c.c. serves as a guide for the treatment of the first fraction; if the amount found is very small (requiring not more than 0.2 or 0.3 c.c. of the standard solution), the whole of the first Ioo c.c. can be treated with Nessler solution and the colour matched as before. If, however, the second fraction contains much ammonia, it is certain that the first will contain very much more, and dilution is necessary, as deep colours cannot be accurately matched. In that case, mix the roo c.c. and take half or a smaller fraction, dilute to roo c.c. with ammoniafree water and proceed as before, the dilution being of course allowed for when calculating the result.

Should the second fraction contain more than a trace of ammonia, a third should be collected; but as a rule all the free and saline ammonia distils over in the first 200 c.c., any found on further distillation, being due to easily decomposable organic matter, such as urea, should be included in the albuminoid ammonia.

It is advisable before commencing the estimation of ammonia in the distillates, to make up standards and "Nesslerize" them, in order that some idea may be obtained of the different depths of colour yielded; but fresh standards must be made for accurate matching, as the colours are not comparable if some have been standing a much longer time than others. It is difficult to match accurately colourations deeper than that given by 2.5 c.c. of the ammonium chloride solution. 
It is essential that the same Nessler solution should be used throughout the experiment, as different solutions vary in sensitiveness.

Example of calculation :-

500 c.c. of sample taken;

Ist 100 c.c. required 2.0 c.c. ammonium chloride, 2nd 100 c.c. 0.2 c.c.

\section{Total 2.2 c.c.}

I c.c. of the standard solution contains 0.00005 gram $\mathrm{NH}_{3}$, hence free and saline ammonia

$=2.2 \times 0.00005$ gram in 500 c.c.

$=2.2 \times 0.00005 \times \frac{100,000}{500}$ gram in 100,000 c.c.

$=0.022$ part per 100,000 .

\section{Albuminoid ammonia.}

Albuminoid (or organic) ammonia does not exist as ammonia in the water, but is derived from nitrogenous organic matter and is obtained by distilling the residue from the previous estimation with an alkaline solution of potassium permanganate, ammonia-free water being also added.

Required :-

materials used in last experiment, also ignited pipeclay

alkaline potassium permanganate solution

Procedure :-

To the residue in the flask (or retort) add 50 c.c. alkaline permanganate solution and wash it in completely with ammoniafree water, the quantity of which should be the same as that distilled off with the free ammonia. Add a piece of freshly ignited pipeclay, connect to the condenser and distil, pro- 
ceeding as in the previous estimation. The albuminoid ammonia distils off more slowly than the free and saline, and it is sometimes necessary to collect three fractions. In exceptionally bad waters the albuminoid ammonia is not, even then, all removed, and when, from the nature of the water, a considerable quantity is expected, a larger amount of distilled water should be added before commencing the distillation with alkaline permanganate, because if the liquid becomes too concentrated the organic matter will be further decomposed and too high a result obtained.

A blank experiment must be made with 50 c.c. of the alkaline permanganate solution and 300 c.c. of ammonia-free water, and if any ammonia is obtained in the first roo c.c. distilled, the amount must be deducted in each estimation.

The calculation is exactly similar to that of the free and saline ammonia, the quantity of sample being, of course, the volume (generally 500 c.c.) originally taken.

The reduction of potassium permanganate in alkaline solutions can be represented as follows :-

$$
{ }_{2} \mathrm{KMnO}_{4}=\mathrm{K}_{2} \mathrm{O} \cdot \mathrm{Mn}_{2} \mathrm{O}_{7} \text {, and } \mathrm{Mn}_{2} \mathrm{O}_{7}=2 \mathrm{MnO}_{2}+3 \mathrm{O} \text {, }
$$

three atoms of oxygen being thus "available" (compare top of page 1 26).

Oxygen absorbed (from acid permanganate), Tidy's process.

This estimation and that of albuminoid ammonia give an indication of the quantity of organic matter present in the water. Since some inorganic substances, such as ferrous salts and nitrites, absorb oxygen from potassium permanganate, two experiments are made; in the first the reaction is allowed to proceed for fifteen minutes and in the second for two or three hours, the inorganic substances being rapidly oxidized whilst the action on organic matter is slow and progressive. If the amount of oxygen absorbed in the longer period is considerably more than that taken up in fifteen minutes, it is proof that the reduction is largely due to organic matter. 
Sulphuric acid is necessary, the reaction proceeding according to the equation

$$
\begin{gathered}
2 \mathrm{KMnO}_{4}+3 \mathrm{H}_{2} \mathrm{SO}_{4}=\mathrm{K}_{2} \mathrm{SO}_{4}+2 \mathrm{MnSO}_{4}+3 \mathrm{H}_{2} \mathrm{O}+5 \mathrm{O}, \\
\text { (or, in simplified form, } \mathrm{Mn}_{2} \mathrm{O}_{7}=2 \mathrm{MnO}+5 \mathrm{O} \text { ). }
\end{gathered}
$$

The temperature at which the reaction takes place is most conveniently that of the laboratory; but if the room temperature is exceptionally low the bottles should be put in a warm place. Some analysts maintain a temperature of $27^{\circ} \mathrm{C}$. $\left(80^{\circ} \mathrm{F}\right.$.) by immersing the bottles in water at that temperature or using an air-bath. The length of time allowed for the second experiment may be two, three or four hours, and so long as the same period is adopted in all water analyses, it matters little which is used. A considerable excess of sulphuric acid, over and above that theoretically required, is first added, then an accurately measured quantity of a standard solution of potassium permanganate, and, at the expiration of the time allowed for the reaction, the excess of permanganate is estimated by treating with potassium iodide and titrating the liberated iodine with sodium thiosulphate solution. The strength of the thiosulphate solution is determined by performing a blank experiment with distilled water.

The reactions which take place in the estimation of the excess of permanganate are represented as follows :-

${ }_{2} \mathrm{KMnO}_{4}+\mathrm{roKI}+8 \mathrm{H}_{2} \mathrm{SO}_{4}=5 \mathrm{I}_{2}+6 \mathrm{~K}_{2} \mathrm{SO}_{4}+2 \mathrm{MnSO}_{4}+8 \mathrm{H}_{2} \mathrm{O}$, and $2 \mathrm{Na}_{2} \mathrm{~S}_{2} \mathrm{O}_{3}+\mathrm{I}_{2}=2 \mathrm{NaI}+\mathrm{Na}_{2} \mathrm{~S}_{4} \mathrm{O}_{6}$.
(thiosulphate)
(tetrathionate)

Required :

3 clear glass stoppered bottles (about 500 c.c.)

burettes and stand

pipette ro c.c.

graduated flask $25^{\circ}$ c.c. potassium permanganate solution (I c.c. $=0.000 \mathrm{I}$ gram available oxygen) sulphuric acid ( $\mathrm{r}$ in 4$)$ sodium thiosulphate solution potassium iodide fresh starch solution 


\section{Procedure :-}

Take three clear glass stoppered bottles, capacity about 500 c.c. ; into one put 250 c.c. of distilled water and into each of the others 250 c.c. of the sample. To each add ro c.c. of sulphuric acid solution ( $\mathrm{I}$ in 4). Into each of the bottles containing the sample run ro c.c. of the standard permanganate solution, accurately measured from a burette, mix and allow to stand, one for fifteen minutes and the other for three hours. At the end of these periods add about ro drops of a colourless solution of potassium iodide (Io per cent.), or a few crystals of the salt, and titrate with sodium thiosulphate until the liquid is pale yellow, then add a few drops of starch solution and continue the titration until the blue colour is just discharged. During the latter part of the titration insert the stopper and shake well after each addition of thiosulphate, completing the reaction as rapidly as possible, because the blue colour returns on standing. To prove that the titration has not been carried too far, add one drop of permanganate, when a blue colour should be restored.

At a convenient time perform the blank experiment. Take the bottle containing distilled water and sulphuric acid, add first potassium iodide then ro c.c. potassium permanganate, and titrate as before. This titration shows the amount of thiosulphate required for the whole io c.c. of permanganate, the previous titrations give the quantities of unchanged permanganate at the end of fifteen minutes and three hours respectively, and from the differences in the amounts of thiosulphate used, the oxygen absorbed is calculated.

N.B.-The reason for adding potassium iodide before permanganate in the blank experiment is that the permanganate is thereby decomposed immediately and cannot act upon any traces of oxidizable matter which might possibly be present. 
Example of calculation.

250 c.c. of sample used in each experiment, thiosulphate required for blank experiment 24.2 c.c.

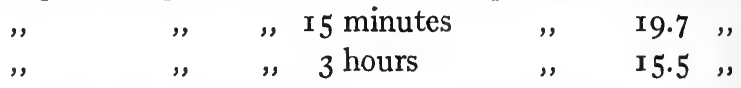

I c.c. $\mathrm{KMnO}_{4}$ contains $0.000 \mathrm{I}$ gram of available oxygen, 24.2 c.c. thiosulphate $=10$ c.c. $\mathrm{KMnO}_{4}=0.00 \mathrm{r}$ gram of oxygen, oxygen absorbed in 15 minutes

$$
\begin{aligned}
& =0.001 \times \frac{24.2-19.7}{24.2} \text { for } 250 \text { c.c. of sample, } \\
& =0.001 \times \frac{24.2-19.7}{24.2} \times \frac{100,000}{250} \text { for } 100,000 \text { c.c. } \\
& =0.074 \text { part per } 100,000 .
\end{aligned}
$$

Similarly,

oxygen absorbed in 3 hours $=0.001 \times \frac{24.2-15.5}{24.2} \times \frac{100,000}{250}$

$$
=0.144 \text { part per } 100,000 \text {. }
$$

In the case of waters containing much oxidizable matter, more than ro c.c. of permanganate may be required, hence the contents of the bottles should be watched and if the colour becomes faint a further ro c.c. (or more, if necessary) should be added, as a considerable excess must be present.

\section{Combined chlorine.}

The chlorine is titrated with standard silver nitrate solution, potassium chromate being used as indicator.

Required :-

2 porcelain dishes, size 4

burette

pipette 50 "c.c.

glass rod silver nitrate solution (I c.c. $=$ 0.0005 gram Cl)

potassium chromate solution

\section{Procedure :-}

Rinse the two dishes and the rod with distilled water, and 
pipette 50 c.c. of the sample into each dish. Add a few drops of potassium chromate solution and titrate one portion with silver nitrate solution until the first change to a faint brown is noticeable, keeping the second dish alongside for comparison. Restore the yellow colour by adding a little more of the sample, and titrate the second 50 c.c., using the liquid in the first dish to compare with. The mean of the two titrations, which should not differ by more than o.I c.c., is taken for the purpose of calculation.

\section{Example of calculation:-}

50 c.c. of sample required (I) 4.3 c.c. (2) 4.2 c.c. $\mathrm{AgNO}_{3}$,

I c.c. $\mathrm{AgNO}_{3}=0.0005$ gram Cl,

Chlorine $=4.25 \times 0.0005$ gram in 50 c.c. of sample,

$$
\begin{aligned}
& =4.25 \times 0.0005 \times \frac{100,000}{50} \text { grams in } 100,000 \text { c.c. } \\
& =4.25 \text { parts per } 100,000 .
\end{aligned}
$$

Nitrogen as nitrates.

Qualitative tests.

I. Evaporate about 25 c.c. of the sample to dryness in a porcelain dish on a water-bath, add I drop of concentrated sulphuric acid and stir in a crystal of brucine ; an orangered colouration is produced if even a minute trace of nitrate is present.

2. Evaporate a portion of the sample as before, add I drop of concentrated sulphuric acid and stir in a crystal of diphenylamine; a blue colouration occurs with a minute trace of nitrate.

N.B. - These reactions are given also by nitrites, which are tested for separately by the methods given below. It is, of course, necessary to ascertain that the sulphuric acid used is quite free from nitric acid, by performing a blank experiment with the materials. 
Estimation of nitrates.

Sprengel's process.

This method depends upon the reaction between nitric acid and phenolsulphonic acid, whereby picric acid is produced; the yellow colour of the latter is matched against that obtained with standard potassium nitrate solution treated similarly. The reaction can be represented by the equation :-

$\mathrm{C}_{6} \mathrm{H}_{4} \mathrm{OH} \cdot \mathrm{SO}_{2} \mathrm{OH}+3 \mathrm{HNO}_{3}=\mathrm{C}_{6} \mathrm{H}_{2}\left(\mathrm{NO}_{2}\right)_{3} \mathrm{OH}+\mathrm{H}_{2} \mathrm{SO}_{4}+2 \mathrm{H}_{2} \mathrm{O}$.

Required :-

porcelain dishes

pipettes

burette and stand

Nessler cylinders

glass rods

measuring cylinder, 50 or

I00 c.c. potassium nitrate solution (I c.c. $=0.0000 \mathrm{I}$ gram nitrogen phenolsulphonic acid ammonium hydrate

\section{Procedure:-}

The quantity of sample to be taken depends upon the amount of nitrates expected; take Io c.c. and 25 c.c., in separate dishes, of a water from a deep source, 25 c.c. and 50 c.c. of an upland surface water, evaporate each until it is just dry and at the same time evaporate Io c.c. of the standard solution (or 5 c.c. for an upland surface water) in another dish. The evaporations should be made on a boiling water-bath; but if greater rapidity is necessary they may be commenced on a sand-bath or a hot plate, taking great care that no liquid is lost by spurting and in every case finishing the evaporation on the water-bath. The dishes should be removed from the bath immediately the drying is complete. Add to each I c.c. of phenolsulphonic acid and stir it well with the residue from the water by means of a short glass rod, leave the rods in the dishes and place them on top of the water-bath, not in contact with the steam, for 15 minutes to complete the reaction. Wash 
the contents of each dish into a Nessler cylinder with about 50 c.c. of distilled water, add about equal quantities of ammonium hydrate to each (about 20 c.c.), sufficient to render alkaline-the liquid must smell distinctly of ammonia after mixing - then make up to roo c.c. with distilled water. Compare the depth of colouration by looking down the length of the cylinders over a white surface in a good light, and select the one containing the sample which is the nearer in depth to the standard. If they are not exactly equal, remove portions of the more deeply coloured liquid to a dry measuring cylinder until on looking down the cylinders the depth of colour is found to be equal. Calculate the quantity of nitrates as in the following examples:-

I. 25 c.c. sample and 5 c.c. standard solution were used, and on comparison it was found necessary to remove 20 c.c. from the roo c.c. containing the sample, in order to match the standard.

The standard contained $5 \times 0.00001=0.00005$ gram of nitrogen, and the quantity of sample matching this $=\frac{80}{100} \times 25=20$ c.c. ; hence nitrogen as nitrates

$$
\begin{aligned}
& =0.00005 \text { gram in } 20 \text { c.c., } \\
& =0.00005 \times \frac{100,000}{20} \text { gram in } 100,000 \text { c.c., } \\
& =0.25 \text { part per } 100,000 .
\end{aligned}
$$

2. The same quantities of sample and of standard solution were used, and it was found necessary to remove 20 c.c. out of the roo c.c. containing the standard in order to match the sample.

The standard then contained :-

$$
\frac{80}{100} \times 5 \times 0.00001=0.00004 \text { gram of nitrogen, }
$$

and the quantity of sample matching this $=25$ c.c., hence, nitrogen as nitrates 


$$
\begin{aligned}
& =0.00004 \text { gram in } 25 \text { c.c., } \\
& =0.00004 \times \frac{100,000}{25} \text { gram in } 100,000 \text { c.c. } \\
& =0.16 \text { part per } 100,000 .
\end{aligned}
$$

Should the amount of standard solution used yield a colouration which does not approximately match either quantity of the sample, a fresh experiment should be made with different amounts.

Sprengel's process does not include nitrites, since the compound formed by phenolsulphonic acid and nitrous acid is colourless.

High chlorides give rise to low results for nitrates in the above process, but this source of error may be eliminated by adding hydrochloric acid in the preparation of the phenolsulphonic acid.

The yellow colour is generally attributed to the formation of picric acid, but it has been stated by Chamot and . Pratt ("Journal of the American Chemical Society," I909 and 1910) that it is really due to a mononitrophenol-sulphonic acid.

Processes which estimate both nitrates and nitrites.

Crum's process.

This method depends upon the production of nitric oxide gas on treatment of nitrates or nitrites with sulphuric acid in presence of mercury. The gas is measured and the weight of nitrogen calculated. The method is particularly useful for waters containing large quantities of nitrates.

\section{Required:-}

nitrometer

graduated flask of suitable size

dish, size 4

beaker, $5^{\circ}$ c.c.

thermometer

glass rod with rubber tip

\section{mercury}

sulphuric acid conc. 


\section{Procedure :-}

Take a quantity of the water, from 100 to 500 c.c., according to the amount of nitrates expected, evaporate to dryness in a dish and treat the residue with a few c.c. of hot distilled water, rubbing the sides and bottom of the dish with a rubbertipped glass rod. Decant the liquid carefully into a small beaker, leaving behind any undissolved material (calcium carbonate, etc.), and wash the residue with a further small quantity of water. Evaporate the solution to about i c.c. and introduce it into a nitrometer filled with mercury, by lowering the control tube and carefully opening the tap, so as to admit the liquid without any air. Rinse the beaker with I c.c. of hot water, then with 2 or 3 c.c. of concentrated sulphuric acid, adding these to the liquid in the nitrometer. If there should be an immediate evolution of gas, it is carbon dioxide, and this must be allowed to escape by raising the control tube and very cautiously opening the tap for a moment. Next shake the nitrometer tube in the direction of its length, when nitric oxide will be evolved. Allow to stand, in order that the gas may attain the temperature of the laboratory, then measure its volume and correct it to normal temperature and pressure; half this volume is nitrogen. Knowing that I c.c. of nitrogen at N.T.P. weighs 0.00125 gram $(=0.0000896$ $\times$ I4), the parts of nitrogen per 100,000 can be calculated.

\section{Example of calculation :-}

$25^{\circ}$ c.c. of water yielded 3.4 c.c. of $\mathrm{NO}$ at $16^{\circ} \mathrm{C}$. and $750 \mathrm{~mm}$., this becomes at N.T.P. $3.4 \times \frac{273}{273+16} \times \frac{75^{\circ}}{760}=3.12$ c.c. $\mathrm{NO}$ which contains $\frac{3.12}{2}=1.56$ c.c. of nitrogen, and the quantity of nitrogen as nitrates and nitrites is

$$
1.56 \times 0.00125 \times \frac{100,000}{250}=0.78 \text { part per } 100,000 .
$$


The reaction which takes place is shown by the equation :-

$$
{ }_{3} \mathrm{Hg}+3 \mathrm{H}_{2} \mathrm{SO}_{4}+2 \mathrm{HNO}_{3}=2 \mathrm{NO}+3 \mathrm{HgSO}_{4}+{ }_{4} \mathrm{H}_{2} \mathrm{O} \text {. }
$$

\section{Warington's method.}

This method depends upon the oxidation of indigo by traces of nitric acid in presence of a large amount of sulphuric acid when heated, the number of c.c. of a standard solution of indigo decolourized showing the quantity of nitrates (and nitrites) present. The indigo solution is checked against $\mathrm{N} / 3200$ potassium nitrate solution, of which 20 c.c. should decolourize 10.5 c.c. of the indigo. The sulphuric acid used is a mixture of one part of Nordhausen (fuming) sulphuric acid and two to three parts of ordinary concentrated sulphuric acid ; when rapidly mixed with its own bulk of water it must raise the temperature above $140^{\circ} \mathrm{C}$.

The reaction being somewhat violent, great care must be exercised in using this process.

\section{Required :-}

burette and stand

pipette, 20 c.c.

cylinder, $5 \circ$ c.c.

wide-mouthed flasks about $25^{\circ}$ c.c. thermometer, $200^{\circ} \mathrm{C}$.

large white plate standard indigo solution $\mathrm{N} / 3200$ potassium nitrate sulphuric acid mixture (as above)

\section{Procedure :-}

Pipette 20 c.c. of the sample into a wide-mouthed flask, add from a burette 5 c.c. of standard indigo solution and run in as rapidly as possible about 25 c.c. of sulphuric acid mixture, standing the flask meanwhile on a plate in a sink (the plate and the outside of the flask must be perfectly dry). The temperature should rise to at least $140^{\circ} \mathrm{C}$., if not, the experiment must be repeated after warming the mixture of water 
and indigo sufficiently (probably to $30^{\circ}$ or $40^{\circ}$ ) in order to attain this temperature on mixing.

If after standing for a minute the blue colour remains deep, take a fresh 20 c.c. of the sample, add a smaller quantity of indigo, warm if necessary and run in the sulphuric acid mixture, the amount of which in each experiment should be about equal to the bulk of water and indigo together. Repeat this procedure until it is found what amount of indigo is required in order to obtain a permanent faint blue colour. Then perform a blank experiment, using 20 c.c. of distilled water and I c.c. (or more, if necessary) of indigo solution, and adding the sulphuric acid mixture; deduct the amount of indigo, required to produce a faint blue colour, from that used by the 20 c.c. of sample. Refer to the table (Appendix, page 226), which gives the result expressed as parts of nitrogen per I00,000.

Should 20 c.c. of the sample completely decolourize 5 c.c. of indigo, repeat the experiment with a larger quantity of indigo, until the actual amount required is found. Should, however, the nitrates be very high, the water must be diluted with distilled water until 20 c.c. of the diluted liquid require about 8 to $\mathrm{I} 2$ c.c. of indigo, the extent of dilution being allowed for in calculating the result.

N.B. - The use of Nordhausen acid can be dispensed with, and ordinary sulphuric acid used alone, if the flask is immersed in a bath of calcium chloride solution kept at the required temperature.

\section{Reduction methods.}

In certain cases, such as those of waters containing very high chlorides, nitrates can most conveniently be estimated by reduction to ammonia. In one method, a zinc-copper couple is employed, that is, zinc which has been coated with copper by immersion in a solution of a copper salt ; in another process aluminium foil and sodium hydrate are used. The 
action is allowed to proceed until no nitrite can, be detected in the solution, then the ammonia is distilled off and estimated in the usual way, a deduction being made for the quantity of free and saline ammonia originally found in the water.

Nitrogen as nitrites.

Qualitative tests.

I. Griess-Ilosvay.

Required:-

Nessler cylinder

\author{
sulphanilic acid solution \\ naphthylamine hydrochloride \\ solution \\ hydrochloric acid dil.
}

\title{
Procedure :-
}

To about 50 c.c. of the sample in a Nessler cylinder add 4 drops each of the solutions of sulphanilic acid and naphthylamine hydrochloride, and 2 drops of dilute hydrochloric acid. Allow to stand for half an hour; a pink colour develops if the faintest trace of nitrite is present, and will appear in a few minutes unless the quantity is very minute. If the colour only makes its appearance after an hour or more, it should not be taken as evidence of the presence of nitrite, it is more probably due to contamination from the atmosphere.

2. Griess test.

Required :-

Nessler cylinder

pipette graduated for I c.c.

metaphenylene-diamine solution

sulphuric acid solution ( 1 to 2 by volume).

\section{Procedure:-}

To about 50 c.c. of the sample in a Nessler cylinder add I c.c. each of the solutions of metaphenylene-diamine and sulphuric 
acid. On standing about fifteen minutes, a brown colour appears if nitrite is present. This reaction is not so delicate as the last one.

\section{Estimation of nitrites.}

It is not often necessary to estimate the amount of nitrites in a water, but when such estimation is required the Griess test is employed, the brown colouration being matched against a standard solution of sodium or potassium nitrite treated similarly.

Required:-

Nessler cylinders

burette and stand

pipette graduated for I c.c. metaphenylene-diamine solution

sulphuric acid solution ( $\mathrm{I}$ to 2 ) standard nitrite solution (I c.c. $=0.0000 \mathrm{I}$ gram nitrogen)

\section{Procedure:-}

Put roo c.c. of the sample into a Nessler cylinder and various quantities of the standard nitrite solution into other similar cylinders, making these up to roo c.c. with distilled water. To each add I c.c. of metaphenylene-diamine and I c.c. of the dilute sulphuric acid, and allow to stand for twenty minutes. Compare the colourations, and, knowing the amounts of nitrogen as nitrite in the standards, calculate the quantity in the sample.

It is important that the reagents should be added to the sample and the standards at the same time, as the colour deepens on standing.

\section{Total solids in solution.}

A measured quantity of the water is evaporated to dryness in a weighed dish and the residue is dried to constant weight at $105^{\circ}$ to $110^{\circ} \mathrm{C}$. 
Required:-

graduated flask of suitable size

evaporating dish, capacity about roo c.c. (preferably
platinum)
desiccator

\section{Procedure :-}

Take a dish of about roo c.c. capacity, support it on a pipeclay triangle and ignite over a bunsen burner. Allow to cool in a desiccator and weigh. Measure a quantity of the sample in a graduated flask (roo c.c. may be taken if time is limited, but 250 or 500 c.c. should be used to obtain an accurate result); evaporate it to dryness in the dish on a boiling water-bath. Transfer the dish and solids to an air-bath kept at $105^{\circ}$ to $110^{\circ} \mathrm{C}$. and dry for three hours; allow to cool in a desiccator and weigh. Heat again for one hour and weigh again, the weighings should be made as quickly as possible on account of the hygroscopic nature of the majority of water-solids. Calculate as usual to parts per roo, 000 .

Some analysts ignite the solid residue and determine the "loss on ignition." Charring indicates the presence of organic matter, but a quantitative experiment on these lines is of very little value, since water of crystallization and carbon dioxide may also be driven off.

\section{Hardness.}

Hardness of water is principally due to the bicarbonates, sulphates and chlorides of calcium and magnesium, which,when the water is used for washing, precipitate the fatty acids of the soap and prevent the formation of a lather until the soap is present in excess. If the water is boiled, calcium and magnesium bicarbonates are decomposed, losing carbon dioxide and precipitating the carbonates; hence the hardness due to these substances is called "temporary hardness." The 
sulphates and other salts are not precipitated on boiling, and so the hardness due to them is termed "permanent hardness."

In Clark's process, the total and the permanent hardness are estimated, the temporary being obtained by difference.

In this process a measured quantity of the water is titrated with standard soap solution, and from the volume required to produce a lather on vigorous shaking the total hardness is found. For the estimation of permanent hardness, some of the water is boiled in order to precipitate the carbonates; it is cooled and made up to the original bulk with distilled water, filtered, and the hardness remaining is estimated as before.

The results of hardness determinations are expressed in parts of calcium carbonate per 100,000.

\section{Required :-}

stoppered bottles about 150 c.c. burette and stand

pipette, 50 c.c. standard soap solution (Clark's) distilled water graduated flask, $5_{5}$ or 200 c.c. beakers about 400 c.c. flask, 300 c.c.

funnel

filter papers

\section{Procedure :-}

If the water contains not more than ${ }_{5}$ or 20 parts of total solids per 100,000, the estimation is made without dilution; but in the case of a hard water it is necessary to dilute the sample with recently boiled and cooled distilled water. The extent of the dilution required can be found by a rapid preliminary titration; the process is most accurate when not more than 8 c.c. of soap solution are used for 50 c.c. of the water as titrated, particularly when magnesium salts are present.

Having diluted the water if necessary, pipette 50 c.c. into 
a stoppered bottle of about I 50 c.c. capacity, shake for a few seconds and suck out the air with the pipette, in order to remove any carbon dioxide liberated. Run in I c.c. of the soap solution from a burette, insert the stopper in the bottle and shake vigorously for two minutes. Continue the addition of soap solution, shaking in the same way each time, until a lather is produced. Place the bottle on its side, and if at the end of five minutes a lather about one-eighth of an inch in depth covers the surface, the titration is finished. Repeat, using another 50 c.c. of water, again adding the soap solution in quantities of I c.c. until approaching the end point, when smaller amounts should be run in at a time. The second titration is taken as the correct one, provided the two do not differ very materially.

Magnesium compounds frequently produce a "false point," that is, before the titration is really finished a lather appears which breaks down on shaking with more soap, hence it is advisable, after the apparent end of the titration, to add another I c.c. of soap solution and shake, in order to ensure that the lather is permanent.

The total hardness, expressed as parts of calcium carbonate per 100,000 , is found by reference to the table of hardness (Appendix, page 225), the result being multiplied by the appropriate factor if the sample has been diluted before titration.

\section{Example of calculation :-}

50 c.c. of sample were diluted to 200 c.c. with distilled water, and 50 c.c. of the mixture titrated;

soap solution required was (I) more than 5.0 , less than 6.0 c.c., (2) 5.4 c.c.

From the table, 5.4 c.c. $=6.57$ parts of $\mathrm{CaCO}_{3}$ per 100,000 , hence the total hardness $=6.57 \times 4=26.28$ parts per 100,000 .

Permanent hardness.

Measure ${ }^{5} 5^{\circ}$ or 200 c.c. of the sample in a graduated flask, 


\section{WATER}

transfer it to a hard glass beaker and boil for half an hour, keeping it at about the original bulk by the addition, from time to time, of small quantities of boiling distilled water; for this purpose it is convenient to mark the level of the water in the beaker at the commencement of the boiling with a piece of gummed paper. Transfer the contents of the beaker to the measuring flask, cool completely and make up accurately to the original bulk with distilled water which has been recently boiled and completely cooled. Mix, and filter through a small filter paper, rejecting the first few c.c. of the filtrate. Estimate the hardness as before, judging the extent of the dilution, if any, required, from the amount of total hardness and from the quantity of precipitate thrown down while boiling.

Temporary hardness is ascertained by deducting the permanent from the total hardness; it is the difference between the quantities of calcium carbonate (per roo,000) found in those estimations.

\section{Example of calculation :-}

After boiling, making up to the original bulk and filtering, the water was diluted with an equal quantity of distilled water and $5 \circ$ c.c. were titrated.

Soap solution used (I) more than 7.0, less than 8.0 c.c.

$$
\text { (2) } 7.7 \text { c.c. }
$$

From the table, 7.7 c.c. of soap solution $=9.86$ parts $\mathrm{CaCO}_{3}$ per 100,000. Hence the permanent hardness $=9.86 \times 2=19.72$ parts per 100,000 , and the temporary hardness $=26.28-19.72$ $=6.56$ parts per 100,000.

Since calcium carbonate is soluble in water to the extent of 3 parts per 100,000, and magnesium carbonate even more soluble, if the total hardness does not exceed 3 parts per I00,000 it is necessarily all permanent.

For Hehner's method for the estimation of temporary hardness see page $\mathrm{I} 7$. 
Reaction to litmus and physical characters.

Required:-

Nessler cylinder neutral litmus solution

two-foot tube with glass ends

wide-mouthed flask aboút

200 c.c.

\section{Procedure :-}

Allow the sample to stand for a few hours, overnight if practicable, and remove any deposit as directed under "water sediments," page I49. Examine the deposit microscopically as soon as possible.

\section{Reaction to litmus.}

Take about 50 c.c. of the sample in a Nessler cylinder and add a sufficient quantity of neutral litmus solution to distinctly colour it. Observe whether the reaction is alkaline, acid or neutral ; waters from deep sources are generally alkaline, but occasionally they are rendered acid by the presence of a large amount of carbon dioxide, such waters on boiling become alkaline. Surface waters are frequently acid, and the possibility of action on lead and other metals has to be remembered.

Colour and clarity.

For this a glass tube two feet long, with glass ends, is employed. Remove one of the ends and fill the tube completely with the water; replace the end and hold the tube so that it points towards a window or a well-illuminated piece of white paper. Notice whether the water is colourless or whether it has a brown or yellow colour. A turbidity is best seen with a dark background; it can generally be observed when the water is measured for the free ammonia estimation.

\section{Odour.}

Place about 50 c.c. of the sample in a wide-mouthed flask, cover it with a watch-glass and warm on a water-bath to about 
$40^{\circ} \mathrm{C}$; ; any odour (of sewage, stagnant pond water, etc.) will thus be accentuated.

Order in which the analysis should be made (for the greatest economy of time):-

I. Commence distillation for free and saline ammonia.

2. Commence the 3 hours oxygen absorbed experiment.

3. Ignite dish for total solids.

4. Commence boiling for permanent hardness.

5. Commence evaporation for nitrates.

6. Weigh dish and commence evaporation for total solids.

7. Commence $\mathrm{r}_{5}$ minutes oxygen absorbed experiment and perform blank.

8. Titrate $I_{5}$ minutes oxygen absorbed.

9. Test for nitrites.

Io. Nesslerize distillates for free and saline ammonia.

II. Commence distillation for albuminoid ammonia.

I2. Estimate chlorine.

r. Estimate total hardness.

I4. Estimate permanent hardness.

I5. Nesslerize albuminoid ammonia.

r6. Estimate nitrates.

I7. Titrate 3 hours oxygen absorbed.

I8. Weigh total solids.

I9. Reaction to litmus and physical characters.

Should the time not be sufficient for the whole of the above, omit the estimations of total solids and hardness.

Interpretation of the Results of Water Analyses

In order to judge the suitability of a particular water supply for drinking and domestic use, a valuable guide is an inspection of the surroundings, as actual or possible sources of pollution may thereby be discovered. For example, many shallow wells close to houses, or sometimes cesspools, would be condemned at sight; but the water from them might conceivably be passed as satisfactory if a single analysis only were made. 
If on inspection it is thought possible that a cesspool or drain is polluting the water, the usual practice is to put into the suspected source of contamination some substance which can easily be detected in the water and is at the same time harmless, for example, a solution of fluorescein, which imparts a greenish fluorescence to the water, or a quantity of common salt, which raises the amount of chlorides, or a culture of bacillus prodigeosus. If after a time the particular material used makes its appearance in the water, it is proof that the cesspool, or whatever it may be, is really causing pollution.

As, however, an inspection of the source is frequently out of the question, chemical analyses and bacteriological examinations must generally be relied upon; it is an advantage to examine the water at frequent intervals and under varying conditions of weather, and analyses should be made when the water is likely to be at its worst, which is generally during a period of heavy rain following a drought. By periodical analyses, slight variations in the composition of a water will draw attention to an amount of contamination too slight to be determined with certainty by a single analysis.

In order to correctly interpret the results of a chemical analysis, the quantities of the impurities, their relation to one another and the nature of the source must all be taken into account. Further, one has to consider the liability to pollution on alteration of the existing conditions, the possibility of a solvent action on lead and the suitability of the water for cooking and washing.

We shall first consider the various impurities separately, with the significance of each.

\section{Free and saline ammonia.}

Ammonia generally occurs in water through the decomposition of animal matter, and its presence is very suspicious, especially if accompanied by organic matter, that is, albuminoid ammonia and "oxygen absorbed." Vegetable matter yields 
very little ammonia on decomposition. In the case of rain water, especially in a town, a high figure for free ammonia is obtained, and in some instances deep wells yield a comparatively large quantity, also traces of nitrites, due to the reduction of nitrates by ferrous compounds in the strata through which it has passed, or by iron tubes in the well. Such waters, however, will contain little or no organic matter.

Average figures for ammonia :-

Rain water (country) $\quad \cdot \quad \cdot 0.03$

", (town) . . 0.2

Upland surface waters . . none to 0.005

Deep well and spring waters . none, or very small quantities, except in rare cases

River waters

Shallow wells up to o.oro

very variable

As a general rule, the free and saline ammonia should not exceed 0.010 part per 100,000 , even this quantity being regarded as excessive if the water yields albuminoid ammonia in addition.

\section{Albuminoid ammonia.}

Albuminoid ammonia is produced from nitrogenous organic matter, which may be of either animal or vegetable origin; it should not usually exceed 0.010 part per 100,000. A peaty upland surface water may, however, yield more, and if unaccompanied by much free ammonia it does not indicate sewage pollution. The maximum albuminoid ammonia allowable in such a case, provided the free and saline ammonia is not more than a trace, is 0.03 part per 100,000 .

In waters which have recently been polluted with sewage, the free and saline ammonia is generally higher than the albuminoid.

Oxygen absorbed.

Oxygen absorbed from permanganate gives an indication of the amount of organic matter present in a water. Ferrous 
compounds and other mineral reducing substances are very rapidly oxidized by permanganate, while organic matter is slowly decomposed, if therefore the result obtained in the three hours' experiment is higher than that found after fifteen minutes' action, organic matter is undoubtedly present. Peaty waters give high results for oxygen absorbed, but if the amount of free ammonia is low vegetable matter only is indicated.

Tidy and Frankland suggested the following standards, "subject to modification by other analytical data" :-

- Upland Surface. Not more

Water of great organic purity

", medium ,
Impure water

than 0.1$$
0.3 \text { to } 0.4
$$

more than 0.4

$$
0.1 \text { to } 0.3
$$

Other Sources. Not more than 0.05 0.05 to 0.15 0.15 to 0.2 more than 0.2

Nitrogen as nitrates.

Nitrates indicate past contamination in contradistinction to ammonia and oxygen absorbed which indicate recent pollution. Nitrates are produced mainly from animal matter, and the oxidation is complete after slow passage of the water through a few feet of soil, hence the significance of their presence depends upon the permanence of the conditions of purification, that is to say, the nature of the source is of the utmost importance in deciding whether the presence of nitrates should condemn a water or not. In the case of deep wells, or deep springs, where the water undergoes prolonged filtration, the conditions affecting the purification of the water generally remain very permanent, and a considerable quantity of nitrates is allowable, as, although it may have originally been derived from animal matter, the complete oxidation of impurities can usually be relied upon, provided there are no great changes in the area whence it derives its water. With all other sources of water, however, the presence of nitrates, although unaccompanied by ammonia or organic matter, indicates potential danger, as excessive rainfall or some other 
cause may produce so rapid an influx of polluting material that the purification is incomplete, and the "past" contamination becomes "present" pollution. Thus, nitrates in a shallow well water in any considerable quantity would render that water unsafe for drinking, and upland surface water containing more than a trace of nitrates is also undesirable.

Average figures for nitrates :-

Upland surface waters . . none to 0.05

Deep well and spring waters . up to $I$ or 2 parts, average 0.5

River waters

- results are between the above figures

Nitrogen as nitrites.

Nitrites even in minute traces always render a water suspicious ; they are produced during the oxidation of ammonia to nitrates, or the reverse process, hence their presence indicates that chemical changes are taking place in the water, generally owing to the recent introduction of nitrogenous organic matter along with bacteria. As already mentioned, nitrites are in rare instances formed in deep well waters by the reduction of nitrates.

\section{Combined chlorine.}

Chlorides are contained in most of the water-bearing rocks, hence underground supplies contain more chlorine than unpolluted surface waters; an increase in the amount generally indicates sewage pollution. The possibility near the sea coast of the infiltration of sea-water has to be borne in mind, as well as any other local conditions which may influence the amount. It is useful to know the quantity of chlorine generally found in surface waters in the neighbourhood of the water under consideration, or in waters from the particular stratum.

As a water which has been purified by oxidation contains practically the same amount of chlorine as the original polluted water, it is obvious that, as in the case of nitrates, the nature 
of the source is of importance in attaching the real significance to its presence.

Average figures for chlorine :-

Rain water . . . . from 0.2 upwards, according to distance from the sea coast

Upland surface waters . . about 1.0 part

Deep well and spring waters . 2 to 5 parts

\section{Hardness.}

Hardness is not so important from the point of view of drinking supplies as from that of industrial uses, and the results of hardness estimations throw no light upon the presence or absence of sewage pollution: Surface waters are generally much softer than waters from underground sources, the latter may contain 20 or 30 parts or even more.

\section{Colour.}

A yellow or brown colour is generally due to the presence of organic matter, probably from peat, or of iron. Water containing iron loses its colour on standing and deposits ferric hydrate.

\section{Turbidity.}

Turbidity in a water is suspicious unless there is an obviously harmless reason for it. It may be due to bacteria, or it may be caused, particularly in a new well, by finely divided mineral matter in suspension; in the latter case it will settle out more or less completely on standing. A water which becomes turbid after rain is very suspicious.

To sum up, a water would generally be condemned on one or more of the following grounds:-

Free ammonia more than 0.010 part per 100,000;

Albuminoid ammonia more than 0.010 part, or more than 0.03 part in peaty water ; 
If both free and albuminoid ammonia are 0.010 part or more, particularly if the free ammonia is higher than the albuminoid, the water should certainly be condemned;

Nitrates in more than traces in surface waters, or high in shallow well waters;

High chlorides, except in waters from deep sources or explained by geological or other considerations ;

Nitrites in most cases.

Excessive vegetable pollution may render a water unfit for drinking.

\section{Water Sediments}

An examination of the sediment from water is usually made in conjunction with the chemical analysis and may be particularly useful in throwing light upon the cause of an odour or turbidity. It may also be of assistance in detecting the presence of sewage pollution.

A microscopical examination will also show if the water requires filtration, or if the mains need cleaning out, and it may prove, from the character of the objects it contains, that surface water is gaining access to a water from a deep source.

The deposit may be obtained from a sample of water by allowing it to stand for a few hours, decanting or syphoning off the greater part of the liquid and transferring the residue to a narrow cylinder, in which it is once more allowed to settle. The deposit is put, along with a few c.c. of water, in a small conical glass, from which a portion can be withdrawn for microscopical examination by means of a narrow glass tube. The deposit can be more quickly obtained by centrifuging.

It is desirable that the microscopical examination should be made as soon as possible, because of the changes which are likely to take place.

The objects found in water sediments may be divided into several classes :-

r. Injurious to persons drinking the water; 
2. Not themselves injurious but indicating the probable presence of sewage pollution;

3. Productive of odours, or causing trouble in filtration or distribution;

4. No special significance.

I. In this class are included the ova of intestinal parasites, also amœbæ and other protozoa associated with certain diseases (dysentery, etc.).

2. This class includes a large number of living animal and vegetable species as well as dead animal and vegetable matter, and in forming an opinion the quantity, as well as the nature, of these objects should be taken into account. Many animal and vegetable organisms may occur in water which otherwise appears comparatively pure, but the fact remains that there must be material to serve as food for them, such food being derived from decaying organic matter. It is frequently noticed that in the lower parts of a stream organisms are present which disappear when the upper, and purer, parts are reached.

Some objects found in water deposits are at once suggestive of sewage contamination, for example, epithelial cells, human hairs, fibres of materials from clothing, such as cotton, linen and wool (sometimes dyed), starches from foods and particles of muscular fibre. As regards linen and cotton fibres, it should be remembered that they may be derived from dusters, etc., used in wiping microscope slides or other apparatus, and some indication of their origin may be obtained by noting whether they appear under the microscope to be clean and probably. freshly introduced, or overgrown with fungus or bacteria and therefore having probably been in the sediment for some time.

Of the forms of animal and vegetable life which indicate organic contamination there is a large number. Amœbæ and other protozoa, such as actinophrys, only live in water containing filth. The flagellated infusoria, such as euglenæ and monads, and the ciliated infusoria, such as paramœcia, 
euplotes and vorticellæ, if found in quantity are a bad sign, indicating the presence of sewage or other organic pollution; they may be derived from dirty pond water.

Higher in the animal kingdom we have rotifers, anguillulæ, crustacea, such as cyclops and daphniæ, and acarinæ (or mites), which do not appear to have any direct significance except that they cannot live in very pure water. Some of these are probably scavengers and help to remove lower forms of life, but they should not be present in large numbers in drinking waters.

Vegetable organisms found in water deposits which have a bad significance are filamentous bacteria, such as beggiatoa alba (one of the "sewage fungi"), which is associated with sulphuretted hydrogen in water, and probably the so-called "blue algæ," of which nostoc and anabœna are examples.

3. Some of the algæ, such as volvox, produce unpleasant odours in water, while various diatoms give rise to an aromatic smell. Most algæ and similar growths produce odours on decomposition, but during life they are among the principal agencies at work in the formation of the scum on sand filters, which is largely responsible for the removal of bacteria and other forms of life from water. Containing, as they do, chlorophyll, they produce oxygen in sunlight and this no doubt contributes materially to the purification of the water. On the other hand, the growth of these organisms is sometimes so rapid that the rate of filtration is greatly reduced, while the decay of the older growths gives rise to odours in the water; the blue algæ are said to be worse in respect of the production of odours than green algæ.

Diatoms also play an important part in the work of filtration. Very many species are met with, they are unicellular plants which have siliceous cell-walls and generally contain brown colouring matter; among the commonest varieties found are navicula, asterionella and synedra.

The so-called " iron bacteria," of which crenothrix is a type, 
are filamentous organisms which are sometimes found in waters containing traces of iron in solution; they appear to require iron for their existence and become coated with ferric oxide. The incrustations formed in iron water-mains by these organisms is sometimes so considerable as to seriously reduce the carrying capacity.

4. Particles of mineral matter are found in the deposits from the purest drinking waters; it may consist of crystals of calcium carbonate, oxide of iron or clay. Some indication of its nature may frequently be obtained by treatment of the deposit on the microscope slide with a drop of dilute hydrochloric acid, followed by a drop of potassium ferrocyanide.

\section{Examples of Water Analyses, with Criticism} Upland surface waters.

I.

Total solids

Free and saline $\mathrm{NH}_{3}$.
Albuminoid $\mathrm{NH}_{3}$

Nitrogen as nitrates

Nitrogen as nitrites

Chlorine

Oxygen absorbed, I 5 mins. . 0.005

2.

6.8

0.003

0.029

$0.0 \mathrm{I}$

none

0.85

0.116

0.207

acid

brownish- yellow yellow

No. I is an example of a very pure water.

No. 2 is a water of peaty origin, as shown by the high albuminoid ammonia (with low free ammonia) and high oxygen absorbed; as the nitrates and chlorides, as well as the free ammonia, are low, and nitrites are absent, there is no evidence of sewage contamination.

No. 3 also contains organic matter in considerable quantity 
but it also affords distinct evidence of sewage pollution. The free ammonia is too high when taken in conjunction with the albuminoid, the nitrates and chlorides are also too high and it contains nitrites.

In all the above, the possibility of plumbo-solvency must be borne in mind.

Deep well waters.

4. $\quad 5 . \quad 6 . \quad 7.68$.

$\begin{array}{llllll}\text { Total solids } & \cdot 37.5 & 4 \mathrm{r} .5 & \text { 24.I } & 28.8 & 67.3\end{array}$

Free and saline

$\begin{array}{llllll}\mathrm{NH}_{3} & \text {. none } & 0.001 & 0.001 & 0.017 & 0.028\end{array}$

Albuminoid

$\mathrm{NH}_{3}$. none 0.001 none 0.0100 .002

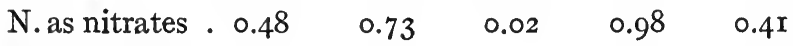

$\mathrm{N}$. as nitrites . none none none none trace

$\begin{array}{llllll}\text { Chlorine } & \cdot 3.55 & 5.25 & 5.40 & 7.00 & \text { II } .40\end{array}$

Oxygen absd.:

$\begin{array}{llllll}15 \text { mins. } & \text { none } & 0.002 & 0.003 & 0.056 & 0.015\end{array}$

$\begin{array}{llllll}3 \text { hours . none } & 0.004 & 0.008 & 0.104 & 0.020\end{array}$

Reaction . alk. acid alk. alk. alk.

Colour . none none none none brownishturbidity

Nos. 4, 5 and 6 are good waters, No. 6 being unusually low in nitrates for a deep well water. The acid reaction of No. 5 was due to carbon dioxide ; after boiling, the water was alkaline.

No. 7 is a water to which sewage has gained access, it would be condemned on the figures for free and albuminoid ammonia, the oxygen absorbed is also high for a water from a deep source and the chlorides are high, unless due to infiltration of a small quantity of sea-water.

No. 8 is a water from the "lower greensand" and presents some remarkable features. The high free ammonia and the nitrites are the result of the reduction of nitrates by ferrous 


\section{PUBLIC HEALTH CHEMISTRY}

iron, the latter precipitating as ferric hydrate and accounting for the turbidity. The iron also is responsible for most of the oxygen absorbed, as shown by the slight difference between the results in $I_{5}$ minutes and 3 hours. The chlorides are derived from the rock. That the results are not an indication of sewage pollution is shown by the low figures obtained for albuminoid ammonia and for oxygen absorbed, both of which tend to prove that very little organic matter is present.

Shallow well waters.

9.

Total solids $\quad 20.4$

Free and saline

\begin{tabular}{lll}
\multicolumn{1}{c}{$\mathrm{NH}_{3}$} & $\cdot$ & $0.00 \mathrm{I}$ \\
Albuminoid $\mathrm{NH}_{3}$ & 0.002 \\
N. as nitrates & $\cdot$ & none \\
N. as nitrites & $\cdot$ & none \\
Chlorine . & I.80 \\
Oxygen absd. : &
\end{tabular}

Io.

33.7

0.001

0.001

I. 20

none

3.05

I 5 mins.

3 hours

Reaction.

Colour .

$$
\begin{array}{rr}
\text {. } & 0.025 \\
\text {. } & 0.049
\end{array}
$$

- alk.

- none

0.005
0.010
alk.

none
II.

I9.8

0.012

0.029

0.47

trace

$4 \cdot 35$

0.068

0.122

neutral

faintly-

brown
I2.

I 76.2

0.006

0.037

9.86

none

20.30

$0 . \operatorname{Ir} 5$

$0.27 \mathrm{I}$

alk.

yellow

No. 9 is a good water, so far as the chemical analysis shows, and if an inspection of the surroundings does not reveal any likelihood of pollution, it is quite suitable for drinking.

No. ro is free from recent pollution, but the high nitrates, in water from a shallow well, render it unsafe (see page ${ }^{4} 46$ ).

Nos. I I and I 2 are polluted waters; No. I 2 showing not only organic matter present but very considerable past contamination, the nitrates and chlorides being phenomenal. The well appeared to collect the dramage from stables, etc. but was for a time used for drinking and caused illness. 


\section{WATER}

River waters.

\begin{tabular}{|c|c|c|c|}
\hline Total solids & . & 5.0 & 5.1 \\
\hline Free and saline $\mathrm{NH}_{3}$ & . & 0.003 & 0.002 \\
\hline Albuminoid $\mathrm{NH}_{3}$. & . & 0.009 & 0.003 \\
\hline N. as nitrates & . & $0.3 \mathrm{I}$ & 0.28 \\
\hline N. as nitrites & . & none & none \\
\hline Chlorine . . & & 1.60 & 1.70 \\
\hline \multicolumn{4}{|l|}{ Oxygen absorbed : } \\
\hline I 5 minutes & . & 0.048 & 0.027 \\
\hline 3 hours & & 0.092 & 0.044 \\
\hline
\end{tabular}

These analyses give an example of the effect of filtration (through sand); the filtered water is used as the supply for a large town.

\section{Water Softening}

The removal of "hardness" from water is sometimes necessary for domestic purposes, when a very hard water is the only one available, causing considerable waste of soap, besides discomfort in washing. Softening is often very essential when the water is required for industrial purposes, especially for boiler feed, in which case it is best to remove both temporary and permanent hardness. Although calcium sulphate, one of the principal causes of permanent hardness, is not precipitated by simply boiling the water, on concentration it may separate, and at the temperature attained in high-pressure boilers it is remarkably insoluble.

For the removal of temporary hardness on a small scale boiling is sufficient, the bicarbonates being thereby deprived of half their carbon dioxide and precipitated as carbonates :For example, $\mathrm{Ca}\left(\mathrm{HCO}_{3}\right)_{2}=\mathrm{CaCO}_{3}+\mathrm{H}_{2} \mathrm{O}+\mathrm{CO}_{2}$.

Temporary hardness may also be removed by the addition of a caustic alkali, such as calcium hydrate, which decomposes the bicarbonates :- 


$$
\mathrm{Ca}\left(\mathrm{HCO}_{3}\right)_{2}+\mathrm{Ca}(\mathrm{OH})_{2}={ }_{2} \mathrm{CaCO}_{3}+2 \mathrm{H}_{2} \mathrm{O} .
$$

Magnesium bicarbonate is similarly converted into the carbonate, which is more soluble than the corresponding calcium compound, and in order to remove the magnesium as completely as possible, sufficient lime should be added to produce magnesium hydrate, which is less soluble :-

$$
\mathrm{MgCO}_{3}+\mathrm{Ca}(\mathrm{OH})_{2}=\mathrm{Mg}(\mathrm{OH})_{2}+\mathrm{CaCO}_{3} \text {. }
$$

It is found in practice that at least twelve hours are required for the precipitate to settle before the water is suitable for use, but by employing various filtering devices the process can be considerably shortened.

Permanent hardness can be removed by treatment of the water with sodium carbonate, whereby the calcium and magnesium sulphates, and other salts, are converted into carbonates :-

For example, $\mathrm{CaSO}_{4}+\mathrm{Na}_{2} \mathrm{CO}_{3}=\mathrm{CaCO}_{3}+\mathrm{Na}_{2} \mathrm{SO}_{4}$.

If caustic soda is used, instead of lime, to remove the temporary hardness, the sodium carbonate formed in the reaction serves to remove permanent hardness.

\section{Permutit process.}

In this process, artificial zeolites are made use of, prepared, according to Don and Chisholm ("Modern Methods of Water Purification"), by melting together silica or quartz, alumina or kaolin; and sodium carbonate ; the resulting compound is a sodium aluminium silicate, and when ordinary hard water is filtered through it the sodium is replaced by lime or magnesium, sodium salts going into solution. The reaction can be represented by the equation :-

$$
\mathrm{Na}_{2} \mathrm{Al}_{2} \mathrm{Si}_{2} \mathrm{O}_{8}+\mathrm{CaSO}_{4}=\mathrm{CaAl}_{2} \mathrm{Si}_{2} \mathrm{O}_{8}+\mathrm{Na}_{2} \mathrm{SO}_{4} \text {. }
$$

(Soda zeolite) (calcium zeolite)

When the permutit becomes saturated with alkaline earths, it can be regenerated by treatment with a strong solution of 
common salt, which in excess replaces the calcium, etc. by sodium, the reaction being reversible.

\section{Poisonous Metals in Water}

The poisonous metal most likely to occur in water supplied to consumers is lead, because lead pipes and cisterns are so largely used for the conveyance and storage of water, while some natural waters have a very marked solvent action on lead.

The waters which dissolve lead most readily are soft moorland waters, especially those containing peaty matter. Such waters are generally acid, owing to the presence of humic and crenic acids produced, according to Houston, by bacilli in the peat, and are more dangerous during heavy rains because of the greater quantity of acid extracted from the peat. In some, if not all, cases, the action commences with the oxidation of the lead by dissolved oxygen in the water, the coating of oxide being subsequently dissolved by the acids in solution.

Another reputed cause of plumbo-solvency is the acidity produced by the action of iron pyrites on water.

The usual remedy for plumbo-solvency is the neutralization of the acidity, either by mixing before distribution with an alkaline water, the addition of lime or sodium carbonate, or filtration through some alkaline material, such as limestone. Previous filtration through sand is advisable, this removing much of the organic matter, or a bed of limestone may be put between layers of sand in the filter. Houston recommends the addition of a small quantity of sodium carbonate to the filtered water, in order to provide a reserve of alkalinity.

Another sort of action of water on lead is known as "erosion"; that is, the formation of an insoluble compound of lead which after a time adheres to the surface of the metal and produces a protective coating. At first, this compound is easily detached and may be sufficient to render the water turbid; although insoluble in water, it easily dissolves in very 
dilute hydrochloric acid, and would be rendered soluble by the gastric juice if the water were consumed in this condition.

For waters likely to dissolve lead the use of tin-lined lead pipes is sometimes recommended ; this, however, is not always free from danger, since the tin lining frequently contains lead and, in any case, a break in the lining will set up a solvent action, owing to the difference of potential between the two metals.

Heap ("Journal of the Society of Chemical Industry," I9I3, 32, 77x, 8II and 847) has added considerably to our knowledge of the action of waters on lead. This experimenter found that pure distilled water, free from dissolved gases, exerts very little action on the metal, but that dissolved gases, particularly oxygen, greatly increase the effect. When both oxygen and carbon dioxide are present, "erosion" takes place, due to the formation firstly of lead hydroxide which is converted into insoluble carbonate by the subsequent action of carbon dioxide. Should carbon dioxide, however, be present in large excess, the carbonate dissolves in the form of bicarbonate.

Distilled water containing dissolved air was found to attack lead more vigorously as the temperature was raised, up to about $50^{\circ} \mathrm{C}$.

Certain salts were found to very much lessen the plumbosolvent action, notably phosphates, while the carbonates and bicarbonates of the alkalis and alkaline earths exert considerable protective power. On the other hand, nitrates, chlorides and sulphates slightly increase the action, and ammonium salts, especially the nitrate, have a very vigorous effect on lead. It was found that waters containing permanent, without temporary, hardness dissolve lead, sometimes in large amounts, and that aluminium sulphate, occasionally used in the purification of waters, has a marked action.

Other metals with which waters are sometimes, though much more rarely, contaminated are copper, from pipes and fittings, zinc, from galvanized iron or occurring naturally, and 
iron. Associated with iron there are frequently found the micro-organisms known as "iron organisms" or "iron bacteria." These apparently need iron for their existence, they become coated with ferric oxide and attach themselves to iron pipes ; not only do they gradually obstruct the watermains but they also corrode the metal. In bad cases the carrying capacity may be reduced by several per cent. annually. The most effective remedy for this evil is the removal of iron from the water, which can often be done by aeration and filtration. Failing this, the iron pipes may be coated with some material to prevent the organisms becoming attached.

Waters which contain iron usually become turbid on standing, owing to the separation of ferric hydrate.

\section{Detection of poisonous metals in water}

Rapid tests.

Required :-

Nessler cylinders fresh ammonium sulphide solution hydrochloric acid dil.

potassium cyanide solution

ammonium hydrate

\section{Procedure :-}

Fill three Nessler cylinders with the water, to two of them add 2 or 3 drops of a fresh solution of ammonium sulphide (this must be colourless) and compare with the water in the third cylinder :-

Lead and copper produce brown colourations.

Iron gives a greenish-brown colouration.

Zinc produces a white turbidity.

If there is a colouration, keep one cylinder for comparison and treat the other as follows:-

Add a few drops of dilute hydrochloric acid; if the colour disappears iron is present.

If the colour does not go, add potassium cyanide and suffi- 
cient ammonium hydrate to render alkaline (the latter will not be necessary unless a great deal of acid has been added); if the colour now disappears, copper is present.

If the colour still remains, the water most probably contains lead.

Confirmatory tests.

Required, in addition to the above materials :-

acetic acid dil. potassium chromate solution

nitric acid conc. potassium ferrocyanide solution

(fresh)

potassium thiocyanate solution

\section{Procedure :-}

Lead. To roo c.c. of the water in a Nessler cylinder add a few drops each of dilute acetic acid and of potassium chromate solution. Allow to stand for a few minutes and examine in a good light against a dark background ; lead is indicated by a yellow turbidity, which may take some time to appear if the quantity is very small. Compare with distilled water, similarly treated.

Copper. To roo c.c. of the water in a Nessler cylinder add a few drops of potassium ferrocyanide solution; copper gives a red colour.

Zinc. To roo c.c. of the water in a Nessler cylinder add fresh solution of potassium ferrocyanide; zinc is shown by a white turbidity.

Iron. I. To roo c.c. of the water in a Nessler cylinder add a few drops each of concentrated nitric acid and of potassium ferrocyanide solution; a blue colouration indicates iron.

2. To another roo c.c. add nitric acid and potassium thiocyanate solution; iron gives a blood-red colour.

N.B.-The above tests are sufficiently delicate for most purposes, if, however, very minute quantities of the metals have to be sought for, the water should be concentrated; and 
if on evaporation the liquid develops a marked colour, owing to the presence of organic matter, a few drops of hydrogen peroxide should be added during the boiling to remove it. With waters containing zinc a precipitate is generally produced on concentration, this must be redissolved by the addition of a drop of dilute hydrochloric acid before applying the tests.

Estimation of lead.

Required:-

Nessler cylinders

burette and stand

graduated cylinders,

50 c.c.

sulphuretted hydrogen solution standard lead solution

(r c.c. $=0.000 \mathrm{r}$ gram of lead)

potassium ferrocyanide solution hydrochloric acid (1 $\frac{1}{4}$ per cent.)

\section{Procedure :-}

To 100 c.c. of the water in a Nessler cylinder add 5 c.c. of hydrochloric acid ( $\frac{1}{4}$ per cent.) and 5 c.c. of a saturated solution of sulphuretted hydrogen, and stir. Match the colouration in the following way: take several Nessler cylinders similar to that containing the sample, into each of these introduce a different quantity of a standard lead solution, measured from a burette, for example, 0.5, I.O and 2.0 c.c., make each up to roo c.c. with distilled water and add the same quantities of hydrochloric acid and sulphuretted hydrogen solution as were used for the sample. Compare the colours with that of the sample, if necessary making fresh standards until the colouration is exactly matched.

Prove the absence of copper, which if present would contribute to the colouration, by applying the ferrocyanide reaction to a fresh quantity of the water.

\section{Example of calculation:-}

I 00 c.c. of the water required I. 5 c.c. of standard lead solution to match the colouration with sulphuretted hydrogen, 
hence, lead $=1.5 \times 0.0001 \times \frac{100,000}{100}=0.15$ part per 100,000 .

Some water has a perceptible colour when compared with distilled water in Nessler cylinders, and, if not allowed for, this colour will be included in the darkening due to the lead sulphide, so giving too high a result. In order to apply the necessary correction, roo c.c. of the sample should be matched with distilled water containing a known quantity of standard lead solution and sulphuretted hydrogen solution ( 0.2 to 0.5 c.c. of the lead solution may be needed), and the quantity of lead solution necessary is deducted from that used in the estimation of the lead in the water.

For example, if in the above estimation the sample had a colour which required 0.3 c.c. lead solution to match, then the real amount of lead would be :-

$$
(1.5-0.3) \times 0.0001 \times \frac{100,000}{100}=0.12 \text { part per } 100,000 \text {. }
$$

An alternative method for the matching of the colouration is the addition of a sufficient quantity of a caramel solution to the standards, before putting in sulphuretted hydrogen solution, to produce, as nearly as possible, the tint of the original sample.

\section{Estimation of copper.}

The ferrocyanide reaction can conveniently be used for the estimation, the red colour being matched against a standard solution of copper ; the colour is intensified by the presence of ammonium salts.

The procedure recommended by Carnelley ("Chemical News," 32,308 ) gives satisfactory results.

Required :-

Nessler cylinders

burette and stand glass tube standard copper solution

(I c.c. $=0.0001$ gram copper)

ammonium nitrate, ro per cent. solution potassium ferrocyanide, 4 per cent. soln. 


\section{WATER}

Procedure:-

Five drops of the potassium ferrocyanide are placed in each cylinder, and then a measured quantity of the witter into one of them $(\Lambda)$, and both filled up to the mark with distilled water, 5 c.c. of the ammonium nitrate solution added to each, and then the standard copper solution run gradually into (B) until the colours in both cylinders are of the same depth, the liquid being well stirred after each addition. The number of c.c. used is then read off.

\section{Estimation of zinc (Thresh).}

The turbidity produced by the addition of dilute sulphuric acid and potassium ferrocyanide solution is matched by adding the same quantities of the reagents to water containing known amounts of a standard solution of zinc.

Required:-

Nessler cylinders

burette and stand

pipettes graduated in c.c. standard zine solution

(I c.c. $=0.0001$ gram zinc) fresh potassium ferrocyanide solution sulphuric acid dil.

\section{Procedure:-}

To 50 c.c. of the sample in a Nessler cylinder add 1 c.c. of dilute sulphuric acid and I c.c. of potassium ferrocyanide solution. Allow to stand about five minutes and match the turbidity by adding the same quantities of the reagents to distilled water to which measured amounts of standard zinc: solution have been added.

Estimation of iron.

The red colour produced on addition of nitric acid and a thiocyanate solution is matched by adding the same quantities of the reagents to distilled water to which standard iron solution has been added in measured quantities. 
Required:-

Nessler cylinders

burette and stand

graduated cylinders, 50 c.c. standard iron solution

(I c.c. $=0.0001$ gram iron) nitric acid solution ( $\mathrm{I}$ in 5 ) ammonium thiocyanate, 5 per cent. solution

\section{Procedure:-}

Put 50 c.c. of the sample into a Nessler cylinder, add 5 c.c. of nitric acid solution and 5 c.c. of thiocyanate solution. Into another cylinder put $5 \circ$ c.c. of distilled water and the same quantities of the reagents, then run in standard iron solution from a burette until the two solutions are equal in depth ; a few minutes should be allowed for the full development of the colour.

Note.-In the above estimations, the quantities of sample recommended to be taken may have to be varied, according to the amounts of the metals present. In some cases it may be necessary to concentrate the water before making the estimations, in others dilution with distilled water may be advisable, as it is not possible to match very deep colours accurately. 


\section{CHAPTER IX}

\section{ANALYSIS OF SEWAGE EFFLUENTS}

THE analysis of sewage effluents is carried out similarly to that of water, but smaller quantities of the sample are used for some of the estimations. In addition, certain determinations rre made which are rarely required in water analysis ; the principal of these are: the solid matter in suspension and the rate of disappearance of dissolved oxygen, both of which are dealt with below.

The free and saline ammonia, and the albuminoid ammonia are estimated in about 50 or 100 c.c. of the effluent, diluted to 500 c.c. with ammonia-free water before distillation, and the first fraction obtained is made up to a definite bulk in a graduated flask and an aliquot part of it "nesslerized." For albuminoid ammonia, it is advisable to add more distilled water than is usual in water analysis, because it is frequently necessary to distil five or more fractions in order to obtain all the ammonia. If the distillation is stopped and more distilled water is added, the result is likely to be too high.

The oxygen absorbed from permanganate is generally estimated in 3 minutes and in 4 hours, the former being determined by direct titration with permanganate, in presence of sulphuric acid, and the latter in a manner similar to the estimation of oxygen absorbed in water. It is customary to keep the liquid at $80^{\circ} \mathrm{F} .\left(27^{\circ} \mathrm{C}\right.$. $)$ during the reaction.

Required :-

2 stoppered bottles, 500 c.c.

burettes and stand

standard potassium permanganate (I c.c. $=0.000 \mathrm{r}$ gram oxygen) 
pipette, ro c.c.

graduated flask, Ioo c.c. sulphuric acid ( $\mathrm{I}$ in 4 ) sodium thiosulphate solution (4 grams per litre) potassium iodide starch solution

\section{Procedure :-}

Put Ioo c.c. of the sample into a stoppered bottle of about 500 c.c. capacity, add Io c.c. of sulphuric acid solution ( $\mathrm{I}$ in 4 ), and run in standard potassium permanganate solution from a burette, a few drops at a time, the titration occupying three minutes, so that there is a slight pink colour at the end of that period. Read the burette and add more permanganate solution to make a total of 50 c.c., immerse the bottle in water at $27^{\circ} \mathrm{C}$. for 4 hours, shaking occasionally, and estimate the unchanged permanganate in the usual way. On account of the larger quantity of permanganate employed it is better to titrate with a thiosulphate solution of about 4 grams per litre.

If the colour becomes faint before the end of the 4 hours, a further quantity of permanganate must be added, so that a considerable excess is present throughout the whole period. A blank experiment is performed with 25 or 50 c.c. of permanganate.

\section{Example of calculation:-}

Ioo c.c. of an effluent required in 3 minutes 4.8 c.c. of $\mathrm{KMnO}_{4}$, a further 45.2 c.c. were added (making 50 c.c. total) and after 4 hours' digestion, and the addition of potassium iodide, 26.5 c.c. of thiosulphate were required in the titration.

The blank experiment required 22.0 c.c. thiosulphate for 25 c.c. of $\mathrm{KMnO}_{4}$.

Oxygen absorbed in 3 minutes $=4.8 \times 0.0001 \times \frac{100,000}{100}$ $=0.48$ part per 100,000; 


\section{SEWAGE EFFLUENTS}

and in 4 hours $=\frac{44.0-26.5}{44.0} \times 0.005 \times \frac{100,000}{100}$

$=r .99$ parts per 100,000 .

Total organic nitrogen is sometimes estimated and serves as a check upon the albuminoid ammonia, which, it should be remembered, does not show the whole of the organic nitrogen present. The organic nitrogen can be estimated by Kjeldahl's process (see under Milk Analysis, page 38), adding pure sulphuric acid before commencing the evaporation and making a deduction for the free ammonia present in the sample.

Suspended matter is a bad feature in an effluent, because of the nuisance likely to arise from the accumulation of putrefying mud and the de-oxygenation of the water above it; also the possible injury to fish that may result. The Royal Commission on Sewage Disposal attached great importance to the elimination, as far as possible, of suspended matter from effluents, and recommended that the standards of purity should be generally based upon the quantity of such matter together with the rate at which dissolved oxygen disappears from the liquid.

The suspended matter may be estimated in various ways :-

I. Mix the sample and filter a measured quantity (from roo c.c. to a litre, according to the condition of the effluent) through a weighed Gooch crucible packed with asbestos, or a dried and weighed filter paper. Dry again to constant weight, the difference in weight gives the amount of suspended matter.

2. Mix the sample and measure a quantity as before, allow it to stand in a graduated cylinder until the suspended matter has settled, then pour off the clear liquid to a definite mark, say the $5 \circ$ c.c. graduation. Transfer the residue to a weighed dish, evaporate to dryness and dry in an air-bath to constant weight; deduct the amount of dissolved solids in 50 c.c. of the clear liquid, previously determined, the difference being the suspended matter. 
3. Separate the suspended matter by means of a centrifuge, dry and weigh in a capsule.

Method I is the process recommended by the Royal Commission.

The rate of disappearance of dissolved oxygen is of great importance as an indication of the effect that an effluent will have upon the aeration of a stream into which it is discharged. An effluent which rapidly consumes oxygen from solution will take up oxygen from the water of the stream, thereby depriving it of its power of self-purification, possibly rendering it foul, and causing the death of fish which may inhabit the stream.

To determine the rate of disappearance of oxygen from solution, a portion of the effluent is shaken with air for about a minute in order to saturate it with oxygen ; a stoppered bottle, capacity about 200 to 300 c.c., is completely filled, and other similar bottles are filled with mixtures, in known proportions, of the aerated effluent and aerated water (good tap water will suffice). The oxygen in solution in the freshly aerated liquid may be estimated, or, if the temperature at which it is bottled is noted, reference can be made to a table of solubility of oxygen in water at different temperatures (see page 226), the oxygen remaining after a certain interval is determined by one of the methods described below, and the difference, multiplied by the dilution, if any, gives the rate of disappearance.

Winkler's method, modified by Rideal and Stewart, is a very convenient one to use and was the process employed by the Royal Commission.

In this method manganous hydrate is precipstated in the liquid by the interaction of manganous chloride and sodium hydrate, this combines with the free oxygen, forming hydrated manganese dioxide; on the addition of potassium iodide and hydrochloric acid a quantity of iodine is liberated equivalent to the oxygen taken up, and this is titrated with sodium thiosulphate solution.

It is convenient to standardize the thiosulphate by means of 
standard potassium permanganate solution, as in the estimation of "oxygen absorbed from permanganate," the value of the thiosulphate in terms of oxygen being thereby directly ascertained.

Required:-

pipettes graduated in c.c. and drawn out to capillaries burettes and stand flask about 500 c.c. plate

manganous chloride solution solution of sodium hydrate and potassium iodide sodium thiosulphate (4 gms. per litre)

potassium permanganate solution (I c.c. $=0.000 \mathrm{I}$ gram oxygen)

sulphuric acid solution ( $\mathrm{I}$ in 4 ) hydrochloric acid conc. potassium iodide starch solution

\section{Procedure:-}

Take the bottle containing the effluent, remove the stopper carefully, so as to avoid spilling any of the contents, and, by means of a pipette drawn out to a long capillary tube, introduce I c.c. of manganous chloride solution to the bottom of the bottle. Next add 3 c.c. of the solution of sodium hydrate and potassium iodide, running it also to the bottom, replace the stopper and shake well; a precipitate forms which has a brown colour if any oxygen remained in solution, otherwise it is white. Allow to stand about Io minutes, for the precipitate to settle, place the bottle on a plate and run in 5 c.c. of concentrated hydrochloric acid. Insert the stopper and shake, the precipitate is completely dissolved and iodine liberated, as shown by the yellow colour. (Should there be no iodine set free, it is proof that no oxygen was remaining in the effluent; in this case one or more of the diluted portions must be treated in the same way.) 
Transfer the liquid quickly to a flask and titrate with sodium thiosulphate solution, using starch solution as indicator when the yellow colour is nearly discharged. Measure the capacity of the bottle, and standardize the thiosulphate, using standard potassium permanganate solution and carrying out the titration as in the blank experiment in the oxygen absorbed estimation.

$N . B$. No correction is made for the volume of reagents added, since these introduce a small quantity of oxygen and the errors approximately counterbalance one another.

\section{Example of calculation:-}

Capacity of bottl

Thiosulphate used

200 c.c.

2.9,

On standardizing the thiosulphate, it was found that ro. 35 c.c. were required for 25 c.c. of standard permanganate, hence I c.c. of thiosulphate $=\frac{0.0025}{10.35}=0.000242$ gram of oxygen; therefore, oxygen in solution $=2.9 \times 0.000242 \times \frac{100.000}{200}$ $=0.35$ part per 100,000 .

If the temperature at which the bottle was filled was $15^{\circ} \mathrm{C}$., then the oxygen in solution at the start was 1.00 part, and the oxygen which has disappeared $=\mathbf{I} .00-0.35=0.65$ part per 100,000 .

The equations representing the reactions are :-

$$
\begin{aligned}
& \mathrm{MnCl}_{2}+2 \mathrm{NaOH}=\mathrm{Mn}(\mathrm{OH})_{2}+2 \mathrm{NaCl} ; \\
& \mathrm{Mn}(\mathrm{OH})_{2}+\mathrm{O}+\mathrm{H}_{2} \mathrm{O}=\mathrm{Mn}(\mathrm{OH})_{4} ; \\
& \mathrm{Mn}(\mathrm{OH})_{4}+2 \mathrm{KI}+4 \mathrm{HCl}=\mathrm{I}_{2}+\mathrm{MnCl}_{2}+2 \mathrm{KCl}+4 \mathrm{H}_{2} \mathrm{O} .
\end{aligned}
$$

The process must be modified as follows if the effluent contains nitrites, which liberate iodine from potassium iodide and so must be destroyed before estimating the oxygen; the modified process should also be adopted if the amount of organic matter is very great.

To the effluent in the bottle add 0.5 c.c. of concentrated sulphuric acid and a sufficient quantity of N/10 potassium 
permanganate solution to leave a slight excess after standing I5 minutes (this can be determined by titrating a separate portion of the sample). Add I c.c. of neutral potassium oxalate solution, to destroy the excess of permanganate, insert the stopper, previously filling up the bottle, if necessary, with a few drops of the sample (it is essential that air should be completely excluded), and allow to stand another 15 minutes. The pink colour having now disappeared, estimate the oxygen as above.

Thresh's method for the estimation of dissolved oxygen.

This method depends upon the fact that when nitrous and hydriodic acids are mixed in a solution containing dissolved oxygen, iodine is liberated, and the reaction will continue, more iodine being set free, until all the oxygen is used up. The oxygen can be estimated by titrating the iodine in an atmosphere free from oxygen.

The effluent is treated with a solution containing potassium iodide and sodium nitrite, and sulphuric acid, in a vessel which is completely filled with the liquid; it is then run into an apparatus, from which the air has been displaced by coal-gas, for titration.

The reactions are represented by the equations :-

$$
\begin{aligned}
& 2 \mathrm{HI}+2 \mathrm{HNO}_{2}=\mathrm{I}_{2}+2 \mathrm{NO}+2 \mathrm{H}_{2} \mathrm{O} ; \\
& 2 \mathrm{NO}+\mathrm{O}+\mathrm{H}_{2} \mathrm{O}=2 \mathrm{HNO}_{2} ;
\end{aligned}
$$

the nitrous acid then reacts with more hydriodic acid, liberating a further quantity of iodine, until all the oxygen has been removed.

As the iodide-nitrite mixture contains free iodine, while the other reagents and the thiosulphate solution contain dissolved oxygen, it is necessary to perform a second experiment in order to find the amount of iodine due to these causes and to correct for it.

The apparatus employed consists of a wide-mouthed bottle having a capacity of about 500 c.c., fitted with a rubber bung which is pierced by four holes; through one passes the stem of a 
stoppered tap-funnel, capacity about $25^{\circ}$ c.c. (this must be accurately determined), through another the jet of a burette, and through the remaining two holes pass glass tubes by means of which coal-gas can be led through the apparatus. To one of these tubes is attached a piece of rubber tubing, and at the other end of the rubber tubing is a short glass tube carrying a cork which fits the mouth of the tap-funnel.

\section{Also required:-}

pipettes graduated in c.c., drawn out to capillarjes

solution of sodium nitrite and potassium iodide

* sodium thiosulphate solution (I c.c. $=0.00025$ gram oxygen)

(The thiosulphate solution should be shaken with air before use)

starch solution

sulphuric acid solution ( $\mathrm{I}$ in 4 )

\section{Procedure:-}

Fill the tap-funnel with the sample, so that when the stopper is inserted no air remains in the vessel. Remove the stopper and add I c.c. each of the iodide-nitrite solution and of the sulphuric acid solution, dipping the end of the pipette below the surface of the liquid, insert the stopper carefully so as to exclude all air, shake and allow to stand for 15 minutes. Insert the stem of the funnel through the hole in the bung, fill the burette with thiosulphate and pass coal-gas through the bottle so as to drive out all the air, after which the gas is lighted at the end of the exit tube and turned low. Remove the stopper from the tap-funnel and insert the cork which is attached to the gas exit tube, open the tap of the funnel and run the liquid into

* As thiosulphate solution does not keep well, it is necessary to standardize it before use, as recommended under Winkler's process. The solution containing 4 grams per litre, which was used in that process, can equally well be employed here. 


\section{SEWAGE EFFLUENTS}

the bottle. Turn off the tap and re-insert the stopper. Next titrate with thiosulphate until the yellow colour is nearly discharged, run in 2 c.c. of starch' solution through the tapfunnel (without introducing any air) and add more thiosulphate to decolourize the solution. Note the quantity of thiosulphate solution used.

The titration represents :-

(a) iodine liberated by the dissolved oxygen in the sample ;

(b) , ", , , oxygen in the reagents and thiosulphate ;

(c) , , , , nitrites, if any, in the sample ;

(d) iodine contained in the iodide-nitrite solution.

In order to determine the amount of thiosulphate used for $(b)$ and $(d)$, introduce into the bottle in succession 5 c.c. of the iodide-nitrite solution, 5 c.c. of the sulphuric acid solution and ro c.c. of starch solution, also a quantity of distilled water, which has been shaken with air, equal to five times the volume of thiosulphate used. Titrate with thiosulphate as before, and deduct one-fifth of the amount of thiosulphate required, from the original titration.

If nitrites are present in the sample, they are estimated by the metaphenylene-diamine process (see page 137), and the quantity of iodine which they will liberate is allowed for in calculating the result :-

${ }_{2} \mathrm{HNO}_{2}$ liberate 2 atoms of iodine $=\mathrm{I}$ atom of oxygen, or, 28 parts of nitrogen as nitrite $=16$ parts of oxygen.

\section{Standards of purity for sewage effuents}

Various standards to which sewage effluents should conform have been adopted by different authorities in the past ; maximum limits have, as a rule, been fixed for albuminoid ammonia and oxygen absorbed from permanganate, that for the former being generally 0.1 part, and for the latter I.0 part per 100,000.

It is generally required, also, that nitrates should be present 
in considerable quantity. Another suggestion is that an effluent after incubation for five days at $37^{\circ} \mathrm{C}$. should not develop an odour of putrefaction.

The Royal Commission on Sewage Disposal, in their eighth report (I9I2), made the following recommendations :-

(a) The law should be altered so that a person discharging sewage matter into a stream should not be deemed to have committed an offence under the Rivers Pollution Prevention Act, 1876 , if the sewage matter is discharged in a form which satisfies the requirements of the prescribed standard.

(b) The standard should be either the general standard or a special standard which will be higher or lower than the general standard as local circumstances require or permit.

(c) An effluent, in order to comply with the general standard, must not contain as discharged more than 3 parts per 100,000 of suspended matter, and with its suspended matters included must not take up at $65^{\circ} \mathrm{F}$. ( $18.3^{\circ} \mathrm{C}$.) more than 2.0 parts per roo, 000 of dissolved oxygen in 5 days. This general standard should be prescribed either by Statute or by Order of the Central Authority, and should be subject to modification by that Authority after an interval of not less than ten years.

(d) In fixing any special standard the dilution afforded by the stream is the chief factor to be considered. If the dilution is very low it may be necessary for the Central Authority, either on their own initiative or on application by the Rivers Board, to prescribe a specially stringent standard, which should also remain in force for a period of not less than ten years.

(e) If the dilution is very great the standard may, with the approval of the Central Authority, be relaxed or suspended altogether. Our experience leads us to think that as a general rule, if the dilution, while not falling below 150 volumes, does not exceed 300 , the dissolved oxygen absorption test may be omitted, and the standard for suspended solids fixed at 6 parts per 100,000. To comply with this test no treatment beyond chemical precipitation would ordinarily be needed. If the 
dilution while not falling below 300 volumes does not exceed 500 the standard for suspended solids may be further relaxed to 15 parts per 100,000. For this purpose tank treatment without chemicals would generally suffice if the tanks were properly worked and regularly cleansed. These relaxed standards should be subject to revision at periods to be fixed by the Central Authority, and the periods should be shorter than those prescribed for the general or for the more stringent standards.

$(f)$ With a dilution of over 500 volumes all tests might be dispensed with, and crude sewage discharged, subject to such conditions as to the provision of screens or detritus tanks as might appear necessary to the Central Authority. 


\section{CHAPTER X}

\section{AIR}

THE composition of pure dry air by volume is :-

Oxygen

Nitrogen

Argon .

Carbon dioxide

Helium, Krypton, Neon, Xenon and Hydrogen

20.94 pęr cent.
78.09 , , ,
0.94 ,"
0.03 , ,

traces

In the ordinary atmosphere there is also water vapour, the quantity being variable but averaging about $\mathbf{r} .4$ per cent., and probably traces of ozone in sea and country air.

These constituents show slight variations according to local conditions. The carbon dioxide is higher in fogs, as much as o.I4 per cent. having been recorded during a dense London fog ; in large towns the amount of oxygen may be slightly less, and in coal mines the quantity is often considerably lower.

Air also contains traces of impurities due to combustion and other causes, these naturally occurring to a greater extent in the atmosphere of towns, such as sulphur dioxide, sulphuric acid, ammonia, organic matter and oxides of nitrogen. Besides these there may be under special circumstances other gaseous impurities, for example carbon monoxide in cases where illuminating-gas or power-gas is escaping into the air, or where incomplete combustion of fuel is taking place.

The air from cesspools and badly constructed sewers may contain organic ammonia derivatives, carbon dioxide, sulphuretted hydrogen, ammonium sulphide, etc., and it has been 
suggested that volatile compounds of the nature of ptomaines are present in the air from these sources. But in properly constructed and ventilated sewers, the air, apart from an increase in the quantity of carbon dioxide, does not materially differ from ordinary air.

Other possible impurities are chlorine, hydrochloric acid, carbon bisulphide vapour, etc., in and around chemical works. Phosphoretted hydrogen and arseniuretted hydrogen are sometimes given off from ferro-silicon, and have caused cases of poisoning on ships carrying this material. Ferro-silicon containing from 30 to 70 per cent. of silicon is said to be the most dangerous, and the Local Government Board have recommended that if this grade is to be conveyed on board ships, it should be exposed to air under cover for at least a month before shipment.

Dust is always present in air in large or small amounts, and contains soot, vegetable matter, sodium chloride, fungus spores, etc.

\section{Changes produced by Respiration and Combustion}

Respiration produces marked alterations in the quantities of some atmospheric impurities, though the percentage of oxygen is scarcely affected. The most notable change is the increase in carbon dioxide, the quantity of which in air expired from the lungs is about 4 per cent. It is calculated that a man produces about 0.6 cubic foot of carbon dioxide per hour, and a woman about one-fifth less; these quantities are greatly increased by muscular exertion. Expired air also contains much aqueous vapour. In a badly ventilated room containing a large number of people, the amount of carbon dioxide may be as high as 0.3 to 0.5 per cent. ( 30 to $5^{\circ}$ parts per 10,000 ), and the quantity of this impurity serves as a useful measure of the vitiation of the air.

The cause of the unpleasant effects of overcrowding has been the subject of much controversy; the old theory was that the 
excess of carbon dioxide, or lack of oxygen, was the cause ; but experiments have shown that air containing 2 to 4 per cent. of carbon dioxide and only 15 per cent. of oxygen is not particularly harmful. Certain observers claimed to have proved by experiments on mice and rabbits that a volatile poison was produced by respiration, but their results were not confirmed. Experiments carried out on healthy persons (by Paul and others at Breslau) seem to prove that the ill effects of an atmosphere vitiated by respiration are due to temperature and humidity. The individuals were placed in a large cabinet, the atmosphere of which was capable of regulation in regard to moisture and temperature, and so long as these were kept low no discomfort was felt; when, however, the temperature reached $80^{\circ} \mathrm{F}$. with moderate humidity, or $70^{\circ}$ with high humidity, various symptoms, such as dizziness, headache and nausea, ensued. These symptoms could be almost immediately alleviated by cooling or drying the air, or by rapidly moving it by means of a fan, without any "chemical change being made. The effects appear to depend upon the interchange of heat between the body and the surrounding atmosphere.

Illuminating-gas when burnt produces about half its volume of carbon dioxide, that is, for an ordinary gas burner, about 2.5 to 5 cubic feet per hour, or as much as several men performing muscular work. In addition, a large amount of water vapour is formed, about equal to the volume of gas burnt.

Ordinary gas contains sulphur compounds, of which carbon bisulphide and sulphuretted hydrogen are the most important, and these burn to sulphur dioxide and sulphuric acid. In some districts the amount of sulphur compounds has to be kept within certain statutory limits.

Since the products of combustion and respiration consist largely of water vapour, which is lighter than air, the mixture of gases tends to rise, and, unless carried off by ventilation, will accumulate in the higher parts of a room. It has been found in theatres and other similar buildings, when these are im- 
perfectly ventilated, that the air in the balconies is more impure than that near the floor.

\section{Detection of Gaseous Impurities in Air}

The gaseous impurities may be recognized by chemical means and also, in some cases, by their physical properties. The following observations and tests should be made before proceeding to apply other reactions :-

I. Colour: Chlorine and oxides of nitrogen, if sufficiently concentrated, show characteristic colours, the remainder of the commoner gases being colourless.

2. Odour: Carbon monoxide and dioxide are odourless.

3. Reaction to litmus (moistened litmus papers should be used): Ammonia and ammonium sulphide are alkaline; hydrochloric acid, sulphur dioxide and oxides of nitrogen are acid ; chlorine bleaches litmus ; sulphuretted hydrogen and carbon dioxide are slightly acid, and the acidity may be demonstrated by the use of a moistened blue litmus paper. Carbon monoxide, carbon bisulphide and coal gas are neutral.

\section{Characteristic tests.}

In order to make the reactions more definite, considerable quantities of the gases may be introduced into cylinders of air and covered with glass plates, the edges of which are smeared with a small quantity of vaseline to render the jars air-tight.

Those tests in which the reagents are introduced on filter paper should be done first, and the test for combustibility last, if possible in a fresh jar of the gas.

If the impurities are to be detected in very small amounts, as is often the case in actual air examinations, the methods must be modified, the air being aspirated through, or over, the reagent for some time.

A simple form of aspirator is made as follows :-

A large bottle, having a tap near the bottom, is fitted with a tightly fitting rubber stopper. Through a hole in the stopper 
is inserted a glass tube, the other end of which just passes through the stopper of a small flask; the latter has a second tube also passing through the stopper, which nearly reaches the bottom of the flask.

To use the aspirator, the large bottle is filled with water, and some suitable absorbent is placed in the flask; the two are then connected. On running the water slowly out of the bottle by means of the tap at the bottom, an equal volume of the air under examination passes through the liquid in the absorption flask, and the solution can then be tested by suitable methods. Required:-

test-tubes

filter papers

small porcelain dishes

spectroscope ordinary reagents, also

Nessler solution

ammonia (0.88o)

absolute alcohol

sodium nitroprusside solution

sulphanilic acid solution

naphthylamine hydrochloride solution

blood solution

starch-potassium iodide papers litmus papers

\section{Ammonia.}

Always present in air in small amounts from the combustion of coal and the decomposition of organic matter.

Ammonia is colourless, has a characteristic pungent odour, is strongly alkaline and very soluble in water, the solution giving the reactions of the gas. It is non-combustible under ordinary conditions.

\section{Reactions :-}

I. Introduce a rod moistened with concentrated hydrochloric acid, white fumes of ammonium chloride are produced :-

$$
\mathrm{NH}_{3}+\mathrm{HCl}=\mathrm{NH}_{4} \mathrm{Cl} \text {. }
$$


2. Treat with water, and to a portion of the solution add a few drops of Nessler solution, a brick-red precipitate $\left(\mathrm{NHg}_{2} \mathrm{I} \cdot \mathrm{H}_{2} \mathrm{O}\right)$ is produced, or, with very small quantities of ammonia, a yellow colouration.

\section{Estimation :-}

Ammonia may be estimated by aspirating a measured volume of the air through ammonia-free water and using the method employed in water analysis (see page 12I).

\section{Chlorine.}

Largely used for bleaching purposes.

Chlorine has a greenish-yellow colour, a characteristic odour, is acid, and bleaches litmus; it is non-combustible.

\section{Reactions :-}

I. Moisten a piece of fresh starch-potassium iodide paper and introduce it into the gas; a blue colour is produced which, if the chlorine is sufficiently concentrated, is rapidly bleached :- .

$$
{ }_{2} \mathrm{KI}+\mathrm{Cl}_{2}=2 \mathrm{KCl}+\mathrm{I}_{2} \text {. }
$$

2. The reaction with litmus paper is characteristic.

\section{Estimation:-}

Chlorine may be estimated by passing the air through a solution of potassium iodide and titrating the liberated iodine with standard sodium thiosulphate solution,

127 parts iodine $=35.5$ parts chlorine.

Sulphuretted hydrogen.

Produced when organic matter containing sulphur decomposes ; sometimes contained in sewer air.

Sulphuretted hydrogen is colourless, has a sweet, sickly taste and a disagreeable odour resembling that of rotten eggs. It is slightly acid to litmus, and burns with the formation of a deposit of sulphur. 
Reaction:-

Introduce filter paper moistened with lead acetate solution, a greyish stain with a metallic lustre is produced, due to the formation of lead sulphide :-

$$
\mathrm{Pb}\left(\mathrm{CH}_{3} \cdot \mathrm{COO}\right)_{2}+\mathrm{H}_{2} \mathrm{~S}=\mathrm{PbS}+{ }_{2} \mathrm{CH}_{3} \cdot \mathrm{COOH} \text {. }
$$

\section{Estimation :-}

Sulphuretted hydrogen may be estimated by passing the air through a measured quantity of standard iodine solution, and titrating the excess of iodine with standard sodium thiosulphate solution :-

$$
\mathrm{H}_{2} \mathrm{~S}+\mathrm{I}_{2}=2 \mathrm{HI}+\mathrm{S} \text {. }
$$

254 parts iodine $=34$ parts sulphuretted hydrogen.

Ammonium sulphide.

Produced when ammonia and sulphuretted hydrogen are present at the same time in air, and is sometimes contained in sewer air. The odour of both these gases is discernible, the reaction to litmus is alkaline.

\section{Reactions :-}

I. Lead acetate gives the same reaction as with sulphuretted hydrogen.

2. Add sodium nitroprusside solution $\left(\mathrm{Na}_{2} \mathrm{FeNOCy}_{5} .2 \mathrm{H}_{2} \mathrm{O}\right)$, a purple colour is produced.

\section{Estimation :-}

As there is likely to be an excess of either ammonia or sulphuretted hydrogen in the air, these gases should be separately estimated. After absorption in water, the ammonia may be determined by adding sodium hydrate, distilling and using the Nessler process; the sulphuretted hydrogen is afterwards estimated by acidifying the residue, distilling and using the iodine method previously described. 
Hydrochloric acid.

May be present in the air in the neighbourhood of chemical works, particularly where sodium carbonate is made by the "salt-cake" process. It is colourless, has a very pungent odour, and is strongly acid.

\section{Reactions :-}

r. Introduce a glass rod moistened with ammonia, white fumes of ammonium chloride are formed; other acid gases, such as sulphur dioxide, give a similar reaction, so this test alone is not conclusive.

2. Add silver nitrate solution, a white curdy precipitate is formed. Add ammonium hydrate, the precipitate dissolves; next add nitric acid in sufficient quantity to neutralize the ammonia, the precipitate is thrown down again :-

$$
\mathrm{AgNO}_{3}+\mathrm{HCl}=\mathrm{AgCl}+\mathrm{HNO}_{3} \text {. }
$$

\section{Estimation:-}

Hydrochloric acid may be estimated by absorbing in water and precipitating with silver nitrate, the silver chloride being weighed.

\section{Sulphur dioxide.}

Produced when fuel containing sulphur is burnt, and frequently present in town air, particularly during foggy weather; sulphuric acid is also found under the same circumstances.

Sulphur dioxide is colourless, has a very irritating odour, is acid to litmus, and non-combustible. It is a powerful.reducing agent.

\section{Reactions :-}

r. Introduce a piece of filter paper moistened with potassium bichromate solution, the colour is changed to green; the reaction may, for simplicity, be regarded as taking place in the following stages :- 


$$
\begin{aligned}
& \mathrm{K}_{2} \mathrm{Cr}_{2} \mathrm{O}_{7}=\mathrm{K}_{2} \mathrm{O} .2 \mathrm{CrO}_{3}, \\
& { }_{2} \mathrm{CrO}_{3}+{ }_{3} \mathrm{SO}_{2}+3 \mathrm{H}_{2} \mathrm{O}=\mathrm{Cr}_{2} \mathrm{O}_{3}+3 \mathrm{H}_{2} \mathrm{SO}_{4}, \\
& \mathrm{Cr}_{2} \mathrm{O}_{3}+3 \mathrm{H}_{2} \mathrm{SO}_{4}=\mathrm{Cr}_{2}\left(\mathrm{SO}_{4}\right)_{3}+3 \mathrm{H}_{2} \mathrm{O}
\end{aligned}
$$

2. Introduce filter paper moistened with ferric chloride and potassium ferricyanide, the green colour is changed to deep blue :-

$$
{ }_{2} \mathrm{FeCl}_{3}+\mathrm{SO}_{2}+{ }_{2} \mathrm{H}_{2} \mathrm{O}=2 \mathrm{FeCl}_{2}+2 \mathrm{HCl}+\mathrm{H}_{2} \mathrm{SO}_{4} \text {, }
$$

ferrous chloride and potassium ferricyanide then yield "Turnbull's Blue."

3. Add dilute solution of potassium permanganate, the colour is discharged; add barium chloride solution, white precipitate :-

$$
\begin{gathered}
{ }_{2} \mathrm{KMnO}_{4}+{ }_{5} \mathrm{SO}_{2}+{ }_{2} \mathrm{H}_{2} \mathrm{O}=\mathrm{K}_{2} \mathrm{SO}_{4}+2 \mathrm{MnSO}_{4}+2 \mathrm{H}_{2} \mathrm{SO}_{4}, \\
\mathrm{H}_{2} \mathrm{SO}_{4}+\mathrm{BaCl}_{2}=\mathrm{BaSO}_{4}+2 \mathrm{HCl} .
\end{gathered}
$$

4. Introduce a piece of starch-potassium iodide paper which has been rendered blue (e.g. by exposure to chlorine for a moment), the colour is discharged.

Sulphur dioxide produces a white precipitate with silver nitrate, soluble in ammonia, but not reprecipitated on addition of nitric acid (distinction from hydrochloric acid).

\section{Estimation:-}

Sulphur dioxide may be estimated by absorption in sodium hydrate solution, oxidation with bromine water and precipitation, of the sulphuric acid formed, with barium chloride, the barium sulphate being weighed :-

$$
\mathrm{SO}_{2}+\mathrm{Br}_{2}+2 \mathrm{H}_{2} \mathrm{O}=\mathrm{H}_{2} \mathrm{SO}_{4}+2 \mathrm{HBr} \text {. }
$$

Nitrous fumes.

Liberated in some chemical processes where nitric acid is employed, and traces are often present in air, particularly after thunderstorms.

Nitrous fumes have a reddish-brown colour and pungent odour, are acid to litmus, and non-combustible. 
Reactions :-

r. Introduce starch-potassium iodide paper, blue colouration.

2. Add water, take a portion of the solution and dilute largely, and add a few drops each of solutions of sulphanilic acid and naphthylamine hydrochloride, a red colouration is produced, due to the presence of nitrous acid in the solution.

$N . B$. If the solution is too concentrated, a yellow colour only is produced; on the other hand, the reaction is exceedingly delicate.

\section{Estimation:-}

The gases are absorbed in water, and the nitrous and nitric acids produced are estimated by the methods used in water analysis (see pages I 32 to 135 ).

Carbon dioxide.

Carbon dioxide is colourless, odourless, and slightly acid to litmus. It is non-combustible.

\section{Reaction:-}

Add lime water and shake; a milkiness is produced owing to the formation of calcium carbonate. Add hydrochloric acid; the precipitate dissolves with effervescence :-

$$
\begin{aligned}
& \mathrm{Ca}(\mathrm{OH})_{2}+\mathrm{CO}_{2}=\mathrm{CaCO}_{3}+\mathrm{H}_{2} \mathrm{O}, \\
& \mathrm{CaCO}_{3}+2 \mathrm{HCl}=\mathrm{CaCl}_{2}+\mathrm{CO}_{2}+\mathrm{H}_{2} \mathrm{O} .
\end{aligned}
$$

For methods of estimation and other particulars, see page 190 .

\section{Carbon monoxide.}

Contained in coal-gas and in larger quantities in water-gas, and is produced in coke ovens and brick kilns.

Is also produced by the incomplete combustion of fuel or by the reduction of carbon dioxide, for example, in cast-iron stoves; also present in tobacco smoke.

Carbon monoxide is colourless, odourless, and neutral to 
litmus ; it is combustible, forming carbon dioxide on burning, and is very poisonous.

\section{Reactions :-}

I. Shake with dilute blood solution (about 0.5 per cent.), take a portion of the solution and dilute it further until it has only a slight pink colour. Pour this into a test-tube, and in a similar tube put some of the original blood solution which has been diluted to the same extent, the blood solution which contains carbon monoxide will have a rose-pink tint distinctly different from the other solution.

2. Into a test-tube put some of the blood solution which has been shaken with the gas, and into another tube some of the original blood solution, and examine each with a spectroscope, in each case two absorption bands are seen in the yellow and green parts of the spectrum respectively. To each add a few drops of freshly prepared ammonium sulphide solution, and after warming slightly examine again by the spectroscope ; in the pure blood solution the two bands will have disappeared, owing to the reduction of the hæmoglobin, and will be replaced by a single broad band (not so well defined), while in the blood containing carbon monoxide the two separate bands will still be visible.

For method of estimation, see page 197 .

Carbon bisulphide vapour.

Carbon bisulphide is used as a solvent of sulphur and of rubber, and the vapour may be present in the atmosphere of certain factories.

It is colourless, has a very disagreeable odour, and is very inflammable. It is neutral to litmus.

\section{Reaction:-}

Shake with a few c.c. of absolute alcohol, add a little ammonium hydrate (.880), and transfer to a small dish. Heat for 
some time on a boiling water-bath, take part of the liquid in a test-tube and add excess of hydrochloric acid and some ferric chloride solution, a blood-red colouration is produced. Should the reaction not be obtained, heat the remainder of the liquid further and test as before.

$N . B$. It is important in this test that the ammonia and alcohol should be as concentrated as possible.

The reaction is represented by the equations:-

$$
\begin{aligned}
&{ }_{3} \mathrm{CS}_{2}+6 \mathrm{NH}_{3}+{ }_{3} \mathrm{H}_{2} \mathrm{O}=2\left(\mathrm{NH}_{4}\right)_{2} \mathrm{CS}_{3}+\left(\mathrm{NH}_{4}\right)_{2} \mathrm{CO}_{3}, \\
& \text { (thiocarbonate) } \\
&\left(\mathrm{NH}_{4}\right)_{2} \mathrm{CS}_{3}=\mathrm{NH}_{4} \mathrm{CNS}+2 \mathrm{H}_{2} \mathrm{~S}, \\
& 3 \mathrm{NH}_{4} \mathrm{CNS}+\mathrm{FeCl}_{3}= \mathrm{Fe}(\mathrm{CNS})_{3}+{ }_{3} \mathrm{NH}_{4} \mathrm{Cl} . \\
& \text { (thiocyanate) }
\end{aligned}
$$

\section{Estimation :-}

Carbon bisulphide may be estimated by absorbing in alcoholic potash, whereby potassium xanthate $\left(\mathrm{CS} . \mathrm{SK} . \mathrm{OC}_{2} \mathrm{H}_{5}\right)$ is formed, adding excess of acetic acid, then excess of sodium bicarbonate, and titrating with standard iodine solution; 127 parts of iodine correspond to 76 parts by weight of $\mathrm{CS}_{\mathbf{2}}$.

Scheme for Identification of the Commoner Gases (IN LARGE QUANTITY)

\section{Coloured:}

Chlorine, greenish-yellow ; Nitrous fumes, reddish-brown.

\section{Colourless :}

Odorous.

Test reaction to litmus.

\begin{tabular}{c|ll|} 
Alkaline : & Acid : & Neutral : \\
Ammonia, & $\begin{array}{l}\text { Hydrochloric } \\
\text { acid, }\end{array}$ & Coal-gas, \\
$\begin{array}{c}\text { Ammonium } \\
\text { sulphide }\end{array}$ & $\begin{array}{l}\text { Sulphur dioxide, } \\
\begin{array}{c}\text { Sulphuretted } \\
\text { hydrogen } \\
\text { (slightly acid) }\end{array}\end{array}$ & $\begin{array}{c}\text { Carbon } \\
\text { bisulphide }\end{array}$ \\
\end{tabular}

Odourless.

Examine separate portions for

Carbon dioxide Carbon monoxide 
Confirm the identity of the gas by as many reactions as possible.

\section{Estimation of Oxygen in Air (Hempel)}

The apparatus consists of a burette and levelling tube, an absorption pipette and a capillary tube bent twice at right angles, by means of which connexion can be made between the burette and absorption pipette, using short pieces of rubber tubing at the junctions.

The burette is graduated into roo c.c., and the upper end, which is constricted, has a glass stopcock or a clip by means of which it can be closed. The levelling tube is not graduated and is open at the top. The lower ends of both tubes are contracted and bent at right angles, and are joined together by thick-walled rubber tubing; they are supported in wooden stands.

The absorption pipette in its simplest form has two bulbs, connected by a glass tube, and a capillary tube, leading from one of the bulbs and bent into the shape of a $U$, on the side which is to be connected with the burette ; the other bulb has a wide exit tube. The bulbs contain the absorbent liquid, which in the case of the estimation of oxygen consists of pyrogallol in strong potassium hydrate solution, and the whole is mounted on a wooden stand. Frequently the pipette has four bulbs, the two extra bulbs containing water to protect the absorbent liquid from the action of the outside air.

\section{Procedure :-}

Open the burette to the air by turning the stopcock, pour water into the levelling tube and raise it until the graduated tube is full of water, then close the stopcock. - The water should be saturated with the gas which is being estimated. To take the sample of air, open the stopcock and lower the levelling tube so that air is drawn into the burette to slightly below 
the roo c.c. mark. To adjust the volume accurately, close the stopcock and squeeze the rubber tubing connecting the burette and levelling tube, until the water stands exactly at the roo c.c. mark. Then, while still compressing the rubber tubing, open the stopcock momentarily to the air and close it again. The volume will now be roo c.c. at atmospheric pressure.

Next, take the absorption pipette and by tilting it and, if necessary, blowing down the wide exit tube, force the liquid into the capillary U-tube, connect the latter with the burette by means of the bent glass tube, at the same time squeezing the rubber connexions, to exclude air as much as possible. Mark the level of the liquid in the U-tube ; after the absorption the liquid must be brought back to this mark. Now raise the levelling tube, open the stopcock and force all the air over into the pipette, close the stopcock, shake the pipette and allow to stand for five minutes. Lower the levelling tube, open the stopcock, and draw the residual gas back into the burette until the liquid reaches the mark on the U-tube, then close the stop-cock. Allow a minute for the burette to drain, hold the levelling tube so that the water stands at the same level in both tubes, and read the volume. Pass the residue of the air once more into the pipette, allow two or three minutes for absorption, bring it back, and read the volume as before. If there is any further diminution in volume, the absorption must be repeated.

The difference between roo c.c. and the final volume is the percentage of oxygen.

N.B. It should be remembered that the alkaline pyrogallol will absorb carbon dioxide as well as oxygen, so that if the gas analysed is not ordinary air, but a mixture of unknown composition, it must be passed into a pipette containing potash, and the diminution measured, before estimating oxygen.

The same apparatus can be used, by employing suitable absorbents, for the estimation of many other gases. 


\section{Carbon Dioxide in Air}

As already mentioned, carbon dioxide is present in the atmosphere to the extent of about 3 parts per 10,000, and there is very little variation in different parts of the world. It originates from chemical reactions taking place in the soil (there is always rather more carbon dioxide just above the soil), respiration, oxidation of organic matter, and mineral springs. The amount is generally large in sewer gas.

Carbon dioxide is not in itself injurious unless the quantity is very large (over 3 per cent), and 30 per cent. is said to be necessary to produce asphyxia. The quantity is, however, a convenient index of the vitiation of air by respiration or combustion, and of the efficiency of ventilation. Haldane and Osborn recommended that a limit of 12 parts of carbon dioxide per 10,000 should be adopted for factories and workshops, at about the breathing level, but that 20 parts might be permitted in cases where gas or oil were used for lighting. ("Report of the Departmental Committee on the Ventilation of Factories and Workshops," Cd. I 302, I903.)

Estimation of carbon dioxide in air.

Pettenkofer's method.

This method depends upon the reduction of the alkalinity of a solution of barium or calcium hydroxide, after exposing it to a measured quantity of the air, owing to the formation of the carbonate :-

$$
\mathrm{Ba}(\mathrm{OH})_{2}+\mathrm{CO}_{2}=\mathrm{BaCO}_{3}+\mathrm{H}_{2} \mathrm{O} \text {. }
$$

The solution of the alkali should be approximately, but not of necessity exactly, decinormal ; it is titrated with decinormal oxalic acid solution and another portion is shaken up with a measured quantity of the air and then titrated with the oxalic acid, and from the difference in the titrations the weight of carbon dioxide in the air is calculated. It is usual to express the result in volumes, so the weight of carbon dioxide is 
converted into volume and corrected for the temperature and pressure of the air at the time the sample was taken.

Required :-

stoppered bottle, capacity 3

litres or more

N/ro oxalic acid solution

graduated cylinder, 2 litres

pipette, 25 c.c.

several small dry flasks

barium hydrate solution (approximately $\mathrm{N} / \mathrm{ro}$ ) phenolphthalein

burette and stand

funnel

thermometer

\section{Procedure :-}

Take a clean and dry stoppered bottle, capacity three litres or more, into the air to be analysed, and by means of a bellows with a long tube attached pump air to the bottom of the bottle for about a quarter of a minute, then insert the stopper. Note the temperature of the air and the height of the barometer. Pipette 50 c.c. of the barium hydrate solution into the bottle, using a 25 c.c. pipette twice (do not blow down the pipette), replace the stopper quickly, and shake well ; lay the bottle on its side and roll it occasionally along the bench, in order to expose the liquid as much as possible to the air in the bottle. Continue this for half an hour, meanwhile pipette 25 c.c. of the original barium hydrate into a narrow-necked flask, using the same pipette as before, add about six drops of phenolphthalein, and titrate with decinormal oxalic acid solution until the pink colour is just discharged. After the half-hour exposure, withdraw 25 c.c. of the barium hydrate from the bottle with the pipette, run it into a narrow-necked flask, and titrate with oxalic acid solution as before. Should the neck of the bottle be too narrow to admit the pipette, pour the baryta quickly through a dry funnel into a small dry flask, in order to withdraw the 25 c.c. for titration. Ascertain the capacity of 
the bottle by filling it with water and emptying into a large graduated cylinder.

From the difference in the titrations of the original baryta and the exposed baryta, calculate the weight of carbon dioxide in the volume of air examined. From this calculate the volume of carbon dioxide under the conditions of temperature and pressure at which the sample was taken, and finally the percentage by volume.

Example of calculation:-

25 c.c. original baryta require 24.5 c.c. N/ro oxalic acid, 25 c.c. exposed baryta require 23.6 c.c. N/1o oxalic acid, capacity of bottle 3620 c.c., temperature of air $14^{\circ} \mathrm{C}$., barometric pressure $755 \mathrm{~mm}$. $5 \circ$ c.c. of original baryta require $2 \times 24.5=49$. 0 c.c. $N /$ io oxalic acid,

50 c.c. of exposed baryta require $2 \times 23.6=47.2$ c.c. $N / 1 \circ 0$ xalic acid,

difference, due to carbon dioxide, $\quad$ r.8 c.c.

I c.c. $\mathrm{N} /$ ro oxalic acid $=0.0022$ gram $\mathrm{CO}_{2}$,

r. 8 c.c. $\mathrm{N} /$ ro oxalic acid $=0.0022 \times \mathrm{r} .8=0.00396 \mathrm{gram} \mathrm{CO}_{2}$.

volume of air analysed $=3620-50$ c.c. (volume occupied by baryta),

$$
=3570 \text { c.c., }
$$

hence the weight of $\mathrm{CO}_{2}$ was 0.00396 gram in 3570 c.c: of air.

To convert weight of $\mathrm{CO}_{2}$ into volume :

I litre of hydrogen at normal temperature and pressure $\left(0^{\circ} \mathrm{C}\right.$. and $760 \mathrm{~mm}$.) weighs $0.0896 \mathrm{gram}$, therefore I c.c. of hydrogen at N.T.P. weighs 0.0000896 gram. The density of $\mathrm{CO}_{2}$ compared with hydrogen is 22 , hence

I c.c. of $\mathrm{CO}_{2}$ at N.T.P. weighs $0.0000896 \times 22 \mathrm{gram}=$ (very nearly) 0.002 gram.

Then the volume occupied by 0.00396 gram of $\mathrm{CO}_{2}$ is

$$
\text { I } \times \frac{0.00396}{0.002}=I .98 \text { c.c. at N.T.P. }
$$

To convert the volume at N.T.P. into volume at $14^{\circ} \mathrm{C}$. and 
755 mm., make use of Boyle's law and Charles' (or Gay Lussac's) law. According to Boyle's law, the volume of a gas is inversely proportional to the pressure, the temperature remaining constant ; for example, if the pressure is doubled the volume is halved.

Thus, I c.c. at $760 \mathrm{~mm}$. becomes $\mathrm{I} \times \frac{760}{755}$ c.c. at $755 \mathrm{~mm}$.

According to Charles' law, the volume of a gas increases by a definite fraction for each rise of $\mathrm{I}^{\circ}$ in temperature, this fraction being $\frac{\mathrm{I}}{273}$ for $\mathrm{I}^{\circ} \mathrm{C}$.

Thus, I c.c. at $\circ^{\circ} \mathrm{C}$. becomes $I+\frac{I}{273}$ c.c. at $I^{\circ}$ C.,

$$
\text { and I c.c. " , ", } \quad \mathrm{I}+\frac{\mathrm{I4}}{273} \text { c.c. at } 14^{\circ} \mathrm{C} \text {. }
$$

In the present example, correcting for temperature and pressure, the volume of $\mathrm{CO}_{\mathbf{2}}$ becomes :-

$$
\begin{aligned}
& \text { I. } 98 \times \frac{760}{755} \times\left(\mathrm{I}+\frac{\mathrm{I} 4}{273}\right) \\
& =\mathrm{I} .98 \times \frac{760}{755} \times \frac{273+\mathrm{I} 4}{273} \\
& =2.095 \text { c.c. in } 3570 \text { c.c. of air, }
\end{aligned}
$$

$=2.095 \times \frac{100}{3570}=0.059$ per cent. by volume, or 5.9 volumes per I0,000.

N.B.- - It is imperative that the baryta should not be exposed to the atmosphere, during transference and titration, more than can possibly be helped.

Haldane's apparatus (for carbon dioxide in air).

The apparatus is a portable one and is enclosed in a wooden case, the whole when ready for use weighing about 5 pounds.

The air burette holds about 20 c.c., and the lower part is a capillary tube graduated into roo divisions, each of which corresponds to one ten-thousandth part of the capacity of "the 
burette; this is connected by a thick-walled rubber tube with a reservoir of mercury. At the upper end of the burette is also a capillary tube which leads to a potash bulb, through a threeway tap, by means of which the burette can be connected either with the potash or with the outside air. The potash bulb is connected with a potash reservoir. Alongside the air burette is a control tube of approximately the same size and shape, the two being enclosed in a water jacket; the control tube is sealed at the lower end, while the upper end is connected with the potash reservoir through another three-way tap, which enables the control tube to be opened to the outside air. On each of the two tubes leading to the potash (from the air burette and control tube respectively) is a mark.

The mercury reservoir is hooked on to a rack and pinion arrangement, by which its height can be easily adjusted.

In using the apparatus the air is first expelled from the burette by opening the three-way tap to the atmosphere, and raising the mercury reservoir. The latter is then lowered and placed on the hook of the rack and pinion arrangement, so that a sample of the air is drawn in, and the level of the mercury falls to near the zero mark. The tap is now turned towards the potash bulb, which is filled to the mark with caustic potash or soda solution (about ro per cent.), and the sample measured with the precautions to be described below. It is then passed over into the absorption bulb, driven partially backwards and forwards two or three times, and again measured after the absorption of the carbon dioxide. The difference between the two readings gives directly the number of volumes of carbon dioxide per 10,000 in the sample of air.

The correctness of the analysis depends entirely on the avoidance of errors of various kinds in the two determinations of the volume of the enclosed air. Mistakes might be caused by slight variations in the temperature of the water, or the pressure under which the sample is measured, or in the degree of saturation with moisture of the sample. A variation of 
$0 . I^{\circ} \mathrm{C}$. in the temperature of the water in the jacket would, for instance, unless compensated, cause an error of fully 3 volumes per 10,000 in the analysis.

In order to have a sharp index of pressure under which the air is measured, the level, not of the mercury, but of the potash solution in the narrow bore tubing of the absorption bulb, is taken as the index of pressure. At the first measurement the level is accurately adjusted to the mark by raising or lowering the mercury by means of the rack and pinion arrangement. At the second reading the potash level is again adjusted in the same way. As the potash has a specific gravity of only about one-twelfth of that of mercury its level is a very delicate index of the pressure. A difference of one ten-thousandth part in the pressure would correspond to a difference of nearly I $\mathrm{mm}$. in the level of the potash solution, which would be very evident to the eye.

To compensate for variations in temperature of the water jacket the control tube is employed. This tube communicates with the potash through a narrow bore glass tube, and before the first measurement is made the level of the potash in the tube is adjusted to the mark by lowering or raising the potash reservoir, which slides up and down in a loosely fitting cork. At the second measurement the same precaution is taken, so that the air in the control tube occupies exactly the same volume as at the first measurement. As an alteration of temperature or of pressure would affect the pressure to an equal extent in the burette and control tube, it is evident that the adjustment of the level of the potash reservoir compensates exactly any error which the alteration of temperature or of pressure would cause in the reading of the burette.

Before the adjustments of the potash levels are made, the water in the jacket is thoroughly mixed by blowing air through it by means of a tube. This manipulation is absolutely essential. As errors may sometimes arise from the potash tubes not being equally wetted above the marks, the rubber 
tubing should be squeezed before a reading is taken, so as to momentarily raise the potash level by about $I$ inch. If the levels do not rise and return sharply and equally there is grease or liquid in the taps or connecting tubes.

In order to obviate error due to variations in the saturation of the air, both the burette and the control tube are left with a little visible moisture inside.

At the end of an analysis, the taps must be turned so as to close the communications between the potash and the burette and control tube ; otherwise potash may be sucked in if there is any considerable fall of temperature or rise of barometric pressure.

The manipulations required during the analysis may be recapitulated as follows: (I) Open the tap of the control tube to the air for a moment, and then turn it so as to connect the control tube and the potash. (2) Turn the tap of the burette so as to connect the burette and the potash. (3) Squeeze the rubber tube of the potash reservoir so as to raise the potash level about an inch above the marks, and see that the level of the potash alters sharply and about equally in the two tubes. (4) Blow air through the water jacket. (5) Raise or lower the potash reservoir and the mercury reservoir (by means of the rack and pinion) until the potash is exactly at the two marks. (6) Read off the mercury level on the scale of the burette to 0.2 of a division. (7) Raise the mercury so as to drive the air into the potash bulb, then lower it a little and raise it twice again so as to wash any carbon dioxide in the connecting tubing into the potash bulb. (8) Return the air to the burette. (9) Blow air through the water jacket. (г) Squeeze the tubing and adjust the two potash levels as before, and read off the mercury level. The first reading subtracted from the second gives the result in volumes per 10,000. (II) Turn the two taps so as to close the communication with the potash bulbs.

About four minutes are needed for the whole process. 
The apparatus can also, by a suitable attachment, be used for the analysis of samples of air collected in small bottles.

(The apparatus is fully described, with diagrams, in the Report on the Ventilation of Factories and Workshops, mentioned above, and in Haldane's "Methods of Air Analysis.")

\section{CARbon Monoxide}

(From papers by Haldane in the "Journal of Physiology ")

The symptoms caused by carbon monoxide depend upon the extent to which the hæmoglobin has been saturated and are due solely to deficiency in the oxygen percentage of the blood.

When air containing carbon monoxide is breathed, about half the quantity of the latter which is present is absorbed, and sensible symptoms are produced in an adult man when about 660 c.c. of the gas have been inhaled. The time required for the symptoms to appear is about ten times as long in a man as in a mouse, hence it is possible with safety to use a mouse as an indicator of the presence of poisonous quantities of carbon monoxide in air.

Distinct symptoms, appreciable during rest, are not produced by carbon monoxide in otherwise normal air until about 0.05 per cent. of the gas is present. With about 0.2 per cent. urgent symptoms are occasioned. The disappearance of carbon monoxide from the blood when fresh air is again breathed is always much slower than the absorption of the gas.

\section{Method of estimation in air.}

The method used by Haldane depends upon the fact that when a blood solution is well shaken with air containing carbon monoxide, the proportion of the hæmoglobin which combines with the curbon monoxide varies with the percentage of carbon monoxide in the air. A known volume of the original blood solution is taken and a carmine solution of suitable strength is added to it from a burette until equality of pinkness is 


\section{8}

\section{PUBLIC HEALTH CHEMISTRY}

established, firstly with the solution which has been shaken with the air, and afterwards with the same blood solution fully saturated with carbon monoxide. From the two results the percentage saturation of the blood solution which was shaken with the sample of air can be determined, and from this the amount of carbon monoxide in that air may be calculated.

The blood solution required is prepared by measuring 0.75 c.c. of blood into 150 c.c. of distilled water to which about 30 drops of strong ammonia have been added.

The sample of air is collected in a bottle of about roo c.c. capacity by sucking the air out of the bottle through a long piece of tubing and quickly putting in the stopper. The bottle is then inverted in a vessel containing the blood solution, and the stopper removed, and by introducing the end of a curved glass tube through the solution into the bottle, sufficient air is allowed to pass out to enable about 5 c.c. of the blood solution to enter the bottle. The stopper is then replaced, the bottle wrapped in a duster, to shield it from light, and shaken as vigorously as possible for five minutes.

To determine the percentage saturation of the hæmoglobin, the solution is poured into a test-tube (No. I) about 0.6 inch in diameter, and 5 c.c. of the original blood solution measured into another exactly similar tube (No. 2). Carmine solution (prepared as below) is added from a burette to the normal blood until the two liquids appear equal in tint. The blood in tube No. I is now saturated with carbon monoxide by shaking with coal-gas, and more carmine solution is added to tube No. 2 until equality is once more restored.

The following example illustrates the method of calculating the result :5 c.c. of blood solution taken.

Carmine required for first point of equality r.05 c.c.

$$
\text { " , ", second ", "7.0 " }
$$

Thus, to produce the tint of total saturation 7.0 c.c. carmine had to be present in $7+5=12$ c.c. of the mixture, while to produce the tint of the solution from the bottle 1.05 c.c. of carmine were 
present in $1.05+5=6.05$ c.c. of the mixture. The percentage saturation $(x)$ is given by the proportion :-

$$
\frac{7}{\mathrm{I} 2}: \frac{\mathrm{I} .05}{6.05}=100: \mathrm{x} \text {, whence } \mathrm{x}=29.8 \text {. }
$$

The percentage of carbon monoxide in the sample of air may be calculated from the formula :-

$$
\mathrm{P}=\frac{\mathrm{S} \times 0.055}{100-\mathrm{S}},
$$

where $\mathrm{P}=$ percentage of carbon monoxide, and $\mathrm{S}=$ percentage saturation of the hæmoglobin.

A stock carmine solution is made by dissolving about 0.5 gram of carmine in strong ammonia and diluting to roo c.c. with water. Sufficient of this is used with water to prepare a solution which when added to a blood solution will exactly reproduce both the depth and the tint of the same blood solution saturated with carbon monoxide. This is found by experiment.

\section{Quantities of Gases likely to CaUSe Rapid INJURY}

\begin{tabular}{|c|c|}
\hline Carbon bisulphide & 0.001 \\
\hline Chlorine . & 0.004 \\
\hline Sulphur dioxide & 0.05 \\
\hline Sulphuretted hydrogen & 0.07 \\
\hline Hydrochloric acid & 0.15 \\
\hline $\begin{array}{l}\text { Carbon monoxide. } \\
\text { Ammonia }\end{array}$ & $\begin{array}{ll} & 0.2(=\text { about } 2 \text { to } 4 \text { per } \\
0.25 \quad \text { cent. coal-gas) }\end{array}$ \\
\hline Carbon dioxide & 20 \\
\hline
\end{tabular}
(According to Lehmann, Taylor and other authorities)

Phosphoretted hydrogen is said to be rapidly fatal to small animals in quantities of 0.02 per cent. and upwards.

\section{Estimation of Dust in Air (Haldane)}

A glass tube about two and a half inches long and half an inch in diameter is drawn out at one end, and a small plug of 
cotton wool is pushed firmly down to the constricted part. Air, dried by passing through a calcium chloride or sulphuric acid absorption tube, is drawn through the cotton wool for some time to dry it, then the end of the tube is corked and the weight ascertained.

At the place where it is desired to determine the dust, the cork is removed and the tube attached by a piece of rubber tubing to the nozzle of an exhausting syringe taking about 200 c.c. or more of air at each stroke, and provided with thoroughly efficient valves. The syringe is held horizontally and a sufficient quantity of air drawn through. The quantity is measured by counting the strokes of the syringe, the capacity of which has been measured beforehand by sucking air through a tube from a measuring cylinder inverted over water.

Care must be taken that at the end of each stroke time is given for the full charge of air to enter, as the resistance of the cotton wool causes a slight delay.

The plug is now dried in the same way as before the collection of the dust, i.e. by drawing dry air through it for some time, after which the tube is corked and re-weighed, the difference in weight being due to the dust collected.

In connection with the study of impurities in the air, the Report of the Committee appointed for the Investigation of Atmospheric Pollution (February, 1916) is of interest.

The interpretation of the expression "Atmospheric Pollution," adopted by the Committee, is : such matter, solid, liquid or gaseous, as reaches the surface of the earth or falls upon the buildings, etc., either by its own gravity or with the assistance of rain.

An analysis of dust filtered out of London air gave the following results :

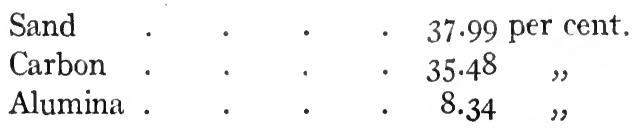




\begin{tabular}{|c|c|c|c|}
\hline Ammonium sulphate & . & \multicolumn{2}{|c|}{5.77 per cent } \\
\hline Calcium sulphate . & . & 5.09 & ", \\
\hline Calcium carbonate & . & 2.17 & ", \\
\hline Ferric oxide & . & 2.44 & , \\
\hline Magnesium carbonate & . & 0.33 & ", \\
\hline Sodium chloride $\quad$. & . & trace & \\
\hline Fibrous matter & & 0.95 & " \\
\hline $\begin{array}{c}\text { Tar (by extraction } \\
\text { carbon bisulphide) }\end{array}$ & . & I.49 & " \\
\hline
\end{tabular}

Of the mineral matter, the sulphates are probably of the greatest importance, because of their destructive effect upon stonework. The vapours to which the Committee attached the most importance were the tarry hydrocarbons, as this tarry material attaches itself to the particles of carbon and renders them adhesive and not easily detached by rain. The gases to which principal attention was directed were the oxides of sulphur and ammonia.

The Committee pointed out that apart from the polluting and destructive effects of these substances, the loss of valuable material must be very great.

The method adopted in the investigation was the collection of the rain and its deposit on gauges of known area, the water and the insoluble matter being separately analysed at the end of each month. The gauges were placed in suitable localities in different parts of the country, so that the results obtained were representative of town, rural, manufacturing and other districts.

The results were recorded in the following manner:-

Rainfall

Total solid matter

Insoluble matter $\left\{\begin{array}{l}\text { tar } \\ \text { other carbonaceous matter } \\ \text { ash }\end{array}\right.$ 
Soluble matter $\left\{\begin{array}{l}\text { organic } \\ \text { inorganic }\end{array}\left\{\begin{array}{l}\text { sulphates } \\ \text { chlorides } \\ \text { ammonia }\end{array}\right.\right.$

The tar in the atmosphere is produced by the imperfect combustion of coal or wood, and possibly also by the tarring of roads; the "other carbonaceous matter" may consist of coal dust, fragments of animal and vegetable matter, etc.; insoluble ash includes dust of mineral origin carried by the wind; the soluble matter contains acids and salts, dissolved in the rain water, which are derived from the combustion of coal. The "soluble organic matter" was determined by loss on ignition and would therefore include ammonium salts, and carbon dioxide from carbonates. Chlorides may be derived from sea water spray, and ammonia is produced along with tar by the combustion of coal, and by the decay of animal refuse.

The results were expressed as "Tons per square kilometre" per month and included the following :-

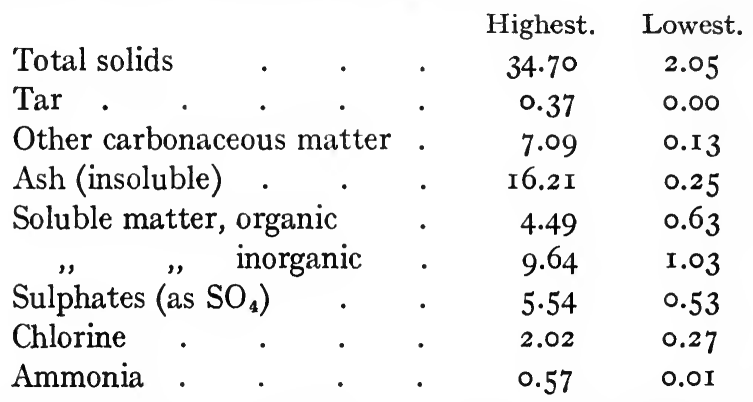

From the results obtained, an average atmosphere may be expected to deposit upon a square kilometre during any one winter month 15 tons of solid matter, including 0.15 ton of tarry matter, 3 tons of other carbonaceous matter, 6 tons of insoluble inorganic dust, 3 tons of sulphuric acid, $I$ ton of chlorine and 0.3 ton of ammonia.

I ton per square kilometre $=9$ pounds per acre $=2.59$ tons per square mile. 


\section{CHAPTER XI}

\section{DISINFECTANTS}

Disinfectants may be classified as follows :-

I. Oxidizing agents ;

2. Reducing agents ;

3. Corrosives and coagulants of albumen.

Besides true disinfectants, there are also :-

4. Antiseptics ;

5. Deodorants.

I. Examples of oxidizing agents are :-

Permanganates (Condy's Fluid contains sodium permanganate);

Hydrogen peroxide (contained in Sanitas);

Chlorine, bromine and iodine;

Bleaching powder ("chloride of lime") and hypochlorites; solutions containing 0.5 per cent. of available chlorine are generally employed. Chlorine is also used for sterilizing drinking water, one part per million being the usual quantity.

Antiformin consists of a solution of chlorinated soda and caustic soda, 2 to 5 per cent. being a strong germicide. It has great power of penetration by reason of the solvent action of the caustic soda.

Chloramine-T., an organic compound containing chlorine combined directly with nitrogen, has been much used of late as a disinfectant for wounds, also mixtures of sodium hypochlorite and boric acid.

From the nature of their chemical action, disinfectants of this class are only effective when there is not much organic matter present, unless used in large excess. 
2. Examples of reducing agents are :-

Sulphurous acid and its compounds (including the fumes of burning sulphur). In using sulphurous acid plenty of moisture must be present; the disadvantages are the bleaching action and the corrosive effect on metals.

Sulphurous acid is also useful for killing vermin.

3. Corrosives, etc.

This class includes a large number of disinfectants derived from coal tar, for example phenol (carbolic acid), cresols and a variety of proprietary disinfectants. Many of the last named contain soap or other emulsifying agent. Emulsions are found to have greater disinfecting power than simple solutions, probably owing to the large surface exposed.

The temperature at which disinfectants are used is of importance, at a higher temperature their action is usually quicker; as an example it has been found that anthrax spores which survived treatment with 5 per cent. carbolic solution for $3^{6}$ days at the room temperature were destroyed in half an hour at $55^{\circ} \mathrm{C}$. and in 3 minutes at $75^{\circ} \mathrm{C}$. (Rosenau, "Preventive Medicine and Hygiene "). The medium in which the bacteria are contained must also be taken into account, for example, it requires a stronger solution to kill organisms in blood serum than in water.

Izal contains 45 per cent. of phenols and tar oils ; Jeyes' Fluid contains cresols with resin soap as an emulsifying agent; Cyllin contains about 60 per cent. of oxidized hydrocarbons and is said to be neither caustic nor toxic; Lysol is prepared from tar oil and linseed oil saponified with caustic potash, and contains about $5 \circ$ per cent. of cresols.

Other disinfectants of this class are :-

Formaldehyde, of which about 0.5 per cent. kills most organisms ;

Formalin, which is a 40 per cent. solution of formaldehyde in water; 
Paraform, which consists of polymerized formaldehyde, used for fumigation, as it produces formaldehyde on heating.

Formaldehyde is used both in the gaseous condition and in solution, but the gas has not much power of penetration. It combines directly with protoplasm and is non-poisonous.

Permanganate-formalin has been recommended; the permanganate is placed in a vessel and formalin poured on to it, oxidation takes place with evolution of heat and formaldehyde gas is liberated.

Mercuric chloride (corrosive sublimate or perchloride of mercury) is most effective when mixed with free hydrochloric acid. A Local Government Board formula gives the following quantities :-

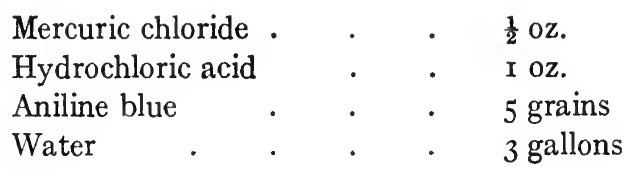

which produces a solution of $\mathrm{I}$ in 980 . Mercuric chloride combines with albuminous substances, and should not be used for disinfecting materials containing much organic matter unless the solution is acidified. It is also precipitated by soap.

Mercuric iod:de is best employed as the double salt with potassium iodide.

Silver nitrate, zinc chloride, copper sulphate, alcohol and lime are other disinfectants of this class.

Notter and Firth ("Theory and Practice of Hygiene") recommend from experimental data the following strengths for use with excreta :-

Mercuric chloride $\mathrm{I}$ in 50 , Mercuric chloride with acid $\mathrm{I}$ in $\mathrm{I} 80$ Phenol . I in 20, Potassium permanganate $I$ in 80 Formalin . I in I4, Izal . . . . I in 50 Cyllin . I in Ioo, Lysol . . . $\mathrm{I}$ in 25 
4. Antiseptics.

Most chemical disinfectants when diluted have antiseptic properties, i.e. they inhibit the growth of bacteria. Many antiseptics are also met with as food preservatives, e.g. boric acid, salicylic acid, benzoic acid, sodium fluoride. Others are iodoform, naphthalene and essential oils such as oil of cloves and oil of eucalyptus.

5. Deodorants. Examples are :-

Charcoal, which has the power of absorbing large quantities of gases; oxidizing agents, such as permanganates, which destroy sulphuretted hydrogen ; and metallic compounds, such as lime, copper sulphate and ferrous sulphate, which absorb sulphuretted hydrogen.

\section{Bleaching powder}

Bleaching powder, also known as "chloride of lime," is pre-pared by the action of chlorine gas on slaked lime, and consists of calcium chlor-hypochlorite, $\mathrm{Ca} \backslash \mathrm{OCl}$, together with unchanged calcium hydrate, the composition of the commercial article being approximately represented by the formula :-

$$
{ }_{2} \mathrm{CaCl} . \mathrm{OCl} \text {. } \mathrm{Ca}(\mathrm{OH})_{2} \text {. }
$$

On treatment with water, it is split up into the chloride and hypochlorite : ${ }_{2} \mathrm{CaCl} . \mathrm{OCl}=\mathrm{CaCl}_{2}+\mathrm{Ca}(\mathrm{OCl})_{2}$.

By reason of the ease with which it gives up its oxygen to reducing substances, bleaching powder is a powerful oxidizing agent, and it is to this fact that it owes much of its disinfectant power.

On treatment with acids chlorine gas is evolved, and in ordinary air slow decomposition goes on with the production of hypochlorous acid, probably owing to the action of carbon dioxide. The following equations represent some of the reactions involved :- - 


$$
\begin{aligned}
& \mathrm{CaCl} . \mathrm{OCl}+\mathrm{HCl}=\mathrm{CaCl}_{2}+\mathrm{HOCl}, \\
& \mathrm{HOCl}+\mathrm{HCl}=\mathrm{Cl}_{2}+\mathrm{H}_{2} \mathrm{O}, \\
& { }_{2} \mathrm{CaCl} . \mathrm{OCl}+\mathrm{CO}_{2}+\mathrm{H}_{2} \mathrm{O}=\mathrm{CaCl}_{2}+\mathrm{CaCO}_{3}+{ }_{2} \mathrm{HOCl} .
\end{aligned}
$$

The strength of bleaching powder may be determined either by its oxidizing power or by the quantity of iodine which it liberates from potassium iodide, the result in either case being expressed as percentage of "available chlorine." For the former method, the reducing agent generally used is arsenious oxide, the reaction being represented by the equation :-

$$
{ }_{2} \mathrm{CaCl} . \mathrm{OCl}+\mathrm{As}_{2} \mathrm{O}_{3}={ }_{2} \mathrm{CaCl}_{2}+\mathrm{As}_{2} \mathrm{O}_{5} \text {. }
$$

A standard solution of arsenious oxide is employed and the indicator used is starch-potassium iodide paper, this producing a blue colour with a drop removed from the liquid, so long as any undecomposed hypochlorite remains.

Preparation of decinormal solution of arsenious oxide.

The reaction can be represented in a simplified form as follows :-

$$
\begin{array}{cc}
\underset{(2 \times 75)+(3 \times 16)}{\mathrm{As}_{2} \mathrm{O}_{3}}+\underset{(2 \times 16)}{\mathrm{O}_{2}} \\
=198 & =3^{2}
\end{array}=\mathrm{As}_{2} \mathrm{O}_{5},
$$

from which it is evident that 198 parts by weight of arsenious oxide combine with $3^{2}$ parts by weight of oxygen ; the equivalent of $\mathrm{As}_{2} \mathrm{O}_{3}$ is the weight which combines with 8 parts of oxygen ( $=\mathrm{I}$ of hydrogen), that is $\frac{198}{4}=49 \cdot 5$, hence to prepare a decinormal solution 4.95 grams must be made up to rooo c.c. Arsenious oxide is not very soluble in water, and in order to dissolve it sodium carbonate is added and the mixture is heated, whereby sodium arsenite is formed.

$$
\text { I c.c. } \mathrm{N} / \mathrm{ro} \mathrm{As}_{2} \mathrm{O}_{3}=0.00355 \text { gram } \mathrm{Cl} \text {. }
$$

To prepare the bleaching powder for titration, it is not sufficient to shake it up with water, it must be repeatedly 
triturated with small quantities of cold water ; these are poured into a graduated flask, and the whole made up to a definite bulk, an aliquot part of the liquid being taken for the titration.

Required:-

burette and stand

beakers

graduated flasks, $25^{\circ}$ and 500 c.c.

mortar and pestle

pipette, 25 c.c.

long glass rod (rubber-tipped)

funnel

weighing-bottle

wash-bottle

watch-glass arsenious oxide sodium carbonaté starch - potassium iodide papers

\section{Procedure :-}

Weigh 1.237 grams of arsenious oxide on a watch-glass, transfer to a beaker with about 200 c.c. of water, add 5 grams of anhydrous sodium carbonate and heat, without actually boiling, until the solution is clear. Transfer to a $25^{\circ}$ c.c. graduated flask, washing out the beaker with a small quantity. of water, cool completely and make up to bulk.

Weigh 5 grams of bleaching powder in a weighing-bottle, transfer the powder to a mortar, add a few c.c. of cold water and grind with a pestle to a thin cream; add more water, stir and allow to settle for a minute. Pour off the liquid through a funnel into a 500 c.c. graduated flask, repeat the triturations several times with fresh quantities of water, decanting the liquid into the flask, until finally all the powder has been transferred. These operations should be performed as quickly as possible. Mix, pipette 25 c.c. of the turbid liquid into a beaker and titrate with decinormal arsenious solution, stirring meanwhile with a long glass rod tipped with rubber tubing. Remove a drop of the liquid from time to time with the rod 
and place it on a piece of starch-potassium iodide paper, continuing the titration until the blue colour is no longer produced, showing that all the hypochlorite has been decomposed. Repeat the titration using fresh solution and running in the greater part of the arsenic solution before testing; perform a third titration which should agree closely with the second.

Example of calculation:-

The titrations were (I) less than 24 c.c. (2) 22.9 c.c. (3) 23.I c.c. average of $(2)$ and (3) 23.0 c.c.,

available chlorine $=23.0 \times 0.00355$ gram in 25 c.c. of solution, $=23.0 \times 0.00355 \times 20$ gram in 500 c.c. of solution,

$=23.0 \times 0.00355 \times 20 \times 20$ grams in 100 grams of bleach,

$=32.7$ per cent.

Bunsen's method.

To a portion of the bleaching solution, prepared as above, water is added, then excess of potassium iodide and some dilute acetic acid. Iodine is liberated, in a quantity equivalent to the amount of available chlorine, and is titrated with standard sodium thiosulphate solution.

Required:-

solution of bleaching powder, potassium iodide prepared as in the last N/ro sodium thiosulphate experiment

flask solution acetic acid dil. pipette, 25 c.c. starch solution graduated cylinder, 50 c.c.

\section{Procedure :-}

Pipette 25 c.c. of the bleach solution, after mixing, into a 
flask, add about 50 c.c. of water and a gram of potassium iodide (or ro c.c. of a ro per cent. solution) and titrate with decinormal thiosulphate solution, until the yellow colour has almost disappeared. Add starch solution and continue the titration until the blue colour is just discharged.

$$
\text { I c.c. } \mathrm{N} / \mathrm{rO} \mathrm{Na}_{2} \mathrm{~S}_{2} \mathrm{O}_{3}=0.00355 \text { gram } \mathrm{Cl} \text {. }
$$

\section{Carbolic powder}

Carbolic disinfectant powders are prepared by incorporating carbolic acid, more or less crude, with some solid material which will absorb it. The solid basis should be a neutral substance; kieselguhr, a siliceous earth, is frequently employed for the purpose. Occasionally lime is used, but this combines with the phenols, forming calcium phenate, and the resulting powder is not so efficient.

In addition to ordinary phenol, $\mathrm{C}_{6} \mathrm{H}_{5} \mathrm{OH}$, higher homologues such as the cresols, $\mathrm{C}_{6} \mathrm{H}_{4} \cdot \mathrm{CH}_{8} \cdot \mathrm{OH}$, are generally present, as well as some neutral tar oils. A good carbolic powder should contain 15 per cent. of total phenols, mixed with a neutral basis. Some disinfectant powders also contain sulphites.

A convenient method of analysis is by dry distillation, the phenols and any neutral oils being removed along with water. As phenols are to some extent soluble in water, the distillate is shaken with a saturated solution of salt in order to render them insoluble, after which the total volume of phenols and neutral oils is measured. The oily layer is separated from the brine and is shaken with 9 per cent. sodium hydrate solution, which dissolves the phenols, and the alkaline solution is removed and acidified, when the phenols are again set free and can be measured over brine as before.

Should neutral oils be absent there will be nothing insoluble in soda and the whole of the volume first measured is calculated as phenols. If the powder contains sulphites, sulphur dioxide is evolved during the distillation and can be recognized by its odour and by the usual chemical reactions. 
Required :-

hard glass retorts about 400 c.c. flask about roo c.c. burette with glass stopcock, fitted with cork

funnel

spatula

filter papers saturated brine

sodium hydrate, 9 per cent.

hydrochloric acid conc. common salt, finely ground

\section{Procedure :-}

Test the reaction of the powder by placing a few particles on a litmus paper and moistening with water; if the powder is alkaline, it must be acidified as follows :-Take 50 grams and grind in a mortar with a mixture of equal volumes of sulphuric acid and water, adding the liquid $a$ few drops at a time and taking care that the powder is not appreciably warmed. Continue the addition of the sulphuric acid solution until the powder is acid to litmus, then distil as below. If the powder is not alkaline, the above treatment is omitted.

Put 50 grams of the powder in a hard glass retort which has a wide tubulure, point the end of the retort upwards while filling, to prevent powder lodging in the neck; the retort should be a long one, no condenser being then necessary. Heat carefully over a bunsen flame, which should be kept in constant motion; phenols distil over, accompanied by any neutral tar oils and water. Collect the distillate in a small flask, placed over the end of the retort, and continue heating until no more liquid comes over, then warm the neck with the flame, in order to drive down any liquid remaining in it. Transfer the distillate to a burette, rinse the receiver with a small quantity of saturated brine and add it to the distillate; cork the burette, shake and allow to stand; measure the volume of the upper layer, which consists of phenols, and neutral oils (if any). Run off the brine through the tap and to the residue in the burette add about twice its volume of sodium hydrate solution 
(9 per cent.). Shake and allow to stand, if a clear solution is obtained, neutral oils are absent. If the solution is not clear, filter into a flask, wash any insoluble portion with a small quantity of soda, pouring this over the filter, and wash the filter with water.

Rinse the burette with water and allow to drain.

To the alkaline solution of the phenols add strong hydrochloric acid, a few drops at a time, and cool the flask in water, until the mixture is acid to litmus, then add powdered salt and shake. Continue the addition of salt until the solution is saturated. Run the liquid back into the burette, wash out the flask with saturated brine, pouring it into the burette, then allow to stand, until the phenols have separated in a clear layer; read the volume.

The percentage of phenols $=$ volume $\times 2 \times 1.05$ (sp. gr. of phenol).

Commercial carbolic acid can be examined by a similar method to the above, water being separated by treatment with brine and neutral oils by sodium hydrate solution; unless the acid is tarry, distillation is not necessary.

In dilute solutions phenol is generally estimated by means of the reaction with bromine water, whereby tribromphenol, $\mathrm{C}_{6} \mathrm{H}_{2} \mathrm{Br}_{3} \mathrm{OH}$, is precipitated. A measured portion of the solution is treated with bromine water (or a solution of bromine in sodium hydrate, and hydrochloric acid), and after shaking and allowing to stand the excess of bromine is estimated by adding potassium iodide and titrating the liberated iodine with standard sodium thiosulphate solution, as in the determination of free chlorine (see page 209).

The reaction is :-

$$
\mathrm{C}_{6} \mathrm{H}_{5} \mathrm{OH}+{ }_{3} \mathrm{Br}_{2}=\mathrm{C}_{6} \mathrm{H}_{2} \mathrm{Br}_{3} \mathrm{OH}+3 \mathrm{HBr} \text {, }
$$

94 parts of phenol taking up 480 parts of bromine. A portion of the bromine solution must be standardized before use, and from the quantity of bromine remaining after the treatment of the phenol solution, the amount of phenol can be calculated. 


\section{Estimation of formaldehyde in formalin}

A measured quantity is treated with hydrogen peroxide in presence of a known amount of alkali; the formaldehyde is oxidized to formic acid, which neutralizes some of the alkali, and by titrating the excess of alkali remaining, the quantity of formaldehyde, in grams per 100 c.c., is found.

If the percentage by weight (grams per Ioo grams) is required, a weighed quantity of the sample is taken for the estimation.

Required:-

$\begin{array}{ll}\text { conical flask } & \text { N/r sodium hydrate solution } \\ \text { graduated flask, 50 c.c. } & \text { N/I sulphuric acid solution } \\ \text { burette and stand } & \text { hydrogen peroxide (ro vol.) } \\ \text { pipettes, 5, 25 and 50 c.c. } & \text { litmus solution } \\ \text { graduated cylinder, 50 c.c. } & \end{array}$

Procedure (for ordinary strong formalin) :-

Pipette 25 c.c. of the sample into a 50 c.c. graduated flask and make up to the mark with water. Mix, and transfer 5 c.c. to a conical flask into which 50 c.c. of normal sodium hydrate solution, accurately measured with a pipette, has previously been placed. Run in 50 c.c. of hydrogen peroxide (which can be measured in a cylinder) from a tap-funnel very slowly with continual shaking, taking about three minutes over this operation, mix well and allow to stand two or three minutes. Add sufficient litmus solution to tint the liquid and titrate the excess of alkali with normal sulphuric acid solution.

Equivalents

$$
\mathrm{H} . \mathrm{CHO}+\mathrm{H}_{2} \mathrm{O}_{2}=\mathrm{H} \cdot \mathrm{COOH}+\mathrm{H}_{2} \mathrm{O} \text {. }
$$

I c.c. $\mathrm{N} / \mathrm{I} \mathrm{NaOH}=0.046$ gram $\mathrm{H} . \mathrm{COOH}=0.030$ gram $\mathrm{H} . \mathrm{CHO}$.

Example of calculation:-

Quantities used as above.

$\mathrm{N} / \mathrm{I} \mathrm{H}_{2} \mathrm{SO}_{4}$ required $=18.5$ c.c. 
Formaldehyde $=(50-18.5) \times 0.03 \times 10 \times 4=37.8$ grams per Io० c.c.

Of dilute solution of formaldehyde (less than 20 per cent.) take ro c.c. and treat with hydrogen peroxide as above, but the flask should be corked and allowed to stand about ten minutes before titration. The acidity of the hydrogen peroxide should be ascertained and allowed for.

For other methods used for dilute solutions of formaldehyde, see Sutton's "Volumetric Analysis."

\section{Estimation of permanganate}

The estimation of oxalic acid by means of standard potassium permanganate has already been described (see page 23), by the reverse process the strength of a permanganate solution can be determined.

Required :-

burette and stand

pipette, ro c.c.

graduated cylinder, 50 c.c.

beaker
N/ro oxalic acid solution sulphuric acid dil.

\section{Procedure:-}

Pipette ro c.c. of decinormal oxalic acid solution into a beaker, dilute with distilled water and add 20 c.c. of dilute sulphuric acid. Heat nearly to boiling and titrate with the permanganate solution until just pink. If necessary, take a larger quantity of the oxalic acid solution for the second titration.

ro c.c. $\mathrm{N} /$ io oxalic acid= ro c.c. $\mathrm{N} / 10 \mathrm{KMnO}_{4}=0.0316$ gram $\mathrm{KMnO}_{4}$, hence the volume of permanganate solution required in the titration (if ro c.c. of the oxalic acid solution were used) contains 0.0316 gram of potassium permanganate, and from this the percentage, or parts per Iooo, can readily be calculated. 


\section{Methods of recognition of disinfectants}

\section{Permanganates.}

I. Colour.

2. Colour discharged by reducing agents (with sulphuric acid), e.g. ferrous salts, sulphites.

Hypochlorites (bleaching powder, chloramine-T., etc.).

I. Odour : add sulphuric acid; chlorine is evolved.

2. Starch-potassium iodide paper rendered blue.

3. Oxidizing action: add the disinfectant to a mixture of ferrous ammonium sulphate, potassium ferrocyanide, and hydrochloric acid; the light blue precipitate is changed to Prussian blue (ferric ferrocyanide).

Hydrogen peroxide.

I. Starch-potassium iodide paper rendered blue.

2. Add dilute sulphuric acid, $\mathrm{r}$ or 2 c.c. of ether and a drop of potassium bichromate, and shake; the ethereal layer becomes blue, owing to the oxidation of chromic acid to perchromic acid.

\section{Sulphites.}

I. Add dilute hydrochloric acid and warm; odour of sulphur dioxide, vapour changes the colour of potassium bichromate to green chromic sulphate (see page 184 ), and discharges the colour of potassium permanganate solution.

2. Treat with bromine water or potassium permanganate solution; sulphuric acid is produced. Then add hydrochloric acid and barium chloride solution; white precipitate of barium sulphate is thrown down.

\section{Formalin.}

I. Odour.

2. Add silver nitrate solution and a drop of ammonium. hydrate, and heat; a mirror of silver is produced. 
3. Add a few drops of a 5 per cent. solution of carbolic acid and pour concentrated sulphuric acid down the side of the tube ; a crimson colour appears at the junction of the liquids.

Phenols (carbolic acid).

I. Odour.

2. Add ferric chloride solution; violet colour produced.

3. To dilute solution add bromine water; a pale yellow (almost white) precipitate, soluble in excess of phenol, results. It consists of tribromphenol $\left(\mathrm{C}_{6} \mathrm{H}_{2} \mathrm{Br}_{3} \mathrm{OH}\right)$.

\section{Mercuric chloride.}

I. To solution add potassium iodide solution; red precipitate of mercuric iodide is produced. Add more potassium iodide ; the precipitate redissolves.

2. To solution add dilute hydrochloric acid and sulphuretted hydrogen solution (or gas); black precipitate produced, which after filtration is unchanged by treatment with hot nitric acid solution ( $\mathrm{I}$ to $\mathrm{I}$ ).

3. The solution gives the ordinary reaction for chlorides, with silver nitrate.

\section{RAG FLOCK}

In I9Io a report on Rag Flock by Dr Farrar was published by the Local Government Board (see Appendix, page 239), following on a report by Dr Parsons in 1885. From Dr Farrar's investigation, it appeared that flock was frequently manufactured, for bedding and upholstery, from rags and cast-off clothing in a most filthy condition; it was stated that "the greater part of the rags bought by the flock manufacturer are torn up into flock and sold to the bedding manufacturer or upholsterer, without undergoing any process of cleansing or sterilization whatever." Also "the proportion of unwashed flock used for bedding alone may safely be estimated at not less than 70 per cent." It was further pointed out that there 
is a danger that unwashed flock may when sold harbour vermin or parasites.

In I9I I the Rag Flock Act was passed, making it an offence to sell flock manufactured from rags, or to use for the purpose of making any article of upholstery, cushions or bedding, flock manufactured from rags, unless the flock conforms to such standard of cleanliness as may be prescribed by regulations made by the Local Government Board.

By the Rag Flock Regulations, 1912, " flock shall be deemed to conform to the standard of cleanliness . . . when the amount of soluble chlorine in the form of chlorides, removed by thorough washing with distilled water at a temperature not exceeding $25^{\circ} \mathrm{C}$. from not less than 40 grams of a well-mixed sample of flock, does not exceed 30 parts of chlorine per 100,000 parts of the flock."

The chlorine may be estimated by concentrating the aqueous extract and precipitating with silver nitrate, the silver chloride being weighed. The ordinary method of titration of chlorides, using potassium chromate as indicator, is not satisfactory, probably owing to the presence of dissolved substances which reduce the chromate, but Volhard's method can be employed (see Sutton's "Volumetric Analysis"). 


\section{APPENDIX}

\section{SPecial Solutions Required}

Milk analysis.

Pavy's solution. Dissolve 4.I57 grams of pure copper sulphate in water and add a cold solution of 21.6 grams of Rochelle salt and I 8.4 grams of caustic soda. To the solution add 300 c.c. of ammonium hydrate (.880) and make up to 1000 c.c.

B.P. quantitative limit test for arsenic.

Solution of arsenic As $T$.

Hydrochloric solution of arsenic (B.P.) . I c.c.

Distilled water sufficient to produce . I,00o ,

Solution of bromine As $T$.

Bromine . . . . . . 30 grams

Potassium bromide . . . . 30 ".

Distilled water sufficient to produce - Ioo c.c

Solution of stannous chloride As $T$. is prepared from the solution of stannous chloride B.P. by adding an equal volume of hydrochloric acid, boiling down to the original bulk and filtering.

Hydrochloric acid As $T$. contains not more than o.I part per million of arsenic, and is free from iron.

Stannated hydrochloric acid As T.

Solution of stannous chloride As T. . . I c.c.

Hydrochloric acid As T. sufficient to produce 100 "

Brominated hydrochloric acid As T.

Solution of bromine As T. . • . . I c.c.

Hydrochloric acid As T. sufficient to produce 100 "

Zinc $A s T$. must not yield any arsenical stain when Io grams are tested, and must be free from iron. 
Calcium hydroxide As $T$. must not yield any arsenical stain when ro grams are tested.

Water analysis.

Nessler solution. Dissolve 62.5 grams of potassium iodide in 250 c.c. of distilled water, reserve a few c.c. and to the remainder add gradually a cold saturated solution of mercuric chloride until the mercuric iodide precipitated ceases to redissolve on shaking. Add the reserved potassium iodide, to redissolve the precipitate, and add more mercuric chloride very gradually until a slight permanent precipitate remains. Dissolve 150 grams of caustic potash in I5O c.c. of distilled water, allow to cool, add it slowly to the first solution and make up to Iooo c.c. with distilled water.

Allow the solution to stand and carefully decant for use.

Alkaline potassium permanganate solution. Dissolve 400 grams of caustic soda in nearly 2 litres of distilled water, add I6 grams of potassium permanganate and boil. When cold make up to 2000 c.c. Before being used, a portion of the solution is placed in a large flask, the level of liquid being marked on the outside, and boiled until concentrated to about nine-tenths. When cold it is made up to the original bulk with ammonia-free distilled water.

Ammonia-free distilled water is prepared by distilling ordinary water, to which a little sodium carbonate has been added, and rejecting the first portion. The distillate subsequently obtained should be tested with Nessler solution, and the distillation should not be carried too far.

Standard ammonium chloride solution. Dissolve $\mathbf{I} .5735$ grams of pure ammonium chloride in ammonia-free distilled water and make up the solution to Iooo c.c. Dilute $I$ in ro for use, the solution contains 0.00005 gram $\mathrm{NH}_{3}$ per I c.c.

Standard potassium permanganate solution. Dissolve 0.395 gram of pure potassium permanganate in distilled water and make up the solution to rooo c.c. I c.c. contains o.00o I gram of available oxygen.

Sodium thiosulphate solution. Dissolve I.2 grams in Iooo c.c. of water.

Sulphuric acid solution ( $\mathrm{I}$ in 4 ). Mix the acid and water in the required proportions (pouring the acid into the water 
slowly and shaking), and while hot add sufficient standard potassium permanganate solution to impart a slight permanent pink colour. When cold, discharge the colour by careful addition of just sufficient sodium thiosulphate solution.

Standard silver nitrate solution. Dissolve 2.40 grams of pure silver nitrate in distilled water and make up the solution to rooo c.c. I c.c. $=0.0005$ gram $\mathrm{Cl}$.

Phenolsulphonic acid. Melt some pure phenol and mix 80 c.c. with 200 c.c. of pure concentrated sulphuric acid in a large porcelain dish ; heat for about 8 hours on a boiling waterbath. When cold, add to this solution $\mathbf{r}_{40}$ c.c. of pure concentrated hydrochloric acid and 420 c.c. of distilled water.

Standard potassium nitrate solution. Dissolve $0.72 \mathrm{I}$ gram of potassium nitrate in Iooo c.c. of distilled water. Dilute $I$ in Io. I c.c. contains 0.00001 gram of nitrogen.

Standard indigo solution. Digest 2.5 grams of indigotin in 12.5 grams of Nordhausen acid, add 30 grams of pure sulphuric acid and digest for a further short period. Dilute considerably, filter and make up to 500 c.c. Take 30 c.c. and make up to rooo c.c. with a solution of sulphuric acid 4 per cent. by volume. Standardize the indigo solution with $\mathrm{N} / 3200$ potassium nitrate solution, 20 c.c. of which should almost decolourize I0.5 c.c. of the indigo when treated with the sulphuric acid mixture as in the estimation of nitrates (see page I34).

Metaphenylene-diamine solution. Dissolve 0.5 gram in roo c.c. of distilled water and slightly acidify with sulphuric acid. This solution should be kept in the dark.

Standard sodium nitrite solution. Dissolve I.Io gram of pure silver nitrite in boiling distilled water and add a solution of pure sodium chloride until there is no further precipitation of silver chloride. Make up to rooo c.c., allow the precipitate to settle and dilute roo c.c. of the clear liquid to rooo c.c. ; then I c.c. contains 0.0000 I gram of nitrogen as nitrite.

This solution should be kept in the dark, in small stoppered bottles completely filled.

Standard soap solution (Clark's). Dissolve 40 grams of Castile soap in spirit of proof strength, make up to rooo c.c. and allow to stand for some time; filter. The soap solution 
is then diluted about I in 5 with proof spirit, the strength being adjusted so that 7.8 c.c. are required for 50 c.c. of the standard calcium chloride solution (see below) when titrated as in hardness determinations.

Standard calcium chloride solution. Dissolve 0.2 gram of pure calcium carbonate (preferably crystalline calcite) in hydrochloric acid, in a platinum dish covered with a clockglass. When effervescence has ceased remove the clock-glass, wash it with distilled water, running the washings into the dish, and evaporate the solution to dryness. Add small quantities of distilled water and evaporate each time to dryness, in order to remove excess of acid. Dissolve the residue in boiled distilled water and make up when quite cold to Iooo c.c. Dilute I to I with boiked and cooled distilled water for use.

Standard lead solution. Dissolve 1.83 grams of lead acetate in distilled water, with the addition of a small quantity of acetic acid. For use dilute $I$ in Io, when I c.c. contains o.0ooI gram of lead.

Standard copper solution. Dissolve 3.93 grams of pure copper sulphate in water and make up to Iooo c.c. For use dilute I in Io, when I c.c. contains o.00o I gram of copper.

Standard iron solution. Dissolve 7.02 grams of ferrous ammonium sulphate in distilled water, acidifying with sulphuric acid, oxidize to the ferric condition by adding the requisite quantity of potassium permanganate solution, and make up to Iooo c.c. Dilute I in Io, when I c.c. contains o.ooo I gram of iron.

Standard zinc solution. Dissolve 4.42 grams of zinc sulphate in 1000 c.c. of distilled water. Dilute $I$ in Io for use, then I c.c. contains 0.000 I gram of zinc.

Manganous chloride solution (for dissolved oxygen). Dissolve 50 grams of manganous chloride in distilled water and make up to roo c.c.

Solution of sodium hydrate and potassium iodide (for dissolved oxygen). Dissolve 50 grams of sodium hydrate and Io grams of potassium iodide in water and make up to roo c.c.

Solution of potassium iodide and sodium nitrite (Thresh's 
method). Dissolve 20 grams of potassium iodide and 0.5 gram of sodium nitrite in water and make up to roo c.c.

\section{Alcohol Table}

\begin{tabular}{|c|c|c|c|c|c|}
\hline $\begin{array}{l}\text { Specific } \\
\text { Gravity } \\
\text { at } 15.5^{\circ} .\end{array}$ & $\begin{array}{l}\text { Per cent. } \\
\text { Alcohol } \\
\text { by weight. }\end{array}$ & $\begin{array}{l}\text { Per cent. } \\
\text { under } \\
\text { proof. }\end{array}$ & $\begin{array}{l}\text { Specific } \\
\text { Gravity } \\
\text { at } 15.5^{\circ} .\end{array}$ & $\begin{array}{l}\text { Per cent. } \\
\text { Alcohol } \\
\text { by weight. }\end{array}$ & $\begin{array}{l}\text { Per cent. } \\
\text { under } \\
\text { proof. }\end{array}$ \\
\hline 0.9999 & 0.05 & 99.89 & 0.9962 & 2.05 & 95.49 \\
\hline .9998 & . I I & 99.76 & $.996 \mathbf{I}$ & . I I & $95 \cdot 36$ \\
\hline .9997 & .16 & 99.65 & .9960 & .17 & 95.23 \\
\hline .9996 & $.2 \mathrm{I}$ & 99.54 & .9959 & .22 & 95.12 \\
\hline .9995 & .26 & 99.43 & .9958 & .28 & 94.99 \\
\hline .9994 & $\cdot 3^{2}$ & 99.29 & .9957 & .34 & 94.86 \\
\hline .9993 & .37 & 99.18 & .9956 & .39 & $94 \cdot 75$ \\
\hline .9992 & .42 & 99.07 & .9955 & .45 & 94.61 \\
\hline .9991 & .47 & 98.96 & .9954 & $\cdot 5^{I}$ & $94 \cdot 4^{8}$ \\
\hline 9990 & .53 & 98.83 & .9953 & .57 & 94.35 \\
\hline .9989 & $.5^{8}$ & 98.72 & $.995^{2}$ & .62 & 94.24 \\
\hline .9988 & .64 & 98.59 & $.995 I$ & .68 & .94 .1 I \\
\hline .9987 & .69 & 98.48 & .9950 & .74 & 93.98 \\
\hline .9986 & .74 & 98.37 & .9949 & .79 & 93.87 \\
\hline .9985 & .80 & 98.24 & $.994^{8}$ & .85 & 93.74 \\
\hline .9984 & .85 & 98.13 & .9947 & $.9 I$ & 93.61 \\
\hline .9983 & $.9 I$ & 97.99 & .9946 & 2.97 & $93.4^{8}$ \\
\hline .9982 & 0.96 & 97.88 & .9945 & 3.02 & $93 \cdot 37$ \\
\hline $.998 I$ & 1.02 & $97 \cdot 75$ & .9944 & .08 & 93.24 \\
\hline .9980 & .07 & 97.63 & .9943 &. $\mathrm{I}_{4}$ & 93.1 I \\
\hline .9979 & .12 & $97 \cdot 53$ & .9942 & .20 & 92.98 \\
\hline .9978 & . I 8 & 97.40 & $.994 I$ & .26 & 92.84 \\
\hline .9977 & .23 & 97.29 & .9940 & $\cdot 32$ & $92.7 I$ \\
\hline .9976 & .29 & 97.16 & .9939 & .37 & 92.60 \\
\hline .9975 & $\cdot 34$ & 97.05 & .9938 & .43 & 92.47 \\
\hline .9974 & .40 & 96.92 & .9937 & .49 & 92.34 \\
\hline .9973 & .45 & $96.8 I$ & .9936 & .55 & 92.21 \\
\hline .9972 & $.5 I$ & 96.68 & .9935 & $.6 \mathrm{I}$ & 92.08 \\
\hline .9971 & .56 & 96.57 & .9934 & .67 & 91.95 \\
\hline .9970 & $.6 I$ & $96.4^{6}$ & .9933 & .73 & 91.82 \\
\hline .9969 & .67 & 96.32 & .9932 & .78 & $9 I .7 I$ \\
\hline .9968 & .73 & 96.19 & .9931 & .84 & $91.5^{8}$ \\
\hline .9967 & .78 & 96.08 & .9930 & .90 & 91.45 \\
\hline .9966 & .83 & 95.97 & .9929 & 3.96 & 91.32 \\
\hline .9965 & .89 & 95.84 & .9928 & 4.02 & 9I.I9 \\
\hline .9964 & .94 & 95.73 & .9927 & .08 & 91.06 \\
\hline .9963 & I.99 & 95.62 & .9926 &.$I_{4}$ & 90.93 \\
\hline
\end{tabular}


Alcohol Table-(continued).

\begin{tabular}{|c|c|c|c|c|c|}
\hline $\begin{array}{l}\text { Specific } \\
\text { Gravity } \\
\text { at } 15.5^{\circ} .\end{array}$ & $\begin{array}{l}\text { Per cent. } \\
\text { Alcohol } \\
\text { by weight. }\end{array}$ & $\begin{array}{l}\text { Per cent. } \\
\text { under } \\
\text { proof. }\end{array}$ & $\begin{array}{l}\text { Specific } \\
\text { Gravity } \\
\text { at } \times 5.5^{\circ} .\end{array}$ & $\begin{array}{l}\text { Per cent. } \\
\text { Alcohol } \\
\text { by weight. }\end{array}$ & $\begin{array}{l}\text { Per cent. } \\
\text { under } \\
\text { proof. }\end{array}$ \\
\hline 0.9925 & 4.20 & 90.80 & 0.9740 & I 8.08 & 61.13 \\
\hline .9924 & .27 & 90.64 & .9730 & I 8.80 & $59 \cdot 5^{2}$ \\
\hline .9923 & .33 & $90.5 \mathrm{I}$ & .9720 & I9.66 & 57.80 \\
\hline .9922 & .39 & . 90.38 & .9710 & 20.50 & 56.06 \\
\hline $.992 \mathrm{I}$ & .45 & 90.25 & .9700 & $2 \mathrm{I} \cdot 3 \mathrm{I}$ & $54 \cdot 37$ \\
\hline .9920 & $\cdot 5^{I}$ & 90.12 & .9690 & 22.08 & 52.77 \\
\hline .9919 & .57 & 89.99 & .9680 & 22.85 & $5 \mathrm{I} . \mathrm{I} 7$ \\
\hline .9918 & .64 & 89.84 & .9670 & 23.62 & 49.59 \\
\hline .9917 & .70 & $89.7 \mathrm{I}$ & .9660 & $24 \cdot 3^{8}$ & 48.00 \\
\hline .9916 & .76 & $89 \cdot 5^{8}$ & .9650 & $25 . I_{4}$ & 46.44 \\
\hline .9915 & .82 & 89.45 & .9640 & 25.86 & 44.97 \\
\hline .9914 & .88 & 89.32 & .9630 & 26.53 & 43.59 \\
\hline .9913 & $4 \cdot 94$ & 89.19 & .9620 & 27.21 & 42.20 \\
\hline .9912 & 5.01 & 89.04 & .9610 & 27.93 & 40.74 \\
\hline .991 I & .07 & $88.9 I$ & .9600 & 28.56 & 39.47 \\
\hline .9910 & .13 & 88.78 & .9590 & 29.20 & 38.18 \\
\hline .9909 & .20 & 88.62 & .9580 & 29.87 & 36.83 \\
\hline .9908 & .26 & 88.49 & $.957^{\circ}$ & 30.44 & 35.68 \\
\hline .9907 & $\cdot 32$ & 88.36 & .9560 & 31.00 & $34 \cdot 57$ \\
\hline .9906 & $\cdot 39$ & 88.21 & .9550 & 31.62 & $33 \cdot 32$ \\
\hline .9905 & .45 & 88.08 & $.954^{\circ}$ & 32.25 & 32.08 \\
\hline .9904 & $\cdot 5 \mathrm{I}$ & 87.95 & .9530 & 32.87 & 30.84 \\
\hline .9903 & $\cdot 5^{8}$ & 87.80 & .9520 & 33.47 & 29.66 \\
\hline .9902 & .64 & 87.67 & .9510 & 34.05 & $28.5^{2}$ \\
\hline $.990 \mathrm{I}$ & .70 & 87.54 & .9500 & $34 \cdot 5^{2}$ & 27.59 \\
\hline .9900 & $5 \cdot 77$ & 87.39 & .9490 & 35.00 & 26.67 \\
\hline .9890 & $6.4^{2}$ & 85.98 & .9480 & 35.50 & 25.70 \\
\hline .9880 & 7.09 & $84 \cdot 53$ & $.947^{\circ}$ & 36.00 & 24.74 \\
\hline .9870 & $7 \cdot 78$ & 83.05 & .9460 & 36.56 & 23.66 \\
\hline .9860 & $8.4^{8}$ & $8 \mathrm{I} \cdot 54$ & $.945^{\circ}$ & 37.1 I & $22.5^{8}$ \\
\hline .9850 & 9.20 & 79.99 & $.944^{\circ}$ & 37.67 & $21 \cdot 50$ \\
\hline .9840 & 9.92 & 78.45 & .9430 & 38.22 & 20.43 \\
\hline .9830 & I0.8I & 76.53 & .9420 & 38.78 & I9.36 \\
\hline .9820 & I I. 62 & 74.83 & .9410 & $39 \cdot 30$ & I8. 36 \\
\hline .9810 & I2.39 & 73.18 & .9400 & 39.80 & $\mathrm{I} 7 \cdot 4 \mathrm{I}$ \\
\hline .9800 & 13.15 & $7 \mathrm{I} .54$ & .9390 & 40.30 & I6.46 \\
\hline .9790 & 13.92 & 69.90 & .9380 & 40.80 & I $5.5 \mathrm{I}$ \\
\hline .9780 & I $4 \cdot 75$ & 68.01 & $.937^{\circ}$ & $4 \mathrm{I} \cdot 30$ & I 4.57 \\
\hline .9770 & I $5.5^{8}$ & 66.22 & .9360 & 41.80 & I 3.63 \\
\hline .9760 & 16.42 & $64 \cdot 54$ & .9350 & 42.29 & $12.7 \mathrm{I}$ \\
\hline $.975^{\circ}$ & 17.25 & 62.87 & $.934^{\circ}$ & 42.76 & I 1.82 \\
\hline
\end{tabular}




\begin{tabular}{|c|c|c|c|c|c|}
\hline $\begin{array}{l}\text { Specific } \\
\text { Gravity } \\
\text { at } 15.5^{\circ} .\end{array}$ & $\begin{array}{c}\text { Per cent. } \\
\text { Alcohol } \\
\text { by weight. }\end{array}$ & $\begin{array}{c}\text { Per cent. } \\
\text { under } \\
\text { proof. }\end{array}$ & $\begin{array}{l}\text { Specific } \\
\text { Gravity } \\
\text { at } 15.5^{\circ} .\end{array}$ & $\begin{array}{l}\text { Per cent. } \\
\text { Alcohol } \\
\text { by weight. }\end{array}$ & $\begin{array}{l}\text { Per cent. } \\
\text { over } \\
\text { proof. }\end{array}$ \\
\hline 0.9330 & 43.24 & I0.94 & 0.9100 & 53.57 & $7.6 \mathrm{I}$ \\
\hline .9320 & 43.7 I & I0.05 & .9000 & 58.05 & I 5.33 \\
\hline .9310 & $44 \cdot 18$ & 9.19 & .8900 & 62.36 & 22.53 \\
\hline .9300 & 44.64 & 8.36 & .8800 & 66.70 & 29.57 \\
\hline .9290 & 45.09 & $7 \cdot 5^{2}$ & .8700 & 70.84 & 36.07 \\
\hline .9280 & 45.55 & 6.69 & .8600 & $75.1_{4}$ & 42.66 \\
\hline .9270 & 46.00 & 5.86 & .8500 & $79.3^{2}$ & 48.84 \\
\hline .9260 & $46.4^{6}$ & 5.03 & .8400 & $83 \cdot 3 I$ & 54.49 \\
\hline .9250 & $46.9 \mathrm{I}$ & $4.2 I$ & .8300 & 87.19 & 59.77 \\
\hline .9240 & $47 \cdot 36$ & $3 \cdot 38$ & .8200 & 91.00 & $64 \cdot 74$ \\
\hline .9230 & 47.82 & 2.56 & .8100 & 94.62 & 69.20 \\
\hline .9220 & 48.27 & I. 74 & .8000 & 98.03 & 73.14 \\
\hline $.92 \mathrm{IO}$ & 48.73 & 0.92 & $\cdot 79384$ & 100.00 & 75.25 \\
\hline .9200 & 49.16 & 0.14 & & & \\
\hline .91984 & 49.24 & Proof & & & \\
\hline
\end{tabular}

Spirit indication, with corresponding degrees of gravity lost

\begin{tabular}{|c|c|c|c|c|c|c|c|c|c|c|}
\hline $\begin{array}{l}\text { Spirit } \\
\text { Indicati }\end{array}$ & .0 &. $\mathbf{I}$ & .2 & $\cdot 3$ & .4 & $\cdot 5$ & .6 & .7 & .8 & .9 \\
\hline o & 0.0 & 0.4 & 0.9 & I. 3 & I. 7 & & 2.6 & 3.0 & $3 \cdot 4$ & 3.8 \\
\hline I & $4 \cdot 3$ & $4 \cdot 7$ & $5 . \mathrm{I}$ & $5 \cdot 5$ & 6.0 & 6.4 & 6.8 & 7.2 & 7.7 & 8.1 \\
\hline 2 & 8.5 & 8.9 & $9 \cdot 4$ & 9.8 & I0.3 & 10.7 & I I. I & I I. 6 & I 2.0 & I 2.5 \\
\hline 3 & & I 3.3 & I3.8 & I 4.2 & $\mathrm{I}_{4} \cdot 7$ & I $5 . \mathrm{I}$ & I 5.5 & I6.0 & I6. 4 & I6.9 \\
\hline 4 & I $7 \cdot 3$ & I 7.8 & I 8.2 & I8.7 & & & 20.0 & 20.5 & 20.9 & $2 \mathrm{I} .4$ \\
\hline 5 & 21.9 & 22.3 & 22.8 & 23.2 & 23.7 & $24 . I$ & 24.6 & 25.0 & 25.5 & 25.9 \\
\hline 6 & 26.4 & 26.9 & $27 \cdot 3$ & 27.8 & 28.2 & 28.7 & 29.2 & 29.6 & & 30.5 \\
\hline 7 & & & & & & & & & & \\
\hline 8 & $35 .^{\prime}$ & 36 & 36.6 & 37.0 & $37 \cdot 5$ & & & 38.9 & & 39.8 \\
\hline 9 & 40.3 & 40.8 & 4 I. 2 & 41.7 & 42.2 & $4^{2.7}$ & 43.1 & & & $44 \cdot 5$ \\
\hline 10 & 45.0 & 45.5 & & 46.5 & & $47 \cdot 4$ & 47.9 & 48.4 & 48.9 & 49.4 \\
\hline I I & 49.9 & 50.4 & 50.9 & $5 \mathrm{I} .4$ & $5 \mathrm{I} .9$ & 52.4 & 52.9 & 53.4 & & $54 \cdot 4$ \\
\hline 12 & 54.9 & $55 \cdot 4$ & 55.9 & 56.4 & 56.9 & $57 \cdot 4$ & 57.9 & $5^{8.4}$ & 58.9 & 59.4 \\
\hline
\end{tabular}


Table of hardness of waters

(50 c.c. of water used)

\begin{tabular}{|c|c|c|c|c|c|}
\hline $\begin{array}{l}\text { Volume } \\
\text { of Soap } \\
\text { solution. }\end{array}$ & $\begin{array}{c}\mathrm{CaCO}_{3} \\
\text { per } \\
\text { 100,000. }\end{array}$ & $\begin{array}{l}\text { Volume } \\
\text { of Soap } \\
\text { solution. }\end{array}$ & $\begin{array}{c}\mathrm{CaCO}_{3} \\
\text { per } \\
\text { roo,ooo. }\end{array}$ & $\begin{array}{l}\text { Volume } \\
\text { of Soap } \\
\text { solution. }\end{array}$ & $\begin{array}{c}\mathrm{CaCO}_{3} \\
\text { per } \\
\text { I00,000. }\end{array}$ \\
\hline c.c. & & c.c. & & c.c. & \\
\hline 0.7 & 0.00 & 4.6 & 5.43 & 8.5 & 11.05 \\
\hline 0.8 & .16 & $4 \cdot 7$ & .57 & 8.6 & .20 \\
\hline 0.9 & .32 & 4.8 & $.7 I$ & 8.7 & .35 \\
\hline I.O & $.4^{8}$ & 4.9 & 5.86 & 8.8 & .50 \\
\hline I.I & .63 & 5.0 & 6.00 & 8.9 & .65 \\
\hline I. 2 & .79 & 5.1 &.$I_{4}$ & 9.0 & .80 \\
\hline I. 3 & 0.95 & 5.2 & .29 & 9.1 & II.95 \\
\hline I. 4 & I.I I & $5 \cdot 3$ & .43 & 9.2 & I2.II \\
\hline I. 5 & .27 & 5.4 & .57 & 9.3 & .26 \\
\hline 1. 6 & .43 & 5.5 & $.7 \mathbf{I}$ & 9.4 & $.4^{I}$ \\
\hline 1.7 & .56 & 5.6 & 6.86 & 9.5 & .56 \\
\hline 1.8 & .69 & 5.7 & 7.00 & 9.6 & .71 \\
\hline 1.9 & .82 & 5.8 &. $\mathrm{I}_{4}$ & 9.7 & I2.86 \\
\hline 2.0 & I.95 & 5.9 & .29 & 9.8 & I 3.01 \\
\hline $2 . I$ & 2.08 & 6.0 & .43 & 9.9 & .16 \\
\hline 2.2 & $.2 \mathrm{I}$ & $6 . \mathrm{I}$ & .57 & 10.0 & $.3 I$ \\
\hline 2.3 & .34 & 6.2 & $.7 \mathrm{I}$ & IO.I & .46 \\
\hline 2.4 & .47 & 6.3 & 7.86 & 10.2 & $.6 \mathrm{I}$ \\
\hline 2.5 & .60 & 6.4 & 8.00 & 10.3 & .76 \\
\hline 2.6 & .73 & 6.5 &. $\mathrm{I}_{4}$ & 10.4 & 13.91 \\
\hline 2.7 & .86 & 6.6 & .29 & 10.5 & 14.06 \\
\hline 2.8 & 2.99 & 6.7 & .43 & 10.6 & .21 \\
\hline 2.9 & 3.12 & 6.8 & .57 & 10.7 & .37 \\
\hline 3.0 & .25 & 6.9 & .71 & 10.8 & .52 \\
\hline 3.1 & .38 & 7.0 & 8.86 & 10.9 & .68 \\
\hline 3.2 & .51 & 7.1 & 9.00 & II.O & I 4.84 \\
\hline 3.3 & .64 & 7.2 &. $\mathrm{I}_{4}$ & II.I & 15.00 \\
\hline 3.4 & .77 & $7 \cdot 3$ & .29 & II.2 & .16 \\
\hline 3.5 & 3.90 & $7 \cdot 4$ & .43 & II. 3 & .32 \\
\hline 3.6 & 4.03 & $7 \cdot 5$ & .57 & II. 4 & $.4^{8}$ \\
\hline 3.7 & .16 & 7.6 & $.7 \mathrm{I}$ & II. 5 & .63 \\
\hline 3.8 & .29 & 7.7 & 9.86 & II. 6 & .79 \\
\hline 3.9 & .43 & 7.8 & 10.00 & I I. 7 & I 5.95 \\
\hline 4.0 & .57 & 7.9 & .15 & II.8 & I6.II \\
\hline 4.1 & .71 & 8.0 & .30 & II.9 & .27 \\
\hline 4.2 & 4.86 & 8.I & .45 & 12.0 & .43 \\
\hline $4 \cdot 3$ & 5.00 & 8.2 & .60 & I2.1 & .59 \\
\hline 4.4 &. $\mathrm{I}_{4}$ & 8.3 & .75 & 12.2 & .75 \\
\hline $4 \cdot 5$ & .29 & 8.4 & 10.90 & 12.3 & 16.90 \\
\hline
\end{tabular}




\section{Nitrates in Water, Warington's Indigo method}

(20 c.c. of water used)

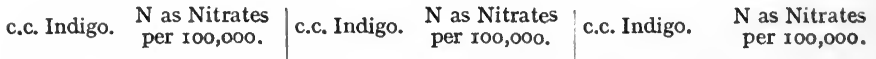

\begin{tabular}{|c|c|c|c|c|c|}
\hline 0.5 & 0.000 & $5 \cdot 5$ & 0.218 & 10.5 & 0.437 \\
\hline I.O & 0.021 & 6.0 & 0.240 & II.O & 0.459 \\
\hline I. 5 & 0.043 & 6.5 & 0.262 & I I. 5 & 0.482 \\
\hline 2.0 & 0.065 & 7.0 & 0.284 & 12.0 & 0.504 \\
\hline 2.5 & 0.087 & $7 \cdot 5$ & 0.306 & I 2.5 & 0.527 \\
\hline 3.0 & 0.109 & 8.0 & 0.328 & I 3.0 & 0.549 \\
\hline 3.5 & $0.13 I$ & 8.5 & 0.350 & 13.5 & 0.572 \\
\hline 4.0 & O.I 53 & 9.0 & $0.37 \mathrm{I}$ & 14.0 & 0.594 \\
\hline $4 \cdot 5$ & 0.175 & 9.5 & 0.393 & I 4.5 & 0.617 \\
\hline 5.0 & 0.196 & IO.0 & 0.4 I 5 & I 5.0 & 0.639 \\
\hline
\end{tabular}

Solubility of oxygen in water

(atmospheric pressure $760 \mathrm{~mm}$. )

\begin{tabular}{|c|c|c|c|c|c|c|c|}
\hline $\begin{array}{l}\text { Temp. } \\
{ }^{\circ} \mathrm{C} .\end{array}$ & $\begin{array}{l}\text { Oxygen } \\
\text { parts per } \\
\text { IOo,ooo. }\end{array}$ & $\begin{array}{c}\text { Temp. } \\
{ }^{\circ} \mathrm{C} .\end{array}$ & $\begin{array}{l}\text { Oxygen } \\
\text { parts per } \\
\text { Ioo,ooo. }\end{array}$ & $\begin{array}{c}\text { Temp. } \\
{ }^{\circ} \mathrm{C} .\end{array}$ & $\begin{array}{l}\text { Oxygen } \\
\text { parts per } \\
\text { 100,000. }\end{array}$ & $\begin{array}{c}\text { Temp. } \\
{ }^{\circ} \mathrm{C} .\end{array}$ & $\begin{array}{c}\text { Oxygen } \\
\text { parts per } \\
\text { 100,000. }\end{array}$ \\
\hline 5 & I. 24 & IO & I. I I & I 5 & 1.00 & 20 & 0.90 \\
\hline 6 & 1.22 & I I & 1.09 & 16 & 0.98 & $2 I$ & 0.88 \\
\hline 7 & I.I9 & 12 & 1.07 & I7 & 0.96 & 22 & 0.87 \\
\hline 8 & I.I 7 & I 3 & I.04 & I8 & 0.94 & 23 & 0.85 \\
\hline 9 & I. I 4 & I 4 & 1.02 & I9 & 0.92 & 24 & 0.84 \\
\hline
\end{tabular}

Atomic weights

\begin{tabular}{|c|c|c|c|c|c|c|c|c|}
\hline ninium & $\mathrm{Al}$ & 27.1 & Copper & $\mathrm{Cu}$ & 63.6 & Phosphorus & $\mathrm{P}$ & \\
\hline nony & $\mathrm{Sb}$ & 120.2 & Fluorine & $\mathrm{F}$ & I9.0 & Platinum & $\mathrm{Pt}$ & \\
\hline Ars & As & 75.0 & lrogen & $\mathrm{H}$ & I.008 & Pota & $\mathrm{K}$ & \\
\hline & $\mathrm{Ba}$ & 137.4 & & I & I 26.9 & & $\mathrm{Si}$ & \\
\hline & $\mathrm{Bi}$ & 208.0 & & & 55.8 & & $\mathrm{Ag}$ & \\
\hline & B & II .O & Le & $\mathrm{Pb}$ & 207.2 & & $\mathrm{Na}$ & \\
\hline & $\mathrm{Br}$ & 79.9 & nesium & $\mathrm{Mg}$ & $24 \cdot 3$ & & $\mathrm{Sr}$ & \\
\hline & $\mathrm{Cd}$ & I 22.4 & & $\mathrm{Mn}$ & & & & \\
\hline & $\mathrm{Ca}$ & $40 . I$ & & $\mathrm{Hg}$ & 200.6 & Tir & Sn & \\
\hline & C & I 2.0 & denum & Mo & 96.0 & & W & \\
\hline & $\mathrm{Cl}$ & & & & 58.7 & & U & \\
\hline & $\mathrm{Cr}$ & & Nitrogen & 17 & 14.0 & Zinc & 21 & \\
\hline Cobalt & Co & 59.0 & Oxygen & & I6́.o & & & \\
\hline
\end{tabular}




\section{EXAMINATION QUESTIONS}

(From papers set for various Diplomas in Public Health.)

\section{Written papers}

State what articles of food are liable to contain arsenic, and describe briefly a method by which the amount may be estimated. (University of Liverpool.)

Write a short account of the preservation of food by means of antiseptics, and give your objections, if any, to this practice.

What is the difference between "cream" and "preserved cream ?" (University of Liverpool.)

What are the differences in composition between wheat flour and bread ? Write an account of the methods employed in the bleaching and "improving" of wheat flour. What animal and vegetable parasites may occur in flour? (University of Cambridge.)

Mention the principal chemical preservatives which have been added to milk. Describe what tests you would use to ascertain the presence or absence of any three of these. (Victoria University of Manchester.)

A sample of beer is sold as having an original gravity of 1034. Explain what is meant by this, and how it may be determined by analysis. (University of Liverpool.)

What is the composition of butter? How would you estimate the volatile fatty acids in a sample of butter ? Fully discuss the importance of such estimation when the butter is suspected of being adulterated. (University of Wales.)

State what injurious substances are likely to be present in the following foodstuffs and their origin, and briefly suggest 
methods for their detection : (a) sugar substitute containing glucose, $(b)$ baking powder, $(c)$ boiled rhubarb leaves. (University of Liverpool.)

Compare the difference in composition between tea, coffee and cocoa. Discuss the use of these substances in a dietary. How would you prove the presence of chicory in a sample of coffee ? (University of Cambridge.)

How would you test for the presence of tin in a sample of tinned pineapple? What method would you adopt for estimating the amount present? (Victoria University of Manchester.)

Give instances of the use of the microscope for the detection of adulterants in foods. To what extent is a microscopical examination of service in the analysis of $(a)$ butter, $(b)$ coffee ? (University of Liverpool.)

How would you make a complete examination of a sample of milk so as to ascertain: (a) its quality, $(b)$ any changes produced by keeping, $(c)$ any changes produced by treatment with the object of preserving it? (Victoria University of Manchester.)

Comment upon the following results of analysis, and state to what extent, if any, the samples are adulterated :-

Butter.

Water

Fat.

Curd and salt Boric acid
Per Cent.

Milk.

Per Cent.

$$
\begin{aligned}
& \text { - I8.40 Fat . . } \quad 2.53 \\
& \text {. } 80.56 \text { Non-fatty solids . } 8.05 \\
& 0.86 \text { Total solids } \quad 10.5^{8} \\
& \text { o.I } 8 \text { Boric acid } 2 \text { grains per pint. }
\end{aligned}
$$

Reichert-Wollny number 27.5

What are the differences between unboiled and boiled cow's milk? Compare the differences between ordinary cow's milk and " condensed " milk as food for infants. (University of Cambridge.) 


\section{EXAMINATION QUESTIONS}

What materials are used in the manufacture of margarine ? What is its legal definition?

State, without giving details of the processes involved, what examination you would make of a sample of margarine in order to ascertain if it is genuine. (University of Liverpool.)

Discuss the dietetic value of alcohol in the light of recent research. Write its chemical history and the means you would adopt to determine its quantity in a sample of brandy. How would you convert a given percentage of alcohol into degrees of proof spirit ? (University of Wales.)

State what you know of the composition of the following: condensed milk, cheese, malt vinegar, baking powder.

Indicate briefly how you would determine the quantity of proteins in one of these foodstuffs. (University of Liverpool.)

Discuss the importance of chlorides and nitrates in drinking water. (University of Oxford.)

Discuss briefly the significance of the ammonia obtained from water by distillation with alkaline potassium permanganate.

A sample of upland surface water is found on analysis to yield 0.025 albuminoid ammonia per roo,ooo. How would you ascertain by chemical means whether or not this is due to sewage pollution? (University of Liverpool.)

State fully the features which may be revealed by a chemical examination of a water, and which would indicate that the water is unfit for domestic purposes. (Victoria University of Manchester.)

Discuss the significance of the presence in a water sediment of (a) paramœcia, $(b)$ cotton fibres, $(c)$ diatoms, $(d)$ epithelial cells. (University of Liverpool.)

What are the sources of nitric acid in $(a)$ rain water, and in (b) shallow well water ? What is the significance of nitrates in drinking water ?

Describe a suitable method of determining nitrates in water samples. (University of Wales.) 
What chemical and bacteriological standards of purity would you adopt for the water from a deep well from chalk ? Contrast these with the standards required for a peaty surface water. (R.C.P. London and R.C.S. England.)

From the following results of the analysis of two samples of water, state which, if either, you would choose as a supply for drinking and domestic use, and discuss the considerations which guide you in coming to a decision :-

$$
\text { No. I No. } 2
$$

Upland surface From a shallow water. well.

Total solids in solution

- 4.45

I 5.76

Oxygen absorbed in 15 mins.

- 0.098

0.014

- 0.187

0.027

Free and saline ammonia

Albuminoid ammonia

Nitrogen as nitrates

Nitrogen as nitrites

Combined chlorine

Reaction to litmus

- 0.003

0.001

- 0.018

0.002

- none

0.86

- none

none

- 0.95

$3 \cdot 55$

- acid

alkaline

(University of Liverpool.)

Consider briefly the best tests for judging the quality of sewage effluents. (University of Oxford.)

State the conditions under which the following may be present in water supplies, and describe the method by which you would prove the presence of each : iron, zinc, phosphates, sodium chloride. (University of Liverpool.)

What are the methods in general use for the estimation of the nitrogen combinations in drinking water? Discuss their relative importance. (Victoria University of Manchester.)

Describe shortly a method of softening "hard" water. (University of Oxford.)

Of what value is the microscopical examination of the sediment from a sample of water? What microscopical evidence would lead you to suspect that a water is polluted with sewage? (University of Liverpool.) 
How much oxygen is contained in potassium permanganate, and how much is available for oxidation in its application to water analysis?

Describe Tidy's method of using it and discuss the value of the procedure. (University of Wales.)

Describe a method for the determination of the amount of dissolved oxygen in water.

An effluent from a sewage farm is found to absorb $\mathrm{I} .5$ parts of dissolved oxygen per I00,000 in five days and to contain 4.8 parts of suspended solids. Judged by the standard prescribed by the Royal Commission on Sewage Disposal, is the effluent fit to be discharged into a stream? (University of Liverpool.)

State your opinions in respect of the use of rain-water, well-water, river-water, and surface-water for drinking purposes in the case of rural areas where a Public Water Supply is non-obtainable. Describe briefly what precautions should be taken and what purification processes adopted. (University of Oxford.)

Describe a method for the estimation of carbon dioxide in air, and discuss the value of this determination as an indication of the efficiency of a system of ventilation. (University of Liverpool.)

What impurities are likely to be introduced into air by the escape of $(a)$ sewer gas, and $(b)$ coal gas, and how may such impurities be detected? (University of Liverpool.)

How would you estimate the amount of hydrogen sulphide in a sample of polluted air ? (Victoria University of Manchester.)

A workshop is heated by means of a coke stove, and it is suspected that the air is thereby vitiated. How would you examine the air to ascertain if this is the case? (University of Liverpool.)

How would you determine the amount of sulphurous acid present in a sample of air? In the case of air containing 
sulphurous acid what precautions would you take in estimating the amount of carbon dioxide present? (Victoria University of Manchester.)

Under what circumstances are the following impurities liable to be present in air? How may the presence of each be detected? (a) sulphur dioxide; (b) carbon monoxide; (c) carbon bisulphide vapour. (University of Liverpool.)

Explain the chemical action of the following disinfectants : chlorine, sulphurous acid, potassium permanganate, mercuric chloride.

Describe a method for the determination of the strength of a solution of sodium hypochlorite. (University of Liverpool.)

Discuss the special uses and relative values of the following disinfectants: formaldehyde, sulphurous acid, bleaching powder, corrosive sublimate. Describe a chemical method for determining the strength of bleaching powder. (University of Wales.)

Give examples of oxidizing agents which are used as disinfectants.

How would you propose to estimate approximately the percentage of phenols in crude carbolic acid ? (University of Liverpool.)

Describe exactly, giving equations, how you would determine the strength of any three of the following watery solutions :-

(a) Solution of hydrogen peroxide. (b) Solution of bleaching powder. (c) Solution of phenol. (d) Solution of formaldehyde. (e) Solution of ethylic alcohol. (Victoria University of Manchester.)

State how you would examine one of the following, in order to ascertain if it conforms to the existing regulations :-

(a) Rag flock. (b) Preserved cream. (University of Liverpool.) 


\section{Practical work}

Estimate the percentage of fat in the sample of milk and examine it for the presence of a preservative.

Assuming the non-fatty solids to be 8.80 per cent. find how the milk compares with the limits prescribed by the Board of Agriculture. (University of Liverpool.)

Test the temperance drink for preservative. (R.C.P. London and R.C.S. England.)

You are given a sample of vinegar which has been diluted with water; ascertain the deficiency in acetic acid. (University of Liverpool.)

Analyse the milk. State your results in percentages, and from the results write a report on the quality of the milk. (University of Cambridge.)

Examine the specimen of wheat flour by the microscope, and report upon it. (University of Liverpool.)

Estimate the lactose in the sample of milk before you and express your result as a percentage. The specific gravity of the milk is 1030, the ash is 0.63 per cent. and the solids not fat amount to 7.65 per cent. What percentage of water has probably been added to the milk? (University of Wales.)

Examine the sample of soda-water quantitatively for lead. (University of Liverpool.)

Estimate the percentage of alcohol in roo c.c. of beer. (University of Wales.)

Determine the "Reichert-Wollny number" of the fat, and calculate the percentage of volatile fatty acids in terms of butyric acid. (University of Liverpool.)

Submit the sample of beer to Reinsch's test for arsenic. (University of Liverpool.) 
Determine the percentage of borate preservative in the sample of butter, expressing the result in terms of boric acid. (University of Liverpool.)

Determine the nitrogen as nitrate and the hardness, temporary and permanent, in the water. The ammonia in this water has been determined as .04 per I00,000 and the albuminoid ammonia .03 per I00,000.

Report as to its potability and probable previous history. (R.C.P. London and R.C.S. England.)

Analyse the sample of water so far as time permits, making such estimations and tests as you consider most important with a view to the detection of sewage pollution. (University of Liverpool.)

Find out and estimate the amount of the poisonous metal dissolved in the water in $\mathrm{C}$ and $\mathrm{D}$. State your results in parts per I00,000. (University of Cambridge.)

You are supplied with a sample of water from a well, thirty feet deep, situated in the neighbourhood of several houses. The water does not show evidence of recent contamination. You are required to analyse it in order to find if the amount of " past pollution" is such as to render the water unsafe for drinking. (University of Liverpool.)

Examine and report on the water sediments. (University of Cambridge.)

You are given two samples of water, before and after filtration, respectively. Find the reduction in the quantity of organic matter in the filtered water as indicated by the oxygen absorbed from permanganate and the albuminoid ammonia. (Note.-The quantity of free and saline ammonia is negligible and need not be estimated.) (University of Liverpool.)

The water has been treated with bleaching powder owing to suspected contamination. Complaints have been made that as a result it is not palatable. Perform experiments bearing on this point. (R.C.P. London and R.C.S. England.) 


\section{EXAMINATION QUESTIONS}

Submit the sample of water to qualitative and quantitative examination so as to pass an opinion as to the fitness of the water for drinking purposes. The reasons for your opinion and the methods by which you arrive at those reasons are to be briefly stated in your report. (N.B.--The total solid matter of the water and the dissolved oxygen need not be estimated.) (University of Wales.)

You are given a sample of upland surface water, which is free from sewage pollution but contains impurities of vegetable origin. Make a sufficient examination to enable you to decide whether the organic matter is reasonable or excessive in amount. (University of Liverpool.)

A sample of water will be submitted for examination. Estimate quantitatively: $(a)$ chlorides ; $(b)$ free and albuminoid ammonia. (University of Oxford.)

Examine the sample of water qualitatively and quantitatively for lead and for nitrates. (University of Liverpool.)

Find the amount of carbon dioxide in the sample of air. (University of Liverpool.)

You are supplied with three samples of air containing, respectively, chlorine, bromine, and nitrogen peroxide. Distinguish between these impurities by their physical characters and by suitable chemical reactions. (University of Liverpool.)

Identify the gaseous impurities in the samples of air. (University of Liverpool.)

The sample is formalin stated to contain 40 per cent. of formaldehyde. Ascertain its actual strength. (University of Liverpool.)

Determine the strength of the bleaching powder, expressing the result as percentage of available chlorine. (University of Liverpool.)

Identify the two disinfectants, and state, as far as you can, to what chemical property the germicidal power of each is due. (University of Liverpool.) 
Determine the amount of phenols in the carbolic disinfectant powder. (University of Liverpool.)

You are given two disinfectant solutions. Ascertain their nature, and determine the strength of one of them by a chemical method. (University of Liverpool.)

Estimate $(a)$ the potassium hydrate in the sample of liquor potassæ, $(b)$ the available chlorine in the solution of chlorinated soda, expressing the result in each case as grams per Ioo c.c. (University of Liverpool.) 


\section{BOOKS, ETC., RECOMMENDED FOR REFERENCE}

Gravimetric Analysis. "Analytical Chemistry," Treadwell, translation by Hall (Wiley).

Volumetric Analysis. "Volumetric Analysis," Sutton, (Churchill).

Milk. "Dairy Chemistry," Droop Richmond (Griffin); Reports to the Local Government Board :-

New Series No. 76: "On the Biological Properties of Milk in Special Relation to the Feeding of Infants," Lane-Claypon, I9r3.

New Series No. 63: "On the Value of Boiled Milk as a Food for Infants and Young Animals," Lane-Claypon, I912.

Milk, butter and other foods. "Aids to the Analysis of Food and Drugs," Moor and Partridge (Baillière, Tindall and Cox).

Reports to the Local Government Board on-

Condensed Milks, with special reference to their use as Infants' Food, New Series No. 56, Food Report No. 15, Coutts, I9II.

Dried milks, with special reference to their use in Infant Feeding, New Series No. I16, Food Report No. 24, Coutts, I9I8.

Flour, the Bleaching of, and the addition of "Improvers" to, New Series No. 49, Food Report No. I2, Hamill and MonierWilliams, I9II.

Bread, the nutritive value of - made from different varieties of wheat flour, Food Report No. I4, Hamill, I9II.

Baking Powder and Self-Raising Flour, the presence of Calcium Sulphate in, New Series No. 46, Food Report No. 13, Hamill, I9I I. 
Proprietary Foods for Infant Feeding, New Series No. 8o, Food Report No. 20, Coutts and Baker, I9I4.

Food Values. "Food and the Principles of Dietetics," Hutchinson (Arnold); “Food Values," McKillop (Routledge).

Microscopical Examination of Foods. " A Compendium of Food-Microscopy, compiled, with additions and revision, from the late Dr A. H. Hassall's works on food," Clayton (Baillière, Tindall and Cox).

Arsenic in Foods. Final Report of the Royal Commission on Arsenical Poisoning, Cd. I848, 1903.

Arsenic in Drugs. " British Pharmacopœia," I9I4.

Tin in Tinned Foods. Report to the Local Government Board, Food Report No. 7, Buchanan and Schryver.

Water Supplies and Water Analysis. "The Examination of Waters and Water Supplies," Thresh (Churchhill).

Geology of Water Supply. "Geology of Water Supply," Woodward (Arnold).

Water Purification. "Modern Methods of Water Purification," Don and Chisholm (Arnold).

Ultra-violet Light in Water Purification. "Hygiene and Public Health," Parkes and Kenwood (Lewis) ; “Preventive Medicine and Hygiene," Rosenau (Appleton).

Water Deposits. "The Examination of Waters and Water Supplies," Thresh (Churchill); "A Compendium of Food Microscopy," Clayton (Baillière, Tindall and Cox).

Sewage Treatment and Disposal. "Hygiene and Public Health," Parkes and Kenwood (Lewis) ; “ Preventive Medicine and Hygiene," Rosenau (Appleton).

Sewage Effluents, Standards and Tests. Eighth Report of the Royal Commission on Sewage Disposal, Vol. I, Cd. 6464, I9I2.

Air Analysis. "Methods of Air Analysis," Haldane (Griffin). 
Carbon Dioxide in Air. Report of the Departmental Committee on the Ventilation of Factories and Workshops, Cd. 1302, 1903.

Carbon Monoxide in Air. Papers by Haldane in the “ Journal of Physiology," I895 and later.

Atmospheric Pollution. Reports of Committee on, "Lancet," I9I 4 and later.

Disinfection. " Hygiene and Public Health," Parkes and Kenwood (Lewis) ; "Preventive Medicine and Hygiene," Rosenau (Appleton).

Antiseptics. "A Handbook of Antiseptics," Dakin and Dunham (Macmillan).

Rag Flock. Reports to the Local Government Board on Public Health and Medical Subjects, New Series No. 27, Rag Flock, r9ro.

Tables, Weights and Measures, etc. "Analyst's Laboratory Companion," Johnson (Churchill). 


\section{INDEX}

ACETIC acid in vinegar, 18

Acidimetry, 15

Acids, standard solutions of, 10

Adams' process, 31

Adulteration of milk, calculation of, 35

Air, composition of, 176 impurities in, 179

Albuminoid ammonia, in sewage effluents, 165 ; in water, 124,145

Alcohol, in beer, 69 test for traces of, 76

Alcohol table, 222

Alcoholic beverages, 69

Alkalimetry, I 5

Alkalinity of water, 17

Alkalis, standard solutions of, Io

Ammonia in air, 180

in sewage effluents, 165

in water, I 21,144

Ammonium oxalate, estimation of, 24

Ammonium sulphide in air, 182

Antiformin, 203

Antiseptics, 206

Apparatus for volumetric analysis, I I

Appendix, 218

Arrowroot, 82, 87

Arsenic, B.P. test, 112,218

gravimetric estimation of, 6

in beer, 102, 104, 108

in foods, 102

Arsenical poisoning, Royal Commission on, 103

Arsenious solution, decinormal, 207

Artesian wells, I 18

Artificial vinegar, 85

Ash of milk, 37

Atmospheric pollution, Report on, 200

Atomic weights, 226
BAking powder, 84

Balance, use of, $\mathbf{I}$

Barley, 82, 84, 87

Bases, standard solutions of, ro

Beer, arsenic in, 102, 104, 108 composition of, 74 estimation of alcohol in, 69 original gravity, 72

Benzoic acid in foods, 93, 94, 97

Beverages, alcoholic, 69

Black pepper, 85

Bleaching of flour, 83

Bleaching powder, 203, 206

Books of reference, 237

Borax and boric acid in foods, 92, 94, 95

Boric acid in butter and margarine, 64

in milk, 44, 46

B. P. test for arsenic, 1 1 2, 218

Brandy, 75

Bread, white, 82

British brandy, 75

Burettes, I I

Butter, analysis of, 53

boric acid in, 64

coconut oil in, 62

composition of, 51

definition of, $5 \mathbf{I}$

estimation of fat in, 54, 56

fluorides in, 67

foreign fats in, 57,60

microscopical examination of, 64

milk-blended, 5 I

preservatives in, 64

Reichert-Wollny process, $5^{8}$

salt in, 55

vegetarian, 80

water in, 54,56 
Butter fat, composition of, 57

Buttermilk, 79

Calcium hydrate in lime-water, I9 Calories, 88

Carbolic acid, 212, 216 powder, 210

Carbon bisulphide in air, 186

Carbon dioxide in air, 185,190

Carbon monoxide in air, I85, 197

Centinormal solutions, Io

Cereals, composition of, 82

Cheese, 79

margarine, 80

Chemical preservatives, 93

Chicory, 82, 88

Chloramine-T, 203

"Chloride of lime," 203, 206

Chlorine in air, I8I in water, 128,147

Chromate, potassium, as indicator, 14

Cocoa, 82, 88

Coconut oil, 6I

Coffee, 8I, 88

Cold storage, 91, 92

Colour of water, 142, 148

Colouring matter in milk, 48

Combustion, changes in air due to, 177

Condensed milk, 77

Copper in foods, 95,98

in water, $158,159,162$

Cornflour, 87

Cottonseed oil, 63

Cream, 79

preserved, 95

Crum's process, 132

Cylinders, graduated, I 2

DECINORMAL arsenious solution, 207

potassium permanganate, 20

silver nitrate, 19

sodium carbonate, I 5

sodium hydrate, 16

solutions, 10

sulphuric acid, 15

Deep wells, I 17, I53

Deodorants, 206
Dirt in milk, 49

Disinfectants, 203

corrosives, etc., 204

oxidizing, 203

reducing, 204

tests for, 215

Dissolved oxygen, 168, 174

Dried milk, 78

Dust in air, 199

EleCtrolytic arsenic apparatus, I I I

Examination questions, 227

FACTORS for standard solutions, 24

Fat in butter, composition of, 57 estimation of, 54,56

in milk, estimation of, $3 \mathbf{I}$

Flock, rag, 216

Flour, bleaching of, 83

"improvers" in, 83

wheat, 83

white, 82

Flourides in butter, 67

Food values, 88

Foods, arsenic in, 102

copper in, 98

lead in, 98

poisonous metals in, 98

preservatives in, 92, 93

tin in, 98

various, 77

zinc in, 98

Foodstuffs, microscopical examination of, 87

Foreign fats in butter, 57,60

Formaldehyde in foods, 92, 94

in formalin, 213

in milk, 45,47

Formalin, 204, 21 3, 215

Free and saline ammonia in sewage effluents, 165

in water, 121, 144

GASEOUS impurities in air, 179,187

Gases, injurious quantities of, 199

Gin, 75

Ginger, 86

Gravimetric estimations, 4 
HALDANE's apparatus, 193

Hardness of water, I 38 , I48, I 55

permanent, I39, I 40

table of, 225

temporary, $17, \mathrm{I}_{3} 8, \mathrm{I}_{4} \mathrm{I}$

Heated milk, 49

Hempel's apparatus, 188

Honey, 81

Hydrochloric acid in air, 183

Hydrogen peroxide, 215

in milk, 45

Hypochlorites, 203, 215

"IMPROVERS" in flour, 83

Indicators, 13

Indigo method for nitrates, I34, 220, 226

Infants' foods, 84

Interpretation of results of water analyses, I 43, I 48

Iron bacteria, I 5 I, 159

Iron, estimation of, by permanganate, 2 I

gravimetric estimation of, 4

in water, 159, 163

organisms, I 5 I, I 59

JAM, 80, 96

benzoic acid in, 97

salicylic acid in, 96

KJELDAHL's process, 38

LACTOSE in milk, 27, 39, 218

Lard, 80

vegetarian, 80

Lead in foods, 98

in water, $157,159,161$

Leffmann-Beam process, 34

Lime-juice, salicylic acid in, 97

Lime-water, calcium hydrate in, 19

Litmus, I4

MAIZE, 82,87

Malt vinegar, 85

Margarine, $5 \mathrm{I}$

analysis of, 53

butter-fat in, 53,63

cheese, 80
Margarine-continued

manufacture of, $5^{2}$

microscopical examination of, 64

preservatives in, 64

Marsh-Berzelius test, 105

Measuring flasks, I I

Mercuric chloride, 205, 216

Metals, poisonous, in foods, 98 in water, 157

Methyl orange, 13

Microscopical examination of butter, 64

- of foodstuffs, 87

of margarine, 64

of water sediments, I 49

Milk, 27

abnormal, 28

adulteration of, 35

(Amendment) Order, 48

analysis of, 29

ash of, 37

boric acid in, 44, 46

calculation of adulteration of, 35

colouring matter in, 48

composition of, 27,28

condensed, 77

dirt in, 49

dried, 78

fat estimation, $3 \mathrm{I}$

formaldehyde in, 45,47

heated, 49

hydrogen peroxide in, 45

lactose in, 27, 39, 218

mineral matter in, 27, 37

nitrogen in, 27, 38

preservatives in, 43

proteins in, 27, 39

Sale of-Regulations, 29

sour, 4I

speciflc gravity of, 29

total solids in, 30

variations in composition of, 28

Milk-blended butter, 5 I

Milk-scale, Richmond's, 35

Mineral matter in milk, 27, 37

Mustard, 86, 88

Mystin, 47 


\section{INDEX}

Nitrates in water, 129, 132, 146

Nitrites in water, 136,147

Nitrogen in milk, 27,38

Nitrous fumes in air, 184

Normal solutions, 9

"Nutritive ratio," 89

OATs, 82,87

Oil, coconut, 6r cottonseed, 63 olive, 86

Olive oil, 86

Olive stones in pepper, 86,88

Organic nitrogen in sewage effluents, 167

Original gravity of beer, 72

Oxalic acid, estimation of, 23

Oxygen absorbed in sewage effluents, 165

in water, 125,145

dissolved, I68, 174

in air, 188

in water, solubility of, 226

PARAFORM, 205

Pavy's process, 39,218

Pearl barley, 84

Pepper, 85, 88

Permanent hardness, I39, I 40

Permanganate, standard solution of, 20, 26

Permanganates, 214, 215

Permutit process, I 56

Pettenkofer's process, I90

Phenolphthalein, I4, I7

Phenols, 210, 216

Phenolsulphonic acid process for nitrates, I 30, 220

Physical characters of waters, 142

Pickling, 92

Pipettes, I I

Plumbo-solvency, I 57

Poisonous metals in foods, 98 in water, 157

Polenske process, 61

Potassium chromate as indicator, 14 permanganate, standard solution of, 20,26

Potato starch, 87
Preservation of foods, 9I

Preservatives in butter, 64, 95

in foods, 92, 93

Departmental Committee on, 94

in margarine, 64, 95

in milk, 43,94

Preserved cream, 95

Proof spirit, 72

Proteins in milk, 27, 39

Public Health (Milk and Cream) Regulations, 44, 95

RAG FLOCK, 216

Regulations, 217

Rain water, I1 5

Reduction methods for nitrates, 135

Refractive indices of fats, 64

Regulations, Sale of Milk, 29

Reichert-Wollny process, 58

Reinsch test, 103

Respiration, changes in air due to, 177

Rice, 82, 83, 87

Richmond's milk scale, 35

River water, I16, 155

Royal Commission on arsenical poisoning, 103 on sewage disposal, 174

Rum, 75

SAGO, 87

Sale of Milk Regulations, 29

Salicylic acid, 93, 94, 96

Salt in butter, 55

Salting, 91, 92

Sampling of water, I 18

Scheme for gases in air, 187 for water analysis, 143

Sediments, water, 149

Seminormal solutions, to

Sesame oil, 63

Sewage disposal, Royal Commission on, 174 effluents, 165 standards for, 173

Sewer air, 176

Shallow wells, I I 7, 154

Sikes' hydrometer, 73 
Silver nitrate, decinormal, 19

Smoking, 9I, 92

Soap solution, standard, 220

Sodium carbonate, decinormal, I 5

hydrate, decinormal, 16

Solubility of oxygen in water, 226

Solutions, standard, 9, 25 special, 218

Sour milk, $4 \mathbf{I}$

Specific gravity by Sprengel tube, 70 of milk, 29

Spent ginger, 86

Spirit indication, 72, 224

Spirits, 74

Sprengel's process, 130

Sprengel tube, 70

Springs, I 18

Standard ammonium chloride solution, 25

potassium permanganate solution, 20, 26

Standard solutions, 9, 25

factors for, 24

Starches, 87

Starch indicator, 14

Starch-potassium iodide indicator, 14

Sterilization by heat, 9 I

Stout, 74

Sugar, 87

Sulphites, 97, 2 I 5

Sulphur dioxide in air, 183

Sulphuretted hydrogen in air, 176 , I8I

Sulphuric acid, decinormal, I 5

Sulphurous acid preservative, 93, 94, 97

Suspended matter in sewage effluents, 167, 174

TALC in pearl barley, 84 in rice, 83

Tapioca, 87

Tea, 8I

Temporary hardness, $17,1_{j} 8,141$

Thresh's process, I7 I

Tin in foods, 98
Tinned foods, $9 \mathbf{I}$

Titrations, 12

Total solids of milk, 30 of water, 137

UPLAND surface waters, 115,152

"Vieth's Ratio," 27

Vinegar, 85

acetic acid in, 18

Vitamines, 89

Volumetric analysis, 9

apparatus required for, II

WARINGTON's process, 134, 226

Water, alkalinity of, I7

analyses, examples of, 152 interpretation of results of, 143,148

analysis, 119, 143, 219

deposits, 149

in butter, 54,56

poisonous metals in, 157

rain, II 5

river, I 16,155

sediments, I 49

softening, 155

supplies, I 5

upland surface, I I $5, I_{52}$

Weighing, I

Wells, 116

artesian, 118

deep, I I 7, I 53

shallow, 117, 154

Werner-Schmid process, 32

Wheat flour, 83,87

starch, 87

Whiskey, 74

White bread, 82

flour, 82

Wines, 75

pepper, 85,88

Winkler's process, 168

ZINC in foods, 98

in water, $158,159,163$ 




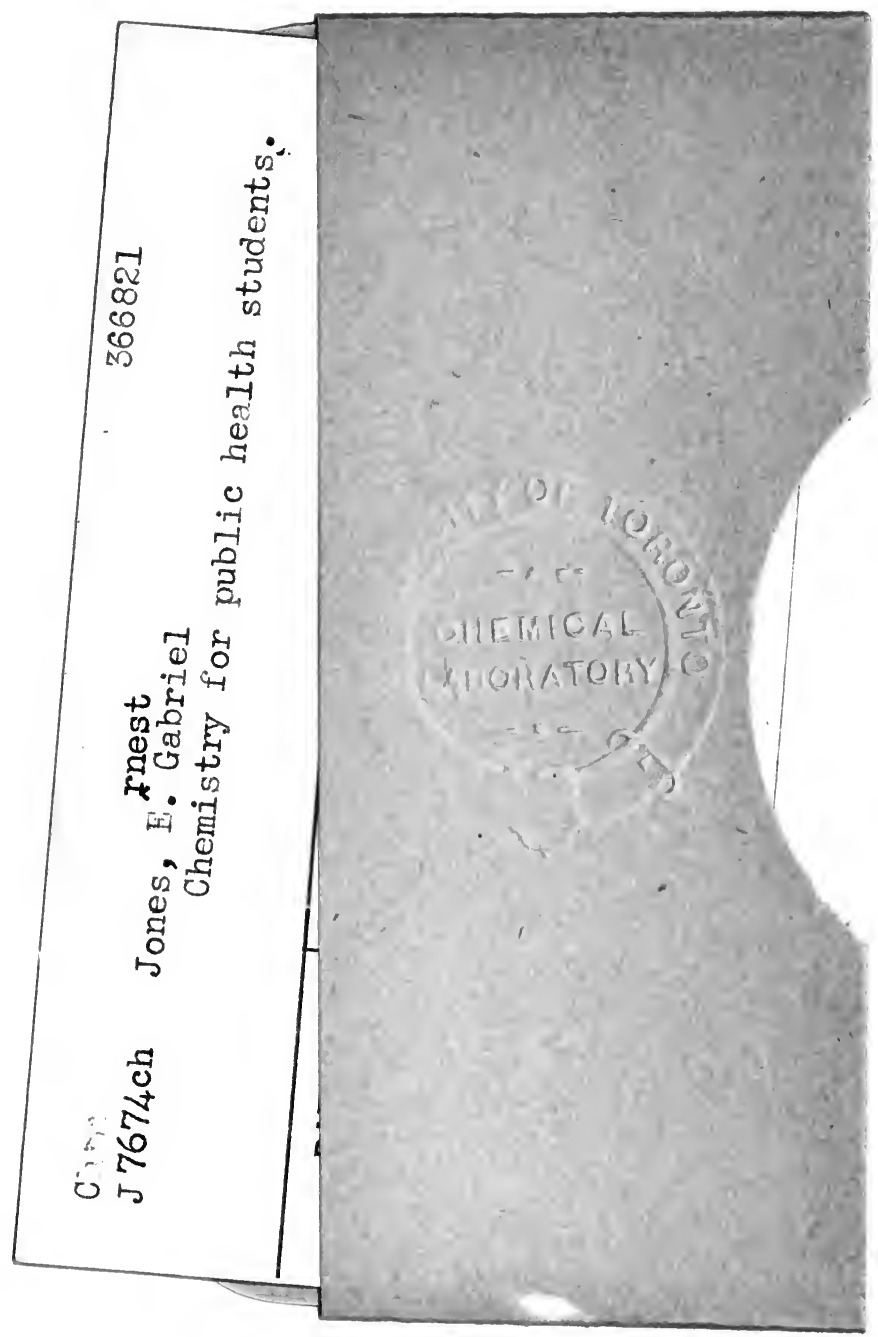




\section{g. \\ T. \\ Whe \\ Whe. \\ 2. 1.}

then

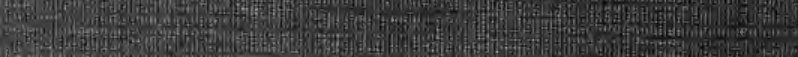

(6.

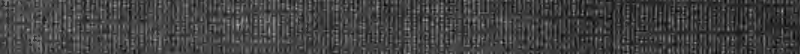

4.

To

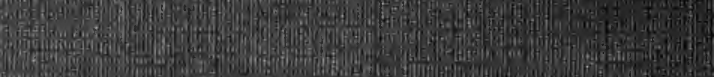

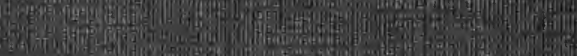 \\ 1.6.

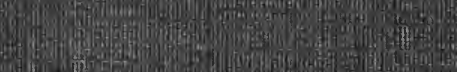 \\ 4 (1)}

Rasing

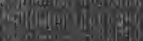

17.

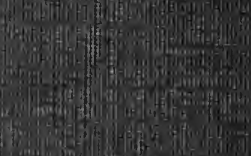

16)

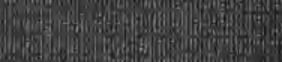

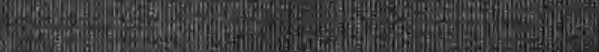

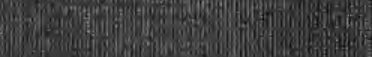

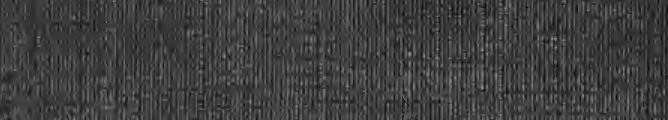

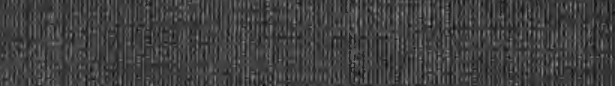

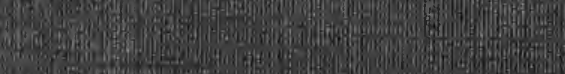

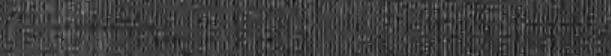

(20)

(4) $\operatorname{lin}^{2}$

(4)

W.

30 now

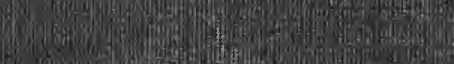

6is. 19.

agves

1.

3.

top

9. 